\title{
THE FAMILY SYSTEM
}

OF THE PARAMARIBO GREOLES 


\section{TO ELLEN}

Willem F.L. Buschkens - 978-90-04-28702-0 Downloaded from Brill.com04/26/2023 12:01:51PM via free access 


\section{VER H A N D E L I N G E N}

VAN HET KONINKLIJK INSTITUUT

VOOR TAAL-, LAND- EN VOLKENKUNDE

71

WILLEM F. L. BUSCHKENS

\section{THE FAMILY SYSTEM OF THE PARAMARIBO CREOLES}


The fieldwork for this study was carried out under a grant from WOSUNA, the former Netherlands Foundation for the Advancement of Research in Surinam and the Netherlands Antilles (at present WOTRO, the Netherlands Foundation for the Advancement of Tropical Research).

The publication and translation were made possible by grants from ZWO, the Netherlands Organization for the Advancement of Pure Research, and from STICUSA, the Netherlands Foundation for Cultural Cooperation with Surinam and the Netherlands Antilles.

The original title was

Het Familiesysteem der Volkscreolen van Paramaribo.

The English translation was prepared by

MARIA J. L. VAN YPEREN

I.S.B.N. 90.247 .1716 .7 


\section{CONTENTS}

INTRODUGTION $\cdot \cdot \cdot \cdot \cdot \cdot \cdot \cdot \cdot \cdot \cdot \cdot \cdot 1$

1.1. General . . . . . . . . . . . . . . . . 1

1.2. Social Research in Surinam . . . . . . . . . 1

1.3. The West Indian Family System . . . . . . . 3

1.3.1. Alternative Unions between Men and Women . . . 3

1.3.2. Female-headed Households and Matrifocality . . . 6

1.3.3. Theories of the Origin of the West Indian Family 10

1.3.3.1. Poverty and the "West Indian" Family System . . . 18

1.4. The Situation in Surinam . . . . . . . . . 20

2. SURINAM . . . . . . . . . . . . . . . 24

2.1. Geography . . . . . . . . . . . . . . . 24

2.2. Political Development . . . . . . . . . . . 25

2.3. History of Agriculture . . . . . . . . . . . 28

2.3.1. Plantation Agriculture . . . . . . . . . . . 28

2.3.2. Small-scale Agriculture . . . . . . . . . . . 32

2.4. Other Sectors of the Economy . . . . . . . . 33

2.5. The Demographic Situation . . . . . . . . . 35

2.5.1. Religious distribution of the population . . . . . 37

2.6. The Creoles . . . . . . . . . . . . . . . 38

2.6.1. The Lower-Class Creoles . . . . . . . . . . 40

3. THE RESEARGH . . . . . . . . . . . . . 42

3.1. The Place of Research . . . . . . . . . . . 42

3.2. The Method of Research . . . . . . . . . . 42

3.2.1. Observation and the Interview . . . . . . . . 43

3.2.2. The Survey . . . . . . . . . . . . . . . 44

3.2.3. The Investigation into the Desired Number of Children 47

3.2.4. The Investigation of the Archives . . . . . . . 48

4. THE INITIAL PERIOD OF SETTLEMENT OF THE PLANTATION GOLONY UP TO THE ABOLITION OF THE SLAVE TRADE IN 1808

4.1. Population . . . . . . . . . . . . . . . . . . 49

4.2. The Organization of Slavery . . . . . . . . . 51 
4.3. The Family Life of the Slaves . . . . . . . . 55

4.3.1. Alternative unions between men and women . . . 55

4.3.2. The Instability of Relationships . . . . . . . . 56

4.3.3. The Slave Household . . . . . . . . . . . 63

4.4. Government, Private and Church Interference in the Family Life of Slaves . . . . . . . . . . 65

4.5. The Family Life of the Masters and the free Mulattoes and free Negroes... . . . . . . . . . 67

5. THE PERIOD FROM 1808 UP TO EMANCIPATION IN 1863 .

5.1. General . . . . . . . . . . . . . . . 74

5.2. The Dwindling Slave Force . . . . . . . . . 74

5.2.1. The Unequal Sex Ratio . . . . . . . . . . 75

5.2.2. Malnutrition, Disease and Poor Housing among the

5.3. Measures for the Improvement of the Slaves' Family Life and Reproductive Capacity . . . . . . . . 80

5.3.1. Private Measures . . . . . . . . . . . . . 81

5.3.2. The Activities of the Missions of the Various Churches 82

5.3.2.1. The Moravian Mission and the Slaves' Family Life . 83

5.3.2.1.1. The Institution of the "Verbond" or "Alliance" . . 85

5.3.2.2. The Roman Catholic Mission and the Slaves' Family

5.3.3. State Interference in Respect of the Family Life of the Slaves . . . . . . . . . . . . . . . 88

5.4. Man-Woman Relationships among the Slaves . . . 96

5.5. The Family Life of the Free Population . . . . . 101

5.5.1. The Family Life of the Europeans . . . . . . . 102

5.5.2. The Family Life of the Free Mulattoes and Free Negroes . . . . . . . . . . . . . . . 102

6. THE POST-EMANCIPATION PERIOD . . . 108

6.1. General . . . . . . . . . . . . . . 108

6.2. The Rural Exodus of the Creole Population . . . 108

6.2.1. The State Supervision of Ex-Slaves (1863-1873) . . 108

6.2.2. The Period after State Supervision . . . . . . 110

6.3. The Creole as Gold Digger and Balata Bleeder . . 113

6.3.1. The Gold Industry . . . . . . . . . . . . 113

6.3.2. The Balata Industry . . . . . . . . . . . . 115

6.4. Other Creole Occupations . . . . . . . . . . 118

6.4.1. The Crafts . . . . . . . . . . . . . . . 118

6.4.2. Bauxite . . . . . . . . . . . . . . . . 118

6.4.3. The Timber Industry . . . . . . . . . . . 120

6.4.4. Other Occupations . . . . . . . . . . . . 120 
6.4.4.1. Women's Occupations . . . . . . . . . . . 120

6.5. Unemployment . . . . . . . . . . . . . . 121

6.5.1. Emigration to the Antilles and the Netherlands . . 123

6.6. The post-Emancipation Family System . . . . . 124

6.6.1. The Period of State Supervision . . . . . . . 125

6.6.2. The Period following State Supervision . . . . . 125

6.6.2.1. The Issue of the Abolition of the Alliance . . . . 127

6.6.2.2. Discrimination in Civil Marriages . . . . . . . 129

7. THE SITUATION AFTER WORLD WAR II . . 132

7.1. General . . . . . . . . . . . . . . . . 132

7.2. Characteristic Features of the Sample Population . . 133

7.2.1. West Indian Traits of the Households included in the

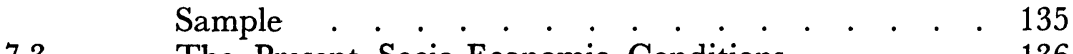

7.3. The Present Socio-Economic Conditions . . . . . 136

7.3.1. Housing . . . . . . . . . . . . . . . . 137

7.3.1.1. Ownership of Houses . . . . . . . . . . . . . 143

7.3.2. Economic Aspects of the Household . . . . . . 144

7.3.2.1. Unemployment, Unemployment Relief and Poor Relief 144

7.3.2.2. The Occupational Structure . . . . . . . . . 146

7.3.3. The Family Income . . . . . . . . . . . . 150

7.3.4. The Pattern of Spending of the Household . . . . 153

7.3.4.1. Expenditure on Food and Drinks . . . . . . . 154

7.3.4.2. Expenditure on Rent, Electricity, Gas and Water . . 155

7.3.4.3. Expenditure on Clothing and Shoes . . . . . . 157

7.3.4.4. Costs of Illness and Funerals . . . . . . . . . 157

7.3.4.5. Other Expenses. . . . . . . . . . . . . . 162

7.3.5. The Degree of Poverty . . . . . . . . . . . 162

8. THE NATURE OF UNIONS AND THE HOUSEHOLD STRUCTURE . . . . . . . . . . . 164

8.1. General . . . . . . . . . . . . . . . . 164

8.2. Alternative Unions between Men and Women . . 164

8.2.1. The Choice of one or other of the Alternative Unions 165

8.2.1.1. Age of the Partners and Nature of the Union . . . 165

8.2.1.2. Socio-economic Status of Married Persons and of Persons living in Concubinage . . . . . . . . 166

8.2.1.3. The Way in which Unions are Realized . . . . . 167

8.2.1.4. Views on Marriage . . . . . . . . . . . . 173

8.2.2. The Stability of Unions . . . . . . . . . . 175

8.2.2.1. The Duration of the dissolved Marriages and Concubinages . . . . . . . . . . . . . . . . 177

8.2.2.2. Reasons for terminating Unions . . . . . . . . 178

8.2.3. Illegitimacy of Births . . . . . . . . . . . 185

8.2.3.1. The Marriage Act for Asians and the Creoles . . . 187 
Page

8.2.3.2. Aspects of Illegitimacy among the Lower-class Creoles 189

8.3. The Structure of Households . . . . . . . . . 194

8.3.1. The Prevalent Types of Household . . . . . . 195

8.3.1.1. Type A: Male Head with Legal Wife . . . . 196

8.3.1.2. Type B: Male Head with Common Law Wife . 197

8.3.1.3. Type G: Male Head without Legal or Common

8.3.1.4. Type D: the Single Man . . . . . . . . . 199

8.3.1.5. Type E: the Female Head with Legal Husband . 199

8.3.1.6. Type F: Female Head with Common Law Husband 199

8.3.1.7. Type G: Female Head without Legal or Common Law Husband . . . . . . . . . . 200

8.3.1.8. Type H: the Single Woman . . . . . . . . 202

8.3.2. The Inter-connectedness of the Different Household Types . . . . . . . . . . . . . . . . . 202

8.3.2.1. Smith's Cycle Theory . . . . . . . . . . . 203

8.3.2.2. The First Phase of the Household . . . . . . . 205

8.3.2.3. The Second Phase of the Household . . . . . . 209

8.4. Unmarried Women and Women not Living in Concubinage and their Children . . . . . . . . 217

9. THE FUNCTIONING OF THE FAMILY SYSTEM 219

9.1. General . . . . . . . . . . . . . . . . 219

9.2. The Desire for Children . . . . . . . . . . . 219

9.3. Birth Control . . . . . . . . . . . . . . 227

9.4. Traditional Practices in Connection with Pregnancy and Childbirth . . . . . . . . . . . . . . 232

9.5. Childhood . . . . . . . . . . . . . . . 237

9.5.1. Social Relations During Childhood . . . . . . . 243

9.5.1.1. With the Parents . . . . . . . . . . . . . 243

9.5.1.2. With Brothers and Sisters . . . . . . . . . . 244

9.5.1.3. With Other Persons . . . . . . . . . . . . 244

9.6. Adulthood . . . . . . . . . . . . . . . . 246

9.6.1. Man-Woman Relationships . . . . . . . . . 246

9.6.2. Homosexual Relations between Women . . . . . 247

9.6.3. Contacts with Other Persons . . . . . . . . . 251

9.7. Old Age . . . . . . . . . . . . . . . . 252

9.8. Death . . . . . . . . . . . . . . . . . 252

9.8.1. Description of the Customs observed in Connection with Death . . . . . . . . . . . . . . . 254

9.8.2. The Memorial Gathering on the Eighth Day . . . 260

10. FINAL REMARKS . . . . . . . . . . . . 263

10.1. General . . . . . . . . . . . . . . . . 263

10.2. The West Indian Family System of Paramaribo as an Adaptation Model . . . . . . . . . . . . . 265 
APPENDIX 1. Letter of Introduction explaining the Nature of the Research . . . . . . . . . . . 271

APPENDIX 2. The Questionnaire . . . . . . . . . . 272

APPENDIX 3. Tables A-R not inserted in the text . . . . 283

APPENDIX 4. Interview Scheme B.O.G. Sample . . . . . 305

BIBLOGRAPHY . . . . . . . . . . . . . . . . 307

INDEX . . . . . . . . . . . . . . . . . . 317

\section{LIST OF FIGURES}

Figure 1. Household 'Type A or B, the latently matrifocal household . . . . . . . . . . . 207

Figure 2. The household in the period of transition from types A or $B$ to type $G$. . . . . . . . . . . . . . . 208

Figure 3. Household type F, female head with common law husband . . . . . . . . . . . . . . 212

Figure 4. Household type G, female head without legal or common law husband. variant 1: without visiting male variant 2: with visiting male

\section{PHOTOGRAPHS}

1. Manifest matrifocal household. Female head, her daughter and five grandchildren . . . . after page 144

2. An example of the poorest yards . . . . after page 144

3. Lower-lower class house . . . . . . . after page 144

4. Upper-lower class houses . . . . . . after page 160

5. A very simple funeral . . . . . . . after page 160

6. In the kitchen . . . . . . . . . . . after page 160 


\section{LIST OF TABLES}

Table 1. Share in the total agrarian output of large-scale and small-scale agriculture respectively, expressed in percentages

Table 2. Composition of the population of Surinam at the end of March, 1964 . . . . . . . . . . . .

Table 3. Distribution of the population in percentages, excluding those living in tribes. . . . . . .

Table 4. Population growth, excluding those living in tribes .

Table 5. Religious distribution of the population of Surinam in 1964

Table 6. The Composition of the population of Surinam (not including Amerindians and Bush Negroes) 1651-1811

Table 7. The population of Surinam, excluding those living in tribes (in percentages)

Table 8. The slave population of Surinam (1830-1863) . .

Table 9. The slave population of Paramaribo in 1863, classified according to sex and age . . . . . . . . .

Table 10. Slave population (4,321) of Paramaribo in 1863, classified according to relationship to the senior member (male or female) of the household (in percentages)

Table 11. Households set out according to the number of generations.

Table 12. Slave households in Paramaribo in 1863, classified according to the sex of the senior member and the number of members . 
Table 13. Family groups of the slave population of Paramaribo and the Lower Suriname and Lower Commewijne Divisions, classified according to the number of members

Table 14. Number of contract workers in the gold-mining industry

Table 15. Registered unemployment in Paramaribo and environs

Table 16. Place of birth of members of the sample population (in percentages)

Table 17. Number of females to every male of the sample population according to age-group .

Table 18. Religious distribution of the sample population (in percentages)

Table 19. The composition of the sample population according to ethnic group .

Table 20. Views of the heads of households of the sample on the state of their homes (in percentages) . . . . . .

Table 21. Number of beds per households (both male- and female-headed) (in percentages) . . . . . . . . 140

Table 22. The age of houses (in percentages) . . . . . . . 141

Table 23. Water supply (in percentages) . . . . . . . . 142

Table 24. Working population of Paramaribo, classified according to employment sector and sex (not including those seeking employment . . . . . . . . . . . .

Table 25. The occupations of the heads of households of the sample . 
Table 26. Table showing the status within the household of the members handing over part of their income to the head of the household

Table 27. Table showing non-members of households giving part of their wages to the head of the household .

Table 28. Number of members and total amount of income of households

Table 29. Cost of living for Creoles living in Paramaribo for the year 1952 .

Table 30. Monthly rent (in percentages)

Table 31. Electricity rates for households connected to the power net (in percentages) . . . . . . . . . . 156

Table 32. The costs of fuel (in percentages) . . . . . . . 156

Table 33. Monthly water rates (in percentages) . . . . . . 157

Table 34. Period of time for which married male heads of households lived in concubinage with their present partners prior to marriage . . . . . . . . . . . . . 166

Table 35. Motives of male respondents for converting their concubinages into marriages . . . . . . . . .

Table 36. Duration of the dissolved marriages and concubinages of the heads and their partners (in percentages) . . 179

Table 37. Baptisms in the Reformed Church of Paramaribo from 1845-1855

Table 38. Births in Paramaribo in 1961-1962.

Table 39. Births in Paramaribo for 1962 
Table 40. Table showing the nature of births among the sample population

Table 41. Marital status of heads of households of type C . . . 198

Table 42. Female heads of households grouped according to age 209

Table 43. Occupations of women from the B.O.G. sample . . 220

Table 44. Religious distribution of the women of the B.O.G. sample . . . . . . . . . . . . . . . . . 220

Table 45. Age at birth of first child of women of the B.O.G. sample. . . . . . . . . . . . . . . . . 221

Table 46. Desired number of children of the women of the B.O.G. sample . . . . . . . . . . . . . . 221

Table 47. Average number of children desired by the women of the B.O.G. sample .

Table 48. Average number of children desired by women of the B.O.G. sample according to marital status . . . .

Table 49. Table showing the number of women of the B.O.G. sample who would have liked more or fewer children than they actually possessed or were satisfied with the number they had

Table 50. Marital status of women of the B.O.G. sample who would like fewer children than they actually possess

Table 51. Conversancy of women of the B.O.G. sample with contraceptive devices and techniques . . . . . 230

Table 52. Table showing the number of women of the B.O.G. sample who had at some time used contraceptive devices and techniques and those who had no past or present Experience with these, set out according to age 
Table 53. Table setting out according to age the women from the B.O.G. sample who had used one or more contraceptive devices or techniques . . . . . . . . 231

Table 54. Reasons against using contraceptive devices or techniques stated by women of the B.O.G. sample, listed according to age.

Table A. Distribution of the total sample population according to sex and age.

Table B. Types of household found in the sample . . . . . 284

Table C. Males over the age of 16 according to marital status

Table D. Women over 16 years of age according to marital status

Table E. Age at time of first marriage of the Creole population of Paramaribo for the year 1962 .

Table F. Income from work or old age benefits and total income of the heads of households in Surinam guilders (in percentages).

Table G. Material possessions of households (in percentages)

Table H. Number of marriages, concubinages and dissolved unions of the household heads and their partners, as well as the number of persons in this group who have never entered into marriage or concubinage . . . .

Table I. The composition of households comprising more than one person . . . . . . . . . . . . . . .

Table J. Distribution of the different household types according to the number of generations . 
Table K. Legitimacy or otherwise of birth of members of households . . . . . . . . . . . . . . . 295

Table L. Households of the sample according to type and number of members . . . . . . . . . . . . . 296

Table M. Heads of households according to age . . . . . . 297

Table N. Number of rooms per household, male- or femaleheaded . . . . . . . . . . . . . . . 298

Table O. Head of household's right of tenure to dwelling . . 299

Table P. Table setting out the weekly expenditure of six housewives (in S. fl.) . . . . . . . . . . . . . 300

Table Q. I. Duration of existing marriages of coresiding partners per age-group of the total sample population

II. Duration of existing common law marriages per age-group of the total sample population . . . 303

Table R. Status within the household of males over 16 years of age

Status within the household of females over 16 years of age... . . . . . . . . . . 304 
Willem F.L. Buschkens - 978-90-04-28702-๑ Downloaded from Brill.come4/26/2023 12:01:51PM via free access 


\section{INTRODUCTION}

\subsection{General}

In this book the family life of the lower-class Creole population of Paramaribo will be discussed. ${ }^{1}$

This group, which will henceforward be referred to as "the lower-class Creoles", possesses a "West Indian" family system, implying that the latter display all the main characteristics of the Caribbean Afro-American family. The Creoles constitute a numerically important ethnic segment of the society of Surinam. This society is composed of different ethnic groups, comprising, besides a handful of Amerindians, an "immigrant population" including people from many different parts of the world. It is made up of Creoles, Indians (or Hindustanis, as they are called in Surinam), Indonesians (Javanese), Chinese, Europeans, Lebanese and Bush Negroes, the latter of whom still live predominantly in tribes.

The Creoles are the descendants of those Negro slaves brought to Surinam from Africa who did not escape from bondage by running away from the plantations into the Bush, as their brothers the Bush Negroes did.

The circumstances under which the bulk of the slaves lived were appalling. Nor were they - or are they still in part at present - much better for their descendants the lower-class Creoles.

Both the slaves and the lower-class Creoles were compelled for the sake of bare survival to adjust their way of life, and more particularly their family system, to these circumstances. We shall trace below the course of this process of adaptation, as well as the way in which the resultant family system functioned in the past and still functions today.

\subsection{Social Research in Surinam}

Descriptions of the society of Surinam containing data on the "Creole Negroes" have appeared ever since the earliest days of colonization. These works by Herlein (1718), Hartsinck (1770), Fermin (1769),

1 For a more detailed explanation of the concepts of Creole and lowerclass Creole see 2.6. and 2.6.1. 
Kappler (1854) and others are extremely valuable for our knowledge of the former social relations in Surinam.

The first sociological research in this country was conducted by Melville J. and Frances S. Herskovits, who published several studies on the Bush Negroes and the Creoles of Paramaribo (Herskovits and Herskovits, 1934 and 1936). These latter contain an abundance of data in support of their hypothesis that African cultural elements have survived to a surprising degree among the Negro population of the New World (cf. Van Lier, 1951, p. 294).

Their work was followed after the Second World War by a sociohistorical analysis of the society of Surinam by Van Lier (1949, English Translation 1971). This laid the foundation for further sociological research. The principle underlying the programme for future systematic social research in Surinam subsequently drawn up by the aforesaid author is that the acquisition of a thorough sociographical knowledge of the different ethnic groups should precede further studies of the existing social and economic problems in order to make for a proper insight into the plural society of Surinam.

Studies of this kind on the various ethnic groups of Surinam have in fact appeared both in conjunction with this programme and independently of it in the past few decades. Of these, the studies on the Hindustanis by De Klerk (1951 and 1953) and Speckmann (1965), on the Indonesians (Van Wengen, 1963; De Waal Malefijt, 1963), the Creoles (Van Renselaar, 1963 a and b; Pierce, 1971), the Bush Negroes (Thoden van Velzen, 1966; Köbben, 1967 and 1968; De Groot, 1963 and 1969), and the Amerindians (Butt, 1966; Rivière, 1966 and 1969; Kloos, 1971) deserve special mention. The present book is the result of a similar study. ${ }^{2}$ It is concentrated on one particular social institution, as is the case with a number of the abovementioned studies. This is an obvious expedient, as it is virtually impossible to give a complete description of one particular ethnic group giving the necessary attention to all of that group's social institutions after only two year's field research.

The institution around which the present study is centered is that of the family, because, as we shall see below, this reflects most clearly the social role and position of the lower-class Creole both in the past and at present. The general characteristics of this institution, or its "West Indian character", will be discussed first.

2 Other sociological studies are, for example, that by Ferrier (1950) on socioeducational problems; Kruijer's (1951) sociograph of the three Guianas; and Pronk's (1962) study containing the results of tentative research on criminality. 


\subsection{The West Indian Family System}

There exists an extensive literature on the family systems of various Negroid ethnic groups of the Caribbean ${ }^{3}$ (cf., among others, Simey, 1947; Matthews, 1952; Henriques, 1953; Clarke, 1957; Raymond Smith, 1956; Blake, 1961; M. G. Smith, 1962).

These systems display a number of common traits, which allow us to speak of "the" West Indian family system. The principal ones are:

(a) The presence of institutionalized alternative unions between men and women. For besides legal marriage there are concubinage, involving the cohabitation of men and women who are not legally married, and the visiting relationship, in which there is a publicly recognized and accepted sexual relationship between a man and a woman whereby the man is a regular visitor to the woman's residential unit.

(b) A high prevalence of female heads of households.

A separate discussion of these characteristics follows below, as this is indispensable for a proper understanding of our further discourse.

\subsubsection{Alternative Unions between Men and Women}

Valuable data on the structure and functioning of the family in the Afro-American cultures of the United States and the Caribbean were given as early as the pre-World War II period in the qualitative studies on these ethnic groups published by Herskovits (1937 and 1964). The presence of alternative unions between men and women is also given the necessary attention in his work.

However, the credit of being the first sociologist to stress the implications of the institution of concubinage for societies in the Caribbean is due to Simey, who carried on where Herskovits left off. In his study entitled Welfare and planning in the West Indies, which appeared in 1946, he discusses the social structure and problems of the West Indian world in the post-war period, giving special attention to the family, because "... it is thus in the strengths and weaknesses of family life

3 Wagley (1960) pointed out that certain areas outside the West Indian archipelago should also be classed with the Caribbean area as a sociological unit. Apart from the West Indian islands, he takes this area, which he designates as "Plantation America", to comprise the Deep South of the U.S.A., the Atlantic coasts of Central America, Colombia and Venezuela, the Guianas, and northeastern Brazil. Hoetink (1961, p. 81) suggested the term "Negroslavery America" or "Afro-America" for this region. 
that the characteristic features of West Indian social organization are most clearly displayed" (Simey, 1947, p. 79).

In this study Simey published the results of the research into the occurrence of different family types among the rural Negroid population of Jamaica conducted in that island by Lewis Davidson. Thus he gained world-wide recognition for the fact that the family types that can be distinguished in this area - which are considered as deviating from the "Western" ideal of monogamous marriage - are by no means marginal, incidental phenomena, but are on the contrary socially accepted types. Besides (a) "The Christian Family, based on marriage and a patriarchal order approximating to that of Christian families in other parts of the world", which comprised only $20 \%$ of the families studied, Simey distinguished three other family types. These were: (b) "Faithful Concubinage, again based on a patriarchal order, possessing no legal status, but well established and enduring for at least three years", making up $29 \%$ of the family types distinguished (thus being numerically predominant over marriage); (c) "The Companionate Family, in which the members live together for pleasure and convenience, and for less than three years"; and (d) "The Disintegrate Family, consisting of women and children only, in which men merely visit the women from time to time, no pattern of conduct being established". The latter two types combined made up $51 \%$ of the total of a sample of 270 rural Jamaican families which, according to the author himself, was not very reliable.

Despite this one shortcoming, Simey's publication, as well as the subsequent research by Henriques (1953), which was similarly conducted in Jamaica (and the results of which included a more subtly differentiated classification of the family types found here), made it clear that what Herskovits and Frazier had found to be the case with the Negro family of the United States, namely that concubinage as a form of cohabitation is institutionalized here, is observable also among the Negroid population of the Caribbean.

The same is probably also true of the visting relationship. In this type of union, a woman lives with her children in a separate residential unit and is regularly visited by a man who either supports her entirely or gives her partial economic assistance, and who is the father of all or some of her children. Much less is known about unions of this type than about concubinage, even though they are known to and accepted by the environment. The reasons for this are: (1) in connection with the secrecy of a number of these visiting relationships, namely where the 
man is married to or living in concubinage with another woman, it is difficult to quantify the occurrence of this form accurately; and (2) in the initial stages especially, these unions are extremely difficult to distinguish from casual affairs or other kinds of short-lived sexual relationships.

As a corollary of the occurrence of these alternative unions, we have here the phenomenon of the higher frequency of broken unions among the lower-class Negro population of the United States and the Caribbean than among the white population of these areas. This is the reason why the family system of the Negro population is characterised as instable. Especially concubinage and the visiting relationship have been seen in the Caribbean to be unions that are liable to be dissolved at a moment's notice by one of the partners.

Hence women here usually go through one or more concubinages, visiting relationships or casual affairs before entering into marriage relatively late in life. Marriage is more or less the crowning achievement of a woman's sexual and procreative career and gives her greater prestige than concubinage. This is the chief reason why marriages are celebrated with such pomp and ceremony and hence entail such high costs here. Once concluded, they are seldom dissolved. It should be understood, however, that not all women end up by marrying, and that for many of them concubinage is the final phase.

The situation among the lower-class Negroes of the United States differs from that in the Caribbean on this point. For the Western family pattern exercises a stronger influence in the former than in the Caribbean. This is probably because in the United States the Negroes form a minority, while a decidedly assimilative influence is exercised by the American majority culture.

Thus research into the North American Negro family has shown that men and women in this group tend to marry in only relatively slightly fewer numbers and at only slightly higher ages than members of the white population (Glick, 1957, pp. $133 \mathrm{ff}$.).

Among the North American Negroes marriage is not regarded, as in the case of the Creole population of the Caribbean area, as a "crowning" achievement, nor is it concluded at a similarly late age. People here usually marry younger and without much ceremony. Generally speaking, North American Negro women will enter into concubinages or have visiting relationships or a series of affairs only after going through at least one marriage, whereas the lower-class Creole woman in the Caribbean will do exactly the reverse, many women here marrying only after 
they have gone through one or more concubinages or visiting relationships.

\subsubsection{Female-headed Households and Matrifocality}

The second characteristic of the West Indian family system, namely the high incidence of female heads of households, is a phenomenon similarly found among the Negro population of the United States.

According to the controversial Moynihan Report of 1965 (Rainwater and Yancey, 1967) concerning the situation as regards the American Negro, $23.1 \%$ of the urban Negro households of the United States were headed by women in 1960 . For the rural areas these percentages were 19.5 and 11.1 for the "rural non farm" and "rural farm" areas respectively.

This disparity in the percentages for the rural and the urban areas indicates that the American urban Negro population has been subject to stronger proletarianising forces than the rural Negro population. As to the whole of the United States, according to the U.S. Bureau of the Census, $31 \%$ of the Negro households were headed by husbandless women in 1966. For white households this percentage was $19 \%^{4}$ (Current Population Reports, 1967). The percentages of female heads of households in the Caribbean are also high. For instance, in (former British) Guyana the percentages of female heads of households were seen by R. T. Smith (1956, p. 64) to come to 36,35 and 17 respectively in the villages of August Town, Better Hope and Perseverance. For the Jamaican rural areas Clarke (1957, p. 206) gives the following figures: for Mocca $31 \%$, Orange Grove $25 \%$, and Sugartown $21 \%$.

In the Caribbean - as in the United States - the percentages for the urban centres are the highest. ${ }^{5}$ For Kingston in Jamaica it is $49 \%$, according to M. G. Smith (1962, p. 227), and for Grenville, in Grenada, even $52 \%$.

On account of the circumstance that in many households a woman is the dominant authority here, the Negro family in both the United States and the Caribbean tends to be styled "mother headed" and "matri-

4 It should be borne in mind in the interpretation of these statistics that the American Negroes were proletarianized to a much higher degree than the white population.

5 The island of Cariacou, where Michael Smith found a percentage of 54, forms an exception. The male population of this island "migrate continuously and in large numbers to Trinidad, Venezuela, Aruba and Curaçao". (M. G. Smith, 1962, p. 24.) 
centric" (Frazier, 1939), matriarchal and maternal (Herskovits, 1958), and matrifocal (R. T. Smith, 1956).

Raymond Smith, who has gone into this matter at great length, views the following as one of the principal features of the West Indian family structure: "The household group tends to be matri-focal in the sense that a woman in the status of 'mother' is usually the de facto leader of the group, and conversely the husband-father, although de jure head of the household group (if present), is usually marginal to the complex of internal relationships of the group. By marginal we mean that he associates relatively infrequently with the other members of the group, and is on the fringe of the effective ties which bind the group together". (R. T. Smith, 1956, p. 223).

In this type of household women usually have more influence and responsibility than men. The woman is shown more affection and loyalty by the other members of the household than the man, who is often absent for a variety of reasons. The woman, on the other hand, is virtually permanently present, so that the children are able to depend and rely more on her than on the father. We can say that on the whole the weak tie with the father has brought out the mother-child relation into bolder relief.

When the man is absent either permanently or temporarily, the woman will see to it that the household is able to survive economically. She usually does so by going out to work. She may receive the necessary assistance to do so from her female relatives, such as her mother, sisters, or mother's sisters, who will in some cases move in with her and take over some of the household duties and look after the children. Hence one frequently comes across three or even four matrilineally related generations living together in this type of household.

The children growing up in such households are accustomed to see mainly women exercising the greatest authority over them and looking after their well-being. They similarly grow up with the idea that maternal kinship ties are stronger than paternal ones, and that it is matrilineal and not patrilineal relatives on whom one falls back in times of need. Hence matrifocality is reflected in the kinship system. Although the latter is bilateral, the stronger emphasis falls on the matrilineal line. Contacts with maternal relatives are more frequent and intensive than with paternal ones, who are not so much regarded as relatives and who may sometimes be complete strangers.

In a great many studies dealing with the Creole lower classes much attention is given to the complex of phenomena connected with matri- 
focality. Here the household is termed matrifocal because the man fulfilling the father role is present irregularly or not at all, and the woman assumes a dominant position. It is interesting to note that the term "matrifocality" has not been further elaborated in any of the studies dealing with these phenomena. But there is another circumstance that claims our attention. For we cannot fail to be struck by the fact that in the literature the term is used for both male-headed and femaleheaded households. Hence the term is applicable to all types of household, and particularly also those in which a man and woman live together in a stable union, whether marriage or concubinage, over a longer period of time and in which the husband is a regular breadwinner and a central figure on whom the wife and children are able to depend.

Hence it would seem useful, in order to make for a better understanding, to distinguish between various types of matrifocality in the West Indian family system with respect to the household. 'The fact that we normally speak of "the" West Indian family system implies that this is generally assumed to be a sub-system of the social structure as a whole. For, as we posited earlier on, alternative unions between men and women are looked upon as institutions in the society of the West Indies.

Although I have given no quantitative illustrations of this, I was able to infer from countless exhaustive interviews that men and women brought up in the lower-class Creole culture are bearers of a specific complex of expectations and attitudes in respect of their relations with members of the opposite sex. Socialized in a society with a predominantly "West Indian family system", they are fully aware that the permanence of any relationship they may enter into can not be taken for granted. Both men and women are embedded in this family system and hence realize what its consequences are. So a woman knows, because of this complex of expectations, that a time may come when her partner will leave her, or when she will have to tell him to leave her. The social system plays a major part in this, as will be described below. On account of it numerous men are incapable of earning a regular living, so that where they are out of work for long periods of time they are more or less necessitated to leave their families. So many women forestall the loss of their partner in this way by placing themselves in as strong as possible a position both inside and outside the home, such as, for instance, by earning their own income.

For these reasons, I would qualify households of which a man is (still) the head as latently matrifocal. In these cases a man and woman may 
live in concubinage or as marriage partners, while the wife is often (though not always) the principal figure as regards the internal affairs and relations of the household, but not with regard to the world outside the household, or the "outside world". The husband is the person who contributes the largest share towards the household's economic survival. Therefore he is regarded as the head by the "outside world". Hence I have classified both stable concubinages and marriages, where husband and wife remain faithful to each other until they are parted by death, as latently matrifocal households. These differ little from Western-type households, except that the two partners are keenly aware, because of the abovementioned complex of expectations, that their union may break up before death comes to either of them. This uncertainty as to the duration of unions is a structural phenomenon which is closely connected with the total social and economic situation in the society of which they are part. "A man may remain true to you for a thousand years, and then all of a sudden just leave you one day," observed one of my female informants.

The period preceding the actual moment when one of the partners will break off the relationship is characterized by quarrelling (over a shorter or longer period), increasingly frequent absences of the husband, outbursts of jealousy, shortage of money, the woman going out to work, unemployment of the husband, and in many cases a female relative moving in. Here, in this transitional phase, the woman often becomes the major contributor to the household's economic survival, so that the husband fades further and further into the background in the entire complex of the household's internal and external relations. Only when a woman has become the actual head of a household in consequence of her husband's death or his deserting her or being sent away by her, does a household become what I would call manifestly matrifocal.

It is then that the woman is responsible for the household's economic survival and comes to be regarded as its head by the outside world as well. Although there are cases of men moving in with such manifestly matrifocal households of which a woman is the head and having sexual relations with this female head, these are exceptions rather than the rule, as we shall see below. These men may share part of their earnings with the head of the household in question, but the household will not be dependent on such a man for its economic upkeep. Households the female heads of which have visiting relationships with a man are similarly manifestly matrifocal. For a description and analysis of the types of household found here, as for a further elaboration of the 
mechanism which we have touched on in the aforegoing, the reader is referred to sections 8.3. en and 8.4.

\subsubsection{Theories of the Origin of the West Indian Family System}

Now what is it that is responsible for the emergence of the complex of phenomena together designated as the "West Indian Family System"? Why is it that neither the ex-slaves nor their descendants, despite their long-standing contact with a predominantly Western culture, have adopted as norm the Western monogamic family system, in which marriage is the virtually universally recognized form of union in which a man and woman may live together? Why does the family system they have evolved deviate from this? In order to find an answer to these questions, a number of theories have been propounded which may be mutually supplementary, or sometimes contradictory.

I shall give a summary of these theories below because they contain a number of extremely useful elements for our further discourse. I shall refrain from going into the merits or demerits of the various theories at too great a depth, however, because it is not one of the objectives of the present book to make a systematic, critical analysis of the current theories on the West Indian family. ${ }^{6}$

The different theories can be roughly distinguished into: (a) those that refer chiefly to historical factors in explaining the West Indian family system; and (b) those citing primarily factors operating in contemporary West Indian society to explain the West Indian family system.

Ad. (a) The most prominent authors attempting to explain the West Indian family system from historical factors in the 1930's are the American scholars Melville J. Herskovits and E. Franklin Frazier.

Herskovits, who set out to prove that many African cultural elements have survived among the Negro populations of the Americas, carried out research in Surinam towards this end in 1928 and 1929. He went there with his wife Frances with the aim of conducting research among the Bush Negroes, who of all the Negro groups in the New World had preserved their African character most intact, as was apparent from the scanty data available on this group.

There was a great surprise awaiting them in the town of Paramaribo.

- Raymond Smith's article entitled "Culture and Social Structure in the Caribbean: some recent work on family and kinship structures" (R. Smith, 1963, p. 64) contains the fullest discussion of this subject. 
For where they had come looking for traces of African culture in the Surinam Bush, much to their amazement they came upon an unsuspected wealth of African cultural elements among the Creole lower classes in this town itself (Van Lier, 1951, pp. 294 ff.). Herskovits (1964, p. 15) says about this: "It was evident, for example, even on initial acquaintance, that many African customs were to be found among the Negro tribes of the Bush, who because of their long isolation had experienced a minimum contact with Europeans. But to one expecting a modicum of Africanisms in the Bush, and an absence of them in the coastal city of Paramaribo, where the Negroes have had close and continuous contact not alone with Europeans, but with Caribs, Javanese, British Indians and Chinese as well, the results of close studies were startling. In the interior, a full-blown African religious system, a smoothly functioning African clan organisation, African place and personal names, African elements in economic life, a style of wood carving that could be traced to African sources showed what might be looked for in the institutions of any isolated culture that is a going concern. In the coastal region, however, underneath such Europeanisms as the use of European clothing and money, or baptismal certificates and literacy, numerous African institutions, beliefs, and canons of behavior were likewise encountered."

Herskovits termed these African cultural elements in the New World "survivals". According to Van Lier (1951, p. 295), the definition of survivals put forward by Tylor (1871) applies here because: "Survivals are processes, customs, opinions and so forth, which have been carried by force of habit into a new society... and ... thus remain as proofs and examples of an older condition of culture out of which a newer has evolved." (Tylor, 1913, I, p. 16).

In contrast to the earlier cultural anthropological schools, Herskovits did not study these African survivals as more or less isolated elements, however. He made Negro groups as a whole the subject of his study, not neglecting any aspect of their life. The African elements are invariably regarded as integral parts of the total culture of the group, and are discussed in their connectedness with other elements, which have been evolved or adopted in the new environment (Van Lier, 1951, p. 296).

Although the form of some of these African elements has been lost, they may still survive in "substance". Hence they are to be regarded as re-interpretations of earlier forms. So Herskovits, when writing about the American Negro family in this context, observes: "Re-interpretation of earlier, pre-American patterns has occurred, but re-adjustment to 
normal conditions of life has been inhibited. We thus must recognize that the elasticity of the marriage concept among Negroes derives in a measure, largely unrecognized, from the need to adjust a polygynous (African) family form to patterns based on a convention of monogamy, in a situation where this has been made the more difficult by economic and psychological complications resulting from the nature of the historical situation." (Herskovits, 1964, p. 170).

This takes place by connecting the psychological value originally attached to the old form to a new pattern, provided the latter is able to justify this by some distinct resemblance to the old one. One of the examples cited by Herskovits is the phenomenon, in cases where the old African polygynous family has disappeared in the New World, of its replacement by a series of relatively rapidly succeeding man-woman relationships which do not lead to permanent, legal marriage. People now tend to seek the psychological gratification formerly offered by a number of concurrent polygynous relationships in a series of successive relationships of relatively short duration (Van Lier, 1951, p. 296). There are other elements of the West Indian family system and of the family system of the North American Negro as well which Herskovits regards as re-interpretations of African cultural elements, such as in particular alternative unions between men and women (concubinage and the visiting relationship) and the important position which women occupy in the family (Herskovits and Herskovits, 1936, pp. 16-23; Herskovits 1964, pp. 167-186).

Although it is extremely difficult to "prove" al this, Herskovits adduces so much convincing evidence from so many regions in the New World in corroboration of his theories that it is impossible for us to ignore the fact that especiallly with respect to the family system the American Negro, in adapting to his new environment, was influenced by the African family system of the region of his origin. Those who believe this influence to have been especially strong regard the West Indian family system as an adaptation of the African family sytem.

Diametrically opposed to Herskovits's theory, which views the American Negroes as "displaced Africans", is Frazier's theory (Frazier, 1939). With respect to the United States he pointed to the disintegrative effects on the Negro family of such socio-economic factors as slavery, discrimination and urbanization. It is as a result of these that the Negro family has come to display certain traits which distinguish it from the family among the white population. He mentions especially the "matriarchal character" of the American Negro family as a product of 
this, saying: "Throughout its development, the Negro family has been influenced in its internal social and psychological organization as well as in its formal structure by the economic and social forces which have determined the character of Negro communities." (Frazier, 1965, p. 306).

Frazier almost completely rejected Herskovits's theory by positing that: "The attempt to explain the sex behaviour and familial life of American Negroes by reference to African culture traits rest upon speculation and specious analogies", although he leaves some margin for Herskovits's approach by pointing out that "among some isolated groups of Negroes in the New World as for example in Haiti and Jamaica, it appears that elements of African culture have been retained in the Negro family" (Frazier, 1965, p. 306).

Because Frazier confined his research among Negroes almost exclusively to the United States, he was much less alive to African "survivals" than Herskovits, who carried out some thorough research in the Caribbean, and more particularly in Trinidad, Haiti and Surinam as well as in the United States. In Surinam the Negro population does not on the whole constitute a minority as in the U.S., and for this reason, among others, is much less assimilated to Western culture than in the United States. When writing about the assimilation process undergone by the American Negroes Herskovits therefore tends to wonder: "What caused the differences between the several parts of the New World in retention of African custom? Though the answer can only be sketched, especially since adequate historical analysis of the data concerning plantation life outside continental North America and Brazil is quite lacking, yet the effective factors are discernible. They were four in number: climate and topography; the organization and operation of the plantations; the numerical ratios of negroes to whites; and the extent to which the contacts between negroes and whites in a given area took place in a rural or urban setting." (Herskovits, 1964, p. 111).

So generally speaking it may probably be justifiably argued that Frazier's views are more tenable as regards the situation in the United States, in particular in the industrialized urban environment, whereas Herskovits's views have greater validity with respect to the situation in the Caribbean, in some rural areas of the United States, and in some of the less industrialized towns of that country. In this context we should mention the 11th proposition appended to Van Lier's dissertation (1949), stating that: "The views of Herskovits and Frazier on the Negro family in the New World are not mutually exclusive, but should be brought into synthetic relation with one another". 
We shall try in the present study to do justice to the theories of both, both of them being equally important, by taking into account not only the disintegrative effects on the Negro family of such socio-economic factors as slavery, discrimination and urbanization, but also the factor of African "survivals" in the family system of the Negro population of Paramaribo. In addition, however, we shall draw more recently developed theories into the discussion as well; these will be summarized below.

Ad. (b) After World War II, when the socio-political climate in the Caribbean area was determined by economic development, a number of publications on the problems of the West Indian family appeared which give special prominence to factors operating in contemporary West Indian society. The analysis of both quantitatively and qualitatively collected data revealed a number of variables which confronted us with the fact that the complex of phenomena constituting the West Indian family system is infinitely more intricate than the theories on this advanced by Herskovits and Frazier - who approached the phenomenon from a purely historical perspective - would lead us to believe.

Thus Raymond Smith (1963-'64, p. 28) observes that: "By the early 1950's a clear distinction had been made between cultural persistence as an explanatory device and the study of contemporary structural arrangements and interconnections. Some writers like Simey, Henriques and Matthews adopted a two-dimensional approach but without pushing very far in either direction. The obvious need was for more detailed studies, both historical and of contemporary structure; the main emphasis in recent work has been on the latter for the simple reason that material is more easily available."

Despite the lack of depth of the works of Simey, Henriques and Matthews to which R. Smith points, their work, combining the historical with the contemporary approach, provides a number of points of departure for further research.

Subsequent researchers who did push further did so solely through research into contemporary structures, however, which is all the more regrettable (although not enough historical material is available in every area) since the historical approach is exceptionally rewarding - especially where it makes use of concepts and ideas evolved by sociology - if combined with a contemporary approach incorporating the same concepts and ideas. By a combination of the two methods of approach (which has been adopted for the present study) the results of historical and contemporary research will form an integrated whole 
enabling us to analyse certain processes by tracing recent developments to certain events and tendencies in the past. This makes for a profounder understanding of such contemporary phenomena as the West Indian family than in the case of an exclusively contemporary approach. Before discussing the authors who have approached the West Indian family chiefly through the study of contemporary factors, I wish to summarize briefly Simey's and Henriques' views.

Simey's work, concentrated chiefly on Jamaica, gives considerable attention to the socio-psychological implications of the colour and class structure of West Indian society, the individual's social position in this type of society being determined principally by his skin colour. Simey's book, which gives the necessary attention to the West Indian family, points out the influence of this on the family system.

Henriques (1953), who went into the matter at greater depth, distinguishes important, historically grown structural differences between the family in the upper and middle classes on the one hand, and the lower classes on the other. The structure and functioning of lower-class households are determined to a significant degree by the unfavourable economic conditions and the connected colour-class system of Jamaican society, the foundations for which were laid during slavery. The lowerclass family differs from the Western "Christian family" of the middle classes and the elite as a result of this. The forms assumed by the family structure in the Caribbean area according to Henriques are "essentially a product of the peculiar conditions of slavery" (Henriques, 1953, p. 103).

All subsequent publications are based almost entirely on research into contemporary factors. R. T. Smith's book (1956) dealing with the family in rural (former British) Guyana, tries to demonstrate that it is impossible for the lower-class Creole male in this colour-class society to fulfil a role of any importance in the family life because of his inferior economic status in consequence of his low and irregular income. "Men, in their role of husband-father, are placed in a position where neither their social status nor their access to, and command of economic resources are of major importance to the functioning of the household group at certain stages of its development." (R. T. Smith, 1956, p. 221).

In the society of Guyana a person's social status was determined chiefly by the colour of his skin. In consequence hereof the rural Negro's opportunities for upward social mobility were exceedingly slight, as they still sometimes are today in the rural areas. (In urban environments colour ceased being a major handicap hampering a person's rise on the 
social ladder much earlier on.) Because as a result of the irregularity of his work as a wage-labourer a man is incapable of contributing much, if anything, to the socio-economic status of his household, he usually occupies a marginal position in it, thus encouraging matrifocality. R. T. Smith's work is extremely important also in that he has pointed out that the different household types, instead of being independent entities, should be regarded rather as phases in the developmental cycle of the family. Hence R. T. Smith was able to make a more subtle analysis of matrifocality in the West Indian family system. I shall discuss this further in section 8.3.2.1.

In Edith Clarke's study (1957), which appeared shortly afterwards, and which is concentrated on three Jamaican communities of different economic levels, the family system of each community is put in relation to the level of prosperity of that community. Her material tends to indicate that the greater a region's economic stability, the higher the percentage of legal marriages and the more stable the relationships between men and women will be in that area.

Another important factor operating on the family system was indicated by Solien de Gonzales (1961, pp. 1264-1279), although other researchers had pointed to it before. She pointed out the connection between the high incidence of male migration for reasons of work and the West Indian family system in the Caribbean area. Thus she also gave prominence to a socio-economic factor. Men are absent from their families in search of paid employment for periods of varying length. The unequal sex ratio which this brings about, according to her, tends to stimulate certain traits characterizing the West Indian family system.

Subsequently M. G. Smith (1962) published a study in which he compared some random samples taken from among the Creole lower classes in various parts of the Caribbean, namely in the isle of Cariacou, in the village of Latante and the town of Grenville in Grenada, and in the rural areas and the town of Kingston in Jamaica.

In his analysis of the West Indian family, M. G. Smith distinguishes four variables determining its structure. These are: (1) the "mating relations" (or visiting relationships, concubinage and marriage); (2) the "distribution of parental roles"; (3) the "form and incidence of different types of domestic groups"; and (4) "the placements of children and grandchildren" in the household types to be found here.

Smith shows by means of a detailed statistical analysis of the five communities studied that the variables distinguished by him are most likely interdependent, but that the "mating relations" should be con- 
sidered the most important. According to Smith, West Indian society offered the ex-slaves scarcely any opportunity of regarding marriage as the obvious type of man-woman relationship after Emancipation (M. G. Smith, 1962, pp. 260-261). In the period of slavery, slaves were not permitted to conclude legal marriages, "but they were free to cohabit consensually or to mate extraresidentially, as they pleased, except that slaves having different owners could scarsely establish a common home. Many old accounts of West Indian slavery describe these conditions. Slave children were the property of their mother's owner. Slaves could contract or dissolve unions informally, at will. Occasional references indicate that slave headman of ten had two or more mates, living with one and visiting the others." There was little change in this pattern after the abolition of slavery. M. G. Smith (1962, p. 261) writes: “..., Emancipation merely permitted the adoption of a new mating form; it could not abolish the old mating system; nor could the new form introduced into this traditional dual system displace either of its original forms."

In Surinam, too, this phenomenon is observable, as we shall see further down in the discussion of the lower-class Creole family after Emancipation.

The series of articles which appeared in 1961 in the journal Social and Economic Studies, edited by Mintz and Davenport, are economically and demographically orientated. In these Cumper (1961, pp. 386-419), among others, established a link between the occupational structure and the composition and functioning of the household in Barbados.

We are able to conclude from the above discussion that we are still far from having reached a consensus of opinion on the factors determining the West Indian family system. A discussion of yet other authors will only strengthen this impression.

By way of introducing some systematic order into the theories on the origin of the West Indian family, Otterbein (1965, pp. 66-79) made an attempt to trace the dependent and independent variables determining the system. Towards this end he analysed and compared twenty different studies on the subject. By testing the tenability of the hypotheses that "the greater the number of men who earn and save money to build a home, the lower the percentage of consensual unions" and "the greater the surplus of females, the higher the percentage of female-headed households", he arrives at the conclusion that both economic and demographic factors and the imbalance between the sexes are the principal determinants of the West Indian family system. Otterbein regards the 
the West Indian family as a phenomenon which may evolve in a fairly complex economic structure, namely a money economy. In such a system husbands and wives may often be separated for long periods of time as a result of the employment situation, in West Indian society because underemployment frequently forced husbands to go away for long periods on end to work in places other than where their families were resident. This phenomenon will usually encourage the development of an unequal sex ratio. (In Surinam, too, the phenomenon of husbands working far away from home is observable both in the past and at present, as we shall see further down.)

Kunstadter, in an attempt to arrive at some sort of a compromise in the theories on the matrifocal family drawing on material from areas outside the Caribbean as well, reaches a similar conclusion, viz.: "The importance of a money economy for the matrifocal family seems to be that money is associated with complex economies, and complex economies are necessary for the type of division of labour which separates most adult males from adult females within the local community. To summarise, the proportion of matrifocal families in the community appears to be a function (in the mathematical and social sense) of the degree of physical separation of adult males and adult females involved in the division of labour. In order for this physical separation to take place, the group in question must be a part of a larger economic system, and that system, as a concomitant of its complexity, usually will use money as a medium of exchange." (Kunstadter, 1963, p. 62).

\subsubsection{Poverty and the "West Indian" Family System}

These conclusions of Otterbein and Kunstadter's are to some extent in concordance with the views of Oscar Lewis, who pointed out that family systems characterized by "matrifocality, a high incidence of consensual unions and high percentage of households headed by women" are also to be found outside the Caribbean area and the Negro culture of the United States (Lewis, 1969, p. 58).

According to Lewis, these features are not "distinctive of Caribbean family organization or of Negro family life in the U.S.A.", but are an aspect of life in a "culture of poverty". This cultural type ${ }^{7}$ has evolved in money economies in many parts of the world. Lewis described it from

7 "While the term 'subculture of poverty' is technically more accurate, I have used 'culture of poverty' as a shorter form", as Lewis (1969, p. 48) informs us. 
the perspective of the institution of the family in Mexico City, Puerto Rico and New York (Lewis, 1959, 1961, 1969).

Lewis says that a "culture of poverty" ensues in the case of the collapse of a stratified socio-economic system, or its supersession by another system, such as the replacement of feudalism by capitalism, or in cases of rapid technological change (Lewis, 1959, p. 50). It thrives in the pre-welfare state phase of capitalism and is therefore endemic in colonized areas, where the socio-economic system of the colonized people has been annihilated and the subjected people are placed in a position of servility (Lewis, 1966, p. 24).

The "culture of poverty" comes to constitute the style of life of a proportion of the poor of a society where the following conditions are present: "(1) the setting is a cash economy, with wage labor and production for profit and with a persistently high rate of unemployment and underemployment, at low wages, for unskilled labour, (2) the society fails to provide social, political and economic organization, on either a voluntary basis or by government imposition, for the low income population, (3) there is a bilateral kinship system, centered on the nuclear progenitive family, as distinguished from the unilateral extended kinship system of lineage and clan, (4) the dominant class asserts a set of values that prizes thrift and the accumulation of wealth and property, stresses the possibility of upward mobility and explains low economic status as the result of individual inadequacy and inferiority." (Lewis, 1966, pp. 21 and 24.)

Not all of the "poor" are participants of this culture in this world. The distinctive feature characterizing the participants of the culture of poverty is that they do not effectively participate in and are not integrated into the principal institutions of the society of which the culture of poverty constitutes a subculture. The causes of this are: the low wages paid them, the chronic unemployment under which they labour, their lack of property or savings, and their perennial shortage of cash (Lewis, 1969, p. 51).

Although Lewis's hypotheses concerning the concept of "culture of poverty" have recently come under fierce attack on methodological grounds (Goetze, 1971, pp. 223-246), his monographs in the field of family sociology in my view are even so sufficiently conclusive for a correlation between poverty and unemployment on the one hand and a matrifocal family structure on the other to be considered plausible (cf., among others, Lewis, 1959, 1961, 1969).

However that may be, it will be convenient for our further discourse 
to proceed from the assumption, despite the lack of ultimate explanations concerning the origin of the "West Indian" family (which may also exist outside this area), that it is possible for this type of family system to evolve where: (1) a proportion of the male members of a society are prevented from earning regular incomes with which to support a wife and children; (2) there is an unequal sex ratio; (3) the society in question possesses a hierarchical structure in which upward social mobility is virtually impossible for the lower classes (in connection with their skin colour or for other reasons).

The family system that develops under these circumstances is to be regarded as an adaptation ${ }^{8}$ to the adverse circumstances under which a given group is forced to live. It should not therefore be viewed as a sign of "disintegration" or characterized as "pathological", but should rather be regarded as a response to the unfavourable circumstances under which certain groups of people were formerly and are at present compelled to live in certain areas all over the world.

The way in which this functioned - and still functions today - in Paramaribo will be discussed in greater detail in the present book, with the aim of determining how this type of system evolved in the course of history and survived down to the present day in this tropical town.

\subsection{The Situation in Surinam}

One might contend that the changes in a society are nowhere better reflected than in the family system. Although this generalization may hold true for most societies, it does not apply to that of Surinam, as here there has been little or no essential change in the family system of the lower-class Creoles, in spite of far-reaching changes in the society at large in the course of the centuries. Whether we contemplate the family system of the Negroid population in the period of slavery, in the postEmancipation period after 1863, or in the contemporary, post-colonial society of Surinam, we cannot fail to be struck by the unchanging uniformity of the characteristics preserved by it in all these periods, and

8 We have used the concept of adaptation here as defined by Schvaneveldt (1966, p. 108), as follows:

"Adaptation is family and individual survival or integration in a given cultural milieu. It refers to the process of adjusting to new or different conditions. It may also be used to indicate cultural modifications to suit a particular human environment. Adaptation is the process of acquiring fitness to live in a given environment." 
by the fact that only a small number of insignificant elements of this system have altered over the years.

The society of Surinam as a whole, on the other hand, has undergone some major changes of character from the days when the plantation colony was founded in the mid-17th century to the present day. It changed from a society whose economy was shaped by extensive farming involving the cultivation of staple products for overseas markets on plantations with the aid of slave labour, and later contract labour, into a society of which intensive farming involving chiefly the cultivation of products for the home market, and bauxite-mining for the overseas market are the principal economic activities.

This change took place by a fairly gradual process - the history of Surinam contains virtually no record of any sudden, drastic changes. We are even so able to mention three events which, especially because they left a particular impress on the Creole population, may serve as period markers in the history of Surinam for the purposes of our present discussion. In the first place we should mention the abolition of the slave trade in 1808 (occasioning a shortage of slave labour on the plantations); secondly, the emancipation of the slaves in 1863, accelerating the decline of the plantation system despite the importation of contract labourers; and thirdly, decolonization in the post-war period, which also brought in its wake many far-reaching changes in the social conditions in Surinam. On the basis of these events I have divided the history of Surinam into the following periods: (1) the period from the foundation of the plantation colony to the abolition of the slave trade in 1808 ; (2) the period from 1808 up to Emancipation in 1863; (3) the period from 1863 up to and including decolonization after World War II; (4) the present, post-decolonization period.

Surprise at the Creole lower-class family's displaying a uniform basic pattern in all of these four periods has led me to formulate a number of hypotheses in connection with the process of social change. They are:

A. Notwithstanding the major social changes that have taken place in the course of the history of Surinam, the family system of the lowerclass Creoles of Paramaribo has remained virtually unchanged.

B. In view of the fact that the social conditions in Surinam have in the course of its history periodically prevented, and are still preventing today, a proportion of the lower-class Creole males from providing for their wives and children, a flexible family system has developed, in which women may to a certain extent take over this function the 
moment a man is unable or unwilling to exercise it. The family system that is in force as a result of this stresses matrilineal kinship ties.

C. Improvement in the socio-economic position of the lower-class Creoles will result in a drop in the number of female-headed households.

I shall endeavour to demonstrate the tenability of these hypotheses below by trying to give an idea on the basis of both historical and contemporary, locally collected material of what the family system of the lower-class Creole looked like in the course of the history of Surinam and what it is like today. I wish at the same time to demonstrate that it was imperative for the lower-class Creole to evolve this system in order to ensure the survival of his group.

I intend to analyse the family system for each of the abovesaid periods by answering, wherever possible, the following questions:

(a) What kinds of man-woman relationships are observable? What is their spread? How are they brought about? How stable are they? What reasons do the respective partners have for entering into any particular one of these kinds of union? What are the consequences of their choice? What social factors which will explain the presence of the existing alternative unions between men and women can we discover?

(b) What types of household can we observe? What is their size and composition? What is their dispersion? What is the cause of this dispersion?

(c) Who is the person exercising authority in the types of household found? What is the reason for this? What are the mutual relations between the head and other members of the household like? Is there any question of matrifocality?

(d) What is life in the various types of household like and what are the circumstances under which it is lived? What are the household's sources of income? Who brings up the children?

(e) What is the attitude of men and women to the prevalent kinds of union between the sexes and the types of household? What are the norms and values regulating the system?

(f) What are the views of the government, private individuals and church leaders on the family system? How do they react to the system?

Following this, we shall try to discover, by comparing the family systems of each of these periods with one another, whether the system has, in fact, remained constant, or whether there have been or are likely to be changes in a particular direction. I also wish to compare my 
material with data on the Negro family in the Western hemisphere collected elsewhere. $^{9}$

The layout of the remainder of the present book is as follows:

Chapter 2 contains a brief description of the geography, history, economy and ethnic composition of Surinam. In the discussion of the different ethnic groups, most of the attention will be given to the lowerclass Creoles and their culture. This chapter will conclude with an explanation of why I have divided the history of Surinam into the abovementioned periods for the purposes of testing my hypotheses as set out above.

In chapter 3 I shall explain why Paramaribo was chosen as the place of research; this will be followed by a description of the methods used in carrying out the research.

Chapters 4, 5 and 6 will follow this up with a description of what the family system looked like in the past.

Chapters 7, 8 and 9, subsequently, contain a description of the contemporary situation, followed in chapter 10 by a discussion in which this system will be represented as a flexible adaptation to the socioeconomically adverse circumstances under which the lower-class Creoles have lived since their arrival in Surinam. We shall further try to find an answer to the question of in what direction the system is likely to develop in the future, or in other words, whether hypothesis C. is tenable.

9 Cf. for Surinam and Curaçao Buschkens and Marks (1966). 


\section{SURINAM}

By way of acquainting the reader with the background of the society of Surinam as a whole, as the setting within which the family system of the lower class Creoles evolved, we give below a brief outline of the geography, history and demography of Surinam.

\subsection{Geography}

Surinam forms part of the Guianas region, located in the northeastern part of the South American continent. The Guianas are bounded in the north and east by the Atlantic Ocean, in the south by the Amazon River and the Rio Negro, and in the west by the Orinoco and Casiquiare Rivers.

Surinam, which covers the middle part of this region, borders in the west on Guyana (former British Guiana), in the east on French Guiana (Cayenne) and in the south on Brazil. The Guiana region comprises not only these three countries, but also part of Venezuela and Brazil. The portion of the Guianas that belongs to Venezuela constitutes part of the territory of Delta Amacuro and the state of Bolivar, while that belonging to Brazil constitutes the federal territory of Amapá, being a semi-autonomous state of that country.

Culturally the Guianas can be classed with the Caribbean area rather than Latin America. Guyana, Surinam and French Guiana in fact maintain closer relations with the Caribbean islands than with Latin America. While further the population of the Guianas displays considerable cultural and racial affinity with the inhabitants of most of the Caribbean countries, especially because the negroid element constitutes a majority and is predominant here.

Surinam is located between $2^{\circ}$ and $6^{\circ}$ north latitude and $54^{\circ}$ and $58^{\circ}$ west longitude. It covers a surface area of 142,822 square kilometres.

The country is situated in a tropical rain forest area, and is divided into four regions extending in a west-east direction, each with its own specific soil conditions. These are intersected by large rivers. These rivers have deposited a belt of fertile, clayey soil along the coast, which can be 
divided into an old and a new coastal plain. The soil of the new coastal plain consists of clay with sand and shell ridges. Here is found the largest proportion of tilled land, which could be cultivated chiefly as a result of the reclamation of these tracts from the sea, and it is in this area that the bulk of the population is concentrated. The old coastal plain comprises a rather more elevated belt located slightly further inland, which is composed of a thick layer of clay mixed with large quantities of sand. The original vegetation of the coastal plain consists of mangroves and primeval forest. This is followed by a strip of savanna with coarse sandy soil, covered with grass, scrub and scattered trees. These savannas grade into a partly mountainous strip of granite and other rock types, which forms part of the Brazilian Shield. The better part of this area is covered with primeval forest.

Paramaribo, the capital of Surinam, is a seaport and administrative centre located on the Suriname River in the coastal plain. It has a population of 110,867 , according to the 1964 census. The climatic and soil conditions of the coastal region render the latter eminently suited for agriculture. Farming has in fact been practised intensively here ever since the definitive settlement of English and Dutch colonists at the beginning of the second half of the 17 th century. Developments in agriculture have left a distinct impress on the history of Surinam. For in this connection it was especially the demand for agricultural labour that explains the presence of different ethnic groups here.

\subsection{Political Development}

The Guianas were discovered by the Spanish in 1499. Rumours to the effect that this was the location of the treasure city of El Dorado soon thereafter lured the English, Dutch and French to the area as well.

In the beginning trade was carried on with the Amerindians only with a view to obtaining tropical products. Attempts at permanent settlement by colonists for the purpose of growing these products themselves at first failed, either because of hostility on the part of the Amerindians or as a result of conflicts between the different colonizing nations mutually. After 1650 Surinam became an organized agricultural colony with many sugar plantations under Francis Willoughby, Baron of Parham, who encouraged about 300 British planters from Barbados to settle in the coastal region of Surinam.

In 1666 Jewish and French refugees from Brazil and Cayenne also arrived, and were assimilated by the rest of the population of the colony. 
These Jewish immigrants were well-to-do persons bringing their wealth and slaves with them and, more important still, turning to account here the knowledge of plantation farming acquired by them in Brazil (cf. Van Lier, 1971, p. 85).

The British period came to a close in 1667, when the Zealander Abraham Crijnssen, as commander of a fleet of seven vessels, conquered Surinam in a war between England and the Republic of the United Netherlands. In that same year the colony was re-conquered by the British, though Surinam was restored to the Republic at the Peace of Breda (1667). On 1st May, 1668, Crijnssen assumed the temporary governorship, this being taken over the following year by Philips Julius van Lichtenbergh.

After protracted wrangling about the sovereignty of this territory between the States General and the States of Zealand, the Dutch West India Company finally became the monopolistic proprietor of the colony through purchase of the same from the States of Zealand and by virtue of a charter from the States General. Shortly after that, in 1683, the Company went into partnership with the city of Amsterdam and the Van Aerssen van Sommelsdijk family to form the company named 'De Geoctroyeerde Sociëteit van Suriname' (The Chartered Society of Surinam). Each of the partners possessed a one third share in the capital and assets of this company, which remained responsible up to 1795 for the exploitation and the government and administration of the colony. In this latter year the Society was wound up by the States General, Surinam coming under direct Dutch rule. During the period of administration by the Society, the Van Aerssens family sold its share to the city of Amsterdam in 1770, the latter thereby becoming the principal proprietor.

The country has remained Dutch territory down to the present day, except for a short British interregnum in the Napoleonic period, when England exercised its rule from 1799-1802 and 1804-1816.

In Surinam the colonial period came to an end in 1954. Together with the Netherlands and the Dutch Antilles the country became one of the three equal partners in the Realm of the Netherlands according to the Statute, a Constitution for the Kingdom of the Netherlands, framed at that time. It possesses full autonomy with regard to all internal affairs. Only external relations and defense are regulated by the three partners jointly in accordance with the articles of the Statute.

The government of Surinam is made up of a Governor, acting as representative of the Queen as sovereign of the Kingdom, and a Cabinet 
Council. The ministers are politically responsible to a Parliament, called the States of Surinam, comprising 36 members.

The population at large has only been participating in the political life of the country since the introduction of the general electoral franchise pursuant to an amendment of the Constitution of Surinam by Act of Parliament of 21st May, 1948. Before that time the Governor had a wide range of powers, whereas the States of Surinam possessed only limited parliamentary rights, with the Mother Country having the right of intervention and the power of enacting laws of a binding nature in special emergency situations. The members of the States were elected by a mere $2 \%$ of the population on the basis of a property qualification and educational qualification franchise. This electoral body consisted virtually exclusively of light-skinned Creoles from the higher social strata. At present every male and female citizen of Surinam in possession of the Dutch nationality and over the age of 23 has the right to vote (cf. Buiskool, 1954, pp. 30 ff.).

The electoral system of Surinam is a mixed one. Of the Staten members 24 are elected directly by the electorate, which is divided into electoral districts instituted by governmental ordinance, while twelve are elected according to the proportional representation system. Paramaribo town comprises one electoral district and has ten representatives, as against 14 for the other electoral districts combined. The Ministers are appointed by the Governor. There are eleven ministerial departments in Surinam.

The composition of the political parties is based chiefly on ethnic principles. An insignificant part is played in this respect by either class distinctions or political ideologies. During the period I was conducting research in Surinam the chief political party was the Nationale Partij Suriname (National Party of Surinam) or NPS, the members of which belonged principally to the Creole lower classes. The second major party was the Verenigde Hindostaanse Partij or VHP (United Hindustani Party), which has its support among the majority of the Hindustani population. The third major party is the Kaum Tani Persatuan Indonesia (KTPI), representing most of the Indonesians. There are further the Progressieve Surinaamse Volkspartij (PSV, = Progressive People's Party of Surinam), a medium-sized party comprising chiefly Roman Catholic Creoles and Chinese; the liberal Surinaamse Democratische Partij (SDP, = Democratic Party of Surinam), which is similarly a medium-sized party made up of Creoles, though it has a stronger middle and upper class representation; as well as a Hindustani Actie Groep 
(AG, = Action Group) and a leftist, nationalistic Partij Nationalistische Republiek (PNR, = Nationalistic Republican Party).

Surinam is divided into the following eight districts: Paramaribo, Suriname, Commewijne, Brokopondo, Nickerie, Coronie, Marowijne and Saramacca. Government at the district level is exercised by district commissioners.

\subsection{History of Agriculture}

It is agriculture that determined the fate of Surinam and its inhabitants, as it will continue to do to a large extent in the future as well. An outline of the development of agriculture is indispensable for a proper understanding of the country, therefore.

\subsubsection{Plantation Agriculture}

Up to the beginning of the 20th century the basis of the economy of Surinam was provided by plantation agriculture, aimed at the supply of overseas markets with its products. Sugar, a luxury commodity, was for a long time the chief export product, which fetched high prices on the European market up to the 19th century.

The development of the plantation system was as follows. Surinam began to develop into an important sugar producer as far back as the earliest period of British colonization under Willoughby. The surface area of farms was on the whole still limited in that period. The colonists worked plots of land located chiefly on the high river-banks on the upper reaches of the rivers - since the idea of draining low-lying land had not yet suggested itself - with the assistance of a handful of Amerindian or Negro slaves and English labourers (who were often convicts). On the lower reaches of the major rivers only the occasional sand ridges which remained dry at high tide were brought into cultivation (Quintus Bosz, 1954, p. 23). Apart from that, farming was practised by the Jewish members of the population in the "Joode Savane", on the right bank of the Suriname River, "ten hours' rowing distance" up-stream from Paramaribo.

The development of agriculture was accelerated when the Dutch took possession of the colony in 1667, as they had considerable experience in farming in low-lying coastal areas. In consequence of their skill at dike construction, land reclamation and drainage, added to the experience in sugar-growing gained in Berbice, Demerara, Essequibo and Brazil, they succeeded in bringing many fertile areas into cultivation, 
so that Surinam began to outstrip its neighbours on the point of agricultural output. The Dutch furthermore proceeded to work larger farms. The necessary land for this was acquired by reclaiming and protecting with dikes large tracts of land situated chiefly on the lower reaches of the Commewijne and Suriname Rivers.

This type of agriculture, involving production for the export market with the aid of slave or contract labour according to a plantation system, has determined the socio-economic structure of Surinam up to the beginning of the present century. The effective functioning of an economy based on this is dependent on three conditions, viz.:

(a) the availability of markets for one's products; (b) capital; and (c) labour with which to till the soil. These conditions were not continuously maximally present, however. Consequently plantation farming experienced many ups and downs, eventually to virtually disappear altogether and give way to small-scale agriculture. This process is described by Van Lier (1971) in his study on the society of Surinam. Shortage of labour can invariably be identified as one of the causes of the decline of the plantation system.

The Dutch West India Company, which monopolized the slave trade to Surinam until 1789, did not always import a sufficient number of slave labourers, as it habitually made light of its obligation to import at least 2500 slaves annually - low imports resulted in high prices for slaves! (Unger, 1956, p. 157). After that time as well, private slave dealers were not always successful in meeting the demand for slaves either. The market for tropical products, and more specifically sugar, posed no problems until the beginning of the 19th century, however. Until then demands always exceeded supplies. Surinam had one significant advantage over Southeast Asian countries producing these same commodities: the shorter route to the European markets. Surinam also had this advantage in respect of the Pacific seaboard regions of America (i.e., before the digging of the Panama Canal).

In the earliest period only small financial investments were made in Surinam by the Netherlands. This situation changed in the 1730's, when more finance became available in the Netherlands for investment in overseas territories. Surinam then experienced an economic boom, being regarded as one of the Republic's wealthiest colonies. Besides sugar, other products such as coffee, cotton and cocoa were now grown as well. This "boom period" was short-lived, however. Bush Negro attacks on the plantations and a slave rebellion in neighbouring Berbice made Surinam a less attractive investment for Dutch investors. The effects of 
the Amsterdam stock exchange crash of 1773 were also disastrous for plantation farming in Surinam, forcing many planters to sell out, so that their plantations fell into the hands of Amsterdam creditors whose sole aim was to make maximum profits with minimum investments, running their properties through the agency of administrateurs or estate superintendents appointed by them.

Other factors exercising a negative influence on plantation farming were the exceptionally poor harvests of 1770 , the fall in prices of agrarian products in the 1770's, the fourth Anglo-Dutch War (1780-'84), and the French Revolution. As a result of Napoleon's Continental Policy major obstacles were thereupon put in the way of exports of commodities to Europe. There was a slight revival of the economy during the British interregnum in Surinam from 1799-1802 and 1804-1816, because it became possible in consequence hereof to sell products to England and the U.S.A. (Panday, 1959).

A factor which finally dealt the plantation system a fatal blow was the abolition of the slave trade by England in 1808. The regulation according to which no slaves were to be imported in any British colony as from 1st March, 1808, also applied to Surinam, as England was governing Surinam at the time. By the time the government of Surinam was taken over by the Netherlands again in 1816, the treaty regarding the abolition of the slave trade meanwhile concluded by England and the Netherlands jointly on 15th August, 1815, had come into force for Surinam (cf. Unger, 1956, pp. 173, 174). Despite the development in consequence of these regulations of a contraband trade which was more brutal than the former official trade had ever been, there arose an ever increasing shortage of labour. The introduction of beet sugar on the European market and competition from other areas (such as, for example, by American cotton) hastened the final collapse of the plantation system, the fate of which was sealed by the abolition of slavery in 1863. Especially the latter event did much to make the problems in connection with the supply of labour manifest themselves fully. Although initially the effects of this were apparently mitigated by the statutory provision decreeing that all newly released slaves should remain under state supervision for a period of ten years, during which time it was compulsory for them to enter into labour contracts, at the end of this period the Negro labourers left the estates in large numbers to seek employment elsewhere.

Both private enterprise and the government endeavoured to deal effectively with the labour shortage ensuing after the abolition of the 
slave trade and subsequent Emancipation through a scheme involving the immigration of contract-labourers. The government imported the first indentured labourers -- 18 Chinese from Java - into Surinam in 1853, i.e., ten years before Emancipation. In that same year similarly 120 Portuguese contract-labourers were brought into the country from Madeira by private individuals, and another 155 the following year. In 1858 another 500 immigrants entered the country with government assistance, this time coming direct from China (De Klerk, 1953, pp. 34 and 35), whence 2014 immigrants were imported by private enterprise in the years between 1866 and 1869. Labourers were further brought here from the Azores, Madeira, the Canary and Cape Verde Islands and from Barbados to make up the shortage. Their numbers proved insufficient in meeting the demand for labour, however, especially when the importation of labourers from China organized by private enterprise came to a halt after 1869, when the British government closed the port of Hongkong, the port of embarkation of most of these labourers, to emigrants to countries other than the British colonies, a measure similarly introduced in respect of the port of Macao by the Portuguese government in 1874. Meanwhile the Chinese government had also proscribed emigration on a contract basis for its subjects (cf. Encyclopaedie, 1917-'19, p. 374).

In order to alleviate the chronic shortage, the Netherlands government concluded a contract with the British government in 1870, under the terms of which it had permission to recruit labour in British India. As a result the situation improved slightly. In the period from 1873-1918, in which year England repealed the treaty, over 34,000 Hindustanis were brought into Surinam, 12,000 of whom repatriated again. A commencement was also made with the supply of labour from Dutch colonies. Thus a total of 32,956 residents of the Netherlands Indies - the greater majority of them Javanese - emigrated to Surinam as contractlabourers in the period between 1890 and 1939, less than 9000 of whom left the country again (cf. Ismael, 1949, pp. 95, 96; De Waal Malefijt, 1963, pp. 26 and 28). These Indonesians - and to a much higher degree the Hindustanis - seldom extended their contracts upon expiry of the term stipulated therein, but settled as smallholders, which trend was encouraged by the government (cf. De Klerk, 1953, pp. 160-179, 199; Speckmann, 1965, p. 39).

It was impossible, despite the renewed immigration of contractlabourers, to redevelop plantation agriculture, so that the latter, as we shall see below, was definitely superseded by smallhold farming after 1900 . 


\subsubsection{Small-scale Agriculture}

This type of agriculture was first practised in Surinam by a group of Dutch farmers settling in the Saramacca district, near the town of Groningen, in 1845. This colonization scheme miscarried as a result of bad organization. Other pioneers of smallhold farming we should mention were a number of manumitted slaves who settled on the outskirts of Paramaribo and tried to sell a portion of their produce on the town market.

The government has always striven to stimulate smallhold farming. In 1862, a year before Emancipation, it laid out a settlement for exslaves in Totness, in the Coronie district. After Emancipation other such settlements were opened for this group, namely in Nieuw Amsterdam and in Domburg, in 1875 and 1877 respectively.

Most of the manumitted slaves settled in other areas, however, occupying derelict plantations, where they took up cocoa-growing and the production of food crops for their personal consumption, after a number of plantations had begun to specialise in this before Emancipation, as cocoa-growing is not labour intensive. The freed slaves carried on with the production of this crop on their smallholdings, out of which many of them made a good to extremely comfortable living up to the turn of the century. Unfortunately the cocoa-growing industry collapsed after 1895, when as a result of the onslaught of the witches'-broom disease on the cocoa trees production declined slowly at first, but with ever increasing speed after that, to disappear almost entirely by 1928 . This deprived most of the Creole smallholders of their livelihood. They moved to Paramaribo town in large numbers, in search of other means of subsistence. Subsequent to the crisis in the industries in the interior (e.g. the balata industry) - where many Creoles from town had found employment - which made itself felt in 1932, there was a drift back to the land on the part of lower class Creoles; so we see the number of lower class Creoles engaged in smallhold farming increase after 1933 (cf. Van Lier, 1971, p. 233). Despite this remigration to the rural areas, the Creole has failed to win himself an important place in smallhold farming. Predominantly Creole communities engaged in small-scale agriculture are to be found only in Coronie and Para today. The Hindustanis and Indonesians fared considerably better in this branch of agriculture. The Hindustanis in particular usually left the plantations immediately upon expiry of their contracts to try and make a living by tilling the plots of land placed at their disposal through the intermediary 
of the government. Both they and the Indonesians began to concentrate especially on rice-growing after 1900 . The latter branch of agriculture expanded considerably as a result. The planting of rice was encouraged by the government in World War I, so that consequently the expansion of rice-growing assumed even larger proportions after that. Notwithstanding the government's incessant exhortations to smallholders to diversify their crops by growing bananas, cocoa, coffee and citrus fruits as well, these have remained to a large extent unheeded, rice being grown on $92 \%$ of the total surface area reserved for annual crops (Second agrarian census Surinam, 1959, p. 25).

The process whereby extensive farming was replaced by small-scale agriculture, the foundations for which were laid in the 19th century, only really gained momentum after 1910, as will become apparent from the table below.

Table 1. Share in the total agrarian output of large-scale and small-scale agriculture respectively, expressed in percentages

\begin{tabular}{ccc}
\hline Year & Large-scale Agriculture & Small-scale Agriculture \\
\hline 1900 & 90 & 10 \\
1910 & 72 & 28 \\
1920 & 29 & 71 \\
1930 & 29 & 71 \\
1940 & 17 & 83 \\
1950 & 10 & 90 \\
\hline
\end{tabular}

(Statistics drawn from N.O.S. 1965, p. 16.)

The agricultural scene in Surinam at present is decidedly dominated by smallhold farming, which latter is monopolized almost entirely by Hindustanis and Indonesians.

\subsection{Other Sectors of the Economy}

After their failure as smallholders the lower class Creoles flocked to Paramaribo in large numbers. A large proportion of these found employment in the gold-mining industry, which was just then in the first stages of development. Gold-mining concessions were granted to private individuals in Surinam as early as 1875 . The necessary labourers for this were recruited mainly from among the Creoles as well as similarly negroid groups in British Guiana, Barbados, St. Lucia and Dominica. The employment in this industry of immigrants whom the government was 
bringing into the country for the benefit of large-scale agriculture was prohibited.

Gold-mining, which is not highly mechanized, is being carried on for the greater part by individual prospectors, who use very primitive methods. Apart from the gold industry, many lower class Creoles also found employment in the balata industry (balata is the dried juice of the bully tree, which is found scattered throughout the forests of Surinam). The collection of balata on a commercial basis was not begun until after 1890. Production steadily increased after 1900, until the balata-producing areas were finally exhausted in the 1920's. At present no more than 500 men, chiefly Bush Negroes and a few Amerindians, are employed in this industry (De West, 6th April, 1965, p. 2).

Logging has also provided a livelihood for many urban lower class Creoles. Initially this activity was carried on exclusively on the so-called timber plantations on which trees cut down in the surrounding forests were processed. After Emancipation these plantations also fell into neglect, after which the work of cutting down trees and transporting the logs down the rivers was taken over almost exclusively by Bush Negroes. After the relations with them became more peaceful they gradually took to timber-felling, selling the logs, which they first cut up into blocks, to dealers or sawmill agents below the falls. By virtue of the principle adopted by the government according to which timber-felling in the Bush could be carried on freely by the Bush Negroes, the latter required no licences for this kind of work and no taxes were levied on the timber felled by them. Towards the end of last century the government also began granting timber-felling licences to small private enterprises in the Bush. These small undertakings also employed Bush Negroes as labourers and carriers (Brons, 1952, pp. 159-160). These industries offered no new employment opportunities to the lower-class Creoles of Paramaribo, however. A flourishing, large-scale timber industry did not develop until after 1947, when the exportation of timber began to yield profits. The principal company engaged in this is N.V. Bruynzeel, which processes part of the timber transported to Paramaribo into finished products locally. It employs Surinamers from all ethnic groups, so that many lower-class Creoles have found a living here.

Although timber-getting and processing are extremely important today, even so the bauxite mining industry can justifiably be described as constituting the principal sector of the economy at present. In 1916 the American Bauxite Company, the present Suriname Aluminium Co. "Suralco", a subsidiary of the Aluminnium Company of America, was 
granted a bauxite mining concession with respect to the bauxite deposits on the Cottica River, near Moengo. Bauxite exports from Surinam first began in 1922. In later years the abovementioned company also began to work the bauxite deposits near the Suriname River, on which spot the town of Paranam sprang up. Years later (in 1941) the Dutch company N.V. Billiton entered the scene as its competitor in the bauxite mining industry at the instigation of the Dutch government (N.O.S. 1965, p. 20).

Bauxite exports in 1964 came to $82 \%$ of the total value of exports (Report of the Central Bank of Surinam 1964, p. 58). Surinam's share in the total world output came to $15 \%$ in 1964 (ibid., p. 59). With a view to processing part of the bauxite mined in Surinam into aluminium locally, instead of exclusively producing raw materials for the export market, Suralco has constructed a dam in the Suriname River - which was completed in February, 1964, near Afobaka, for generating the necessary power for processing. This has produced the extensive lake called Prof. Dr. Ir. W. J. van Blommesteinmeer. Aluminium is now being locally produced by the electrolytic method in the aluminium smelting works at Paranam.

Surinam is a developing country. The standard of living of the majority of its citizens is extremely modest. The per capita annual income in 1960 was about 500 Surinam florins (Kool, 1964, p. 123), the equivalent of about $\$ 250$.- . Even so, the population has on the whole made marked progress socially since the beginning of World War II. The real per capita national product (at factor cost) increased by $34 \%$ in the period from 1955 - the year in which the first Ten Year Plan was implemented - to 1968 (Van Lier, 1971, p. 396). Unfortunately unemployment is high here despite these improvements, being especially so in the urban areas. Because of the fact that most directly productive investments are creating few employment opportunities, the chances of curbing the process of rising unemployment and the resultant growing poverty, especially among the urban population, are low.

\subsection{The Demographic Situation}

As became apparent from the above, the population of Surinam is extremely heterogenous as a consequence of the immigration of labourers from various parts of the world. The society is classed as a so-called plural society, which term is generally used with reference to societies composed of two or more ethnic groups, each with a different culture. 
The different ethnic groups are clearly distinguishable in Surinam, in spite of assimilation and amalgamation. Each group has its own culture and language. Sranang (or Negro English) is spoken by the Creoles, Hindi by the Hindustanis, Javanese by the Indonesians, and Hakka, a Chinese dialect, by the Chinese, while the various Amerindian and Bush Negro groups also each speak their own language. For interethnic communication the different groups frequently resort to Sranang. The official language is Dutch, however, being used as medium in education.

According to the 1964 general census, the population in that year presented the following picture:

Table 2. Composition of the Population of Surinam at the end of March, 1964

\begin{tabular}{|c|c|c|c|c|c|c|}
\hline \multirow[t]{2}{*}{ Nationality } & \multicolumn{3}{|c|}{ Paramaribo } & \multicolumn{3}{|c|}{ Whole of Surinam } \\
\hline & $\mathbf{M}$ & $\mathbf{F}$ & $\mathrm{T}$ & $\mathbf{M}$ & $\mathbf{F}$ & $\mathrm{T}$ \\
\hline \multicolumn{7}{|c|}{$\begin{array}{l}\text { (Excluding those } \\
\text { living in tribes) }\end{array}$} \\
\hline Greole & 31,892 & 35,652 & 67,544 & 56,078 & 58,883 & 114,961 \\
\hline Hindustani & 12,701 & 12,736 & 25,437 & 56,984 & 55,739 & 112,633 \\
\hline Indonesian & 3,915 & 4,048 & 7,963 & 24,733 & 23,730 & 48,463 \\
\hline Amerindian & 613 & 729 & 1,342 & 1,434 & 1,545 & 2,979 \\
\hline Chinese & 2,126 & 1,743 & 3,869 & 2,962 & 2,377 & 5,339 \\
\hline European & 1,074 & 1,123 & 2,197 & 2,160 & 2,162 & 4,322 \\
\hline Others & 842 & 899 & 1,741 & 1,781 & 1,727 & 3,508 \\
\hline Total & 53,163 & 56,930 & 110,093 & 146,042 & 146,163 & 292,205 \\
\hline \multicolumn{7}{|l|}{ (living in tribes) } \\
\hline Bush Negroes & 385 & 283 & 668 & 13,603 & 14,095 & 27,698 \\
\hline Amerindians & 57 & 49 & 106 & 2,210 & 2,098 & 4,308 \\
\hline Total & 442 & 332 & 774 & 15,813 & 16,193 & 32,006 \\
\hline General Total & 53,605 & 57,262 & 110,867 & 161,855 & 162,356 & 324,211 \\
\hline
\end{tabular}

(Statistics drawn from General Census 1964.)

Quantitatively the most important groups are formed by the Creoles, the Hindustanis and the Indonesians. The majority of the Creoles live in and around Paramaribo. The percentage of the total population comprised by the Creoles has decreased steadily since the arrival of Hindustanis and Indonesians migrating to Surinam as contract-labourers. 
This has given rise to a feeling of discomfort on their part, afraid as they are of losing their dominant politico-economic position. The Hindustanis are increasing at a faster rate than the Creoles. As a result the population composition has changed radically over the past three decades, as will be clear from the following table.

Table 3. Distribution of the population in percentages, excluding those living in tribes

\begin{tabular}{lrrr}
\hline & 1922 & 1950 & 1964 \\
\hline Creoles & 50.0 & 41.0 & 39.0 \\
Hindustanis & 27,0 & 35.0 & 38.5 \\
Indonesians & 17.0 & 20.0 & 16.5 \\
Others & 6.0 & 4.0 & 6.0 \\
\cline { 2 - 4 } Total & 100.0 & 100.0 & 100.0 \\
\hline
\end{tabular}

(Statistics drawn from: Van der Kuyp, Walvis and Van Lier, 1959, General Census 1964.)

Apart from the drastic changes in ethnic composition of the population over the past fifty years, a substantial change has also occurred in the total population figure.

Table 4. Population growth, excluding those living in tribes

\begin{tabular}{ccc}
\hline & Paramaribo & Whole of Surinam \\
\hline 1914 & 35,530 & 85,536 \\
1922 & 43,757 & 110,933 \\
1950 & 74,337 & 204,730 \\
1964 & 110,093 & 292,205 \\
\hline
\end{tabular}

At the beginning of the 1920's the growth rate was $1.4 \%$. It thereupon increased rapidly, rising to $3.5 \%$ between 1951 and 1955. In 1959 it rose to even $4 \%$, this being one of the highest in the world (cf. Lamur, 1973, pp. 135-136).

\subsubsection{Religious distribution of the population}

One of the corollaries of the plurality of the society is the exceptionally large number of religions and religious denominations in Surinam. 
Table 5. Religious distribution of the population of Surinam in 1964

\begin{tabular}{lrr}
\hline & Paramaribo & Whole of Surinam \\
\hline Moslem & 13,055 & 63,809 \\
Hindu & 16,179 & 87,575 \\
Roman Catholic & 36,278 & 71,166 \\
Moravian & 26,761 & 54,326 \\
Lutheran & 3,337 & 4,764 \\
Reformed Dutch & 7,977 & 11,977 \\
Confusian & 108 & 147 \\
Others & 1,983 & 3,680 \\
Unknown & 4,415 & 8,932 \\
Amerindian religions & - & 960 \\
Bush Negro religions & - & 16,875 \\
Total & 110,093 & 324,211 \\
\hline
\end{tabular}

(General Census 1964.)

The Moslem faith is professed by over a quarter of the Hindustanis and the majority of the Indonesians. The Roman Catholic Church has its largest following among the lower-class Creoles. As a result of more recent proselytism a number of Hindustanis, Indonesians, Amerindians and Bush Negroes and the majority of the Chinese population have gone over to the Catholicism as well. The Reformed Dutch and Lutheran Churches count most of their followers among the Creole middle classes, while the Church of the Moravian Brethren (or E.B.G., short for Evangelische Broedergemeente) is principally the church of the lowerclass Creoles and a percentage of the converted Bush Negroes. The followers of Confucianism are exclusively restricted to a small minority of Chinese who have defied conversion to any of the Christian religions. The category of "others" embraces the Dutch and Portuguese Israelitic communities, as well as a number of smaller Christian denominations.

\subsection{The Creoles}

At present in Surinam the word Creole is generally understood to indicate a person whose ancestors were wholly or partly African Negroes formerly brought here as slaves.

The term once had a different meaning. For in the earliest years of the colonial period it was used with reference to persons born locally of white parentage. As a result of the influx of African Negroes, who were employed for the greater part as slave labourers on the estates, the meaning of the term changed, however. The Negro slaves began 
to be distinguished into "Creole Negroes", i.e., those born in Surinam, and "Salt Water Negroes", or those brought into the country from overseas.

The number of Creole Negroes soon exceeded that of the Europeans born in the colony, so that gradually whenever the term "Creole" was used by itself, the hearer would associate it in the first place with a descendant of African slaves, either with or without an admixture of European blood. This usage seems to have been generally established by as early as the end of the 18th century (cf. Van Lier, 1971, p. 2). Quite possibly the term "Creole" underwent a parallel change in North Brazil and the West Indian islands, where the negroid group is similarly strongly represented. For here, too, a Negro or a negroid person is understood by the term Creole at present. In areas of the New World where there is either a small Negro population or none at all, as, for example, in the southern U.S.A., Venezuela, Colombia, the Andes Republics, Chili and Argentine, the word Creole has survived in its original meaning, denoting locally born Europeans. Although in the colonial period these may have belonged to the upper strata of society, they enjoyed fewer rights in their native land than did natives of Spain or Portugal.

In consequence of the more recent influx of immigrants in Surinam, such as Hindustanis, Indonesians and Chinese, the term is now also used for the sake of distinguishing the negroid section of the population from these other ethnic groups. It is the Creoles who, by virtue of their "oldest rights", identify themselves most with Surinam. This contrasts sharply with the other groups who, culturally orientated as they still are to some extent towards India, Indonesia or China, are now consciously reorientating themselves towards these regions. The Creoles have also incorporated more Western elements into their culture, such as the language and religion, than any of the other groups.

Latterly there has been a tendency to refer to the Bush Negroes, the descendants of former runaway slaves from the plantations who formed independent communities in the Bush, as "Bush Creoles" in official documents so as to eschew the loaded term "Negro". This has come about, according to popular belief, at the instigation of the political leaders of the N.P.S., whose members, as was observed above (section 2.2.), belonged principally to the Greole lower classes. It was supposedly hoped that this new name would make the Bush Negroes feel and act more as "Creoles" as well, so that as a result they might strengthen the N.P.S. with their vote. 


\subsubsection{The Lower-Class Creoles}

Members of the Creole group are today found in every socio-economic stratum of the society of Surinam. Differentiation within the Creole group goes back to the early colonial period. As a result of miscegenation between slaves and Europeans a group of persons developing into a separate class in between the European group and the slave population evolved. ${ }^{1}$ They maintained close relations with the white masters, whose children, housekeepers or slave overseers they often were, identifying themselves closely with them, as a result of which they adopted much of the European culture. It is chiefly from their culture that the later Creole elite and middle class culture developed.

The great mass of slaves, however, took no part in this assimilation process in which the influence of the white masters was so dominant. They evolved a culture of their own, which I shall refer to as the Surinam slave culture here for convenience sake. The slaves, hailing from culturally divergent African groups as they did, did not develop a culture that can be described as a variant of any particular African culture (although many linguistic and cultural elements from the coast of Guinea can be distinguished in this culture), but developed an entirely new and unique culture of their own. This was composed of elements from the culture of the slave owners (British, Hollanders, Zealanders and Portuguese Jews) and the "Red Slaves" (Amerindians with whom they came into contact on the plantations especially in the earliest period) combined with cultural elements from a variety of African tribal cultures of which the slaves were the bearers. The Surinam slave culture has evolved its own language, religion and social organization. ${ }^{2}$ The process of acculturation to the culture of the white masters was guided by these in the sense that they deliberately withheld part of their

1 Although we are using the concept of lower class, middle class and upper class (elite) by way of distinguishing between certain social groups in the present book, the concept of "class" is not altogether appropriate for the situation in Surinam. For in this plural society somatic traits also play a part in determining the individual's position on the social scale, apart from income and property.

Because of the rapid social changes and individual mobility (which differs from one ethnic group to the other) a division into "status groups" or "strata" is similarly untenable. The lack of a subtler nomenclature, as well as the fact that the terms "lower class", "middle class" and "upper class" are commonly used in Surinam itself, have induced me to continue to use the concept of "class" in my present discourse, however. It will thus be used in the same sense as in American sociological literature.

2 See Voorhoeve and Van Renselaar (undated) on the origin of the Creole culture. 
culture from the slaves. For the masters were afraid that too much knowledge would make the slave force more intractable. This way the conversion of slaves to Christianity, for instance, was for a long time obstructed by the planters, and did not really get underway until the beginning of the 19th century. The slave children were also denied education up to 1844. Only in that year were missionaries of the Moravian community given permission to teach slave children.

The slave culture with its distinctive character developed into a popular culture after Emancipation. But its character partly changed as a consequence of the government's guided acculturation policy. By ordinance of 8th December, 1876, compulsory school attendance for all children between the ages of seven and twelve, with Dutch as medium of instruction, was prescribed. The Moravian and Roman Catholic Churches made more determined efforts after Emancipation than ever before to imbue ex-slaves with Christian norms and values and induce them to give up their "pagan" practices. This way a layer of Western culture became superimposed on the Surinam slave culture or popular culture, in which at present differences according to socio-economic class can be discerned. By tentatively dividing the Creoles into an elite, a middle class and a lower class it becomes apparent that among the elite Western culture has become most thoroughly assimilated, while there are virtually no visible traces of the underlying Surinam slave culture left here. Among the middle classes, Western culture has also been adopted, though with obvious local variants. The layer of Western culture that is unmistakably present in the lower class as well, on the other hand, is only thin, Western elements, especially norms and values, having been internalized in only an incomplete way. Their culture as a result bears a markedly dualistic character, this being obvious especially in the religion(s).

The events which had the strongest repercussions for the fate of the lower-class Creoles and for their family life in the course of the history of Surinam were the abolition of the slave trade, Emancipation and decolonization. Although these events did much to change their fate, at any rate from a legal standpoint, they failed to place them in the necessary socio-economic position for creating more favourable conditions for changing their family system, which received its characteristic form in the past through adaptation to their position during and after slavery. It might be posited that although the position of the lowerclass Creoles has become economically better, it has not become economically stable. I shall go into this at greater length in the discussion of the family system in the different periods of history. 


\section{THE RESEARCH}

Before proceeding to deal with the actual subject of the present study, I wish to make it clear to the reader why this study was made in Paramaribo and how the research was conducted.

\subsection{The Place of Research}

The reason prompting me to study the family system of the lowerclass urban Creoles was that the majority of this ethnic group are either resident in or orientated towards Paramaribo. Table 2 shows that more than half of the Creole population of Surinam is resident in this town. Moreover, a large number of Creoles of the Suriname district surrounding the metropolitan area of Paramaribo and partly belonging to the agglomeration of Paramaribo is strongly orientated towards this town. Roughly stated, the Creoles are the urban and the Hindustanis and Javanese the rural inhabitants of Surinam. Speaking in broad generalization, one intellectual from Surinam once said to me that he lived in a South American country with a "Negro capital" and an "Asian" countryside.

As regards the past, I have given my attention not only to the culture of the urban population, but also to that of the Creoles on the plantations. The Creoles, who only came to Paramaribo to live in large numbers around the turn of the century, were for the greater part employed as slaves or working as subsistence farmers in the agrarian sector prior to this. The main foundations for their family system were laid under the circumstances in which they lived on the plantations, as we shall see below.

\subsection{The Method of Research}

I spent the period from July, 1964, to October, 1965, in Paramaribo. During that time I conducted research by the observation, interview and questionnaire methods, as well as by an investigation of the archives.

The unit of research decided on was the group we shall henceforward 
refer to as "the household", because this constitutes the principal unit of the family system. I have taken the term "household" to include all persons living together in the one residential unit who regularly have their meals and sleep there. These need not necessarily be relatives, either consanguineal or affinal. I shall take the term "head of household" to refer to the person acknowledged as such by the other members, and whose voice is decisive in any decisions taken. I have regarded as members of a household all persons considered as such by the head of the household.

\subsubsection{Observation and the Interview}

The first part of the period of research was spent chiefly in collecting information on the lower-class Creole's family life through observation and interviewing. My principal aim here was to make case studies of a number of households. For this purpose I established contact with about forty households, to which I was introduced by persons with professional connections with the Creole lower classes. These "introducers" included officials of the Social Welfare Department and a number of teachers. These first provided me with a quantity of basic information on the family life of the lower-class Creole. Their advice on how to behave as a visitor to the latter's homes also proved invaluable.

It was my express aim to become acquainted with as large a number of "types" of household as possible. For this purpose I studied first 20 households with a male and next 20 with a female head. In choosing the latter, as even as possible a distribution over the age-groups found among them was aimed at. I had numerous interviews with heads and members of households, enabling me to take a great many notes by using the observation technique. During the first visits these interviews had an "open" character. I tried, in my role as "researcher" planning to write a book on the Creoles of Paramaribo, to get the respondents to speak as freely as possible. Thus, in my experience, especially topics about which the respondents felt very strongly at that particular moment were usually brought up for discussion by them without any prompting on my part as soon as their confidence had been won. As these often bore on the family life either directly or indirectly, it was usually possible for me, by practising some patience, to obtain the required information without giving too strong a direction to the interview. In subsequent interviews the data still required would be gathered more systematically, 
or certain subjects would be gone into at greater depth. I endeavoured throughout the entire period of my stay to share the life of the lowerclass Creoles as much as I could. I became friendly with a number of men and women, who in time came to act as indispensable basic informants. Through their intermediary I was able to take part in numerous activities and attend such events as weddings, birthday parties, wakes, dances, non-Christian magico-religious meetings and ceremonies at which folk-medicine was practised. I would sometimes make people gifts of money or presents such as cigars, alcoholic beverages, or sweets for the children, for allowing me to attend such occasions or lending me their services as basic informants. My knowledge of Sranang, imperfect though it was, offered a number of distinct advantages in establishing rapport, as this language is the most frequently used among the bilingual Creoles. The qualitative material obtained through observation and interviews provided me with a definite insight into many aspects of the family life, although it did not offer sufficient scope for a quantitative approach to certain problems, such as, for instance, the frequency with which particular types of household are found, the actual extent of the instability of relations between men and women, and the extent to which there is a demonstrable connection between income bracket and the prevailing types of man-woman relationship. The survey is the most appropriate method of finding answers to such questions.

\subsubsection{The Survey}

On the basis of the data compiled by means of the abovementioned methods a questionnaire was drawn up. This I intended to have distributed by interviewers among a sufficiently large number of households to obtain a fair cross section of the whole of the group of lowerclass Creoles of Paramaribo from the data thus collected.

For this purpose a sample had to be taken from this group. The latter is in many cases an anything but easy task outside the Euro-American culture province, where the lack of reliable basic statistical material of ten compels one to adopt simple sampling procedures (cf. Speckmann, 1967 , p. 18). In many areas up-to-date demographic charts, street directories or electoral rolls are lacking. In Surinam one faces the additional difficulty posed by the plural character of this society, moreover, which further complicates the procedure of drawing a representative sample if the researcher is concentrating on a certain socio- 
economic class of one particular ethnic group. For most of the official records contain no indication of a person's ethnic affiliation, official policy being focused on cultural assimilation. Furthermore, they obviously contain no mention of a person's socio-economic position.

For the purpose of taking my sample, the so-called family files in the Registers of Births, Deaths and Marriages proved the most useful source of information. These files mention the address and composition in respect of the head of the household of each family, as well as the occupation and religious affiliation of the members registered here. They do not mention the ethnic groups to which the persons so registered belong, however. It is possible, though, to make a rough guess on the basis of the family names recorded herein (Dutch or English for Creoles and Europeans, Hindi or Urdu for the Hindustanis, Javanese for Indonesians and Chinese for Chinese) as to the ethnic group to which a particular family may belong, although of course these are not infallible guides. The son of a Chinese father and Creole mother, for instance, will have a Chinese family name if he is legitimate or has been legitimated; he is even so a Creole according to the definition of a Creole which I have used, becaused he has ancestors who were former imported Negro slaves (in this case via his mother).

These files proved useful for our purposes nonetheless, as the family names, occupations and religious faith combined provided a rough clue as to whether or not the persons in question belonged to the Creole lower class. I have classed as "lower-class" - after sounding the common opinion on this in the period of observation and interviewing - any person meeting at least four of the following six requirements:

(1) the lower-class Creole earns his livelihood by manual labour;

(2) the lower-class Creole's education extends no further than an elementary school education;

(3) the lower-class Creole usually speaks Sranang at home;

(4) the lower-class Creole's house has no separate rooms for every occupant;

(5) the lower-class Creole's income is less than 300 Surinam florins a month;

(6) the lower-class Creole is christened either by a Moravian minister or a Roman Catholic priest.

With the consent of the head of the department in charge of keeping the registers of births, deaths and marriages, I was in a position to take a random sample from the family files. This was no easy task, as the 
size of the group of which a cross section had to be obtained was unknown, and the family files were not arranged according to ethnic group. The cards of these files are $29 \times 42 \mathrm{~cm}$., and are arranged in alphabetical order according to the family name and initials of the head of the family in large, uncovered wooden trays. Age, climatic conditions and ravages of insects had rendered many of these cards unfit for use, while, moreover, a number of others had dropped to the bottom of the trays, so that they were not considered for inclusion in the sample at all. So as to have a frame of reference nonetheless, I estimated on the basis of the data of the population census that the total population should cover approximately 21,000 cards. For according to the 1964 census, there were 20,734 households in Paramaribo in that year, namely 12,907 Creole, 3,953 Hindustani, 1,832 Indonesian, 205 Amerindian, 903 Chinese, 579 European, 350 "others", and five households the ethnic affiliation of the members of which was unknown. From these files we copied 750 addresses of families which in all probability belonged to the Creole lower class. During the survey phase it became apparent that for 232 of the 750 addresses collected the questionnaire could not be filled in completely, because: (a) 180 families were no longer resident at the addresses stated on their cards - people evidently often fail to register changes of address with the officials in charge of the Register of Births, Deaths and Marriages, although this is punishable by law; (b) 11 families were not classifiable as lower-class Creole according to the abovementioned criteria; (c) 16 heads of households failed to answer the questions fully, although they did grant the interviewer an interview; (d) 21 heads of households refused to give their cooperation, mostly by pretending not to be at home; (e) 4 turned out to belong to other ethnic groups.

Where the number of Creole lower-class families in Paramaribo is estimated roughly at 12,000 , I collected data from more than $4 \%$ of them by selecting 518 households for my sample. It is difficult to say how representative a cross section of the "Creole lower-class population of Paramaribo" this has provided, as there are no other statistical data available on these.

We should take the following factors into account as being likely to distort the overall picture: it seems not unlikely that the households mentioned under (a), (c) and (d) above belonged to the bottommost layers of the Creole lower class. For this group is known to have an aversion to anything at all to do with the authorities, administration and registration. This will affect the results of our survey in the sense 
that the lowest strata of the lower class are most likely underrepresented in our sample.

The team of interviewers comprised 7 men and 2 women, all of them government-employed interviewers wishing to earn some extra money. After being duly instructed and coached - by getting them to collect data on about 10 households not included in the sample with the aid of a trial questionnaire - they began interviewing on 18th April, 1965. This part of the work took up $11 / 2$ months. The questionnaire was kept as simple as possible (see Appendix 2). It is designed primarily for the collection of data on the structure of the household and the economic life. In order to remove as much as possible any suspicion on the part of the respondents they were sent by regular mail a letter explaining the nature of the research which was personally signed by myself (Appendix 1). A few days prior to commencement of the survey an explanation of the aim of the survey was given in an evening radio programme by a radio commentator who is particularly popular with the lower-class Creoles. He pointed out among other things that it had nothing to do with taxes or distributions under the poor relief scheme. This was also repeated by the interviewers before each interview.

\subsubsection{The Investigation into the Desired Number of Children}

Besides the abovementioned survey, part of the research was focused on family planning. As we shall see below, it turned out to be necessary in order to gain an insight into the functioning of the family system of the lower-class Creoles to collect data on the number of children desired by Creole women, with attention similarly being given to the question of what contraceptive methods are known to or used by women here.

It appeared in practice to be rather difficult to talk about family planning with the respondents in their own homes, however, as here the presence of children, husbands or neighbours often made any reference to this subject taboo. The request to be allowed to talk to women by themselves met with all kinds of objections of a practical nature there had to be someone to mind the children, neighbourhood gossip had to be avoided, etc. In the course of a discussion of this problem with Dr. E. van der Kuyp, the then Director of the Bureau voor Openbare Gezondheidszorg (Public Health Service) of Paramaribo, the idea of interviewing lower-class Creole women at the Health Service's office was put forward. This seemed most practical as Creole women come in large numbers to the Health Service with their children for con- 
sultation. Especially many come to the helminthiasis outpatients' clinic, as most children suffer from this condition. Because numerous women from all ethnic groups come here with their children for treatment, there is ample opportunity for taking from among them a sample of lower-class Creole women that might give us a fair cross section of the views and practices in respect of family planning here. The head of this clinic, B. E. J. Oostburg, a specialist in tropical parasitic diseases, was asked for his cooperation in realizing this particular project. He expressed his willingness to lend his cooperation for the project, in which, moreover, he showed a keen interest. Thus I was enabled to take interviews in a separate room at his outpatients' clinic for two mornings a week. Dr. Oostburg and his staff of nurses, who enjoyed the confidence of a large section of the population, would send women of the agegroups previously specified in to talk to me after being asked to give their cooperation. The response was positive, only five women refusing to exchange views on the subject.

\subsubsection{The Investigation of the Archives}

There appeared to be insufficient historical data for testing my hypotheses available in the literature. Hence supplementary archive research had to be conducted in the Central Record Office, the records of the Registrar of Births, Deaths and Marriages, and the manuscript collection of the Museum of Surinam in Paramaribo in order to collect the material that was still lacking. Back in Holland, a number of supplementary data were collected at the General Public Record Office in The Hague, where a large number of documents pertaining to Surinam are kept. 


\section{THE INITIAL PERIOD OF SETTLEMENT OF THE PLANTATION COLONY UP TO THE ABOLITION OF THE SLAVE TRADE IN 1808}

The foundations for the West Indian family system of the slave population, the free Mulattoes and the free Negroes were laid in the earliest beginning of the period discussed in the present chapter. The question of in what way the social system of the early colonial period determined the structure and functioning of the West Indian family system forms the subject of this chapter.

As we shall see, the slaves as well as the free Mulattoes and free Negroes mostly entered into unions other than marriage, so that "alternative" man-woman relationships can be observed in this group right from the beginning. The phenomenon of women acting as heads of households is common among both the slave population and the free Mulattoes and free Negroes. Hence matrifocal households were characteristic of these groups even in the past.

\subsection{Population}

It is up to around 1770 that Surinam enjoyed its "best years" economically speaking, as was observed above in the discussion of plantation agriculture (2.3.1.). Many colonists - most of them European investors - succeeded in amassing large fortunes as owners of sugar plantations. In the 1770's this boom ceased due to a variety of reasons; plantation owners were forced to sell their properties and the period of absentee ownership set in. A large number of plantations passed into the ownership of banking firms. So we can observe that around 1800 most of the money-lenders were resident outside Surinam. Where money was short, the plantations were kept going chiefly through maximal exploitation of the slave population through the agency of specially appointed administrateurs (estate superintendents or attorneys) and managers. As a result the living conditions of the former deteriorated steadily in the period under discussion.

There was a substantial population growth in Surinam in this period. 
The available data concerning the number and composition of the population are scanty and as far as the 17 th century is concerned unreliable. The following table may help to give some idea of the changes in the population figure, though the figures contained in it do not include either Amerindians or Bush Negroes.

Table 6. The Composition of the Population of Surinam

(not including. Amerindians and Bush Negroes) from 1651-1811

\begin{tabular}{|c|c|c|c|c|c|c|c|c|c|}
\hline & \multicolumn{3}{|c|}{ PARAMARIBO } & \multicolumn{3}{|c|}{ COUNTRY DISTRICTS } & \multicolumn{3}{|c|}{ WHOLE OF SURINAM } \\
\hline & $\begin{array}{c}\text { Free } \\
\text { Citizens }\end{array}$ & Slaves & Total & $\begin{array}{c}\text { Free } \\
\text { Citizens }\end{array}$ & Slaves & Total & $\begin{array}{c}\text { Free } \\
\text { Citizens }\end{array}$ & Slaves & Total \\
\hline 65 & - & - & - & - & - & - & - & - & 300 \\
\hline 661 & - & - & - & - & - & - & - & - & 1,000 \\
\hline 1663 & - & - & - & - & - & - & - & - & 4,000 \\
\hline 1671 & - & - & - & - & - & - & 800 & 3,000 & 3,800 \\
\hline 1684 & - & - & - & - & - & - & 811 & 4,281 & 5,092 \\
\hline 1694 & - & - & - & - & - & - & - & - & 6,423 \\
\hline 1762 & - & 8,000 & - & - & 66,500 & - & - & 74,500 & - \\
\hline 178 & 650 & 7,000 & & 3,356 & 50,000 & 356 & 6,006 & 57,000 & 63,006 \\
\hline 1790 & 3,000 & 12,000 & 15,000 & 2,000 & 41,000 & 43,000 & 5,000 & 53,000 & 58,000 \\
\hline 1805 & - & - & - & - & - & - & 6,075 & 58,527 & 64,602 \\
\hline 1811 & 4,405 & 10,197 & 14,602 & 940 & 43,911 & 44,851 & 5,345 & 54,108 & 59,453 \\
\hline
\end{tabular}

(Statistics drawn from: Encyclopaedie 1914-'17, pp. 553, 665;

Van Sypesteyn 1854, pp. 93, 152 ; and Abbenhuis 1943, pp. 238, 239.)

We are able to conclude from this that the bulk of the slave population was resident in the districts or "divisions" and hence on the estates. The majority of "free citizens" lived in Paramaribo. These "free citizens" were further specified in the first official census of 1787, which showed them to comprise 2,000 Europeans, including 615 Portuguese and 430 German Jews. The balance of 650 was made up of "Creoles", free Mulattoes and free Negroes. Most of these "free citizens" were ex-slaves in possession of manumission certificates, together with their descendants. They were for the greater part the children, housekeepers, or especially highly valued servants of white masters who had been redeemed by these. The majority of them had their abode in Paramaribo. They did not possess the same civil or political rights as the Europeans, and their freedom was restricted by numerous official rules and regulations applying especially to them, with an additional distinction being drawn between Mulattoes and Negroes. This group eventually 
came to form a special intermediate class between the colonists and the slave population.

The slave population consisted principally of Negroes. The number of Amerindian slaves who were initially used as labourers for the plantations gradually decreased. The Negro slaves were divided into town and plantation slaves. The town slaves were further subdivided into domestic slaves, artisans and field slaves. The former were employed as domestic servants. Artisans provided a source of income for their owners after learning some craft, such as carpentry or bricklaying, for instance. The urban field slaves were usually resident in town and were either hired out to some estate on the outskirts of Paramaribo or employed as gardeners in the town itself. The plantation slaves, who constituted by far the greater majority of the slave population, were also divided into the same categories, with field slaves making up the largest group, whose lot was moreover the hardest.

\subsection{The Organization of Slavery}

Negro slaves were first brought into Surinam by the English and by Portuguese Jewish colonists as far back as the 16th century. After the Republic gained possession of Surinam in 1667 slave trading to the Dutch possessions in America was taken up on a large scale. The slaves were acquired for the greater part on the West coast of Africa. The Netherlanders built forts on that coast for this purpose. According to Van Lier it is likely that most of the slaves were imported from the coast of Guinea, which serves to explain why the influence exercised by the culture and languages of this region on the Negro of Surinam was so dominant.

Slave imports continued officially until 1808, the year in which the British Government, which was ruling Surinam at the time, prohibited slave trading. However, there was a flourishing contraband trade in slaves until 1826, when the system of registration of the slave population was improved, thus continuing until well after the administration was taken over by the Dutch again in 1816. The total number of slaves brought into Surinam is estimated at somewhere between 300,000 and 350,000 (Van Lier, 1971, pp. 119, 125).

The slaves were seldom brought here together with their families. Initially African tribal chiefs sold only prisoners of war to the European traders. Later on, some of these chiefs, proceeded to organise slave raids on neighbouring tribes as a means of satisfying their increasing need for 
textiles, metal implements and liquor. Sometimes also subjects enslaved for crimes or debts were sold (cf. Encyclopaedie 1914-'17, p. 635, and Van Lier, 1971, p. 117). It was in consequence of these practices and because of the greater demand for males than females that slaves were seldom transported to Surinam and offered for sale there together with their wives and children. Men and women were accommodated in separate quarters on the slave transports. The autobiography of the German sailor Nettelbeck, who called at Surinam with a slave ship in 1750 and 1772, tells us that "The dormitories on board were in the forecastle; the sexes were separated by thick walls $(\ldots$.$) . During the$ daytime, while on deck, the men were kept separated from the women and children as well; they could only hear, but never see one another." (Staal, 1928, pp. 171, 172). The only kinship ties that were kept intact by the slave traders were those between mothers and children, and this from practical considerations. The bulk of the slaves came to Surinam alone. On arrival there they were put up for sale, the procedure by which this was done being subject to specific rules and regulations. According to the West India Company Charter of 1682 slaves had to be sold by public sale. They were sold in pairs of either two men, a man and a woman, or two boys, and so on (cf. Herlein, 1718, p. 91; Abbenhuis, 1946, p. 95). This measure was introduced in order to give small planters an opportunity to make purchases as well, as the captains of slave ships were sometimes wont to sell their entire cargo en masse to some big planter privately in contravention of the regulations (cf. Encyclopaedie 1914-'17, p. 638). The great majority of the Salt Water Negroes, as newcomers from Africa were called, were conveyed to the plantations, whereas in town the "Creole Negroes", or those born locally in Surinam, constituted the majority.

One anonymous author observed around 1740 that slaves were not immediately put to work as full-time field labourers on arrival at the plantations. They had to do light work first "for eight or ten days, until they gain sufficient strength and are used to the daily fare." The practice of allocating newly arrived female slaves as wives to certain of the male slaves as a means of habituating them to the local language and customs was prevalent. The men were accommodated in the huts of slaves who were already used to plantation life, though the manager of the plantation often had to keep a strict watch to prevent "that they're bullied too much, as it is usual for such a new slave to be compelled to serve in the house of an old one and look after it like a servant until he understands the language and the work, or, obtaining a wife, sets up 
house on his own" (Abbenhuis, 1946, p. 197). After this short period of "socialization" the slaves were then put to work as field labourers.

The treatment of plantation slaves in Surinam was exceptionally harsh as compared with other plantation economies of the New World. The work was exceedingly heavy, while the working-hours especially on the sugar plantations were extremely long. Furthermore, the vastness of the country and the resultant opportunity for escape necessitated the enforcement of an extraordinarily strict discipline among them by means of excessively savage penal measures. Moreover, the size of the slave force gave rise to constant apprehensions about slave rebellions (cf. De Groot, 1963, p. 6). However, a widespread slave rebellion such as in neighbouring Berbice in 1762 never actually occurred in Surinam. The free minority succeeded in spite of the numerical odds against them (see table 7) in dominating and exploiting the slaves by intimidation throughout.

Table 7. The Population of Surinam, excluding those living in tribes (in percentages)

\begin{tabular}{lcc}
\hline & free citizens & slaves \\
\hline 1671 & 21 & 79 \\
1787 & 10 & 90 \\
1805 & 9 & 91 \\
1830 & 14 & 86 \\
1860 & 30 & 70 \\
\hline
\end{tabular}

(Statistics drawn from: Van Sypesteyn, 1854;

Abbenhuis, 1943, facing p. 238; Teenstra, 1835, II, p. 203.)

The Government introduced a number of regulations for protecting the slaves against their masters to some degree. The so-called Plantaadjereglement or Plantation Code and the later Slave Code, which were gradually amended and elaborated in the course of time, contain numerous regulations on the treatment of slaves which were designed to improve their lot as well as their legal condition, at least theoretically so. Because virtually unlimited authority was wielded by the masters, while the slaves had almost no rights, little or no supervision or control was exercised over masters in respect of their treatment of slaves, so that abuses against and improper conduct towards slaves on the part of the free members of the population went virtually unpunished (cf. Goveia, 1960; Quintus Bosz, 1964). 
The fact that many slaves fled the plantations to hide in the bush further had most adverse repercussions for the treatment of their fellows. The "Runaways" united to form groups the descendants of which are still living in tribes in the bush of Surinam to this day. These so-called Bush Negroes made plundering raids on the estates from their settlements, carrying off women, implements and weapons as their booty. These raids caused widespread trepidation among the white population. It was vainly tried to destroy their settlements and render them harmless by means of a series of military expeditions. As early as 1749 treaties whereby they were declared free citizens were concluded with them in an effort to safeguard the European community from further attacks and prevent that other fugitives should join them (cf. De Groot, 1963, pp. $8 \mathrm{ff}$.).

The lot of town slaves in Paramaribo contrasted sharply with that of the plantation slaves. Living conditions for the former were considerably better because the work they were expected to do was much lighter than that of plantation slaves. The "township" of Paramaribo, which according to Governor van Aerssen consisted of no more than "seven-or eight-and-twenty houses, mostly inns and smugglers' taverns" in 1683 (Hartsinck, 1770, II, p. 647) soon afterwards developed rapidly into an administrative and trade centre of some considerable size. By 1765 the number of main buildings had come to 800 , and by 1787 to 1119 . The pace for town society was set by senior colonial officials, plantation owners and, later on, the latter's administrateurs or estate superintendents or attorneys. Their style of life was decidedly consumer-oriented. They surrounded themselves with literally dozens of slave servants. According to Herlein (1718, p. 48) every household had "as many slaves as it can with decency support, and has itself served by these in a seignorial enough fashion; if he has no need of them himself he sends them out to work for other persons for a day's hire..." The more slaves a person kept for his personal attendance, the greater social prestige he enjoyed. The average number of house slaves per household in town varied between ten and thirty (Van Lier, 1971, p. 149). Many of these idled away the time exclusively in the performance of such menial tasks as filling the master's pipe, carrying the master's prayerbook on Sundays, and so on. Although the town slave was less seriously exploited physically than was the plantation slave, he was on the other hand in many cases much more at the mercy of his master's moods and whims than his plantation counterpart. 


\subsection{The Family Life of the Slaves}

\subsubsection{Alternative unions between men and women}

One of the corollaries of the legal rule which viewed the slave as a chattel rather than a person was that it was impossible for him to conclude marriages. In the Republic of the United Netherlands - and hence also in the Colony of Surinam - the laws derived mainly from Roman Law, the slave laws in force here even being based almost entirely on this. According to this Law the slave was a mere chattel, a legal object that could have no property or rights, could not give evidence under oath and could not make contracts. It was this latter regulation that made it impossible for him to marry (cf. Quintus Bosz, 1964, pp. 1-22), though it did not entail that the slave was totally deprived of the possibility of having sexual relations with women.

With his master's consent a slave could usually enter into some more or less permanent relationship with a woman. Two of the forms of "slave marriage" were that in which the husband and wife lived together, and that in which the two partners lived in separate dwellings. In the latter case the husband usually had his master's permission to visit his spouse regularly at nights or on Sundays. We shall refer to the former type as "coresidential union" and to the latter as "visiting relationship".

For information on the way in which slave marriages were made in the 18th century we dispose over Hartsinck's statement (1770, p. 910) according to which, "Every slave is given a wife by his master who, if they prove incompatible, dismisses the partners again and marries them each off to some other person. The marriage is celebrated without much ceremony, only with a bottle of kilthum (a kind of rum)."

We are unable to deduce from the available literature which of the above two forms of marriage was most prevalent on the plantations. It is even probable that in the earliest, British period, it was difficult for a slave to find a suitable partner on his own plantation, because at that time the number of slave labourers employed on the plantations was small and these were chiefly men, moreover. Consequently coresidential unions probably formed an exception. When the Netherlanders began to run much larger plantations with larger slave forces, it became easier for slaves to find a partner on the plantation on which they themselves were employed. It even so remained usual for a man to have a wife on some other plantation, usually one in the neighbourhood. The masters looked askance at this, however. According to 
Hartsinck $(1718$, p. 97) the planters were most in favour of their slaves' "marrying" on their own plantations, as they were otherwise more liable to vagrancy and pilfering. In many cases it proved impossible for slaves to find a wife on their own plantation, however, as sometimes the entire slave population of a plantation, especially the older plantations, was related by blood ties, so that "marriage" between them was an impossibility (cf. Van Renselaar, 1963, b, p. 474).

The "visiting relationship" prevailed in town. The coresidential union was within reach only of slaves carrying on an independent trade by which they provided their masters with an income and as a result enjoyed certain privileges. As a rule, slaves lived in their master's compound, i.e., in the quarters behind his house. These slaves, most of whom were domestic servants, were obliged to be always on hand. Only during his days or evenings off was a slave allowed to visit his wife. We can infer from Herlein's notes that masters in Paramaribo similarly preferred their slaves to take one of their own female slaves to wife. He says: "Those in Paramaribo most prefer it this way, too; but it is impracticable, as they do not have sufficient slaves, so that sometimes they are compelled to allow their slaves to marry elsewhere, though mostly grudgingly so." (Herlein 1718, p. 97).

A number of privileged slaves possessed more than one wife. On the plantations these were usually the bassias or slave overseers, and in town the independent slave artisans who had attained a certain degree of prosperity and sometimes themselves bought slave labourers. Polygyny made for an even greater number of "visiting relationships", as it was not usual for men to live with more than one woman in one and the same house.

\subsubsection{The Instability of Relationships}

It is exceptionally difficult to give an opinion on the degree of instability of slave relationships on the basis of the available data without falling into gross generalization. While there are no quantitative data on this subject available, the qualitative data at our disposal - the utterances of various writers on this aspect of the life of the slaves are in all probability somewhat exaggerated and distorted.

We must make allowance for the fact that in the past, too, observers describing non-Western areas were inclined to push marginal phenomena into the foreground, and are certain to have done so when discussing a subject such as "promiscuity" among black men and women. 
The contemporary readers of these authors will unquestionably have been determined to find confirmation of their prejudices as regards the promiscuous inclinations of the descendants of Ham in the literature consulted by them. Though conversely it may equally be presumed that as a result of a variety of circumstances many slaves most likely entertained no illusions about permanence until death should part them and their partners when entering into a relationship of either the coresidential or the visiting type. We are able to infer from the observations of authors writing about the period in question that numerous slave relationships were impermanent, both in town and on the plantations. Quarrels between the partners will have been the most common cause of the breaking up of relationships. The medical doctor Hostmann asserted that whereas the men were usually eager to enter into relationships, the women were on the other hand inclined to put off doing so for as long as possible. "With the prospect of the slavery involved in marriages of this kind before them, no wonder they are inclined to prolong the term of their liberty as long as they can! (...) All uncivilized peoples treat their womenfolk as slaves, a fact of which the female Negroes are thoroughly aware." (Hostmann, 1850, p. 44.) Conjugal conflicts seem to have been especially rife where husband and wife each came from different African tribes. "On the whole the slaves most prefer to marry women of their own tribes, and in such cases one will not soon discover any quarrels or mutual jealousies or bad housekeeping to ensue", as one anonymous author states around 1740 (Abbenhuis, 1946, p. 95). Conflicts about real or imagined infidelity also constituted an important factor in the breaking up of relationships. Fermin considered the slaves even more prone to jealousy than the Italians (1769, I, p. 137). He reports that a husband was likely to poison his wife on the merest suspicion of faithlessness with another Negro slave or an Indian. ${ }^{1}$ This would suggest that perhaps under the immense pressure of slavery many men and women were so strongly attached emotionally to their partners as to cause inconstancy to be taken very seriously. Fermin (1769, I, p. 138) as a result tends to have a fairly high opinion of the stability of slave unions, saying: "Les mariages de ces peuples sont beaucoup plus solides que ceux des Indiens ou naturels du pays, ..." (The marriages of these people are much more constant than those of the

1 Fermin rather naively considers it worth noting that it did not occur to a man to resort to violence if his wife committed adultery with a white man, but on the contrary considered it an honour and harboured not the least resentment about this. (Fermin, 1769, I, p. 137.) 
Indians or aboriginals of the country.) The information furnished by the planter Blom also suggests that we should by no means imagine that all relationships between slaves were short-lived. He did observe, however, that sometimes slave couples broke up without any ceremony, though amid a great deal of quarrelling, at the end of one or two years, but that on the other hand there were also slaves who remained true to each other through many a long year until they were separated by death (Abbenhuis, 1946, p. 130). Hartsinck (1770, II, p. 907) writes that "Men seldom stick to the one wife but like to have others, or concubines, besides here and there, as in their country of origin; but as they have not the power to prevent their wives from doing the same, the latter carry on in a like manner; however, they usually remain loyal to one another if they have children together." Kuhn (1828, p. 25) notes that although there are many Negroes, both male and female, living in virtue and irreproachable domesticity, remaining together all their lives and having several children with one another, a large proportion are living dissolute and promiscuous lives, "which habit of unrestraint must needs lead to an immoral way of life that is most deleterious to their procreative capacity." All these reports lead to the conclusion that although the breaking up of relationships between men and women was a frequent phenomenon, there is definitely nothing to suggest that this was the general rule.

The following factors, which are corollaries of the institution of slavery, doubtless exercised a strong influence on the nature of the relationships between slaves. They are: (a) The practice of selling or hiring out husbands and wives separately; (b) the unequal sex ratio; (c) women's economic independence of their husbands; and (d) the example set by the white masters and free Mulattoes and Negroes.

\section{Ad. (a)}

Until the beginning of the crisis of 1770 , after which difficult times began for the plantation system, it was not customary for men and women who had entered into some form of relationship to be allowed to be sold separately. After that time, however, this became a normal practice (cf. Van Lier, 1971, pp. 154 ff.), while even mothers and young children were now sometimes sold separately. There further existed the practice of hiring out husbands and wives separately, with husbands sometimes being sent to work on some other, distant plantation for years on end. It goes without saying that this practice of selling or 
hiring out husbands and wives separately was not exactly conducive to stability in slave marriages.

A memorandum on the family life of slaves dated 17th July, 1858, and addressed to the Governor of Surinam by the Reverend Th. C. van Calker, Head Missionary of the Moravian Mission of Surinam, states concerning this subject: "When male or female slaves are sold, transferred, expelled or hired out no questions are asked about whether this is causing the long-term, or even permanent, separation of a man from his wife and family. The consequences hereof are abominable, as the practice of hiring out slaves, mostly men or women by themselves, is a most frequent one, so that every case of hiring out slaves brings about the separation of husbands and wives for an indefinite period of time. As a result the men sooner or later take other wives on the plantations to which they are hired out, which they are in some cases even encouraged to do by their temporary owner from considerations of selfinterest." (Van Calker, 1858). Although this memorandum was written outside the period dealt with in the present chapter, Van Calker's observations are no doubt relevant as regards practices observed in the period under discussion here as well.

Even though instances of the separate sale or hiring out of slaves doubtless occurred, we should bear in mind that such practices were not to be observed daily. There was a virtually perennial shortage of labour on the plantations, so that slaves were seldom sold or hired out. We may reasonably assume that there was question of selling or hiring out slaves singly almost exclusively in cases of bankruptcy or liquidation of estates.

\section{Ad. (b)}

The unequal sex ratio, besides the practice of selling or hiring out slaves separately, also made for instability in relationships between slaves. In town, where there was a greater demand for cheap domestic servants, there was a surplus of women, while on the plantations, where the employment of male slaves proved more economic, there was a surplus of men. On the plantations women, because they were in such "short supply", possessed a certain measure of power. Here it was easy for a woman to abandon her husband for another lover, while she might also try to earn some extra income by having sexual relations with more than one man. Nonetheless, despite the shortage of women on the plantations, no institutionalized form of polyandry evolved. Van Calker (1858) observes in this respect that, "Polyandry, or the practice of 
having more than one husband at one time, is so unnatural as to be rare among the heathen in general, and among the local Negroes in particular.

It is never practised in the open, like polygamy, but always in such a way that women tend to keep the fact that they are living with other men a secret from each of their several husbands."

Fermin's observation (1769, I, p. 137) regarding the deep-seated jealousy of slaves which we referred to above is also worth noting in this context. As he says, a man might resort to aggressive behaviour (poisoning) on the slightest suspicion of unfaithfulness on his wife's part.

In town, where there was a surplus of women, the situation was altogether different from that prevailing on the plantations. Here a man was able to follow the pattern that constituted the ideal throughout the whole of Black Africa, namely that of having more than one wife at one time. "All customary laws in Africa, without exception, allowed, indeed encouraged, a man to have as many wives as he pleased. There is no legal restriction in number, as for example in Islamic law, where the maximum is four. The possession of several wives was regarded as a mark of importance and prestige, and it has been known for rich men or chiefs to have as many as fifty or even a hundred wives simultaneously." (Cotran, 1968, p. 17). In West Africa, whence most of the slaves originally came, it was customary for men to possess several wives, each with a hut of her own. Visiting relationships were a corollary of this pattern. In Paramaribo with its surplus of women, where as a result visiting relationships predominated, slaves had more opportunity for perpetuating the African family pattern than on the plantations.

So we find Lammens asserting, when writing about life in town, "that where possible these have several wives, but this seldom has any negative consequences (...) I have been assured that when one of these women is receiving visitors, having invited others to call on her, and her husband is also present, this takes place with all due decorum - he appears here as the husband of the hostess: the one thing the woman will never tolerate is for another to sleep in her bed - it is her holy of holies." (Lammens, 1816-'27, XIII, p. 75.)

Ad. (c)

Another factor affecting the instability of slave unions was the phenomenon of these relationships coming to display more and more what should be regarded as the "ideally typical" essential characteristics of a "Neigungsehe" ("love-match") rather than of a "Situationsehe" 
(marriage of convenience). The "Situationsehe", according to Vierkandt's typology, is concluded from motives of social and material advantage rather than feelings of mutual affection. It is concluded on social considerations such as ensuring the continuity of a particular family or keeping certain property within a family, or in order to be assured of labour. A "Neigungsehe", on the other hand, is entered into chiefly on the basis of mutual affection between a man and a woman. The character of the latter is on the whole more unstable than that of the "Situationsehe", where husband and wife are bound to each other by strong economic ties. "In dem einen (Neigungsehe) ist die Liebe die Seele der Ehe, im anderen (Situationsehe) tritt sie zurück. Im einen Fall schöpft die Ehe wesentlich ihre Kraft von innen, im anderen Fall hauptsächlich von aussen, nämlich aus den objektiven Mächten der Situation" (Vierkandt, 1928, p. 449). (In the one kind (the love-match) love is the soul of the marriage, while in the other (marriage of convenience) it retires into the background. In the one case the union draws its essential strength from within, in the other chiefly from external factors, namely from the objective forces of the situation.)

The essential characteristics of the "Situationsehe" marked relationships between slaves up to the mid-eighteenth century. Up to that time it was usual for plantation slaves to be given the responsibility for their own provision plots (cf. Van Lier, 1971, p. 164). Hartsinck (1770, II, pp. 915, 196) writes, "And every Family has its individual Hut and Provision Plots which they plant with Yams, Potatoes, Manioc, Maize, Bananas, Cassava, Tobacco and Spanish Peppers for their subsistence; their Masters hand out one or one and one half Pounds of Meat, a little groats, Peas or Broad Beans only on Saturday evenings, while they are also occasionally given a dram of Kilthum; also some short Pipes and Tobacco." A partner's assistance in tilling the provision plot was indispensable for both men and women up to that time, so that existing relationships were not lightly broken off by them, as they were tied to each other by economic necessity.

When the system of giving slaves the responsibility for their own food plots proved no longer profitable under the effects of the decline of the plantation system - it was more efficient to make slaves devote their time exclusively to the cultivation of plantation crops - this measure made men and women virtually independent of one another economically. The slaves were from now on solely given food allowances for their subsistence. Whether or not they were living together made virtually no difference thenceforward, as they were assured of the 
allowance due to them anyway. In view of this development relationships between slaves assumed almost universally the character of the "Neigungsehe".

As Van Calker (1858) writes in this respect: "It (is) slavery itself, the carefreeness of the slave with respect to his livelihood, that is making it impossible for him to fulfil his duty as his family's breadwinner. The wife receives her master's allowance independently of her husband, and he does likewise. Even so, they do render each other certain services, the woman doing her husband's cooking, washing and sewing, in return for which he fetches her fire-wood, sharpens her implements, and so on; but the husband does not have the task of providing for his family. Although he toils in the sweat of his brow - as does his wife - this is not as a means whereby to gain his wife's and children's livelihood. Husbands have no need to provide for their families, nor do they learn to do so; and so this carefreeness, so widely extolled by the unwise, is disastrous to the Negroes, and ..."

The slightest conflict was likely to break up a relationship, so that after around 1770 a situation arose among the slaves on many plantations whereby promiscuity among a number of them was encouraged. This was anything but unwelcome to some of the planters. Schneider (1893, p. 176) says about this: "Indeed, on many estates it was even the rule, for reasons from the explanation of which we hope to be excused, to separate couples who had been living together for some considerable time and order them to enter into new relationships among themselves." We should not attach too much credence to his statement that on many plantations this practice was the rule, however. The author, a German minister of the Moravian Community, wrote his book on the basis of oral and written reports of Moravian missionaries without ever visiting Surinam personally. However, we read in Frazier (1965, p. 307) that slavery could give rise to similar situations in the United States. He says: "Some masters with no regard for the preference of their slaves mated them as they did their stock. There were instances where Negro males were used as stallions."

Ad. (d)

In conclusion, relationships between male and female slaves were no doubt greatly influenced by the master's attitude. White masters gave little encouragement to slave men and women to have stable relationships. What is more, the organization of the family life of the masters, the free Mulattoes and the free Negroes, about which I shall have more 
to say further down (4.5.), in no way inspired slaves, as far as the practices observable here were concerned, to be monogamous or aspire to "conjugal fidelity". For it was customary for many white masters to have sexual relations with suitable female slaves apart from their spouses or housekeepers. Some slave-owners in town even had their female slaves earn them an income by prostitution (cf. Steinberg, 1933, p. 89). Jean Nepveu, who after a long administrative career in Surinam eventually became Governor of this Colony, writes the following about the masters' indifference in 1765: "Relationships with the master's knowledge do not normally outlast the amorous urge which inspired them, whereupon indeed they often separate either amicably, or, more often, amid much discord, unless the master or mistress were frequently to keep a stricter eye on this and discourage it through severe punishments. As long as their love lasts, they may also be quite jealous in love, but once it is over and they go on living together out of sheer habit, then jealousy no longer comes into play either and they may willingly share their wives with other man in return for an acknowledgement of some sort; the men further seldom stick to the one wife but like to have others, or concubines, besides here and there, as in their country of origin; but as they have not the power to prevent their wives from doing the same, the latter carry on in a like manner; however, they usually remain loyal to one another if they have children together." (Nepveu, 1765).

This information of Nepveu's, noted down before the crisis of 1770 , shows that despite the lack of control by masters over the slaves' relationships, there was no indication of anomie prevailing. It is interesting that Nepveu should refer to the African family system when talking of the family life of the slaves.

\subsubsection{The Slave Household}

The basic unit of the slaves' social organization, which was based on their kinship organization, was formed by the household, or in other words, all persons living together, eating and sleeping under the one roof. With respect to the nature of the dwellings of the plantation slaves - usually built next to one another in rows - Hartsinck (1770, II, p. 915) writes: "Their Huts on the Estates are usually constructed of wood and contain a Door, but no windows; they are about 30 Feet long by 15 Feet wide, and are thatched with Tas (Geonoma baculifera Kunth) or Pite leaves. In the centre is the Hearth; so that the Smoke 
has to escape via the door; they lie around the same on two or three planks which are slightly elevated above the ground."

There was scanty furniture, and this consisted mainly of some mats, a number of pots and pans, a few benches and some implements for cultivating the vegetable plot belonging to the household.

Where husband and wife cohabited, slave households on the plantations comprised the husband and wife and their children; and in the case of visiting relationships they consisted of the woman and her children. In either case the daughters' children might live in with them. In many cases girls had children born of casual affairs prior to entering into a more permanent kind of relationship.

After the mother's death, brothers, sisters and sisters' children would sometimes continue to live together under the same roof or under different roofs close together. This way extended families developed on the plantations, in which kinship was reckoned chiefly along matrilineal lines. In the household internally the mother was more important to her children than the father, and the strongest of ties might develop between mothers and children, while those with the father were usually weak. For the latter might be employed elsewhere, or sold separately from his wife. Also the fact that a number of fathers spent only the evenings or Sundays with their families because they had entered into "visiting relationships" stood in the way of the development of a strong tie between them and their children. Hostmann (1850, pp. 45, 46) attests that "Children are much more attached to their mother than to the father, while what little attachment they feel for him grows weaker with increasing age. Paternal love is hardly ever to be observed, while maternal love also leaves much to be desired."

As a result of the instability of man-women relationships discussed above, and of the lack of economic dependence of women on men, women were usually the heart of the slave household. Whenever a particular relationship broke up the children would remain in the mother's household, as they were the property of their mother's owner. Thus in many cases women were the head of the household, as on the plantations as well numerous women had "visiting relationships" with men and many women were widowed - there being a higher male than female mortality.

So we see that the slave household displayed markedly matrifocal features. Even when the husband was at home, his influence on the course of affairs was negligible, as the woman's economic independence - which further increased after 1770 as a result of the abolition of the 
system of provision plots -- made the household virtually independent of the man for its continued existence. It was the mother from whom the children derived some sense of security. However, we should not form too exaggerated an idea of the actual influence a woman could exercise on her children. Her, too, the children usually saw only in the evenings. Women with children were not exempted from field work on the plantations. Infants were normally taken to the fields by their mothers. When older they were entrusted to the care of an elderly Negress called "Creolenmamma" (Creole Mammy), usually an elderly female slave with the special task of minding the slave children during the daytime.

The situation in Paramaribo did not differ significantly from that on the plantations. As in town visiting relationships predominated, here similarly households usually comprised only mothers and their children, possibly supplemented by their daughters' children. In town, too, women were virtually independent economically of the men with whom they had relationships, and we see them occupying a central position in the family here as well, with their children deriving their sense of security from them. It was the mother, and not the incidentally visiting father, who dominated the urban slave household as well.

\subsection{Government, Private and Church Interference in the Family Life of Slaves}

The government paid little attention to the family life of slaves in the period under discussion here. We do not come across any laws or ordinances directed at the slaves' family life until 1743, when Governor Mauricius decreed that before a slave could be sold details of his or her family had to be supplied. In his diary entry of January, 1743, he refers to the prevalent rule not to separate families on being sold, this allegedly being in force in the West India Company period as well. Sales by which families were separated could be annulled. According to Van Lier (1971, p. 155) an end was put to this rule by the 1770 crisis, when a large number of estates exchanged owners and the slaves of these estates were sometimes sold separately. The practice of selling mothers and children separately was prohibited by an edict of 4th August, 1782, which makes no mention of the separation of fathers from their families, however - a custom that seems to have become the established rule by that time. The edict was promulgated once more in 1828 (G.B., or Government Gazette, No. 5) without any attempt being made to prevent the separation of fathers from their families through supplementary regulations. There are no statistics available concerning the number of 
separate sales, but we may assume that this was a frequent phenomenon in the second half of the 18th century and the beginning of the 19 th century.

Little effort was made on the part of private citizens, and more specifically plantation owners and managers, either, to regulate the family life of the slaves. They were not primarily dependent on natural reproduction among the slaves in Surinam itself for keeping the slave force up to strength. It was usually considerable cheaper to import slaves than acquire them through natural reproduction. Teenstra (1842, p. 86) writes in this respect: "So there are examples of white Christians having pregnant negro wenches, black heathens, buried half under the ground in order to produce an abortion, so as to be able to put the Negress concerned back to work in the fields forthwith. Purchasing Salt Water Negroes was held to be much cheaper than raising Creole children."

Up to the beginning of the 19th century the missions similarly had little opportunity of interfering with the slaves' family life. For in the early period the colonists were little inclined to permit missionaries to visit their slaves. This was partly due to the fact that in the early period of colonization the legal view that a slave is free from the moment he becomes a Christian obtained (cf. Von Sack, 1821, I, p. 189). This view was later thrown overboard. After that the Calvinist Reformed Dutch clergy were free to christen slaves provided the owners' permission had been secured beforehand (cf. Von Sack, 1821, II, p. 131). Even so it continued to be objectionable for reasons of prestige to admit slaves to the Calvinist Reformed Dutch State Church, which was the Church of the masters. It was feared that mass conversion of the slaves to Christianity would weaken the masters' position. We come across one of the first and best-known references to a slave becoming a member of the Calvinist Reformed Dutch Church in 1747, when a Society Negro slave named Benjamin was christened and admitted as member of this Church under the name of Jan Jacob van Paramaribo. (Cf. General Public Record Office, The Hague, old archives of the Government Secretary's Office, 1st June, 1747.) It is apparent from a missive from Governor Mauricius dated 15th July, 1747, reporting on this matter to the executive board of the West India Company (General Public Record Office, The Hague, Letters and Documents from Surinam) that this was regarded as a unique event. He says: "Your Worships will discover in the entries of 31st May and 4th June of the same Journal that a Society Negro has been converted to the Christian faith. I con- 
sider it my duty to assure Your Worships in this connection that we have every reason to trust that the conversion is sincere. He put in the necessary application of his own accord as many as three years ago, thereafter to apply himself diligently to learning to read and write and further to receiving Religious instruction. During that period his conduct has been irreproachable, and he was finally confirmed with so much dignity as to bring tears to the eyes of us all. At present he is the best and virtually the only cook in the Honourable Society's service. But he has personally averred himself to have no wordly aspirations to freedom. I leave it with due respect to Your Worships' goodness of heart, however, to decide whether and to what extent it may please Your Worships to grant him freedom, on condition that he continue to perform his duties as Government cook."

Slave christenings continued to be exceptions in the Calvinist Reformed Dutch Church, however. In the Lutheran Church the christening of slaves was similarly rare. Hence it was not the "masters' Churches" but the "Popular Churches" such as that of the Moravian Brethren and the Roman Catholic Church which undertook the large-scale conversion of slaves. These were not given freedom to evangelize actively among the slave population until the beginning of the 19th century. After first the Lutheran Church receiving permission to hold religious services besides the Calvinist Reformed Church, the same permission was granted to the Moravian Missionaries around 1776. Similarly the Roman Catholic section of the population was allowed to profess its religion openly, though subject to certain restrictions, in 1785 (Encyclopaedie 1914-'17, p. 473). I shall go at greater length into the influence exercised by the Moravian Brethren and the Roman Catholic missionaries on the family life of the slaves through their conversion of the latter in the next chapter.

\subsection{The Family Life of the Masters and the free Mulattoes and free Negroes}

It is important not only to study the way in which the slaves themselves regulated their mutual relations in respect of their sex and family life in a historical analysis of the origins of the family life of the lowerclass Creoles, but also to consider the nature of the family life of the masters and freedmen if we wish to understand one of the forces that operated in determining the initial stages of development of lower-class Creole family life. A considerable portion of the culture of both the 
abovenamed groups was adopted by the slaves. For the nature of the work and the pattern of relations between slaves and members of the other two groups made for the gradual development of close relations between many of the slaves and persons belonging to the group of the masters and freedmen. The example set by the masters and free population in respect of relations between the sexes cannot fail to have set its stamp on the organization of the family life of the slaves and, later on, the emancipated ex-slaves.

In the earliest years of the period discussed here the colonists were mostly men of simple requirements, tilling their land with the assistance of their wives and a few slaves. Their marriages were celebrated with church ceremonies, as was also usual in the Netherlands at the time. Citizens of Portuguese Jewish descent had their marriages solemnized in the synagogue, having been granted a special privilege allowing them among other things to conclude marriages in accordance with their own rites as early as 1665 .

Even after the plantations developed into extensive holdings it continued for a long time to be the rule for planters to be family men. This situation came to an end in 1773, however, when as a result of the crisis on the Amsterdam stock exchange many planters lost their titles to their estates and were lucky if they were allowed to stay on as managers of their former properties. The plantations passed into the ownership of overseas investors who as a rule had administrateurs (i.e., estate superintendents or attorneys) based on Paramaribo act as their representatives. A large number of former plantation owners left Surinam with their families, and managers and estate overseers were appointed in their stead, these being recruited from the ranks of men who were eager to make quick fortunes abroad in order to settle in the Netherlands afterwards. They were usually men without families, so that like many other exploitation colonies Surinam now had a shortage of white women (cf. Van Lier, 1971, pp. 42, 43, 86).

This development brought about changes in the family system of the white masters, this being further encouraged by, among other things, the new system of ruthless exploitation of the plantations. It was forbidden to directors of plantations, which were now organized along strict hierarchical lines, to be too familiar in their dealings with overseers (white officers). In order to prevent that the discipline should be undermined by directors' wives becoming intimate with the wives of subordinate employees, the Administrateurs in Paramaribo decreed that plantation directors should be unmarried. Any person disobeying this 
rule was liable to be dismissed (cf. Teenstra, 1842, p. 25). The white overseers, who most of them came to Surinam as single men, similarly seldom entered into marriage because of these measures, as this might prove an obstacle to advancement to the rank of manager.

What now happened was that white men on the plantations took in some female slave or free woman to do the housekeeping instead of a wife. They mostly chose Creoles for this, preferably mulattoes. With these women they had children who - if the mother was a slave were born in bondage and thus became members of the plantation's slave force unless their fathers redeemed them. The latter was attended with much difficulty and expense (Kappler, 1854, p. 50). The form of concubinage which developed in this way was designated "Surinamstyle marriage". Unions of this kind were also frequently entered into in town owing to the shortage of white women here. Concubinage developed into an institution with its own rules of etiquette. Although a white man usually had little difficulty in persuading a coloured or Negro girl to live with him, he even so had to ask her mother's permission first, at any rate if she was a free person. According to Teenstra (1842, p. 48) there are virtually no instances of girls letting themselves be induced to enter into concubinage with white men without their mothers' prior consent. It appears to have been more difficult for a man to persuade a girl to become one of his mistresses in a noncoresidential relationship (cf. Teenstra, 1842, p. 64).

These housekeepers were not treated as equals by their husbands and the people with whom they kept company. Lammens (1816-'22, VIII, p. 78) writes about them: "Housekeepers do not normally accompany their husband when he goes out on visits, and are not admitted into white company anywhere: - they exchange visits among themselves and with their respective relatives: they have no right, either for themselves or for their children, to the property of the man with whom they cohabit, either before or after his death: - although the father will speak of his daughter or son as such, and of the mother of his children, he will never refer to his housekeeper as his wife: he keeps his distance from her: - those of the lowest sort will condescend to sit down to meals at the same table as they, although children normally also sit at the same table: - these women are not ashamed of their condition, which is as it were sanctioned by custom here: - and their way of thinking in this respect differs completely from the conventions in Europe, though even so being far removed in every way from immorality: many of these women are reportedly extremely virtuous: - 
there are those who are bent on carrying their honour to such lengths that even if they are informed that their husbands have had affairs with other women in their absence, they will not let this shake them out of their virtue: - I hope to be forgiven for believing that this is a general rule: - it would seem much more natural for them to be of an extremely jealous disposition: - in the event of the husband leaving for Europe they are pleased to see the children accompany the father in the conviction that this will contribute to their welfare: - they themselves prefer to remain in the Colony, however, imagining that they will be looked upon with contempt in Europe: - if they are convinced of their husband's return they will conduct themselves with the utmost propriety during his absence; if not, they will establish a new liaison without the slightest hesitation. - On the estates, the housekeeper of the manager, who according to the established custom is unmarried, is often a Mulatto; or a Negress belonging to the estate who is still in a condition of bondage: - however, the majority of housekeepers are free or manumitted."

It is evident from the above text that relationships of this kind might sometimes endure over many years, and might last until the husband left for Europe. According to Kappler (1854, p. 34) officers living in concubinage took their concubines with them to every post in the Colony to which they were detached. Usually any children they had with free housekeepers were ligitimated. Those who were not legitimated either used their mother's family name or adopted a family name that was a corruption or inversion of the father's name (thus Klemen might become Nemelk, for example).

Surinam-style marriage did not find wide acceptance with the Jewish section of the population of Surinam. According to Van Lier (1971, p. 110, 111) many of them were of an orthodox piety that did not allow of their establishing and maintaining extra-marital relations lightly during the period of slavery.

The shortage of white women did not induce white men to marry Mulatto or Negro girls until much later on in the period under discussion in the present chapter. Since Governor van Aerssen van Sommelsdijck's prohibition on marriage and fornication with "blacks" in 1683 (Herlein, 1718, p. 51) there had never been a marriage of this kind. ${ }^{2}$ It was not until 1767 that the controversial marriage of the

2 According to Teenstra (1842, p. 65) it was forbidden by law, on pain of heavy fines, for a free father to disclose his identity as such on registering the birth of a slave child. 
wealthy free Negress Elisabeth Samson to the white Mr. Zobre put an end to this social convention (cf. Van Lier, 1971, pp. 67-69). But even after that time marriages between white men and Negro women continued to be rare exceptions, although there was a higher proportion of marriages between white men and Mulatto girls. Surinam-style marriages continued to prevail, however.

Unions of this type were on the whole less stable in character than conventional marriages; they might be of long but also of extremely short duration, as is apparent from the statement that "other men regard this form of cohabitation as a kind of monthly marriage..." (Teenstra, 1842, II, p. 66). The latter was especially true of men who were in the Colony for only a brief stay or belonged to the lower classes of white colonist society. The soldier, for instance, who "despite his white skin is not respected even by Negroes" on account of his habitual drunkenness and licentiousness, established concubinage type relations of a most unstable nature, and "Children born of relationships of this kind between members of the lower classes and soldiers grow up as the lilies of the field, that is to say, without anyone to care for them" (Kappler, 1854, pp. 33, 34).

The free Mulattoes and free Negroes copied the example of "Surinamstyle marriages" off the whites; "Mulattoes rarely marry within their own group or with blacks" (Lammens, 1816-'22, p. 78). Hence the great majority of free Mulattoes and Negroes lived in concubinage. The latter was just as much subject to rules as conventional marriage. For instance, if a man wished to enter into concubinage with a virgin girl he was obliged "to purchase the young maiden's first favours with certain gifts or cash, the mother's consent being prerequisite for this: - sometimes the price of these favours is as high as a thousand guilders: - for which she receives a bed, lodgings, clothes and finery: this being duly paid and handed over, the man acquires the right of coresidence, - it is not a prelude to a lasting relationship, however, and they are afterwards completely free one of the other: - she subsequently proceeds to establish other relationships without informing her mother accordingly, as she is then considered her own mistress, being regarded as a major." (Lammens, 1816-'22, XIII, pp. 74, 75).

It is evident from the above text that not all relationships established in this way were lasting ones. A large number of women entered into concubinage one or several more times more after their first relationship of this kind, or became the mistress of a man married to or living in concubinage with another woman. Well-to-do men sometimes kept a 
number of wives, each living in a separate house with her children (Teenstra, 1842, p. 48).

The households of white masters living in concubinage as well as those of the free Mulattoes and Negroes possessed a number of matrifocal traits. Any woman living in concubinage with a white man was aware that their union would not last until death, but rather until her husband should leave for the Netherlands. Although white men from the higher social strata sometimes did take their children born of such unions to the Netherlands with them, this was definitely not the rule. And it was almost never done by whites from the lower social classes. For as long as a woman lived in concubinage with a man she would try to accumulate as many possessions as she could so as to have some security for the time after his departure as well. It was customary, moreover, to give these women certain economic advantages where possible. Lammens (1816-'22, XIII, p. 80) observes: "Even though housekeepers are not recognized as wives, and are regarded as decidedly inferior creatures, they are usually most generously rewarded, some of them succeeding in acquiring means of subsistence or possessions both for themselves and for their children thereby: - they are given furniture and slaves according to the husband's financial capacity, and are sometimes appointed as heirs: - furniture and slaves cost money; if one adds to this that most of them are fond of fripperies and hence extravagance it will be easy to see that this arrangement is in the long run likely to entail considerable expense, the more so as the interests of husband and wife are so widely divergent."

That this was a little too much for some of the more frugally inclined Dutch is apparent from Lammens' text where he complains that: "Housekeepers restrict themselves to exercising control and supervision in the house and among the slaves: they do little or no housework: they go about in headlong pursuit amusement, and their gossip sessions (singing and dancing parties), visits, Does, all these various things run up huge expenditures on the debit sheet of their husbands' accounts."

Since in spite of, or perhaps precisely because of their inferior status housekeepers could evidently get away with a lot of things of which their husbands disapproval as far as their housekeeping was concerned, their influence should not be underestimated. Although to the outside world the husband appeared as head of the household, the wife was inclined, partly because she anticipated the end of the union with the man in question sooner or later, to assume a more important role inside the household than her husband, especially as regards the children. So 
as a result the type of household formed by the white man with his concubine can be characterized as latently matrifocal. It became manifestly so the moment the husband left for the Netherlands, leaving the wife behind with the children. Matrifocality of households is also observable among the free Mulattoes and Negroes. The social system often made it impossible for a man to earn a steady income, so that he occupied a weak position in the household as a result. There were many cases of women going to work outside the home, so that their households were often dependent on them for their livelihood. 


\section{THE PERIOD FROM 1808 UP TO EMANCIPATION IN 1863}

\subsection{General}

As we saw in the preceding chapter, the colonists concerned themselves extraordinarily little about the family life of their slaves. Aside from observing a few rules forbidding the separate sale of husbands and wives or mothers and children, virtually nothing was done to promote a stable family life among them.

This situation changed for the better after the abolition of the slave trade by the British in 1808. This measure brought the colonists face to face with the problem of how to keep the dwindling slave population, which had up to then been kept at a constant level largely through imports, up to strength. The latter was essential for the survival of the Colony's economy, which was based almost exclusively on the production of tropical agrarian products with the aid of slave labour.

Both the Government and private slave owners gradually began to look for a solution to this problem through the introduction of certain measures for the "improvement" of the slaves' family life. In this process the Western Christian monogamous model was settled on. The argument adopted was that if the relationships between men and women were to assume a more stable character among the slaves, the birth rate would increase. This natural increase would compensate for the reduction in the numbers of slaves resulting from the discontinuation of imports.

However, for various reasons to be discussed below, no action was ever taken to institute legal marriage for slaves, as this would have made it impossible for husbands and wives to be sold separately. The halfhearted efforts to pursue a "population policy" in respect of slaves in this period once more go to show how much Dutch colonial policy was dominated by short-sighted motives of self-interest at the time.

\subsection{The Dwindling Slave Force}

Up to the abolition of the slave trade the colonists showed little concern at the low reproduction rate of their slaves. They made up for 
existing shortages by fresh imports from overseas. Hence in most years the death rate exceeded the birth rate among the slaves. Their reproductive capacity was further reduced by the unequal sex ratio among them, as well as poor health caused by ill-treatment, inadequate food and poor housing. According to Stedman the annual rate at which the slave population decreased was $5 \%$. Their numbers were kept up to strength by importing exactly the same percentage (Stedman, 1813, II, p. 290). In the 19th century this rate decreased due to better treatment when further imports were prohibited after 1814, although according to Kuhn in his study of 1828 it was still $21 / 2$ to $3 \%$ at that time (Kuhn, 1828 , p. 23). The situation gradually grew better, the slave force diminishing at a rate of only $1 \%$ per annum in the last two decades preceding Emancipation (Van Sypesteyn, 1854, p. 171).

I shall now proceed to discuss separately the several factors responsible for the unsatisfactory reproduction rate of the slave force, going into the unequal sex ratio and the position as regards food and housing for slaves at the same time. After that I shall deal with the measures aimed at "improving" the slaves' family life which were introduced by private slaveholders, the government and the missions.

\subsubsection{The Unequal Sex Ratio}

As was explained in part 4.3.2., there was an imbalance between the sexes among the slave population in the period discussed in the preceeding chapter, resulting in a surplus of women in the town and a shortage of women on the plantations. This phenomenon continued to be observable to the same extent in the period under discussion in the present chapter, thus precluding maximal reproduction among the slave population.

I was able to draw up the following table (see p. 76) by combining data from the available literature with the results of a count I made in the Register of Freed Persons of Paramaribo, in which the slave population was registered in the years 1862 and 1863.

As regards the town, we can see that the surplus of women continued in the period at present under discussion as well. This was not calculated to ensure maximal reproduction. The number of urban male slaves further decreased sharply in this period because a proportion of these were sold to the plantations as a result of the shortage of farm labourers.

It is apparent from Table 9 that the surplus of women in Paramaribo was highest in the higher age groups. This imbalance is due not only 
to the transference of men to the country districts, but also to the fact that the life expectancy was lower for men than for women.

Table 8. The Slave Population of Surinam (1830-1863)

\begin{tabular}{|c|c|c|c|c|c|c|}
\hline & \multicolumn{2}{|c|}{ Paramaribo } & \multicolumn{2}{|c|}{ Country Districts } & \multicolumn{2}{|c|}{ Whole of Surinam } \\
\hline & $\mathbf{M}$ & $\mathbf{F}$ & $\mathbf{M}$ & $\mathbf{F}$ & $\mathbf{M}$ & $\mathbf{F}$ \\
\hline 1830 & 4,065 & 4,515 & 21,023 & 19,181 & 25,088 & 23,696 \\
\hline 1850 & 2,795 & 4,306 & 16,395 & 16,815 & 19,190 & 21,121 \\
\hline $1862 / 63$ & 1,784 & 2,537 & 15,378 & 16,785 & 17,162 & 19,322 \\
\hline
\end{tabular}

(Data derived from: Teenstra (1835, II, p. 203) ; Van Sypesteyn (1854, pp. 93, 152); Encyclopaedie 1914-'17, p. 665; and Register of Freed Persons of Paramaribo, in Records of Births, Deaths and Marriages.)

Table 9. The Slave Population of Paramaribo in 1863, Classified According to Sex and Age

\begin{tabular}{|c|c|c|c|c|c|c|c|}
\hline \multirow[t]{2}{*}{ Ages } & \multicolumn{3}{|c|}{ Numbers } & \multicolumn{3}{|c|}{ Percentages } & \multirow{2}{*}{$\begin{array}{c}\text { Number of } \\
\text { Women per } \\
\text { Man }\end{array}$} \\
\hline & Men & Women & Total & Men & Women & Total & \\
\hline $0-4$ & 235 & 268 & 503 & 5.4 & 6.2 & 11.6 & 1.14 \\
\hline $5-9$ & 181 & 235 & 416 & 4.2 & 5.4 & 9.6 & 1.29 \\
\hline $10-14$ & 206 & 234 & 440 & 4.8 & 5.4 & 10.2 & 1.13 \\
\hline $15-19$ & 211 & 229 & 440 & 4.9 & 5.3 & 10.2 & 1.08 \\
\hline $20-24$ & 182 & 210 & 392 & 4.3 & 4.9 & 9.2 & 1.15 \\
\hline $25-29$ & 159 & 183 & 342 & 3.7 & 4.2 & 7.9 & 1.15 \\
\hline $30-34$ & 149 & 184 & 333 & 3.4 & 4.3 & 7.7 & 1.23 \\
\hline $35-39$ & 95 & 156 & 251 & 2.2 & 3.6 & 5.8 & 1.64 \\
\hline $40-44$ & 100 & 165 & 265 & 2.3 & 3.8 & 6.1 & 1.65 \\
\hline $45-49$ & 74 & 158 & 232 & 1.7 & 3.7 & 5.4 & 2.13 \\
\hline $50-54$ & 72 & 153 & 225 & 1.7 & 3.5 & 5.2 & 2.12 \\
\hline $55-59$ & 47 & 119 & 166 & 1.1 & 2.8 & 3.9 & 2.53 \\
\hline $60-64$ & 44 & 123 & 167 & 1.0 & 2.9 & 3.9 & 2.79 \\
\hline $65-69$ & 8 & 45 & 53 & 0.2 & 1.0 & 1.2 & 5.62 \\
\hline $70-74$ & 7 & 26 & 33 & 0.1 & 0.6 & 0.7 & 3.71 \\
\hline $75+$ & 5 & 27 & 32 & 0.1 & 0.6 & 0.7 & 5.40 \\
\hline Unknown & 9 & 22 & 31 & 0.2 & 0.5 & 0.7 & 2.44 \\
\hline Total & 1,784 & 2,537 & 4,321 & 41.3 & 58.7 & 100.0 & 1.42 \\
\hline
\end{tabular}

(Compiled from the Register of Freed Persons of Paramaribo, Register of Births, Deaths and Marriages, Registrar's Office, Paramaribo.)

As regards the position on the plantations, Table 8 shows that there was still a serious shortage of women in 1830. Because of their small 
numbers women were extremely important, which stimulated them to adopt a way of life that was in no way conducive to reproduction. The instability of relations between the sexes was thereby encouraged, and prostitution developed. The number of births per woman here, too, remained below the absolute minimum necessary for natural replacement. By 1850, however, we see the unequal sex ratio redress itself on the plantations, women now even constituting a slight majority, which further increased in 1862-'63.

\subsubsection{Malnutrition, Disease and Poor Housing among the Slave Population}

The slaves' reproduction rate was similarly adversely affected by the fact that the food with which they were supplied was on the whole inadequate as compared to the excessively hard work they were required to do. Especially on the sugar plantations - the most prevalent kind where generally the most dangerous and heaviest type of work had to be performed and the slaves were deprived of much of their daily rest during harvest time, the position was extremely unfavourable. According to Von Sack (1821, II, p. 141) these slaves had fewer children because of lack of rest and because they were required to do one third more work than the slaves of cotton and coffee plantations.

Van der Kuyp (1958, pp. 16-30), a medical doctor, has drawn up a report on the slaves' diet for the data for which he drew on the texts of edicts, ordinances and descriptions of the slaves' daily habits, from which it is plain that this was generally speaking inadequate. Cheap foods with a high carbo-hydrate content such as bananas, and in some areas cassava, constituted the staple of this diet. This was sometimes supplemented with salted meat or fish seasoned with pepper. By calculating the nutritive content of the food supplied to the slaves up to and including 1850, Van der Kuyp has computed that the latter must as a rule have suffered from serious calory, protein (especially animal), fat, calcium, phosphorus, vitamin $A$ and $B^{1}$, riboflavin and niacine deficiencies. According to him this serves to explain the high mortality among them. Furthermore, the so-called "treefgeloof" or superstition that the eating of particular foods brought on leprosy, aggravated the deficiences in certain nutrients of the slaves' diet because it led them to refuse to eat specific foods.

Whenever heavy rains, violent storms or long droughts caused the failure of the banana crop, serious food scarcity if not actual famine 
resulted on the plantations. The shortage of fresh drinking-water resulting from the general inadequacy of water tanks in supplying the entire slave force with water in times of prolonged drought obliged slaves to content themselves with well or swamp water. The slaves tried to supplement their diet by raising chickens or ducks, gathering forest products, and growing crops on special provision plots. The latter was possible only if the estate manager placed a special plot of land at their disposal for this. They also sometimes tried to make up for certain shortages by stealing. Banana-growers usually made allowance for the loss of one third of their crop due to falling trees as a result of strong winds and pilfering by slaves (Van Sypesteyn, 1866, p. 82).

There was a slight improvement in the food supply after the Code of 1851, containing a number of regulations with regard to feeding and clothing slaves, came into force. This resulted in dietary improvements in some cases, though in others no change at all occurred in the status quo.

Aside from loss of strength and disease as a result of malnutrition, numerous slaves died from such diseases as dysentry, tuberculosis, malaria, leprosy, filaria, framboesia and venereal disease. Medical care was nominal, so that there was also a disproportionately high infant mortality. As the art of the midwife usually left much to be desired, many new mothers died with their newborn children in childbed. As a rule Negro women had to go back to field work three months after their confinement, and sometimes sooner. The infant was carried wrapped in a shawl on its mother's back, which according to the medical doctor Kuhn $(1828$, pp. 32, 33) was definitely detrimental to the child's health.

Young children did not on the whole receive much care, what is more. The children of field slaves were committed to the care of an elderly Negro woman after weaning. The health of young children appears further to have been adversely affected by the method by which they were fed, namely the so-called "kanten" method. Whenever a child was given food, such as gruel, it would be placed on its mother's or some other woman's lap with its head bent back over her knees. She would hold the child's nose with one hand and with the other pour the gruel down its mouth until the child was full and its stomach began to swell. Next the woman would blow vigorously up the child's nostrils in order to remove any remaining food particles from them. Water and medicine were administered to the child in the same manner (the latter still being given this way today). Kuhn (1828, p. 34) considered this method of feeding extremely injurious to the intestines, aside from the 
danger of asphyxiation. As a result planters forbade their female slaves to apply it, though mostly without effect (cf. Lammens, 1816-'22, p. 80).

Closely connected with the slaves' bad food and poor physical condition is the fact that both on the plantations and in town their accommodation was substandard. The dwellings on the plantations were built on a level, frequently damp piece of ground. The floors of these huts, if any, were very close to the ground, so that the atmosphere inside was dank, especially in the wet season (Winkels, 1856, p. 72). The roof and walls were made for the greater part of the bark of the wild areca palm (Areca Catechu) (Kuhn, 1827, p. 13). The dimensions of these huts, usually built in blocks, were small. According to Benoit (1839, pp. 53, 54) they were 9-10 ft. high, $10 \mathrm{ft}$. deep en and $12 \mathrm{ft}$. long. A hole in the roof served as window and chimney. The occupants slept on the floor or on beds of plaited bamboo, rolled up in a linen blanket. At nights the huts were shut completely. In the humid tropical climate these dwellings rapidly decayed, which further reduced their fitness for human habitation.

In town the slave dwellings were erected behind the main buildings of the master's house - which fronted the street - in the so-called "yards" or compounds. Access to these yards was provided by an empty space of about a meter's width in between the main buildings, which was styled the "Negro gateway". The main kitchen as well as a storeroom and a well were usually also situated in this yard. The slave huts, which from the mid-18th century onwards were built of wood (Van Lier, 1971 , pp. 166, 167), were generally of the type of the so-called one-room dwelling. They were composite, rectangular living-units constructed adjoining one another on small, approximately $40 \mathrm{~cm}$. high corbels, and were erected in blocks. According to Lammens (1816-'22) these dwellings were $15 \mathrm{ft}$. long by $10 \mathrm{ft}$., or slightly more, wide, and hence were a little roomier than the slave huts of the plantations. As a spacesaving measure these single-room dwellings sometimes also had an extra storey built onto them, a stair and a gallery in that case giving access to the upper floor. Such space-saving measures were usually essential in town as here the slave force was too large for the available space in the master's yards. For prestige reasons the white masters sometimes kept around thirty servants. Apart from these, slaves hired out to other persons or sent out to earn their masters a cash income as vendors or artisans, for instance, were frequently also accommodated in these yards. As a result there was general over-crowding in the latter. Such over- 
crowded conditions no doubt were not exactly conducive to good mental or physical health.

\subsection{Measures for the Improvement of the Slaves' Family Life and Reproductive Capacity}

In the 19th century a change for the better in the position of the slave population occurred. There was a growing awareness in Europe that slavery was in conflict with the dignity and the individual rights of man. Under the impulse of the Enlightenment as a revival of a deeper Christian consciousness (e.g. William Wilberforce in England and the Réveil movement in the Netherlands) a number of Christian and humanitarian groups in France, England and the Netherlands, were seen to exert themselves on behalf of the cause of the abolition of slavery. Articles advocating the emancipation of slaves began to appear in newspapers and magazines, in pamphlets, in petitions and memoranda to the King, in books and in special pro-emancipation periodicals in the Netherlands.

Partly under the influence of this the Colonial Administration now took steps to improve the slaves' lot.

Quintus Bosz, who has given a description of the development of the slaves' legal position, writes that in 1817 the Plantation Code was again brought to the citizens' notice, seeing that "there are many who fail to live up to the benign intentions of our Predecessors, the latter on the contrary being more and more and on most points disregarded and ignored, which can only serve to do the plantations and estates much harm, and indeed may give rise to disorderliness, unrest and all manner of irregularities in this Colony."

Not long afterwards (1823) a sharp increase in the money fines fixed for this offence was deemed necessary so as to provide greater assurance of good quality estate managers and consequently of a better treatment of slaves. In order to ensure that plantation slaves were properly fed, exceptionally high sums (fl. 1,000 to fl. 5,000) were fixed as fines for failure to comply with the obligation to lay out sufficient provision plots and supply slaves with adequate food in 1824 .

In 1839 once more stringent regulations were added to the existing rules. Measures were introduced at that time for placing the Negroes of plantations where differences between co-owners or administrateurs of such a nature "as to disturb the peace and order and the due subordination among the Negro force of the plantation" had arisen, under the supervision of one or more "impartial" persons. 
In 1828 and 1829 the separate sale of female slaves and their children other than with the intention of presenting the slaves so purchased with letters of manumission, was expressly prohibited. The sanctions in respect of this were also made progressively more severe (cf. Quintus Bosz, 1964, pp. 16-18).

No ban was ever placed on the separate sale of husbands and wives by the colonial administration, however, as we shall see in the following. The latter did, however, introduce a number of measures for improving the slaves' family life, the principal objective of which was to keep up the numeric strength of the slave force.

Although I have not come across any unreserved utterances by either private citizens or government officials stating explicitly that it had become necessary in view of the abolition of the slave trade to improve the family life of the slaves so as to stimulate their reproductive capacity either in the literature I have studied or in the archives I have investigated. Nevertheless, the measures for the "improvement of the family life" of the slaves taken by both the private sector and the Government after 1808 - including measures encouraging the missions of the various Churches in their activities - are such manifest adaptations to the economic situation that we can safely assume that here, too, a number of ostensibly "ethical" and "Christian" measures were prompted by motives of economic self-interest, that is, the interests of the slave-owners.

I shall try to analyse the measures aimed at improving the slaves' family life in relation to one another below. They include: (1) measures introduced by private individuals involving (2) the stimulation of the activities of the various missions in combination with (3) Government measures.

\subsubsection{Private Measures}

According as plantation owners domiciled in town observed that many of their female plantation slaves had miscarriages due to both carelessness on their own part and the fact that they were insufficiently spared with regard to the work, many of them had their female slaves come to town in the last stages of their pregnancies in order to have them looked after in their own homes until after their confinement (cf. Von Sack, 1821, I, pp. 144 ff.).

As increasingly more slave-owners began to do this at the beginning of the 19th century, specially equipped homes run by midwives were 
opened in Paramaribo, where pregnant Negro women could have their babies at their owners' expense (cf. Benoit, 1839, p. 54). There is nothing anywhere in the literature to suggest that this kind of treatment was ever given before the abolition of the slave trade. They were obviously measures aimed at keeping up the numeric strength of the slave force after the abolition of this trade. Before that, pregnancies of female field slaves were often considered undesirable, pressure sometimes being put on pregnant slaves to procure abortions (cf. in this connection Teenstra's statement, cited in section 4.4.). It is impossible to trace the extent to which this was a general practice.

Although in the period under discussion here there was a marked change in owners' attitudes, they nonetheless never did anything to encourage the introduction of an officially recognized registration of "slave marriages". They were much averse to the institution of a legal entity of this nature, as it would have the implication that slaves so married could no longer be sold separately. This was too much in conflict with their financial interests at a time when prices of slaves were sky-rocketing because of the latter's scarcity. The Government slaves also received more attention because of this scarcity. In 1828 the local administration of the Colony of Surinam made the polder boards responsible for ensuring that slaves received proper treatment and that the sick as well as pregnant women and new mothers received appropriate care, and for the policing of any other measure designed to boost natural reproduction (Encyclopaedie, 1914-'17, p. 640).

\subsubsection{The Activities of the Missions of the Various Churches}

After a definite stop was finally put to slave imports in 1826, both the government and the individual planters allowed the various missions greater scope for spreading the Christian faith among the slave population of the plantations. They reasoned that the conversion of slaves to Christianity on a large scale would make for greater stability of their family life, and hence increased reproduction.

The masters did not turn to their own churches to help realize this objective. As we saw in the preceding chapter, neither the Calvinist Reformed Church nor the Lutheran Community did much to spread the Gospel among the slave population. Nor did the Jewish masters try to convert their slaves to their religion. At most the few descendants they had by female slaves embraced Judaism.

The mass conversion of slaves to Christianity did not get underway 
until 1828 (two years after the definitive stop to the illicit trade in slaves), when a "Maatschappij tot bevordering van het godsdienstig onderwijs onder de slavenbevolking in Suriname" (Society for the promotion of religious instruction among the slave population of Surinam) was founded at the instigation of Commissioner General Johannes van den Bosch - who was just then on a tour to the West. Numerous planters and Government officials joined this Society. The Society had as objective the propagation of Christianity among the slaves by the Moravian Brethren. Why the Moravian Brethren were chosen for the fulfilment of this task became apparent at the first General Meeting of a subsidiary of the Society based on The Hague, where the argument was advanced that the intention behind sending Brethren was "not to alienate the slaves from the subordination to their masters or cause them to become a danger to the Colony" (Steinberg, 1933, p. 127).

Apart from the Moravian Brethren, the Roman Catholic Mission (which was prohibited up to 1816 from proselytising among the slaves) was given increasingly greater opportunity for doing so. I shall discuss the significance of the Moravian and Roman Catholic missions in respect of the slaves' family life in the next two sections.

\subsubsection{The Moravian Mission and the Slaves' Family Life}

The Unity of Brethren, the members of which are commonly also designated as Moravian Brethren, was founded by Nicolaus Ludwig, Count of Zinzendorf, in Saxony between the years 1722 and 1727, being composed of Protestants from Moravia and Bohemia persecuted for religion's sake. They proceeded to combine missionary activities with the exercise of a trade or craft. In so doing, the missionaries earnt their living by the work of their own hands. They regarded Surinam as part of their mission field at an early stage. After consultations with the "Geoctroyeerde Sociëteit van Suriname" (Chartered Society of Surinam), the first Brethren to go to Surinam arrived there in 1735. Their missionary activities were in the beginning concentrated on the Amerindians and Bush Negroes. Missionary work among the slaves did not commence until 1754, when a few Brethren settled in Paramaribo as artisans. They hired slaves, whom they taught their craft and to whom they preached the Gospel. They christened the first Negro slave in 1776; he was followed by eight more male slaves and one female slave in that same year. 
Missionary activities among the slaves were restricted almost exclusively to Paramaribo in the 18th century. These got underway only very slowly. The number of converts from 1765 to 1830 was quite small, these being resident chiefly in town, moreover. The number of converts on the plantations increased sharply after 1830, when Christianity began to be preached there as well, as is apparent from the table below.

\begin{tabular}{llrr}
\hline & Total & Paramaribo & Country Districts \\
\hline 1830 & approx. 2,000 & $1,800=90 \%$ & $200=10 \%$ \\
1863 & approx. 27,400 & $5,600=24 \%$ & $21,800=76 \%$ \\
\hline
\end{tabular}

(Source: Steinberg, 1933, p. 136.)

Initially the missionaries received little cooperation from either the planters or the government. It was made virtually impossible for them to carry on missionary work on the plantations up to the 1830 's. It is evident from passages from the journal and the reports of the Moravian Brethren of Paramaribo published by Steinberg (1933, pp. 89, 90) that, moreover, a great many owners in Paramaribo itself were anything but favourably disposed towards the missionaries' doings. "On 25th August a married Sister (Baptized member) came to see us; she complained tearfully that her lord had sinfully tried to abuse her. But she had found it impossible to consent to this, as she was now the property, body and soul, of Jesus Christ and wished to remain so. We advised her to remain true to Him and submit to being beaten rather than commit a sin. The next day she came to tell us that the Lord had helped her, for when she remained obdurate, her master, although dismissing her peremptorily with a stream of angry words and threats against the mission, had left her alone for the rest." (Journal Paramaribo, 1782).

"On 25th May an applicant for baptism came to see us, and complained amid bitter tears that she had just been told that she would either be transferred to an estate or compelled to earn her lordship a weekly income of 5.50 florins by prostitution here in town. But it was now impossible for her to do the latter." (Journal Paramaribo, 1784).

After the founding of the abovementioned Maatschappij the Brethren were free to proclaim the Gospel actively among the plantation slaves. The opposition from managers abated and the missionaries were lent increasingly more cooperation and financial assistance as the conviction grew that Christian slaves were the best and most reliable workers (Encyclopaedie 1914-'17, p. 80). 
However, the owners successfully opposed the introduction of the legal entity of a "slave marriage" up to Emancipation.

Although "ersatz" marriages such as alliances and Roman Catholic church marriages were tolerated after 1850, these never received official government sanction, so that slaves who were "married" in this way could still be sold separately.

\subsection{The Institution of the "Verbond" or "Alliance"}

In the missionaries' view the family life of their converts was nardly in accordance with the Christian norms and ideals propagated by them. In order to strengthen the bond between men and women who were living together, they officially proceeded around 1850 to give their converts, who were forbidden by the law to enter into legal marriage, the opportunity to conclude so-called "Alliances". Even before that time the conclusion of such unions was a custom connived at by the authorities. For as early as 1782 the Journal of the Moravian Brethren of Paramaribo refers to a certain female slave as "a married sister (Baptized member)" (Steinberg, 1933, p. 89).

In order to conclude an Alliance both partners had to appear before the missionary and promise to live together faithfully as a Christian husband and wife. The Alliance could not be solemnized, as the missionary had no power to perform the necessary rites (Schneider, 1893, p. 180). Moreover, the law proscribed church marriages except in cases where the husband and wife were first married before the law. The witnesses were fellow church members, and the ceremony was coupled with some ritual. The conclusion of an Alliance never took place in secret and was never in any way opposed. It had no juridical consequences for the slaves' social status, however.

It was hoped by the missionaries that the conclusion of this kind of union would have a stabilising effect on the family life of the slaves. The fact that families continued to be torn apart by separate sales right up to Emancipation shows plainly that the planters did not cooperate in encouraging the continuance of unions of this type. Steinberg's (1933, pp. $91 \mathrm{ff}$.) quotation from the report of the mission post at Salem informs us that: "Elias John is baptized in Paramaribo in 1830. He is sold to Coronie and forced to leave his wife and children in 1833 . He marries a second time. In 1844 his second wife and their children are sold to Paramaribo. He remains behind alone and marries for the third time. In 1856 he is about to be sold to Nickerie and thus be parted from 
his family once again; but luckily he is spared this fate just in the nick of time."

Despite such separations, the institution of the Alliance nonetheless had some stabilising effect on the family life of slaves, although it proved impossible for the majority of the slaves to live up to the high ideals propagated by the missionaries in respect of "conjugal fidelity".

Governor Schimpf observed on this subject in an official report of 1858: "No matter what positive results of religious instruction some people like to flatter themselves with, abstention from polygamy and polyandry so far is exceptional, cases hereof being indeed rare exceptions among both the slaves and the classes that are on a par with them on the point of morality and culture. They will need to have made considerably greater moral progress, but might perhaps also have to be transferred to a different climate with a different disposition for conjugal fidelity to become the norm with them. Though the Moravian Brethren may well flatter themselves that their teachings are having considerable positive results, they are sadly deluding themselves in this respect." (Schimpf, 1858). The fact that the owners did not cooperate in preventing the separation of slaves who had concluded an Alliance is not taken account of in Schimpf's report.

\subsubsection{The Roman Catholic Mission and the Slaves' Family Life}

We are able to observe that in 1816, eight years after the abolition of the slave trade, the Roman Catholic Mission was also granted permission to take part in the attempts to convert the slave population to Christianity. Prior to that the Roman Catholic Church's activities were severely restricted by the Government.

There were Roman Catholics both among the free citizens and the slaves from the earliest years of the colony as a Plantation. Reports in the journals of the Moravian Brethren show that Portuguese or Brazilian priests had been engaged in christening slaves - who were thereupon shipped to Surinam, where they continued to adhere to this religion at the Dutch settlement of St. George d'Elmina in West Africa (cf. Abbenhuis, 1956, p. 119). Despite opposition from the West India Company, the liberal-minded Governor van Aerssen admitted three Franciscans and a lay brother to look after their spiritual welfare in 1683. These were at the same time granted permission to proselytise among the Amerindians. Three years later the death of these priests, who were never replaced, put an end to this work. The Roman Catholics 
remained without any spiritual leaders for over a century, until in 1786 they were allowed to profess their religion subject to a number of restrictive conditions. It was at the same time stipulated among other things that Roman Catholic priests should be permitted to discharge their duties solely among the free citizens. They were expressly forbidden to christen slaves. These regulations were partially repealed in 1816, when missionaries were given permission thenceforward to work among the slaves on privately owned plantations. These privileges were further extended to include freedom to preach among the slaves in the government leprosaria in 1822, and among all other government slaves in 1840. The number of Roman Catholics in Surinam rapidly grew after 1825 , increasing from around 1300 to about 12,000 in the years from 1825-1863, chiefly as a result of missionary activities among slaves. The Roman Catholic mission was especially active in the town and the areas immediately surrounding it. Partly in consequence of this the Roman Catholic Church developed principally into an urban Creole church (Abbenhuis, 1956, pp. 119, 120, 136).

The family life of the slaves constituted a matter of grave concern for the missionaries. Despite the prohibition of proselytism among slaves, some missionaries performed church marriage ceremonies - mostly in secret - among the slaves christened by them. An endeavour was made to legalize this practice and to improve the slaves' living conditions in 1819. In that year P. Wennekers, praefect of the Roman Catholic mission in Surinam and pastor of Surinam, submitted a remarkably progressive petition to King William I of the Netherlands. In it he requested with respect to the family life of the slaves:

(1) marriages that were at least solemnized in church;

(2) a prohibition if not on separate sales, at any rate on separations of the kind which prevented persons married to each other by some kind of religious ceremony with their owners' knowledge from seeing each other;

(3) permission to christen Creoles (i.e., locally born slave children) and aged persons. (Cf. Abbenhuis, 1953, p. 42.)

A similar request had been sent from Guraçao two years previous, in 1817, by Father J. Stöppel, O.F.M. He addressed his petition to a certain Father Thomas in The Hague, over the heads of his immediate superior and the colonial administration, with the request to impart the contents to the arch priest J. Cramer and pass them on to the King 
(cf. Goslinga, 1956, pp. 42 and 178). Like Stöppel's attempt, this petition of Wennekers' forced the governments in both the mother country and the colony to express their views on marriage among slaves.

\subsubsection{State Interference in Respect of the Family Life of the Slaves}

In response to Father Wennekers' petition the Minister of Education and National Industry and Arts asked the Governor of Surinam for an explanation concerning this matter. The latter referred the questions asked here to a committee composed of J. Bruyning and H. C. Perret Gentil, both of them members of the Court of Policy, and the Reverend Mr. H. Uden Masman for these gentlemen's advice. The recommendations submitted by them on 31 st January, 1820, plainly reflect what kind of views and ideas the colonial elite entertained in respect of the family life of the slaves. They similarly show that there was little inclination on the part of senior colonial officials to dispute the owners' proprietary rights, such as by proposing a ban on the separate sale of husbands and wives. I quote below a few passages from this Report (General Public Record Office, The Hague):

"The undersigned, in reply to the questions of His Excellency in behalf of the Department of Education, National Industry, excerpted from the Register of Transactions and Resolutions, 28th September, 1819, No. $4 / 83$.

Replies.

Question no. 1. Whether it would in fact be altogether impossible to introduce slave marriage in the various West Indian Colonies.

Reply. They consider that the purport of this question should be restricted not so much to the possibility or impossibility as to the advisability and desirability of such a measure.

They have deemed it necessary similarly to keep in view the following in their reply to these questions. That the first question in particular has in mind not so much the civilized European or the free native who, it is to be hoped, will have formed certain ideas of the morally binding nature of laws or social relations, as the Negro slave, that crude, sensual creature who follows only the promptings of his animal nature, and upon whom it is most difficult to impress any idea at all of the moral significance of marriage, of the binding authority of the same, and of certain duties - while further the confirmation of the agreement 
between husband and wife to enter into marriage, without which after all this agreement is utterly null and void, should be kept in view here.

Marriage can be viewed from either a civil and social angle or a religious perspective.

Viewed from the civil and social perspective the same is: a mutual contract between two persons duly authorized and empowered by the civil law to live together, to bring up any children born of the union together, and to look after each other's and the common domestic interests; a contract scrutinized by the Civil Authorities and accordingly legitimated and ratified by the same.

Viewed from this angle, the undersigned have no hesitation in declaring the same undesirable and in all respects unadvisable with regard to the slaves of this Colony, -

For the special reason that the slave, not constituting a legal person in society, cannot as a result be granted any authority to conclude any kind of contract whatever, no more than one is able to grant such authority to minors at law. -

By introducing marriage for slaves one would thus be giving them the authority to make contracts which, entering into the same of their own accord, they are then able also to break of their own free will; thus they would advance from the category of subordinate creatures, which they constitute at present in the society, to the class of independent free citizens; -

The Negro slave, incapable as he is of proper analysis, would soon raise himself above his station and allow himself certain liberties which are in contradiction with the established order and in conflict with the present status of these people, which might possibly give rise to scenes that might bring the most catastrophic consequences in their wake.

Added to this there is also the disposition of the Negro slaves themselves to be considered, it being obvious to anyone acquainted with these people in that they are utterly inconstant and fickle, and extremely inconstant in the gratification of their sexual urges: it would consequently need to be feared that the introduction of marriage, far from attaining the beneficial goal aimed at, would have a contrary effect and give rise to perpetual dissolution and all manner of other confusion.

In contemplating the possible introduction of marriage for slaves, the following difficulties have moreover occurred to the undersigned, which they feel it their duty to put forward on the present occasion, but the solution of which, they must at the same time confess, would appear extremely difficult to them. 
Marriage makes a wife subordinate to her husband, but how is a female slave... belonging to $A$. to become subordinate to a certain slave belonging to B.? Will not the master's authority suffer severely by this?

In what way is a man who is not a person to put into operation the law on marriage?

Is the slave to assume the responsibility of providing for the family and for the children's upbringing, and how much discord will not this sow?

In what manner are these marriages to be sanctioned, under observance of certain formalities, and what are to be the grounds for their dissolution?

All of them objections which the undersigned readily admit are far from easy to resolve.

In respect of the religious viewpoint from which the marrying of slaves may be regarded, the undersigned profess themselves to have an even greater number of objections.

The great majority of Negro slaves have virtually no notion, or at any rate a very vague and confused one, about the nature of the Supreme Being and His worship; the majority of them are so much under the influence of superstitious and idolatrous ideas, which they have instilled into them from early childhood, that it is rarely possible to persuade them to give these up altogether, and if so, always with the greatest of difficulty.

Now, how does one expect a bond of which they have no knowledge to operate among such people, to force them to fulfil duties of which they have not the faintest idea and of the beneficial effect and binding authority of which they are incapable of forming any notion whatever.

Not to mention the difficult, indeed the utterly impossible situation which would be created for both the public authorities and the clergy by the introduction of marriage for slaves, together with the ratification of the same in the usual manner in the way that after all any marriage must be confirmed if it is to have any binding force?

These arguments will be sufficient, so the undersigned trust, to bring home the inadvisability of marriage for slaves with the present position of these people being what it is in the Colony of Surinam.

The undersigned have further devoted themselves to a consideration of the second question.

Whether the joint sale of husbands and wives with such of their children as are as yet incapable of work, and consequently the pro- 
hibition on selling any of the members of a family separately, would be so utterly in conflict with the interests of holders as to deter the government from giving its consideration to regulations on this subject.

The undersigned would be observe with reference to this that the regulations existing in respect of the sale of mothers and children, and which have been enacted by decree in this Colony, have been ratified in such a way:

as to leave nothing to be desired on this point, it being in fact forbidden to sell families, mothers and children separately unless such is done for the purpose of releasing said persons.

As regards the separation of husbands and wives, the opinions of all those at all familiar with the conditions and relations of Negro slaves will no doubt concur.

To the effect that no changes can be made lightly in the existing laws on this subject without causing serious injury to the owners, while further the undersigned find it impossible to believe that the goals aimed at would be achieved by such changes. Unions between men and women among the slaves endure only for as long as their animal instincts and sexual urges operate - a few isolated examples cannot be made to serve as general rule - while, the Negro's fickle nature being quickly satisfied, he will equally soon abandon the object of his passion; for which reason Negroes rarely content themselves with one wife, but usually have two or three, indeed, sometimes several.

Matters standing thus, it will be inadvisable to oblige slaveholders, except to their serious disadvantage, to sacrifice their interests for the sake of a short-lived and inconstant union and to buy or sell husbands and wives together, as the same would not be nearly as advantageous to these individuals as would seem at first sight."

Especially the final sentence makes it obvious that government officials were little disposed to oppose the plantocrats' interests. Slightly more subtly worded than this committee's recommendations is Governor Vaillant's missive dated 22nd February, 1820, sent by him to the Minister (General Public Record Office, The Hague, missives from the Government of Surinam, 1820). Marriage for slaves did not seem so objectionable to him, "provided the same has no implications for the slaves' status or the obligations in connection therewith, and does not violate the masters' rights, so that if it is in the masters' interests to separate the partners, these shall be obliged to submit." (My own italics.) 
Vaillant did not consider there was much likelihood of church marriage catching on with slaves on the plantations due to faulty communication, inadequate religious instruction and the foreseeable lack of cooperation of administrateurs and managers, as conversion to Christianity might well give rise to absenteeism.

$\mathrm{He}$ expresses himself in somewhat more positive terms in respect of the slaves in Paramaribo, among whom there were already a great many Christians (Moravians, Roman Catholics and Calvinist Reformed), saying, "These people, who all live in the same town and are able to visit each other during their hours off from work without neglecting their duty, and are able to live together with their respective masters' prior consent without much inconvenience to the same, might well be permitted to conclude marriages by means of church ceremonies. Such ceremonies might in that case be prescribed by the clergyman concerned and might even be confirmed by the same in accordance with the principles of the individual formulae of the different religious persuasions, while the responsibility for admonishing the couple in respect of the observance of conjugal fidelity and the care and upbringing of the children, as well as for taking corrective measures in the case of disobedience of these rules, would also have to be left to the clergy. The government would not be required to do anything in this connection for the moment, except grant admission on written evidence of the masters' consent being produced."

Vaillant did not propose a ban on the separate sale of husbands and wives, however. In reponse to the recommendations of Messrs. Bruyning, Perret Gentil and Masman as well as to Vaillant's missive (together with the documents relating to the situation in Curaçao) the Commission for the Affairs of the Protestant Churches in the East and West Indies at The Hague drew up a final report addressed to the Councillor of State who was also Director General for the affairs of the Reformed Church. This posited among other things that the introduction of marriage for slaves was impracticable on account of their lascivious passions and in order to avoid violation of the masters' proprietary rights (cf. Abbenhuis, 1953, p. 45).

Despite these definitive recommendations, one of the consequences of bringing this matter up for discussion was even so that thenceforward the authorities turned a blind eye to church marriages and Alliances for slaves. No measure was ever introduced to prevent the separate sale of slaves "married" in this way, however. No-one had the courage to oppose the interests of the planters who, though mostly themselves 
resident overseas, wielded in actual fact unlimited power in the Colony through their attorneys. This is apparent once again in 1848, when a recommendation was put to planters and attorneys by the Minister of Colonies J. G. Rijk, a former Governor of Surinam, urging them to observe the following rules as regards slaves in the interests of the Colony:

(1) to practise moderation in, and where possible avoidance of corporal punishment;

(2) to give proper attention to and exercise closer supervision of the accommodation of slaves;

(3) (to supply) adequate and better quality food than that hitherto received by the slaves;

(4) to give more generous clothing allowances in order to prevent disease and combat immorality;

(5) to reduce the compulsory working-hours to nine hours a day, for example; to introduce a compulsory day of rest on Sundays in order to give the slaves time for religious instruction, among other things;

(6) to bestow proper attention on the medical care of the sick and of pregnant women and children; hospitals, instead of resembling gaols, should be roomy and airy.

These recommendations do not even mention the occurrence of separate sales (cf. Steinberg, 1933, pp. 93, 94).

It was not until 1858, five years before Emancipation, that direct government attempts to improve the slaves' family life were made. The initiative for this was taken by the Mother Country this time. Because Emancipation had to be deferred in consequence of certain objections being raised in the Lower House to the various bills on the abolition of slavery, the Minister of Colonies deemed it desirable to promote the family life of the slaves as a means whereby to appease their feelings, excited as they were at the repeated postponement of Emancipation, and to prepare them for freedom (cf. Van Lier, 1971, pp. $155 \mathrm{ff}$.). In a letter to the Governor of Surinam dated 10th April, 1858, which is kept in the National Archives in Paramaribo, the Minister put forward the proposal that to begin with, all slaves on the Government plantation Catharina Sophia, and later on those of the Government plantation of Rustenburg, who were living with only one wife, with whom they had made a vow in the presence of a missionary of the Moravian Church to live together faithful as Christian husband and wife in future after entering into an "Alliance": 
(1) should be given a separate, better furnished dwelling, as well as some furniture, at the plantation's expense, so as to distinguish them as acknowledged heads of households above the others;

(2) should be allocated a plot of land on which to sow and plant and to raise a little livestock of the smaller varieties for their own profit;

(3) should be given one day a week, e.g. Saturdays, off from work on condition that the day be spent in working the plot allocated to them and not in gadding about or loafing; and that their wives and any of their children living with them should be enabled to enjoy the day off with them;

(4) that members of such households should not be subjected to corporal punishment without due permission from the Attorney General after examination of the charges brought against them.

So as to have these measures introduced in the same spirit among the slaves of privately owned plantations as well, the Minister sent a duplicate of this letter to the Committee of persons with interests in agriculture in Surinam in Amsterdam, in order this way to induce private owners to grant their monogamous slaves similar privileges. The Governor sent a memorandum to his top officials as well as to the Leader of the Moravian Mission with reference to the Minister's letter. In this he stated himself to have no objections to the proposal under (2), as every slave, male or female, who so desired could have a plot of land allotted to him under the existing regulations. According to him this was even supposed to be encouraged by those in charge of plantations.

The Governor did have certain objections to the proposals put forward under (1), (3) and (4), however, as the introduction of these measures would exacerbate the rivalries and jealousies between slaves. Moreover, the Governor considered the imposition of the condition of "conjugal fidelity" possible only when the slaves should have made greater moral progress. He did not think that the Moravian Mission was having much influence on slave families in this respect, notwithstanding the fact that their teaching activities were having markedly positive results in other fields.

The Governor considered it a further disadvantage that the unequal sex ratio on some estates, as a result of which it was not possible for every person wishing to do so to enter into a union, might give cause for discontent at being denied particular privileges. He also considered it a shortcoming that the special favours promised might act as a lure 
to boys and girls to have sexual relations at an even earlier age than at present, which was prematurely early as it was. And further, men with more than one wife might feel tempted to break off existing relationships in order also to receive a day off from work, which might also arouse discontentment. Furthermore, the introduction of these measures might give rise to dissatisfaction among the better educated slaves such as Negro overseers, engineers and artisans, who could as a rule afford to be polygamous because of their privileged position, and who would now be denied privileges which their subordinates would enjoy instead of them. The Governor was also skeptical about the introduction of the proposed measures on privately owned plantations. It was financially unjustifiable to require planters to give some of their slaves a regular day off from work. This way deep resentment would be aroused among the slaves of private plantations at being denied the privileges which the said measures were allowing slaves on Government plantations.

In a missive of 9th July, 1858, in reply to the Governor's memorandum, Attorney General Gefken, who strongly favoured Emancipation, similarly took a strong stand against granting certain privileges to monogamous slaves. He did advocate legal recognition of church marriages for slaves, however. It would be useful to register unions of this type in the slave registers, thus making separations through separate sales impossible in future. The leader of the Moravian Community, Van Calker, also expressed himself in similar terms. In a memorandum to the Governor dated 17th July, 1858, he advocated the introduction of official measures preventing the separation of husbands and wives as well. He proposed in this connection that the registers of names of slaves should classify them according to families so as to facilitate control over separate sales where these occurred.

The Minister's proposal, together with the various memoranda drawn up in response to it, were brought up for discussion at the Colonial Council meeting of 14th August, 1858. Apprehensions lest any new measures taken in anticipation of Emancipation might stir up unrest prompted the resolution not to carry out the Minister's proposals, this marking the end of all government efforts to interfere in the family life of the slaves (Van Lier, 1971, p. 156).

Neither the government nor any of the Churches ever succeeded in putting a stop to the practice of selling slaves separately. I shall discuss in the next section the effects of the insecurity of the slaves with regard to the durability of their relationships. 


\subsection{Man-Woman Relationships among the Slaves}

In comparison with the period discussed in the preceding chapter, there was little actual change in the nature of the relationships between slaves in the present one. Possibly the introduction of the "Alliance" and Roman Catholic church marriages had some effect in stabilizing relationships between men and women slightly. Missionaries of the various churches tried to exercise some social control over slaves. According to Wolbers (1861, p. 767) it was particularly the Moravian rather than the Roman Catholic missionaries who kept a strict eye "on the morality of those committed to their care". Some manumitted slaves went over to the Reformed Dutch Church in order to escape this strict discipline (cf. Koloniaal Verslag Suriname or Colonial Report of Surinam, 1855).

The introduction and official sanctioning of the "Alliance" and Roman Catholic church marriages did nothing to alter the slaves' legal position, and the possibility of selling separately a man and woman joined in matrimony by a church ceremony remained.

Whenever two people entered into a union legitimated by the church, they did so in the knowledge that it would last only as long as the owner considered desirable. There were instances of the separation of couples joined together through either the "Alliance" or a Roman Catholic church marriage right up to Emancipation. Because husbands and wives were virtually or wholly independent of one another economically, slave relationships in this period, too, can be characterized chiefly as "Neigungsehen" or love matches.

The government's refusal to attach any significance to slave marriages solemnized by the churches became once more apparent at Emancipation, when the slaves passed from the sphere of the law of objects to that of the law of persons, necessitating their registration in the civil "registers of freed persons". Registration of this type was regulated by the 21st article of the law on the abolition of slavery in the Colony of Surinam of 8th August, 1862. The following regulations were enacted in this: "The future free slaves shall adopt a family name whereunder they shall be registered, and shall be so registered according to families, where possible, in the appropriate registers. They shall be presented with a certificate of such registration, stating: the registration number, the name and Christian names and the date of birth or estimated age. The Governor of the Colony shall be responsible for the due execution of registration upon the abolition of slavery."

The majority of 3407 members of the slave population of Paramaribo, 
which comprised 4321 souls, was registered according to families in the register of freed persons. The remaining 914 were entered individually. What did the lawgiver take the term "registration according to families" to mean?

It can be inferred from the text of the abovenamed law that this was understood to refer to registration according to households; there is mention of "households" and "heads of households" further on in this law. ${ }^{1}$ Apparently it was customary to use the terms "family" and "household" interchangeably. This is evident also from the reference to hiring out "families" in a model contract for the hiring of migrant labourers a year after this. A note to this model contract states that, "If the entire family is hired, the names and ages of the persons comprising the family should also be filled in,..." (cf. Gov. Resolution 29th April, 1863, No. 2, Art. 7).

The registers of released slaves drawn up in this manner fill up nine volumes. Volumes 1 and 2 contain data concerning the urban district of Paramaribo, the other volumes containing entries relating to persons in the districts of Perica and Commetewane (vol. 3), Upper and Lower Saramacca (vol. 4), Nickerie and Coronie (vol. 5), Upper Cottica and Upper Commewijne (vol. 6), Lower Commewijne and Matappica (vol. 7), Lower and Upper Suriname (vol. 8), and Lower Cottica (vol. 9). There are no registers for the districts of Upper and Lower Para.

The responsibility for the supervision of registration was given to the district governors and district secretaries, appointed shortly before this consequent upon the redivision of the Colony into districts (K.B. (Royal Decree) of 21st December, 1863, no. 26). ${ }^{2}$ These functionaries went around visiting the plantations in their respective districts, registering and allocating family names to the prospective emancipated slaves up to 1st July, 1863, the day of Emancipation (cf. Van Sypesteyn, 1866, p. 26). It is easy to see why they should have been made responsible for registration, as the district governors also acted as registrars of births, deaths and marriages in their respective districts (Gouvernementsbladen (Government Gazette) 1863, no. 11).

1 "That any persons over the age of 60 shall remain with the families to whom they belong, as shall children below the age of 15 , who will in any case follow their mothers."

2 Prior to that Surinam was divided into eight "divisions" administered by polder boards (the members of which were simultaneously honorary members of the Colonial Council) and two districts - those of Nickery and Coronie administered by government officials known as bailiffs (cf. Van Sypesteyn, 1866, p. 26). 
The registers were drawn up as follows. Every slave due for release was given a registration number, with the family name received by him on this occasion together with any Christian name or names written after it. His date of birth or his estimated age was recorded after that, as well as the name by which the person concerned had up to then been known. The place of residence prior to 1st July, 1863, was also stated, while under the heading "Special Remarks" a person's family relationship in respect of the head of the household was noted down, that is to say, if he was being registered according to family and not individually. Although the sex of the person so registered was not recorded, it is even so possible to infer from the Christian name chosen and the relationship to the head of the household (son, daughter, grandson, and so on) recorded here whether the person in question was male or female. All persons registered as members of one particular family bear the same family name. The register of Paramaribo does not always include full particulars of the mutual relationships within families.

The lawgiver adopted a legally formalistic rather than a sociological standpoint as regards the definition of the concept of "family" when drawing up the registers. As we know, slaves were precluded from marrying at law, so that as a result the term "legitimate" household was taken to comprise either a woman and any of her matrilineal descendants living with her, or any of the matrilineally related descendants of a deceased woman living together. Only between the woman and her children did a "legal tie" exist, according to the slave laws in force up to that moment. After all, slave children were the property of the mother's and not the father's owner. Children could not be sold separately from their mothers. At that time no male slave making up a household together with a woman and their joint children, if any, was registered as a member of that "household". Not even in cases of slaves who were joined in matrimony under the terms of the "Alliance" or a Roman Catholic church marriage was this done, since, as we saw above, the government did not officially allow such "marriages" (cf. 5.3.3.).

As a result of the above it is impossible, regrettably so, to infer the composition of slave households in relation to the husbandfather from the registers, as only matrilineally related persons living together under the one roof were registered as a "household". If there was a man living with them he was registered either individually or as a member of his mother's household.

This deficiency notwithstanding, we are nonetheless able to infer a number of facts from the registers which may add to our knowledge of 
the family life of slave families in Paramaribo immediately prior to Emancipation. To begin with, we are able to deduce the composition of households in respect of the senior member. Most of the latter were women. Wherever a man is referred to as the senior member of a household in the registers, the family in question comprised the descendants of a deceased woman (her sons, daughters and daughters' children) who continued to live together under the same roof after her death. In such cases the eldest brother was designated as senior member of the household by the lawgiver.

The following table sets out the composition of households:

Table 10. Slave Population (4,321) of Paramaribo in 1863, classified according to relationship to the senior member (male or female) of the household (in percentages)

\begin{tabular}{|c|c|c|c|}
\hline & $\begin{array}{l}\text { Male Senior } \\
\text { Member of } \\
\text { Household }\end{array}$ & $\begin{array}{c}\text { Female Senior } \\
\text { Member of } \\
\text { Household }\end{array}$ & Total \\
\hline & $(n=122)$ & $(\mathrm{n}=742)$ & $(n=864)$ \\
\hline son & - & 27.0 & 24.0 \\
\hline daughter & - & 31.0 & 28.0 \\
\hline daughter's son & - & 7.0 & 6.0 \\
\hline daughter's daughter & - & 8.0 & 8.0 \\
\hline great-grandson & - & 0.0 & 0.0 \\
\hline great-granddaughter & - & 0.0 & 0.0 \\
\hline brother & 24.0 & 2.0 & 5.0 \\
\hline sister & 26.0 & 3.0 & 6.0 \\
\hline nephew & 13.0 & 1.5 & 2.0 \\
\hline niece & 13.0 & 1.5 & 3.0 \\
\hline unspecified male relative & 12.0 & 8.0 & 8.0 \\
\hline \multirow[t]{2}{*}{ unspecified female relative } & 12,0 & 10,0 & 10,0 \\
\hline & 100.0 & 100.0 & 100.0 \\
\hline
\end{tabular}

In the cases of households with a male senior member there were no children of the latter on record. This is a logical corollary of the fact that children were the property of the mother's and not the father's owner, and hence lived under their mother's roof. We do find a fairly large percentage of brothers and sisters and nieces and nephews of male senior members of households, on the other hand. The latter two categories of relatives comprise the children of the sister(s) of the senior household members in question.

Sons and daughters of senior members of households are listed where the latter are females. Daughters' children are also included in these 
households, though not sons' children, as these belonged to the household of their mothers, who were resident elsewhere. The category of great-grandchildren - of which there are remarkably few on record in these families would comprise daughter's daughters' children. The category of nieces and nephews in this case comprises either sisters' sons and daughters, or sisters' daughters' children. There is a surprisingly large number of households with a female as senior member covering three or more generations.

Table 11. Households set out according to the Number of Generations

\begin{tabular}{cccc}
\hline $\begin{array}{c}\text { Number of } \\
\text { Generations }\end{array}$ & $\begin{array}{c}\text { Male } \\
\text { Senior Member }\end{array}$ & $\begin{array}{c}\text { Female } \\
\text { Senior Member }\end{array}$ & Total \\
\hline 1 & 52 & 20 & 72 \\
2 & 25 & 397 & 422 \\
3 & 1 & 113 & 114 \\
4 & - & 7 & 7 \\
\hline Total & 78 & 537 & 615 \\
\hline
\end{tabular}

(N.B. Only households of which the number of generations can be deduced from the text of the registers are included in this table. The total number of households was 864.)

These are all households composed of a woman, her children and her daughters' children. Where there are four generations, these include matrilineal great-grandchildren.

The following table will throw some light on the numbers of which slave households were composed.

Table 12. Slave households in Paramaribo in 1863, classified according to the sex of the senior member and the number of members

\begin{tabular}{cccc}
\hline & \multicolumn{2}{l}{ Sex of Senior Member of Household } & \\
\cline { 2 - 4 } Number of & Male & Female & Total \\
Members & & & \\
\hline 2 & 51 & 236 & 287 \\
3 & 23 & 160 & 183 \\
4 & 18 & 126 & 144 \\
5 & 8 & 77 & 85 \\
6 & 8 & 52 & 60 \\
7 & 4 & 33 & 37 \\
8 & 6 & 18 & 24 \\
9 & 1 & 17 & 18 \\
10 or more & 3 & 23 & 26 \\
\hline Total & 122 & 742 & 864 \\
\hline
\end{tabular}


My supposition that urban slave households may generally speaking have been smaller than those on the plantations turned out to be correct. In order to investigate this, I made a comparison of the size of slave households in Paramaribo with those of the Lower Suriname and Lower Commewijne districts. To ensure a correct analysis I have accounted all individually registered persons as families in my calculations.

Table 13. Family groups of the Slave Population of Paramaribo and the Lower Suriname and Lower Commewijne Divisions, Classified according to the Number of Members

\begin{tabular}{|c|c|c|c|c|c|c|}
\hline \multirow{2}{*}{$\begin{array}{l}\text { Number of } \\
\text { Members }\end{array}$} & \multicolumn{2}{|c|}{ Paramaribo } & \multicolumn{2}{|c|}{ Lower Suriname } & \multirow[t]{2}{*}{ Lower } & \multirow{2}{*}{$\begin{array}{c}\text { Commewijne } \\
\%\end{array}$} \\
\hline & & $\%$ & & $\%$ & & \\
\hline 1 & 914 & 51.4 & 348 & 42.8 & 237 & 38.4 \\
\hline 2 & 287 & 16.1 & 97 & 11.8 & 77 & 12.5 \\
\hline 3 & 183 & 10.3 & 72 & 8.8 & 58 & 9.4 \\
\hline 4 & 144 & 8.1 & 38 & 4.7 & 48 & 7.8 \\
\hline 5 & 85 & 4.8 & 54 & 7.0 & 35 & 5.7 \\
\hline 6 & 60 & 3.4 & 39 & 4.8 & 25 & 4.0 \\
\hline 7 & 37 & 2.1 & 32 & 3.8 & 38 & 6.1 \\
\hline 8 & 24 & 1.3 & 27 & 3.2 & 40 & 6.5 \\
\hline 9 & 18 & 1.0 & 20 & 2.5 & 9 & 1.5 \\
\hline $10+$ & 26 & 1.5 & 86 & 10.6 & 50 & 8.1 \\
\hline Total & 1,778 & 100.0 & 813 & 100.0 & 617 & 100.0 \\
\hline
\end{tabular}

The number of single persons appeared to be higher in the town than in the country districts, and the family size larger in the districts than in town. The latter phenomenon doubtless has some connection with the fact that in the year studied here the sex ratio on the plantations had regained its equilibrium (there being even a slight surplus of women), while that in town had remained extremely unequal as a result of a substantial surplus of women (cf. table 9).

\subsection{The Family Life of the Free Population}

I wish to conclude the present chapter with a number of further remarks about the family life of the free population, including whites, free Mulattoes and free Negroes, because in this period as well the conduct of these groups in many instances served a proportion of the slave population as model. 


\subsubsection{The Family Life of the Europeans}

In the period under discussion here, there was a slight decline in "Surinam-style marriages" among the white population. It became more and more the custom for Dutch government officials and officers to take a wife with them from Holland or marry a middle-class Mulatto girl in Surinam. Even so, Surinam-style marriages continued to be the most prevalent kind of union. We are able to infer from Teenstra's (1835, II, p. 203) Generale Staat der Bevolking van Suriname (General Survey of the Population of Surinam) concerning the year 1830 that out of a total European adult population of 1843 persons ( 1263 men and 580 women) in Surinam, only 496 (i.e. $27 \%$ ) were married. By this time marriage had become a status symbol among those enjoying the greatest social prestige, such as the Governor, senior government officials, senior officers and a proportion of the plantocracy among the white population. Members of the Jewish section of the community, where, as was observed in the preceding chapter (section 4.5.), Surinam-style marriages were rare, continued to marry according to their own rites in the period under discussion here as well. A number of them, however, especially those who had renounced orthodox Judaism, now sometimes also entered into Surinam-style marriages with Mulatto girls.

In addition to the wife to whom they were joined in either traditional or Surinam-style marriages, a large number of whites kept one or more mistresses, who were either Mulatto or Negro women. These women disposed over a dwelling of their own, and they and their children were provided for by the visiting man.

\subsubsection{The Family Life of the Free Mulattoes and Free Negroes}

The group of free Mulattoes and free Negroes had grown apace as a result of manumission, of which there was a steadily increasing number of cases towards the end of the period discussed here. The majority of these lived in Paramaribo. Teenstra (1833, II, p. 203) reports that according to his calculations 4642 of the total of 5041 freed persons were living in Paramaribo in 1830. On the whole the experiences with regard to their industry do not seem to have been very positive. Contemporary authors report that freed persons were averse to farming as they possessed no slaves. We should take into account in this connection that most of these manumitted persons were former domestic slaves or artisans and thus were not used to agricultural work. A decree of 3rd October, 1844 (G.B. (Government Gazette) No. 5) as a result sets 
out a number of provisions against shiftlessness and vagrancy, stipulating among other things that thenceforward no letters of manumission should be granted save on condition that the person so manumitted was able to exercise a particular trade or craft inside the Colony of Surinam (cf. Encycl. 1914-'17, p. 63).

Most of the freedmen were Mulattoes. Teenstra's statistics for the whole of Surinam in 1835 mention 3947 Mulatto as against 1094 black freedmen (Teenstra 1835, II, p. 203). Of a total of 2037 adult Mulatto freedmen only 47 were married, while of the 857 adult black freedmen only two were married. Women were in the majority among the free citizens - there being 3004 women to 2037 men.

Not all of the freedmen occupied identical socio-economic positions. Among the Mulattoes there were two clearly distinguishable categories from the very beginning, namely the one consisting of persons born of Surinam-style marriages between European men and Negro of Mulatto women, and the other consisting of persons born of casual relationships between white men and black or coloured women. The former in many cases received a good education and formed the nucleus of a developing middle class. There were some among them who were recognized and/or legitimated by their fathers. Coloured children born of loose relationships usually received little or no support for their education from their procreators. They were mostly children born of fleeting affairs between white soldiers or sailors and Negro women. They grew up entirely without discipline and posed the government some difficult problems. They were absorbed for the greater part by the free Negro proletariat.

There was a deep social gap between the two coloured groups. An official division into two coloured groups was made by the administration in 1835, when the New Regulations for the civic militia of Paramaribo were promulgated, involving an attempt at changing the traditional division into white, Mulatto and Negro companies. A division into four companies was envisaged hereby, the first having to consist of married men and widowers and any persons who, though themselves unmarried, were born of legal marriages or legitimated through a later marriage or letters of legitimation. The second and third companies were to be composed of single men neither born of legal marriages nor legitimated through a later marriage or letters of legitimation; the fourth was to comprise freeborn and manumitted Negroes, either single or married. The implication of this measure was that the first company would in actual fact be composed of whites and any of their coloured sons 
recognized and/or legitimated by them, and the second and third companies of Mulattoes born of temporary relationships.

The promulgation of the New Regulations aroused a storm of protest. The public felt that this was making a reprehensible distinction between different categories of citizens (the old classification according to colour evidently being considered normal). When a large number of citizens voiced their objections to the proposed regulations, the Governor suspended their enforcement, though instructing the Committee in charge of enrollment for the Civic Militia to draw up a register for registering married and single, legitimate and illegitimate, and freeborn and manumitted men separately, with the objective of organizing the Civic Militia in accordance with the literal content of the Regulations enacted by the Governor in consultation with the Colonial Council.

All this provoked widespread resentment, so that in May 1837 there were some riots the nature of which was grave enough for the Governor to issue orders to train the cannon of Fort Zeelandia and of the warships anchored in the roads on the town. In order to avoid provoking further rioting the Governor had the Regulation amended shortly afterwards, the Civic Militia thus being restored to its former status quo (cf. Wolbers, 1861, pp. $678 \mathrm{ff}$.).

Hence the formation of an elite on the basis of legitimacy of birth or legal recognition was prevented as a result of this incident. The above nonetheless goes to show plainly that there was a definite tendency towards this in the society of Surinam.

As regards the family life of the free middle-class Mulattoes, it should be observed that in this group, too, Surinam-style marriages were the most frequent type of union. Most middle-class Mulattoes maintained kinship relations with Europeans, being for the greater part the sons and daughters of white men. Moreover, this group provided the Europeans with women for Surinam-style marriages. Women from the coloured group lived in concubinage preferably with Europeans. A relationship of this type endowed them and their families with a certain prestige and influence, as well as assuring them of a regular income (the fact aside that from a social viewpoint legal marriage with a white man was out of the question, especially at the beginning of this period).

As the 19th century progressed and more and more white men preferred legal marriage with a woman from either their own or the coloured group to concubinage with a Mulatto girl, Mulattoes, who came to occupy increasingly prominent positions, also began to conclude marriages, as concubinage came to be regarded as an obstacle to social 
mobility. A number of white men, for instance, showed themselves indisposed to entertain coloured persons "living in sin", i.e. in concubinage, at their homes, in many cases due to the influence of their wives.

For the less ambitious middle-class coloured persons Surinam-style marriage preserved its position as the "normal" relationship between men and women in this period. In this group as well, it was customary for many men who had entered into either conventional or Surinamstyle marriages to have one or more mistresses.

The family life of coloured and Negro lower-class freedmen provided a sharp contrast to that of the free middle-class Mulattoes. For their family life was subject to the effects of the lack of opportunity for men belonging to this class to earn a steady income even at that time, as well as the unequal sex ratio among them.

As regards the irregularity of their incomes, Van Lier (1971, p. 114) informs us that a percentage of the black freedmen belonging to this group possessed garden or provision plots in the vicinity of Paramaribo in which they grew such products as vegetables and bananas. They also raised some chickens, which they sold in town. They did not run their farms along very intensive lines, however, and were anything but prosperous. But the great majority of black freedmen, as a considerable proportion of the coloured ones likewise, had no regular work and hence no regular source of income.

Governor Van Raders (1845-1852) exerted himself to some degree to stimulate the "Lower-Class Creoles" to greater industry. He made some effort to combat the prevalent prejudice that field work is degrading to a free man (cf. Wolbers, 1861, pp. $710 \mathrm{ff}$.). For the notion prevailed among them that field work put a free man on the same level as slaves. By taking up a spade himself and helping with the gardening in his own garden, Van Raders succeeded in overcoming the prejudice of a number of lower-class Creoles against this kind of work and in inducing them to help with the work of diverting Steenbakkers Canal outside Paramaribo. "They turned up on the appointed day, be it still a little reluctantly; still they were lacking in moral courage to take up a spade; until the Governor himself picked up a spade and began to dig calmly. His example had the desired effect and was soon diligently followed. Only a few moments more, and the contempt in which excavation work by freedmen was held was overcome. Both whites and free Mulattoes and Negroes walked with a certain pride through the streets of Paramaribo carrying their spades on their shoulders. In order 
to make this victory a lasting one a celebration such as had never been witnessed before in Surinam was ordered." (Wolbers, 1861, p. 712).

The change in attitude effected by Van Raders did not last long. It was counteracted by the lack of employment for the lower-class Creole.

Van Raders was fully aware of this and looked for a more permanent solution in the digging of a canal from Paramaribo to Kwatta, where about sixty farmers' families might be settled. Because of the high costs this enterprise entailed it was rejected by the Minister of Colonies, so that the work had to be stopped, despite Van Raders' efforts to go ahead with the project nonetheless.

This threw a large number of lower-class Creoles out of work. The incident furnishes an excellent example of the Lower-class Creole's perpetual uncertainty of sufficient work. Hence their indigence was doubtless not primarily the outcome of laziness, as was popularly believed to be the case, but rather of lack of employment. In 1860 a number of lower-class Creoles applied for the notoriously backbreaking work of digging on a certain plantation, but were rejected by the planter(s) because the latter did not wish to have manumitted persons working side by side with their slaves, notwithstanding the fact that there was a shortage of slave labour (cf. Wolbers, 1861, p. 771).

In consequene of Van Raders' activities a Society for the promotion of agriculture among the free population was founded in 1847. But this society failed to achieve its objective because the necessary financial assistance from the private sector was not forthcoming.

In respect of the lower-class Creole farmers settled around Paramaribo we should observe in addition that their unfavourable economic position of ten led them to give up this kind of work and seek employment mostly in vain - in this town. This made for ever greater unemployment in town. Competition from white agriculturalists growing foodstuffs for the urban market with the assistance of slaves on the outskirts of Paramaribo proved too strong (cf. Van Lier, 1971, pp. 96, 97). Hence urban lower-class Creoles seldom disposed over the necessary regular income for providing for a family.

Lower-class Creoles seldom concluded marriages. The abovementioned Report of the Surinam Advisory Committee with respect to the family life of slaves (cf. section 5.3.3.) touches incidentally on the question of marriage among free persons. In this connection, the Bruyning, Perret Gentil and Uden Masman committee gave its consideration to the desirability of encouraging marriage among the manumitted and so- 
called coloured persons, as it was to be foreseen "that in but a few more years' time marriage will have disappeared altogether among this class of people unless resolute counter-measures are taken." The Committee, when speaking of the children in this group, describes them in the following terms: "Born of unions involving the unlawful cohabitation of men and women, they are in a different position from slave children, whose well-being and life are so bound up with their master's interests that the latter are not infrequently prepared to make many sacrifices for the same; but alas, they are only too often left to their own devices, and in later age tend to follow the immoral example of the authors of their existence, which is easy enough in view of the latter's dissoluteness."

By way of encouraging marriage among this group, the Committee recommended the granting of special rights to married persons, raising the status of their children above that of legitimated children in certain cases, and giving them certain rights to particular services or exempting them from particular obligations.

These recommendations mention not a word about the lack of employment with which the lower-class Creole had to cope even at that time. The extreme irregularity of their income made for instability of the relationships between men and women. This instability was further increased by the fact that there was a considerable surplus of women in this group in Paramaribo.

Even at that time it was the woman who kept the family "going" by taking a job as laundress or maidservant or setting up as a food vendor, making and selling such products as pies, biscuits and lemonade, or selling fruit and vegetables, in the lower-class Creole group in Paramaribo. As a result her authority in the household was often exceedingly great, so that the latter possessed a markedly matrifocal character. There was a high frequency of female heads of households. Hence the family system of the lower-class Creoles in the period under discussion here was just as typically "West Indian" as that of the as yet unemancipated slaves.

After Emancipation, when the great majority of ex-slaves merged with the free proletariat of lower-class Creoles, no changes occurred in the family system. I shall discuss a number of factors which were responsible for this turn of events in greater detail in the following chapter. 


\section{THE POST-EMANGIPATION PERIOD}

\subsection{General}

Slavery was officially abolished in Surinam on 1st July, 1863, bringing in its wake a number of sweeping changes in the social relations in this country. It is interesting to study the effects of Emancipation on the ex-slaves' West Indian family system.

One could imagine the slaves taking the fullest possible advantage of their new legal status - which as a result of the above event had become equal to that of the free citizens - such as, for instance, by converting the existing types of man-woman relationship into legal marriages. This did not as a rule happen, however, and up to the present day civil marriage is still not common among the lower-class Creoles, concubinage and visiting relationships continuing to be socially acceptable alternatives. A large proportion of such relationships are instable and there are many women, most of them husbandless, acting as heads of households. In the present chapter I shall analyse the factors encouraging these trends in the post-Emancipation period. I shall then proceed in the following chapters to analyse on the basis of the on-thespot field work the contemporary factors determining these phenomena and to discuss the way in which the family system is functioning at the moment and what its implications are for the lower-class Creole in the society of Surinam.

\subsection{The Rural Exodus of the Creole Population}

In the passages following below I shall first give an outline of the uncertain economic circumstances affecting the lower-class Creole's life after Emancipation, as these exercised a decisive influence on the nature of his family life. Their economically insecure position drove a great many lower-class Creoles to town. We shall now proceed to discuss various aspects of this migration, which is connected with the struggle for greater economic security.

\subsubsection{The State Supervision of Ex-Slaves (1863-1873)}

There is to this day a marked tendency for Creoles to leave the rural areas for Paramaribo. Life in this town had a strong appeal for the 
Creole population for a variety of reasons. Hence the apprehensions of the planters that a mass exodus of emancipated slaves from the plantations would take place after Emancipation, thus depriving the latter of their labour, were not altogether unfounded. The Act on the Abolition of Slavery in the Colony of Surinam of 8th August, 1862, contained a provision to guard against this, clause 24 stipulating that all emancipated persons between the ages of 15 and 60 either living on or with regular employment on plantations or farms were supposed to conclude labour contracts for plantation work with planters or farmers of their own choice. Those of the same age group who were not employed on plantations or farms were similarly obliged to conclude contracts for labour or for rendering certain services. Only persons capable of furnishing proof that they were carrying on some trade, craft or business enabling them to support themselves and their families were exempted from this obligation. The owners were granted indemnification for the loss of their slaves. These measures were in force during the so-called period of "State Supervision", which was to last ten years. The aim hereof was to protect the emancipated slaves and make them ready for life as members of families and of society. The prevention of idleness and the regulation of compulsory labour, the promotion of general and religious education and the introduction of provisions for the care of invalids and the sick were seen as means towards this end.

Neither in town nor in the districts was Emancipation attended with disturbances. When work had to be resumed five days after Emancipation day, however, there were some outbreaks of discontent among the emancipated slaves of several plantations - particularly in the Lower Cottica district - who refused to go back to work for the awarded wages, while in some places there were cases of open resistance. It proved extremely difficult to induce the newly emancipated to conclude labour contracts on the plantations. Three months after Emancipation day - the term set for the conclusion of compulsory labour contracts by emancipated slaves - the great majority of the latter appeared to have done so, however. The "hard" line taken by the administration, which was even coupled with some display of force, succeeded in persuading most of the work-shy to conclude labour contracts in spite of themselves. The reason for this was probably that the administration was authorized to put any persons who had failed to enter into contracts of this kind within three months after Emancipation to work on government plantations or on public works.

As the newly emancipated were free to conclude contracts with an 
employer of their own choice, there was much coming and going up and down the length of the country among them. The bulk of them concluded contracts with their former masters, however, probably from motives of attachment to their native soil. There was a tendency among ex-slaves living on plantations which were distant from Paramaribo to leave these in preference for plantations closer to town. As a result the running of the remoter plantations became increasingly difficult (cf. Van Sypesteyn, 1866, p. 78). Some even concluded sham contracts so as to be able to move closer to or right into town. The majority of craftsmen and domestic servants on the plantations who were exempted from the obligation to conclude contracts on the grounds of their ability to provide for themselves and their families also moved to town. This was one of the causes of the population increase in Paramaribo. The population of the latter in the year of Emancipation (1863) was 18,666, while at the end of the period of State Supervision (1873) it came to 22,191 (Encyclopaedie, 1914-'17, p. 553). Moreover, the number of people living in the immediate environs of the town also rose sharply in this period (cf. Van Lier, 1971, pp. 181, 182).

So after the period of State Supervision there were fears that a complete exodus of plantation labourers to town over a brief space of time would take place. This process was much slower than anticipated, however, because a large number of Creoles settled as small farmers (cf. Kruyer, 1951, p. 63). It was not until after the tragic collapse of Creole mixed farming around the turn of the century that the mass migration to town really began. This migration received a further impetus from the settlement in Paramaribo of labourers employed in the industries in the interior (the balata and timber industries) which now developed here (cf. Van Lier, 1971, p. 254).

\subsubsection{The Period after State Supervision}

The expectation of a great many planters that it might be impossible to induce their Creole labourers to take up farm work except by coercion proved false when it turned out that a large proportion of them settled as mixed farmers after the period of State Supervision.

So as to offer the emancipated slaves some opportunities for making a living for themselves upon termination of the period of State Supervision, a number of small-scale farm settlements were set up on the initiative of Governor van Sypesteyn. These were located in the vicinity of plantations in order to provide the farmers with an opportunity of 
earning some extra income here in the event of the yields of their own soil being insufficient for their livelihood.

It is a known fact that the Creole small-scale farmers who settled in the vicinity of Paramaribo never attained the slightest degree of prosperity. For when the plantations stopped supplying the town with foodstuffs because all the available labour that was still left here was diverted for the cultivation of staple products, the Creole smallholders failed to seize the opportunity thus offered them. It was a number of newly arrived immigrant Dutch farmers who took advantage of the situation. They became the provisioners of the town (Van Lier, 1971, p. 225). The Creole farmers around Paramaribo lived a life of relative poverty on their provision plots, which they tilled primarily for their own subsistence. They were able to supplement their livelihood by taking on occasional odd jobs in town. They ended up by settling in town, where they fused with the urban proletariat. At present there are virtually no Creole small-scale farmers left living in the vicinity of Paramaribo.

Initially Creole small-scale farmers settling on uncleared land or on nearby private or Government-owned plantations in the rural districts fared better. We are able to distinguish three different areas in which Creole smallholders settled, viz.: 1. along the main rivers, particularly the Saramacca; 2. the Coronie district; and 3. the Upper Suriname and Para districts.

The areas along the big rivers developed into by far the most important agricultural centres. The Creole small-scale farmers concentrated primarily on cacao-growing, which turned out to be most lucrative, despite competition from several plantations which had begun to specialize in this product earlier on. Cacao-growing had become important again by the mid-19th century because of the great demand for this product that had arisen in the United States. This high demand made it possible for small-scale farmers growing cacao for the market to hold their own even in the face of competition from cacao-producing plantations.

The boom in this industry lasted until 1895, when the first symptoms of the so-called witches'-broom disease - a disease in the form of a noxious fungus growth - manifested themselves in the Saramacca district. It spread by degrees to the other districts. This was an especially serious blow to small-scale farmers, because they in most cases possessed too little capital resources or know-how to be able to use the existing methods of combatting the disease effectively in the same way as some of the planters. They did not succeed in finding another crop to replace 
cacao either. So they moved to town in search of a new livelihood, a percentage of them finding one in the industries in the interior. Only a small number of Creoles has continued to live along the major rivers, where they are living in relative poverty.

The farmers in the Coronie district were more fortunate. After Emancipation the planters in this area were obliged to sell their land to their labourers as a means of paying them the amounts outstanding in wages. The new owners of the land thus acquired began to specialize in coconut-growing, from which - later supplemented by rice-growing and pig-raising - they managed to make a reasonable living up to the 1960 's. This has changed in recent years as a result of a portion of the farmland in the Coronie district being rendered unfit for tillage by silting, the sea-defence works in this district having proved inadequate. In the past few years many younger people have moved from Coronie to Paramaribo to try to make a regular living there owing to lack of opportunities in agriculture.

As regards small-scale farming in the Para and Upper Suriname districts, in conclusion, it should be noted that this never at any time enabled the Creoles engaged in it to attain any degree of prosperity. They worked their land almost exclusively for their own subsistence. Lumbering on the former timber plantations remained their principal activity after Emancipation, these plantations having passed into the communal ownership of the ex-slaves after the abolition of slavery. As a result of the absence of efficient methods of running these plantations, this industry soon ceased yielding profits, thus forcing many inhabitants of Para to move to town.

The greatest exodus of Creoles to town occurred around the turn of the century as a result of the collapse of small-scale farming (except in Coronie). According to Van Lier (1971, p. 233) there was an apparent reversal of this trend around 1908, the number of Creole small-scale farmers even increasing again after this year. However, their number fell again after 1922. The crisis in the industries in the interior, which began to make itself felt as early as 1932, drove the Creoles back to the land in large numbers, and the number of small-scale farmers among them again rose after 1933. Like the Hindustanis and Javanese, they now also took to rice-growing, a branch of farming which they had hitherto always considered beneath their dignity and had left entirely to "coolies" (Hindustanis and Javanese) to carry on.

Both the local government and the Moravian and Roman Catholic Churches encouraged the Creoles to return to farming before World 
War II, though for the greater part vainly so. As there were American troops stationed in Surinam during the Second World War, a high temporary demand for labour arose in Paramaribo, prompting many Creoles once again to abandon their plots to take advantage of the boom in town. There was a slight reflux in the post-War period, but on the other hand the drift to town on the part of country Creoles continued, with Hindustanis and Javanese now also taking part.

It was chiefly the setbacks in the small-scale farming industry that caused the Creoles to become town-dwellers in Surinam. They migrated to town not because they had an aversion to farming (as is generally supposed) but because they possessed insufficient resources to enable them to hold their own as small-scale farmers under adverse circumstances. This was further aggravated by the partial or almost total lack of government assistance. Added to this, many people were under the illusion that the town offered more opportunities than it actually did. According to Van Dusseldorp (1963, p. 40), it was not so much the repellent force of the rural areas as the magnetic force of Paramaribo that was responsible for the Creole exodus to town.

\subsection{The Creole as Gold Digger and Balata Bleeder}

As we saw above, there was no immediate Creole mass exodus to town after the period of State Supervision, when they were completely free, as a large proportion of them succeeded in drawing a reasonable living from small-scale farming up to about the turn of the century. A percentage of them who failed to do so and moved to town before the turn of the century, like a percentage of the Creoles already living in Paramaribo before that, attained a certain degree of temporary prosperity. The years after 1870 witnessed the rise of two different industries which offered the Creole section of the population a fairly good, albeit precarious living. These were the gold and balata industries.

\subsubsection{The Gold Industry}

After an unsuccessful gold-mining enterprise launched in the 1840's, several different companies worked gold mines with varying success after 1872. The labour employed here comprised chiefly Surinam Creoles and Creoles from British Guiana and the West Indian Islands. ${ }^{1}$ The

1 It was forbidden by law to employ Hindustani or Javanese ex-immigrants brought to the country as labourers for plantation agriculture in gold-mining in Surinam. 
gold was mined by man power. Production increased up to 1897, after which it showed a downward trend. In order to reverse this trend several vain attempts at mechanizing the industry were made by British and American companies between 1897 and 1908, but this method of mining turned out to be technically unfeasible. Most of the companies were forced by lack of funds to stop operating. They again reverted to the use of man power in the production process, although from then onward a number of these companies adopted a different system for this.

Many of the former employees were now granted permits for working leases on their own account against direct payment to the company of $10-15 \%$ of the gross returns on the gold so extracted. These independently operating labourers were called "sub-lessees". This system has survived up to the present day, this method of mining proving more productive than mechanized methods. Although according to Van Traa (1946, p. 142) the ordinary man now also had an opportunity to take part in gold-mining, the sub-lease method did not correspond with what the local population understood by the term "small-scale industry". For what they took the term to imply was a change-over to the Demerara system, whereby every independent labourer - popularly called "porckknocker" in Demerara (Guyana) - was granted the opportunity, without having to complete any undue formalities or to pay anything, of trying his luck at gold prospecting. The government of Surinam was opposed to this, but in 1931 it gave in to the wishes of the public to a limited degree with the aim in mind of alleviating unemployment hereby. Thereafter the gold-mining industry was taken over for the greater part by Creoles, who usually set out to prospect for gold either alone or in small groups. Occasionally one of them would make a lucky strike, but on the whole this adventurous way of life failed to offer them the kind of reward that was at all commensurate with all the hardship they had to endure.

Their earnings were as irregular as those of the miners working under contract for the major companies. The latter would sign contracts for periods ranging from three to five months. The wages paid in the gold-mining industry were by and large much higher than those paid at the same time to Creoles working as labourers on plantations or on their own holdings. The workers in the gold industry, moreover, were entitled to an advance on their wages before commencing work, so that they could enjoy a spree in town before going away to work. There was also much lavish spending on the part of gold industry workers when they returned to town with the wages earnt in the interior. 
Since the mining companies were often in financial difficulties, the labourers were never assured of renewal of their contracts after expiry of the old ones. Hence there were marked fluctuations in the number of contract workers, as is apparent from the table below, which I have copied from the Encyclopaedie (1914-'17, p. 316).

Table 14. Number of Contract Workers in the Gold-mining Industry

\begin{tabular}{ll}
\hline $1899-4457$ & $1906-4604$ \\
$1900-5313$ & $1907=4339$ \\
$1901-5551$ & $1908-3247$ \\
$1902-3498$ & $1909=2909$ \\
$1903-3035$ & $1910-3028$ \\
$1904-3584$ & $1911=2138$ \\
$1905-4523$ & $1912-1816$ \\
\hline
\end{tabular}

As a result of this circumstance there were often large numbers of miners living in town while waiting for work.

After the Second World War mechanization of the gold-mining industry was (re)introduced on a modest scale, so that there was a temporary upward trend in production figures (N.O.S. 1965, 11). After 1965 production fell again, however (cf. Verslag Centrale Bank van Suriname (Report of the Central Bank of Surinam), 1967).

Although there were a great many Creoles drawing their livelihood from gold-mining, this industry was never at any time or in any of the forms outlined above capable of offering them any economic security or stability, either as contract workers, as sub-lessees or as "porck-knockers". Prospectors would leave their families behind in town for long periods on end in order to go and work in the interior. They sometimes returned with a lot of money - with which they often had to pay off debts made by their families or which they frittered away in no time at all. Nor was it rare for these adventurers to get into debt themselves in periods of unemployment. There seems to be no need for me to describe at greater length the adverse effects of this way of life on the stability of relations between men and women, whether in the form of legal marriage or concubinage.

\subsubsection{The Balata Industry}

Besides gold-mining, many Creoles found employment in the balata industry, which flourished slightly later. Balata gum is collected by 
making incisions in the bark of the bully tree which grows in the forests of Surinam. The latter cannot be tapped again until these incisions have healed completely and are covered with a new layer of bark, which takes anything from 5 to 10 years (cf. Van Traa, 1946, p. 128). Hence they are not as suitable for planting in plantations as the rubberproducing Hevea tree, which does not possess this characteristic. As a result balata has never become anything more than an irregularly collected bush product. The qualities of balata are different from those of the ordinary variety of rubber, and it is used chiefly in the manufacture of driving-belts, of the protective outer layers of submarine telegraph cables and of golf balls.

After balata production was first begun in neighbouring Guyana, a British firm began collecting balata in Surinam in 1890. This proved a successful venture, so that other firms soon followed suit by similarly applying for permits for collecting balata in specified tracts of bushland. The commercial collection of this product gradually developed into an industry that yielded large profits, both for those engaged in the industry and the population at large. In 1902 the number of workers employed here was 2800, increasing to 5600 in 1911. As in gold-mining, a large number of "English", or labourers from the neighbouring British colonies, were employed in this industry. The work here was seasonal, the tappers or "bleeders" travelling into the bush along the rivers in mid-January, and returning to town again towards the end of April. Then they would go back into the bush again towards the middle of June, to come back home again in mid-August. The work in the balata industry covers an average of $51 / 2$ months of the year (Encyclopaedie, 1914-'17, p. 71).

There were marked fluctuations in the incomes drawn by labourers (as well as entrepreneurs) from balata-collecting, depending on the weather. If too little rain had fallen in the months before the expeditions were due to go inland, it was difficult, if not impossible, to cross the rapids in the rivers along which they had to pass. So a party might either reach the forest too late or not at all, while production was affected by the shortness of the time left for collecting. If, on the other hand, the season for collecting had been favourable, but insufficient rainfall caused the level of the rivers to drop subsequently, part of the yield might sometimes have to be left behind in the bush. There were major fluctuations in both production and exports, and hence, closely connected with this, in the earnings of the labourers in the industry (cf. Van Traa, 1946, p. 130). 
The bleeder would normally get his employer to pay him an advance on his wages before setting out for the bush, as he was required to take his own provisions for the period he expected to be away with him. On his return to town the amount of this advance would be deducted from the sum eventually paid to him for the balata brought back. As the latter was sometimes the lesser of the two amounts, because, for example, it had been impossible due to bad weather to commence tapping on time, many bleeders were indebted to the concessionaires for whom they worked or their collectors. In other cases, bleeders would come back from the bush with large quantities of balata for which they received large sums of money. Many of them would squander this money - after the boredom of life in the bush - in a matter of a few days, so that they were then obliged to ask for another advance.

Despite the fact that neither the balata nor the gold industry provided the lower-class Creoles with a regular source of income, they have nonetheless offered many lower-class Creole families a reasonable livelihood over the years.

In consequence of the inefficient methods employed in working the balata tracts, rising costs, and the decreasing demand for this product, balata has now virtually stopped being a factor of any significance for the economy of Surinam. Production steadily declined after 1917, the lowest point being reached in 1932, when the largest company, the "Balata Compagnie Suriname", stopped production. The closing down of this plant was a major blow to the balata bleeders. By way of compensation the Government issued permits for setting up so-called oneman companies, thus offering small entrepreneurs an opportunity of carrying on balata-collecting on a small scale by making loans available to them. This method of balata-collecting has survived down to the present day, the output of the one-man companies even exceeding that of the major enterprises still in operation in the years from 1939 to 1942 (Brons, 1952, p. 168). The post-War period witnessed a revival of the balata industry in the 1950's. By 1965 , however, balata production had to come to occupy a marginal position in the economy of Surinam as a result of rising transport costs, competition from Guyana and the introduction of synthetic products. Most Creole labourers considered the money to be made in this industry insufficient. There are at present only 500 men - chiefly Bush Negroes and a handful of Amerindians, who are willing to work for lower wages than the Creoles - still employed as balata bleeders (cf. De West, 6th April, 1965, p. 2). Like gold-mining, balata-collecting failed to provide the Creoles with 
sufficiently stable incomes. Men were forced to be absent from their families for long periods on end, without being able to assure them of a stable income. In many cases wives had to find jobs or ask for loans, or have affairs with other men so as to be able to provide adequately for their families. Hence this constituted another factor making for instability of the family life of many Creoles.

\subsection{Other Creole Occupations}

\subsubsection{The Crafts}

In Surinam the crafts were virtually monopolized by Creoles until after World War II. Even in the period of slavery there were slaves and freedmen carrying on trades in town and on the plantations. It was especially during this period, when plantation agriculture flourished, that there was ample work for them. Hence any craftsman who was not a slave was able to make a good living.

The decline of plantation agriculture after Emancipation also adversely affected the livelihood of a large number of craftsmen. Shipbuilders engaged in the construction of punts for conveying agricultural produce along the rivers, carpenters engaged in the construction of water works on the old sugar plantations or in home-building in town, and bricklayers employed in the construction of sluices on the plantations or also in home-building in town, were all thrown out of work.

Hence the crafts failed to develop into flourishing occupations after Emancipation. There were too many of every category of craftsmen, so that there was no regular employment for all (Encyclopaedie, 1914-'17, p. 41). The competition resulting from the importation of manufactured articles from overseas also made it impossible for many skilled artisans to earn a respectable living. When, moreover, a number of Hindustanis (who worked against lower payment) also began to carry on trades after the Second World War, it became even more difficult for Creoles to gain a decent living in this sector.

\subsubsection{Bauxite}

After World War I bauxite-mining in the bauxite fields of Surinam offered a number of urban Creoles employment opportunities. The Surinaamse Bauxiet Maatschappij (Bauxite Company of Surinam), a subsidiary of the Aluminium Company of America, began production in the former Bush Negro village of Moengo at the end of 1917; but 
production ceased and more than half the labourers employed here were laid off at the end of 1918 because of delays in passing the Bauxite Mining Act. The negotiations between the Netherlands and the Colonial Government were conducted at such a slow pace that the mining company concerned did not know where it stood and hence virtually stopped production, this leading to the abovementioned mass dismissals (cf. Van Traa, 1946, p. 148).

Production was resumed in 1920 after the introduction of the necessary statutory regulations, but had to be stopped almost completely again in 1921 because of the economic depression of the 1920's, and in 1922 a proportion of the employees once more had to be laid off (cf. Van Traa, 1946, p. 149). There was a revival, which lasted for five years, after 1924. As a result of the crisis in the United States in 1929, business had to be curtailed in the following year. The decrease in production, which lasted until 1934, again led to the dismissal of a number of employees. Thereafter business improved, and the improvement proved a lasting, vigorous one. The number of employees increased again, and by 1939 came to 939 . The business was expanded by extending its activities to the Para River in 1938. The Dutch Biliton Company was also granted concessions on this river, in the town of Onverdacht, in 1939.

During World War II bauxite was one of the principal raw materials for the war industry in the United States, bauxite production in Surinam therefore increasing by leaps and bounds after 1940. Surinam now enjoyed a period of unprecendented prosperity. The U.S. sent troops for the defense of the bauxite deposits, thereby creating favourable employment opportunities and causing a general rise in wages, partly through the construction of defense works.

This favourable economic development continued after World War II, particularly as a result of the construction of a dam in the Suriname River near Afobaka. In consequence hereof, construction on a hydroelectric power station, which was opened in 1964, could be commenced in 1959. Here the necessary power for processing part of the locally mined bauxite into alum and aluminium is generated. The construction of the dam and the hydroelectric power station created temporary job opportunities for a number of unemployed lower-class Creoles. Termination of the work on this rendered a proportion of these, for the greater part unskilled, labourers jobless again as no provisions had been made for their employment in another development project on completion of the above one. Despite the dismissal of these labourers there 
has even so been an increase in the total number of employees in the bauxite-mining, alum-processing and aluminium-smelting industries since that time (cf. Verslag Centrale Bank van Suriname (Report of the Central Bank of Surinam) for the year 1965, p. 56).

Summarizing, it can be said that up to a few years before the Second World War the bauxite industry offered its workers no stable employment opportunities. The Creole part of the population, from which the bulk of the employees in this industry were drawn, as a result suffered most by this. This had decided repercussions for the situation as regards the family. After that time, however, the bauxite industry offered a large number of lower-class Creole families a stable and reasonable living.

\subsubsection{The Timber Industry}

A number of lumber companies engaged in timber-getting with the aid of Bush Negro and lower-class Creole wage-labourers in certain tracts of the bush sprang up towards the end of the nineteenth century.

These enterprises had countless difficulties to contend with (Kruijer, 1951, p. 147), so that this industry offered no scope to large numbers of Creoles to gain a regular living either. The situation changed after War, when the Bruynzeel Company and other Dutch companies directed timber-getting and -processing into entirely new channels, and timber exports rose sharply. The activities of the Bruynzeel Suriname Houtmaatschappij N.V. at present range from timber-felling to timberprocessing in a large number of timber plants. The industry counts about 1300 employees, including a large percentage of Creoles.

\subsubsection{Other Occupations}

There is a small number of Creoles employed in small service industries and public utilities based on Paramaribo. As in so many other developing countries, the civil service is at present the largest single employer of the predominantly Creole urban population. Of the total population of 320,000 , about 15,000 are public servants. The majority of these are resident in Paramaribo.

\subsubsection{Women's Occupations}

The working woman has of old been a familiar figure in the Creole 
group. The number of women with jobs or taking in washing or sewing at home has always been extremely high.

There is a close connection between this phenomenon and the fact that many women are compelled (both at present and in the past) to provide for their families in cases where they have been left by their husbands either for good or only temporarily (because, for instance, the latter have gone away to work in the gold fields or as balata bleeders), or where their husbands are out of work. This latter was often temporarily the case in the balata and gold eras. If the husband was living in town while waiting for a new job the wife would also go out to work.

The report entitled Het Ambacht in Suriname (Crafts in Surinam) (1912) states that there were 1298 laundresses and 1014 female domestic servants, of whom 754 were over and 260 under 21, in Paramaribo in 1910; these figures are definitely on the high side for a town of only 31,817 inhabitants (Encyclopaedie 1914-'17, p. 553). The number of Creole market-women was also extremely high at that time. Most of the latter have now been replaced by Hindustani women.

According to a survey carried out in the working-class areas of Paramaribo by Kruijer in 1948, the percentage of women between the ages of 21 and 59 earning an income of their own was extremely high, namely $41 \%$ (Kruijer, 1951, p. 101). Although this percentage included women from all ethnic groups, the percentage for the Creole group will have been more or less the same; the proletariat of Paramaribo comprised for the greater part Creoles at that time.

My own researches have shown that out of a total of 224 female heads of households, 134 had jobs. Of the wives of male heads of households with legal or common law wives (254), there were 38 who had jobs.

The opportunity for women to earn an income of their own by going out to work has increased Creole women's independence from an early period onward. This made it possible for husbandless women to provide for their families, while further it strengthened women's authority within the family, thus encouraging matrifocality. This effect was partially offset by unemployment among women as well as men in Paramaribo, however.

\subsection{Unemployment}

It was after Emancipation, when large numbers of the surplus slaves resident in Paramaribo were no longer kept by their masters that un- 
employment first occurred. The migration to town which was started originally by Creoles, together with the fairly high excess of births over deaths, made for the growth of a disproportionately large town for a sparsely populated country like Surinam. Thus Kruijer (1951, p. 266) observed that Paramaribo is too large because its functions are too few in proportion to the number of its residents, so that it offers its citizens insufficient opportunities of gaining an adequate livelihood.

According to Van Lier (1971, p. 248) unemployment in town began to assume really serious proportions for the lower-class groups after 1924, when a recession in the gold and balata industries threw a large number of Creole labourers out of work. Competition in some trades with Hindustanis who had similarly migrated to town also led to increased unemployment among Creoles. The situation became especially grave around 1931, when the liquidation of the Balata Compagnie Suriname further reduced what little employment there was.

These circumstances led to serious disturbances in Paramaribo in 1931. Urban unemployment slightly decreased during World War II, only to increase again after the end of the War.

Kruijer (1951, p. 101) discovered in the course of a survey conducted in the town in 1948 that $16 \%$ of the males in the productive age-group (21-59 years) were unemployed. A survey which I carried out among lower-class Creoles showed $14.5 \%$ of the men and $7.6 \%$ of the women above the age of 16 to be out of work. Official estimates of the structural unemployment for the whole of the country in 1965 (De West, 13th January, 1965) put this at $10 \%$ of the working population. The percentage for the town is significantly higher than that for the rest of the country. So as to provide some unemployment relief the Government set up a Labour Exchange and Employment Service, through whose intermediary the necessary labour for the execution of various public works is provided. This Service employs a large number of residents of Paramaribo, as the following table shows:

Table 15. Registered Unemployment in Paramaribo and Environs

\begin{tabular}{|c|c|c|c|c|c|c|}
\hline & \multicolumn{2}{|c|}{$\begin{array}{c}\text { Wholly } \\
\text { Unemployed }\end{array}$} & \multicolumn{2}{|c|}{$\begin{array}{l}\text { Employed under } \\
\text { Unemployment } \\
\text { Relief Scheme }\end{array}$} & \multicolumn{2}{|c|}{ Total } \\
\hline & men & women & men & women & men & women \\
\hline 1964 & 449 & 162 & 2,156 & 260 & 2,605 & 422 \\
\hline
\end{tabular}


The figures in the "Wholly Unemployed" column do not give a proper representation of the actual situation. For a large number of those out of work fail to register, as no unemployment benefit is paid.

All this is making it necessary for the government to spend a disproportionate amount of its revenues on the personnel sector. This it does via the abovenamed Unemployment Relief Scheme, by giving allowances to the poor and needy under the so-called Distribution Scheme, and by disproportionately expanding the bureaucratic machine, among other things. The Distribution Scheme provided 4000 persons a week with money and/or food in Paramaribo in 1965, according to information supplied by an official of the Department of Social Services. Most of the beneficiaries under this scheme are women, and almost three quarters of them are members of the Creole population group. According to a statement by the same official, the Distribution Scheme was costing the government 2,000,000.- Surinam florins annually, i.e., approximately $2 \%$ of the total government expenditure for 1965 .

The government is also trying to combat unemployment by extending the bureaucratic machine, as indicated above. The country is supporting a bureaucracy of 15,000 head, out of a total population of 320,000 .

\subsubsection{Emigration to the Antilles and the Netherlands}

The lack of opportunities for making a living at home has induced many Creoles to go overseas in search of a better livelihood. Scores of Surinamers left their country as early as immediately after the First World War, going for the most part to the United States, Brazil, the Dutch East Indies or Holland. A mass migration of Surinamers, mostly Creoles, to Curaçao, and Aruba began after 1925. A large proportion of these found employment there as labourers with the oil refining companies. This migration gradually came to a stop around the 1950's. The majority of the migrants were men leaving Surinam without their families. In 19432140 of the 3541 Surinamers living in the Netherlands Antilles were men and 864 women between the ages of 18 and 50 . According to the results of the 1960 census, there were 4200 Surinamers resident in Curaçao and 1048 in Aruba in that year. There are at present many Surinamers who have been resident in the Netherlands Antilles for decades. (Cf. Encyclopaedie Nederlandse Antillen, 1969, pp. 86 and 541).

Before the Second World War it was customary among the Creole upper middle class and elite as well to have their children educated in 
Holland, in imitation of the colonial officials temporarily stationed in Surinam. ${ }^{2}$ Even at that time there were a number of families who settled in Holland for good. The Creole group was culturally strongly orientated towards the Netherlands, and a visit to Holland conferred a certain social prestige.

After the Second World War a mass migration of Surinamers, chiefly Creoles, to Holland got underway. It was now no longer only the privileged but also lower-class people who joined this exodus. And in recent years there has been an obvious acceleration in the stream of migrants from Surinam to Holland. Van Amersfoort (1968) estimates that the number of Surinamers in Holland has increased by about 1000 annually in the past few years. Their number in 1966 was estimated at 13,000 , this being the equivalent of $4 \%$ of the total population of Surinam. The majority of the migrants, most of them Creoles, come here to study or seek employment as labourers (cf. Bayer, 1965). These migrants, too, like the Surinamers in the Antilles, are mostly men.

\subsection{The post-Emancipation Family System}

Although a de jure change was introduced in the family system of the emancipated slaves in consequence of Emancipation - everyone was now free to marry at law, and it was no longer possible for husbands and wives to be separated against their will - there was little de facto change, as we shall see below. The family system retained its West Indian character. The existing range of alternative unions between men and women was simply extended by the institution of legal marriage after the abolition of slavery. People now had a choice out of legal marriage, common law marriage and the visiting relationship. Those who chose legal marriage could have this solemnised in church only if the marriage had been performed at the registry office first. The many people who chose concubinage could have their unions confirmed by a Moravian missionary and thus enter into an "Alliance" until around 1893. In addition, the second characteristic of the West Indian family which has remained observable to the present day is the occurrence of a large number of female heads of households.

Details of the events which influenced the development of the family system of the lower-class Creoles will be given in the sections below.

2 Prior to this there were Creoles travelling to the Netherlands in the 18th century (cf. Buve, 1963, pp. 8-17). 
These will be supplied first for the period of State Supervision, and next for the period from 1873 to the present day.

\subsubsection{The Period of State Supervision}

The emancipated slaves did not proceed to take advantage en masse of their newly acquired right to conclude legal marriages after Emancipation. In the period immediately following Emancipation, or the initial period of State Supervision, both the government and the churches did their utmost to encourage legal marriage among the exslaves. The colonial administration in particular did so by decreeing by Government Resolution of 11th September, 1863, i.e. not long after Emancipation day, that all persons placed under State Supervision were exempted from payment of the fees normally due to the registrar of births, deaths and marriages on registering their marriages, even where they failed to produce a certificate of poverty. This measure was introduced by the government in the belief that the costs involved in registering marriages might deter persons place- under State Supervision from concluding legal marriages. This concession notwithstanding, the state wards never got around to viewing legal marriage as the most obvious type of union between men and women on a large scale.

In the latter half of 1863 only 32 couples of which both husband and wife had been placed under government supervision concluded marriages in the whole of Surinam. While similarly 29 couples of which only the wife and three couples of which only the husband were state wards entered into legal marriage (cf. Van Sypesteyn, 1866, p. 29). In the ten years of State Supervision a total of 2145 couples belonging to the category of ex-slaves concluded legal marriages. Van Lier (1971, p. 187) states that only one marriage was solemnized per every 14 emancipated persons. So only a small minority opted for this form of union, the majority continuing to live in concubinage, either sanctioned by an "Alliance" or not.

\subsubsection{The Period following State Supervision}

The conclusion of legal marriage did not become a generally accepted norm for the lower-class Creole wishing to enter into a union with a member of the opposite sex after the period of State Supervision either. Although at present the number of marriages among the lower-class Creoles is higher than that of concubinages, the latter type of union is 
still a socially acceptable alternative among them. Its replacement by civil marriages is a process that is still going on and the outcome of which is still undecided.

There is unfortunately too little statistical material available to enable us to determine the ratio between the number of marriages and concubinages in the period under discussion here. For obvious reasons the registers of births, deaths and marriages contain records only of the numbers of legal marriages actually solemnized, and none of that of common law marriages. The notes of a number of authors enable us to deduce the ratios approximately, however.

The Moravian missionary Schneider, who devotes a separate chapter of his book entitled Foto (Sranang for "town") to the position as regards marriage among the Creoles on the basis of oral and written reports of missionaries in Surinam, writes with reference to the 1890's: "Alas, both the white and coloured inhabitants of Surinam as a whole generally lack to a high degree the Christian church view of the sanctity and indissolubility of marriage. Instead, we find what are termed "loose relationships", which are entered into for indefinite periods only, dependent solely on the mutual affection or aversion of the partners, indeed, sometimes arbitrarily broken off by either one of them withour the permission of the other." It is apparent from what Schneider says after this that not all concubinages were unstable. He writes: "Such relationships, for the rest, may of ten also last until the death of one of the partners and may be kept intact just as if they had been solemnized in church. Not only do they enjoy the unconditional sanction of public tolerance, but the moral conscience of the public is (we hardly know how to put it) so underdeveloped, or so gross, that this form of cohabitation of men and women is considered equivalent to either civil and religious marriage combined or simply civil marriage by itself, or under certain circumstances is even preferred to the latter." (Schneider, 1893 , p. 172). In this undifferentiated apology of "respectability", Schneider shows himself in this self-righteous statement to have little understanding for the values in respect of man-woman relationships which had evolved under the institution of slavery. Van Panhuys wrote about the lower-class Creoles a little less than ten years later (1898, p. 27): "Although legal marriage is becoming increasingly popular, thanks to the diligent efforts of teachers of the different religious denominations and the recently introduced reduction in the costs of the formalities involved, even so most women proceed to live with a man without this legal sanction." As this author, too, points out, concubinage 
need not per se be unstable, and many people entering into this type of union could remain faithful to one another for many years.

The results of the 1950 census show that $42 \%$ of the coresiding Creole couples in Paramaribo were living in concubinage (this percentage being 59 for the country districts). (Statistische Berichten (Statistical Reports) No. 23, December 1957, p. 2). A random sample test conducted by me among the lower-class Creoles in 1965 revealed that $43.5 \%$ of the coresiding couples were living in concubinage.

\subsubsection{The Issue of the Abolition of the Alliance}

An issue which stirred up popular feelings in Surinam to some extent at the end of the 19th century was the abolition of the institution of the "Alliance" introduced during the period of slavery.

As a result of Emancipation all emancipated persons were thenceforward bound by the same laws that were in force for free citizens before Emancipation - hence also the law of marriage. Up to 1st January, 1941, only civil marriage, that is, any marriage registered by the Registrar of Births, Deaths and Marriages, was valid in Surinam. This was changed on the above date as a result of a special Marriage Act, the "Asiatic Marriage Act" for Moslems and Hindus, coming into force for the Hindustani and Javanese ethnic groups. As a result all marriages celebrated and registered by their priests or other religious leaders possess legal validity even if they have not been solemnized in the presence of the Registrar of Births, Deaths and Marriages first.

Hereby the customary law marriages of members of the Hindustani and Javanese groups are given legal force. On the other hand, marriages celebrated by the clergy of the other denominations - both Christian and Jewish - have no legal validity. As in Holland, the clergy of these denominations are forbidden by law to confirm or solemnize any marriage unless preceded by a civil ceremony.

This Act has given rise to some confusion among the ex-slaves. For prior to Emancipation it was possible for them to "marry" in church, entering either into an Alliance or a Roman Catholic religious marriage, without this having to be preceded by a civil marriage ceremony. After Emancipation, however, it was compulsory for people wishing to marry in church to show the clergyman performing the church ceremony a marriage certificate issued by the civil authorities. Added to this was the fact that for many people the civil marriage ceremony was too expensive, because after the period of State Supervision this could be 
performed free of charge only if the parties concerned were prepared to submit to a number of humiliating rules, as we shall see further down. As a result a large number of Creoles wanted the "Alliance" to remain, as this could be celebrated without a prior civil marriage ceremony. For them this form of union was in fact "marriage".

So when after Emancipation the Moravian missionaries decided to abolish the "Alliance" and demand that the members of their church conclude religious marriages - which, by law, had to be preceded by a civil ceremony - many ex-slaves found this an incomprehensible measure. The missionaries proceeded to prohibit coresidence of men and women who had failed to marry at law, and subsequently in church, and even to punish this under ecclesiastical law. They decided that where the opportunity of registering marriages and having the same solemnized now existed, the church should do everything in its power to encourage this. So the catch-phrase: "No coresiding unmarried men and women can become members of the Moravian Church without making themselves liable to punishment under ecclesiastical law 'in the third degree', namely complete excommunication" came into being (cf. Steinberg, 1933, p. 170). As a result there were no less than 2300 persons in the whole of Surinam in the year 1879, i.e. 16 years after the abolition of slavery and six years after the abolition of State Supervision, who were punished under this section of the ecclesiastical law because of failure to comply with this ecclesiastical injunction. This entailed disqualification for burial in the Moravian church-yard, which was (and still is) considered a deep disgrace. As a result 3100 members of the Moravian community left this Church, many of them going over to the Roman Catholic Church, which was more tolerant in respect of unmarried people living together, or to other Protestant Churches. The above figures refer for by far the greater part to the urban parishes (cf. Schneider, 1893, pp. 193, 194).

This situation gave rise to bitter resentment among members of the Moravian community. These feelings came to a head in 1880, when in the course of a religious service the missionary Bernard Heijde publicly denounced the practice of making unmarried persons living together liable to punishment under ecclesiastical law 'in the third degree'. The entire parish rallied to Heijde's support, and it was with difficulty that a riot and acts of violence against the responsible authorities could be prevented. The situation grew so grave that two members of the mission board in Herrnhut, including the ex-leader for Surinam, Th. van Calker, had to come posthaste to Surinam in order to restore order and give 
guidelines for new ways of dealing with the situation. A resolution was passed at a general convention of missionaries together with the two members of the mission board whereby ecclesiastical law could be applied only 'in the second degree' in cases of unmarried men and women living together. This only involved their exclusion from Holy Communion. And so it became possible once more for people to enter into "Alliances" (Steinberg, 1933, pp. $171 \mathrm{ff}$.).

Some time afterwards the missionary Haller pointed out that the recently introduced measure where by ecclesiastical law in the second degree' should be applied to coresidung unmarried couples was still too rigourous. He proposed that couples living together under the provisions of the Alliance should be allowed to take Communion as well. The missionaries in Surinam supported him in this, but the mission board in Herrnhut declared itself against the proposal. Consequently another crisis threatened, whereupon the mission board gave its provisional permission for couples "married" according to the terms of the Alliance to be admitted to Holy Communion.

In 1893 the government introduced a number of new regulations, partly on the advice of Moravian missionaries, reducing the expenses involved in concluding legal marriages. At the government's request the missionaries hereupon stopped providing facilities for concluding Alliances. ${ }^{3}$ They once again made it obligatory for members of their Church to conclude religious marriages, which could be done only after the prior performance of a civil marriage. Not all members of the Moravian Church have complied with this rule, however.

Similarly the lower-class Creole members of the other denominations have continued to prefer concubinage to legal marriage. A number of factors which go to explain this behaviour will be discussed in the section below.

\subsubsection{Discrimination in Civil Marriages}

The high costs and red tape involved in having a marriage registered by the civil authorities prevented many members of the lower classes from getting married. In order to have one's marriage registered one had to pay the relatively high fee of 12.50 florins, while a further fl. 3.had to be paid for every child born out of wedlock which the couple concerned wished to legitimate (Schneider, 1893, p. 184). At present,

3 Moravian missionaries are still solemnizing "Alliances" among the Bush Negroes to this day. 
too, a certain fee is payable for registering a marriage, the amount of which varies according to the day of the week on which the marriage is formalized. Although this paltry sum no longer constitutes an obstacle preventing the ordinary man from concluding a marriage, this definitely was the case in the 19th century and the beginning of the present century. An important factor that has come into play here is that nowadays many lower-class Creoles consider marrying on "cheap" days a degradation. In order to keep up appearances they tend preferably to fix on one of the more expensive days.

The special facilities for freed slaves to marry free of charge introduced during the period of State Supervision were also kept in force at the end of this period in the sense that the "poor" were able to do so. The discrimination to which brides- and bridegrooms-to-be were subjected on account of this probably deterred many of them from taking recourse to this form of "charity". According to Schneider (1893, p. 184) the procedure followed in the case of this type of marriage was as follows: "The couple concerned are required to get their local warden to issue them with a certificate of poverty, which they then have to show at the Registrar's Office. Such a certificate is not difficult to come by. But the recipient couple is consequently obliged to marry and live as real paupers. They are not allowed to drive to the Registry Office, but are expected to go on foot; they are not allowed to appear in bridal array, but to come barefooted; they are not allowed to give a wedding breakfast, but are expected to spend their wedding-day like any other ordinary day." These discriminative measures remained in force, though with minor variations and modifications, until well into the present century.

Not only those for whom legal marriage constituted a financial obstacle were obliged to submit to the kind of treatment which made registry office weddings such an unattractive business, however, but also people prepared to pay the costs were often discouraged by the formalities that had to be completed. The official documents required before a marriage could be solemnized, namely a birth certificate or, in the case of ex-slaves, a certificate of registration in the Registers of Freed Persons, were usually teeming with errors due to the illiteracy of those registering the birth of a new-born child or having themselves registered in the above Registers. While indifference on the part of the officials responsible for keeping the Registers or drawing up birth certificates was probably also a contributing factor.

But the conclusion of a marriage was conditional upon these 
documents being duly approved. The necessary changes in the birth certificates or the Registers of Freed Persons could be made only on the orders of the court. But the expense this entailed was so high a legal expert having to be consulted for this - that many people avoided taking this course and preferred to live together without getting officially married. Then there was the rather arrogant attitude of the Registry Office officials, whites and mulattoes alike, who felt superior to "those niggers" by virtue of their own literacy and skin colour, which undoubtedly did much to discourage a great many lower-class Creoles from exercising their right to conclude legal marriages:

Although at present the conditions outlined above have improved beyond sight, the idea that the registration of a marriage is attended with numerous difficulties still lives on in the minds of many lowerclass Creoles. In order to obviate these they often give up all thought of doing so and prefer concubinage.

Apart from this apprehensiveness there are various other factors as well which deter people from concluding legal marriages. These will be dealt with in the following chapters. 


\section{THE SITUATION AFTER WORLD WAR II}

\subsection{General}

As we saw in the preceding chapters, conditions in the society of Surinam made it virtually impossible for slaves to take care of a family. Here it became evident also that after Emancipation the lower-class Creole was on the whole offered little opportunity to earn a regular living, this exercising a distinct influence on his family life. Short-sighted regulations set forth by both the government and the churches far from encouraged the removal of obstacles in the way of people desiring to conclude marriages. Hence the type of family system characterized as "West Indian", the development of which we have described above, was perpetuated among them.

For a short while it seemed as though the Second World War would alter this situation. For unemployment among lower-class Creoles fell and over-employment arose in Paramaribo as a result of the employment opportunities offered Creoles in connection with the defense works executed by American troops stationed in Surinam. The bauxite deposits which were of such strategic importance in the conduct of the war had to be properly defended. Because of this the town experienced a kind of "boom" period during the war years, which, however, also exercised a certain negative influence on the lower-class Creole family. Young lower-class Creoles suddenly found themselves with large sums of money to spend, which they did almost as quickly as it was earnt, while many girls had temporary affairs with American and Dutch servicemen in order thus to put themselves in a position to acquire the luxury articles they coveted. Social control among the lower-class Creoles grew weaker as a result of increased mobility among them. Organized prostitution, hitherto unknown here, sprang up. Many older people attribute certain present-day conditions which they consider immoral to the effects of this period. After the withdrawal of the American troops another period of unemployment ensued. The new regime, which came to power under the influences of the decolonization process, has failed to introduce effective changes with regard to employment in Surinam. Hence the lower-class Creole family system has retained the characteristics described above for the preceding periods. 
Before proceeding to describe the way in which this system has been functioning latterly, I shall first give below an outline of the socioeconomic circumstances under which the lower-class Creoles of Paramaribo are living on the basis of my own personal observations in 1964 and 1965, and more particularly on the basis of the material collected by means of questionnaires. ${ }^{1}$

\subsection{Characteristic Features of the Sample Population}

By interviewing 518 households, data on 2827 persons were obtained. It is interesting to note that almost a quarter of these persons $(22.5 \%)$ were born outside the urban district of Paramaribo.

Table 16. Place of Birth of Members of the Sample Population (in percentages)

\begin{tabular}{lc}
\hline Urban District of Paramaribo & 77.5 \\
Suriname District & 7.9 \\
Commewijne District & 2.8 \\
Marowijne District & 1.8 \\
Brokopondo District & 0.4 \\
Saramacca District & 1.9 \\
Coroni District & 3.4 \\
Nickeri District & 1.9 \\
French Guiana & 0.2 \\
(former British) Guyana & 0.5 \\
Barbados & 0.1 \\
St. Lucia & 0.1 \\
Dutch Antilles & 1.4 \\
Elsewhere & 0.1 \\
Total & $100.0 \quad(\mathrm{n}=2827)$ \\
\hline
\end{tabular}

The majority of those born outside Paramaribo are natives of the neighbouring Suriname district. Part of this district can be classified as part of the urban agglomeration of Paramaribo.

A large number of lower-class Creoles have also moved into town from the Commewijne district, located on the opposite side of the Suriname River. While similarly the exodus to town from Coronie where large tracts of farmland were spoilt by increasing salinity as a result of seawater flooding, which, combined with the decline in the coconut-growing industry, caused an economic depression here - was considerable. Employment in this district dropped sharply. Most young

1 Chapter 3 contains a description of the methods used in the research. 
people are moving away from Coronie in order to try and make a living in town. Table A, appendix 3, shows the composition of the sample population according to age and sex. Here we see that $54.2 \%$ of this was under 21, while the sex ratio, furthermore, is also seen to be unequal, there being 1.17 females to every male. Although this does not suggest an uncommonly great disparity, the imbalance is seen on differentiation of the data collected according to age to become increasingly greater in proportion with increasing age.

Table 17. Number of Females to every Male of the Sample Population According to Age-Group

\begin{tabular}{ll}
\hline Age & \\
\cline { 2 - 2 } $0-15$ & 0.98 \\
$16-30$ & 1.02 \\
$31-45$ & 1.59 \\
$46+$ & 1.70 \\
\hline
\end{tabular}

The migration of men in search of employment elsewhere and the fact that males tend to die younger than females constitute important factors determining this.

As regards the religious distribution of the sample population, we should observe that the latter is heterogeneous in this respect.

Table 18. Religious Distribution of the Sample Population (in percentages)

\begin{tabular}{lr}
\hline Moravian & 51.7 \\
Roman Catholic & 38.7 \\
Reformed Dutch & 5.2 \\
Evangelic-Lutheran & 2.4 \\
Other Christian Denominations & 1.6 \\
Israelitic & 0.2 \\
Moslem & 0.2 \\
Total & $100.0 \quad(\mathrm{n}=2827)$ \\
\hline
\end{tabular}

The Moravian Church has succeeded in maintaining its position as the popular lower-class Creole Church, although it has of late been losing many of its members to a number of smaller Christian sects, some of which are proselytizing in Surinam. Furthermore, a large number of lower-class Creoles who have risen on the social scale are 
leaving the Moravian Church in many cases to join the Reformed Dutch Church. Membership of this Church, also called Bakra Kirki here, which is the former church of the whites and is now dominated by the Creole middle class, confers considerable social prestige. There are no (or no longer are any) sharp religious divisions, such as, for example, that between Roman Catholics and Moravians in Coronie, in Paramaribo.

Islam counts a number of lower-class Creole adherents who have embraced this faith after marrying a Moslem of Hindustani descent.

Lower-class Creole households were seen to include but few persons from other ethnic groups, as is apparent from the table below.

Table 19. The Composition of the Sample Population according to Ethnic Group

\begin{tabular}{lrr}
\hline Creoles & 2796 & $98.9 \%$ \\
Hindustanis & 9 & $0.3 \%$ \\
Javanese & 9 & $0.3 \%$ \\
Amerindians & 1 & $0.0 \%$ \\
Chinese & 2 & $0.1 \%$ \\
Bush Negroes & 10 & $0.3 \%$ \\
& 2827 & $100.0 \%$ \\
\hline
\end{tabular}

There is obviously little assimilation and amalgamation between the various ethnic groups within the Creole household.

\subsubsection{West Indian Traits of the Households included in the Sample}

In the Introduction we mentioned as characteristic features of the West Indian family: (1) the presence of institutionalized alternative unions between men and women; and (2) the prevalence of female heads of households. Both features are distinguishable in the sample.

The sample households, classified on the basis of: (a) sex of the head; (b) whether or not the latter was coresiding with a partner in his or her residential unit; and (c) the nature of the union with the partner in question, were distinguished into eight different types, namely households consisting of:
A. a male head with legal spouse
B. male head with common law wife
C. male head without legal or common law wife 
D. a single man

E. a female head with legal husband

F. female head with common law husband

G. female head without legal or common law husband

H. a single woman.

We are able to conclude from Table B, Appendix 3, setting out the distribution of the abovementioned types of household, that:

1. Alternative unions between men and women do occur - of the heads of households living with a partner (types A, B, E, and F, covering 269 households in total), 152 or $56.5 \%$ are married and 117 or $43.5 \%$ are living in concubinage;

2. There is similarly an obvious prevalence of female heads of households, $43.2 \%$ of the households being headed by women.

\subsection{The Present Socio-Economic Conditions}

Before going on to a description at greater depth of the West Indian traits of the sample population in the following chapter, I shall give below a description of the socio-economic conditions under which the lower-class Creoles are living at present. As stated in sections 1.3.3.1. and 1.4., the West Indian family system should be regarded chiefly as the product of adaptation to poverty and unemployment. As we saw there, there was physical exploitation, social and legal inequality, undernourishment, disease, inadequate accommodation and underemployment among the Negro slaves as well as among many of their descendants, the lower-class Creoles, in the past. By way of reaction to this longstanding socio-economic inferiority the lower-class Creole of Paramaribo developed a mental attitude in which there is no longer room for any hope that his circumstances will ever change for the better. This attitude is hardened by anxiety lest economic competition from Hindustani migrants to town result in increased poverty for the (lower-class) Creole.

Members of the Creole group are in fact aware that their socioeconomic position will deteriorate with increasing speed - despite countless promises by their political leaders. These feelings have found expression in the effusions of the Creole W., in an article bearing the dramatic title "Ik ween om de naderende ondergang van de Creool" (I weep for the approaching downfall of the Creole) in De West of 20th January, 1965. He writes: 
"No-one who does not close his eyes to reality will deny that the Creoles are slowly but surely coming to form the category of the havenots. (...) Where are all the garden plots, estates and houses once owned by Creoles? The late Staten member Comvalius once stated that everyone who is not a land-owner is a stranger. Is the Creole, who has sold his second birth-right through his own fault well on the way to becoming a stranger to the land that was rendered fertile by the sweat and blood of his forbears? While other groups are forging ahead by industry and economy, the moment does not yet seem to have come for the Creole to follow the good example of his compatriots of Asian origin.

It is an incontrovertible fact that the zest for work of the majority of the Creoles is, regrettably, constantly declining, despite the fact that it is being shouted daily from the roof-tops that our country is making progress.

I want to impute this social decadence of my fellow Creoles partly to the failure of successive Creole political leaders to do anything, anything at all, to check the rapid decline of their followers."

It will become clear to the reader from the results of our research as set out below how distressing the socio-economic situation was for the lower-class Creoles in 1964-1965. I shall commence with a discussion of their housing conditions, because, as Kurt W. Back (1962, p. 3) so forcefully puts it: "The image of the living conditions of a people, from the cursory impression of a traveler to the serious evalution by experts, hinges to a great extent on housing conditions. The pattern of houses in towns and along the country side, the materials of which they are built, the relative amount of space and overcrowding, maintenance and dilapidation, form one of the most visible aspects of people's lives."

I shall subsequently discuss the occupational structure and the pattern of incomes and expenditures. The data collected here, which are the results of what was no more than a tentative exploration and makes no claim to be a profound economic analysis of the problem of poverty among the lower-class Creoles, will serve to demonstrate to the reader that on the whole the socio-economic position of the lower-class Creole of Paramaribo has been anything but promising up to the present day.

\subsubsection{Housing}

One comes across lower-class Creoles in almost every part of Paramaribo. Except for part of the district of "Zorg en Hoop", which is inhabited almost exclusively by members of the upper middle class and the elite, the different classes and races found in this town mostly 
live side by side with each other in every quarter. In the centre of town are found the "Great Houses" fronting the streets, which were formerly the residences of the elite and at present house shops and offices. To one side of these buildings there is a gate-way, popularly called the "Negro gate", leading to the yard in which the squalid dwellings of the ordinary working people are found, which are thus hidden from view. Most of the buildings in Paramaribo are made of wood. The picture presented by the centre of the town is marked by the presence of wide streets with rows of large, shady trees planted here in the old days, and to left and right mostly white painted timber houses, which are built quite close to one another though detached. They are mostly two-storey houses some of which have pillared verandahs. The yards at the rear of the main houses in the centre of town are not exactly spacious - they are referred to as "pikin jari", or small yards. These seldom contain more than ten dwellings. The latter are occupied principally by lower-class Creoles. Further away from the centre there are the more expensive houses, though also some simple ones, fronting the street and with similarly behind them yards which may in some cases be extremely large. These "bigi jari", which contain a great many more dwellings - sometimes as many as thirty or over - are occupied for the greater part by Hindustanis and Javanese, although there are some lower-class Creoles found living in these large compounds as well. But the Creole generally prefers to live in the smaller yards. Paramaribo counts more than 14,000 such compounds. Many of these yard dwellings as well as the houses fronting the street in the outer districts are in extremely poor condition and can be designated as outright slum dwellings.

This became apparent from, among other things, an official investigation into housing conditions in Paramaribo proper, the houses here being classified as follows:
A. "sub-standard dwellings"
B. "reasonably good dwellings"
C. "high standard homes"
$39 \%$ of all residential units
$50 \%$,
$11 \% ", \quad " \quad$ "

The state of repair in which these houses were was as follows for the different categories:

\begin{tabular}{lccc}
\hline & A. & B. & C. \\
in good repair & $47 \%$ & $74 \%$ & $100 \%$ \\
capable of repair & $33 \%$ & $16 \%$ & - \\
beyond repair & $20 \%$ & $10 \%$ & - \\
\hline
\end{tabular}


The floor space of $25 \%$ of the "sub-standard dwellings" is less than 20 square metres, and of $33 \%$ of them 20-40 square metres. A high degree of overcrowding was observed (cf. Durward Badgley et al., 1962).

The lower-class Creoles live for the greater part in the "sub-standard" category of dwellings, and to a much lower degree in homes classified as reasonably good. To me their housing conditions seemed appallingly poor. In order to find out their own views on this, we asked the heads of households to state their opinion on their accommodation. The answers were as follows:

Table 20. Views of the Heads of Households of the Sample on the State of their Homes (in percentages)

\begin{tabular}{lccc}
\hline & Good & Indifferent & Poor \\
\hline Male heads (types ABCD) $(\mathrm{n}=294)$ & 43.4 & 38.6 & 18.0 \\
Female heads (types EFGH) $(\mathrm{n}=224)$ & 44.4 & 33.6 & 22.0 \\
Male and female heads together $(\mathrm{n}=518)$ & 43.8 & 36.5 & 19.7 \\
\hline
\end{tabular}

These opinions seem to me to be rather on the mild side when one actually considers the poor state of repair of most homes. The occupants of such dilapidated dwellings often complain about owners' laxity in having repairs carried out or doing anything else to improve their property. There are numerous complaints about leaky roofs. However, it is not only these discomforts that are brought up by the occupants, their main complaint concerning lack of space. Although the climate in Surinam offers every opportunity for outdoor living - especially yard dwellers are in a position to take advantage of this where mutual relations between them are harmonious - residential overcrowding is a great strain on the occupants of under-sized dwellings. The members of both male- and female-headed households have on the average an $11 / 20$ th part of one small room at their disposal each. Table $\mathrm{N}$ in Appendix 3 shows that many large households occupy homes with a minimal number of rooms. One is able to calculate from this table that $68 \%$ of the female-headed and $72 \%$ of the male-headed households comprising two or more persons occupy dwellings of which the number of occupants exceeds the number of rooms. ${ }^{2}$

2 On comparing these percentages it seems surprising that the slightly less well-off female-headed households should have slightly more space at their disposal than their male-headed counterparts. This difference is probably accounted for by the desertion or death of husbands leaving more room available. 
Such a degree of over-crowding may of course not be as serious in the tropics as in more temperate zones. For during the daytime usually not much time is spent indoors, housewives mostly doing their cooking in the open air under some kind of roof-shelter, while most household members have their meals outside. But at nights, when bed-time comes, these overcrowded conditions are bound to have a disturbing effect on the family life of the lower-class Creole. Lack of space makes it necessary in many cases even for older children to sleep in the same room as the grown-up members of the household. In $27 \%$ of the households with children over 10 years of age the head sleeps in the same room as these children. This situation is considered definitely unsatisfactory, and people try to screen off parts of the rooms so shared by hanging curtains or placing screens between the beds at nights. In some cases also the older children may be sent out of the house in the evening hours if their mother is expecting a visit from a man in order that she may thus have the necessary privacy.

Most lower-class Creole houses are hermetically sealed at nights, so that they then become stuffy and pitch dark. People sleep on mats on the floor or in beds - the former being considered cooler. Beds are becoming more and more popular, however, especially among the elderly.

Table 21. Number of Beds per Households (both Male- and Female-headed) (in percentages)

\begin{tabular}{lccc}
\hline $\begin{array}{l}\text { Number of Beds } \\
\text { per Member of } \\
\text { the Household }\end{array}$ & $\begin{array}{c}\text { Male-headed } \\
\text { Households } \\
(\mathrm{n}=294)\end{array}$ & $\begin{array}{c}\text { Female-headed } \\
\text { Households } \\
(\mathrm{n}=244)\end{array}$ & $\begin{array}{c}\text { Total } \\
(\mathrm{n}=518)\end{array}$ \\
\hline 1 to 1 & 34.6 & 41.4 & 37.5 \\
1 to 2 & 24.7 & 19.7 & 22.6 \\
1 to 3 & 12.5 & 7.2 & 10.2 \\
1 to 4 & 8.5 & 7.2 & 7.9 \\
1 to 5 & 4.1 & 5.8 & 4.8 \\
1 to 6 & 5.8 & 4.9 & 0.4 \\
1 to 7 & 1.0 & 0.4 & 6.2 \\
1 to 8 & 4.4 & 8.5 & 4.6 \\
no beds & 4.4 & 4.9 & 100.0 \\
\hline
\end{tabular}

Lack of space is often the reason for the low number of beds per household. Those living in really cramped conditions often have beds which are used as a couch during the day-time. The older members of 
the household (husband and wife, or mother and daughter) may use this for sleeping on at night, while the younger children sleep around it on mats on the wooden floor.

As a result of neglect, houses are often in a deplorable condition within a few years after building. The hot, humid climate exercises a very destructive effect, so that unless a house is painted or creosoted regularly, it will have a neglected look within a very short space of time, usually in but a few years. Most houses are painted only once during their lifetime, however - that is to say, immediately after building as most owners are bent on making maximum profits from their tenants, who often pay their rent irregularly, for the rest. Only the more wellto-do lower-class Creoles live in well-kept, neatly painted houses.

Table 22. The Age of Houses (in percentages)

\begin{tabular}{lccc}
\hline & $\begin{array}{c}\text { Male-headed } \\
\text { Households } \\
(\mathrm{n}=294)\end{array}$ & $\begin{array}{c}\text { Female-headed } \\
\text { Households } \\
(\mathrm{n}=244)\end{array}$ & $\begin{array}{c}\text { Total } \\
(\mathrm{n}=518)\end{array}$ \\
\hline $0-5$ years & 9.5 & 4.9 & 7.5 \\
$6-10$ years & 18.6 & 11.3 & 15.5 \\
$11-20$ years & 19.7 & 17.0 & 18.5 \\
$20+$ & 22.7 & 27.8 & 24.9 \\
unknown & 29.5 & 39.0 & 33.6 \\
Total & 100.0 & 100.0 & 100.0 \\
\hline
\end{tabular}

In a country where there are no tornadoes, such tumble-down wooden buildings may reach very high ages. So one may come across huts dating from the period of slavery in some of the yards.

Not all houses have water laid on. Although technically speaking Paramaribo has a good water-supply, only one third of the houses of the sample population turned out to have running water. The occupants of houses without running water get their water - often against payment - from the communal tap in their compound or from a neighbour who does have tap water. Formerly people used to draw their watersupply from wells or by catching rain-water in closed metal tanks or water-butts. In most compounds the wells have been filled in to eliminate the risk of children drowning.

Bathrooms and toilet facilities are usually outdoors. Of the households studied, $68 \%$ had outdoor sanitation, while $32 \%$ had indoor water closets. Privies are usually used by more than one household, and they are often in shocking condition and most unhygienic. The same applies 
to bathrooms, which are also outdoors in $68 \%$ of the cases, $32 \%$ of the houses containing indoor shower-recesses with running water. These

Table 23. Water Supply (in percentages)

\begin{tabular}{lccc}
\hline & $\begin{array}{c}\text { Male-headed } \\
\text { Households } \\
(\mathrm{n}=294)\end{array}$ & $\begin{array}{c}\text { Female-headed } \\
\text { Households } \\
(\mathrm{n}=224)\end{array}$ & $\begin{array}{c}\text { Total } \\
(\mathrm{n}=518)\end{array}$ \\
\hline Tap water & 39.3 & 26.5 & 33.8 \\
No tap water & 59.7 & 72.2 & 65.0 \\
Tank & 0.7 & 0.4 & 0.6 \\
Other & 0.3 & 0.9 & 0.6 \\
Total & 100.0 & 100.0 & 100.0 \\
\hline
\end{tabular}

bathrooms, where people have to make do with a bucket of water to bathe themselves with, are used by more than one household in $36.2 \%$ of the cases. Especially in the yards, bathroom facilities and sanitation are deplorable.

As far as lighting is concerned, it was discovered that $92.9 \%$ of the male-headed and $87.9 \%$ of the female-headed households were connected up to the main power net. Those without electricity usually make do with kerosene lamps. Only $22.8 \%$ of the households appeared to have gas laid on. In most households kerosene (36.1\%), charcoal $(25.3 \%)$ or butane gas $(15.6 \%)$ is used for cooking. In only one household $(0.2 \%)$ was an electric appliance used for this. As was stated above, many housewives do their cooking outdoors, under a roof-shelter. If they do this indoors, they use a special annex built onto one of the rooms for this - the so-called kookraam or cooking-recess, where there is somewhere for the smoke to escape, or, where present, a kitchen.

Houses are on the whole scantily furnished, a number of straightbacked chairs and a plain wooden table constituting the chief items of furniture. Only the more well-to-do possess easy chairs - these are made of wood and are called "bakstoelen". The walls are decorated with calendars, usually from Chinese shop-keepers, framed diplomas (or even marriage certificates) and pictures clipped from magazines. In one corner there is often a shelf about a man's height from the floor, on which is displayed the family's china and glassware. The crockery is ranged on racks along the wall. The poorer types of home contain hardly any closets or cupboards, and clothes here have to be stored in trunks. 


\subsubsection{Ownership of Houses}

It is the ideal of the lower-class Creole to own his own home, as this relieves him of the necessity of paying a monthly rent and constitutes some sort of security for his old age. In the latter case he will use the building in question as accommodation for himself and his relatives, who will provide him with food and clothing in return. As a result of ownership of a house a man or woman may remain head of a household comprising more than one person for a considerable length of time.

Table $O$ in appendix 3 shows the number of heads of households of each of the different categories who are either home-owners or tenants. What strikes us here is that more than half the married male heads are owners. Not excluding owners of houses purchased on the hire-purchase system, the number of owners is $66.2 \%$. Fewer male heads with common law wives than legally married male heads own houses - $40.8 \%$ of them appeared to be owners, thus making for a significant difference $\left(\mathrm{x}^{2}=13.94, \mathrm{p}<0.001\right)$. Among the female heads of households without a legal or common law husband there was seen to be a relatively high percentage of home-owners, namely $44.6 \%$. People do not generally become owners until a fairly late age. So we discovered $68 \%$ of the home-owners to be older than 50. People renting houses are expected to pay their rent monthly, although in actual practice they may be as much as 3-6 months behind. The rent is usually collected by an agent of the owner's. This is normally attended with a great deal of conflict.

A number of owners of houses built in yards in the centre of town, near Saramacca Street, are trying to evict their lower-class Creole tenants from the houses they have let to them. The presence of large numbers of Bush Negroes on temporary visits to town has made the letting of these dwellings to Bush Negroes for overnight stays (at approx. 0.25 Surinam florins per person per night) much more lucrative than renting them to lower-class Creole families at low monthly rents (10 Surinam florins). It is common knowledge in Paramaribo that owners (including Creoles) prefer renting their houses to Javanese because the latter are generally considered to be the quietest tenants. Owners are usually less eager to rent their properties to Hindustanis, though they least prefer lower-class Creole tenants, as the latter are inclined to be aggressive and are usually the worst rentpayers, according to landlords - even Creole landlords. 


\subsubsection{Economic Aspects of the Household}

Most lower-class Creoles live in a cash economy. The household is dependent for its livelihood on the cash income brought in by one or more of its members from paid employment.

When a man and woman have made up their minds to live together either as lawfully wedded husband and wife or as common law marriage partners, the woman expects the man to (be able to) provide for her and her children. She does not expect him to hand over his entire wages to her, but only a reasonable part thereof, sufficient for her to run the household on. "Provided a man hands over enough money and regularly fulfils his bedroom duties, his Creole wife will be absolutely faithful to him", stated one female informant of about forty. If the husband does not earn sufficiently or spends his wages on other women, his Creole wife will start looking for another partner, "because she does not want to live in poverty". As we saw above (section 6.4.4.1.), working wives are not an uncommon phenomenon among the lower-class Creoles. Many women - both legally married and, more especially, those living in concubinage - are seen to have some kind of employment for the sake of supplementing the family income. In addition to these, there are the female heads of households without legal or common law husbands who provide for their households by taking on a job. The latter is of ten no simple task in a town in which there is also chronic female unemployment.

\subsubsection{Unemployment, Unemployment Relief and Poor Relief}

The economic structure of Paramaribo is such that in many cases it offers lower-class males insufficient opportunity to earn a steady income. Owing to the mass migration to town and the lack of an industrialization policy aimed at dealing effectively with this growing surplus of mainly unskilled labourers, the supply of unskilled labour is exceeding demand. As a result there is widespread unemployment in the town, as was discussed in section 6.5.; this the authorities are trying to counteract by means of unemployment relief work schemes.

Unemploment is aggravated by lack of coordination of the major development projects, which is responsible for large numbers of labourers being suddenly thrown out of work. This is what happened when, for example, work on the storage lake near Affobakka was completed (see section 6.4.2.). It is impossible to deal effectively with the problem of unemployment except by creating extra jobs by means of such projects. 


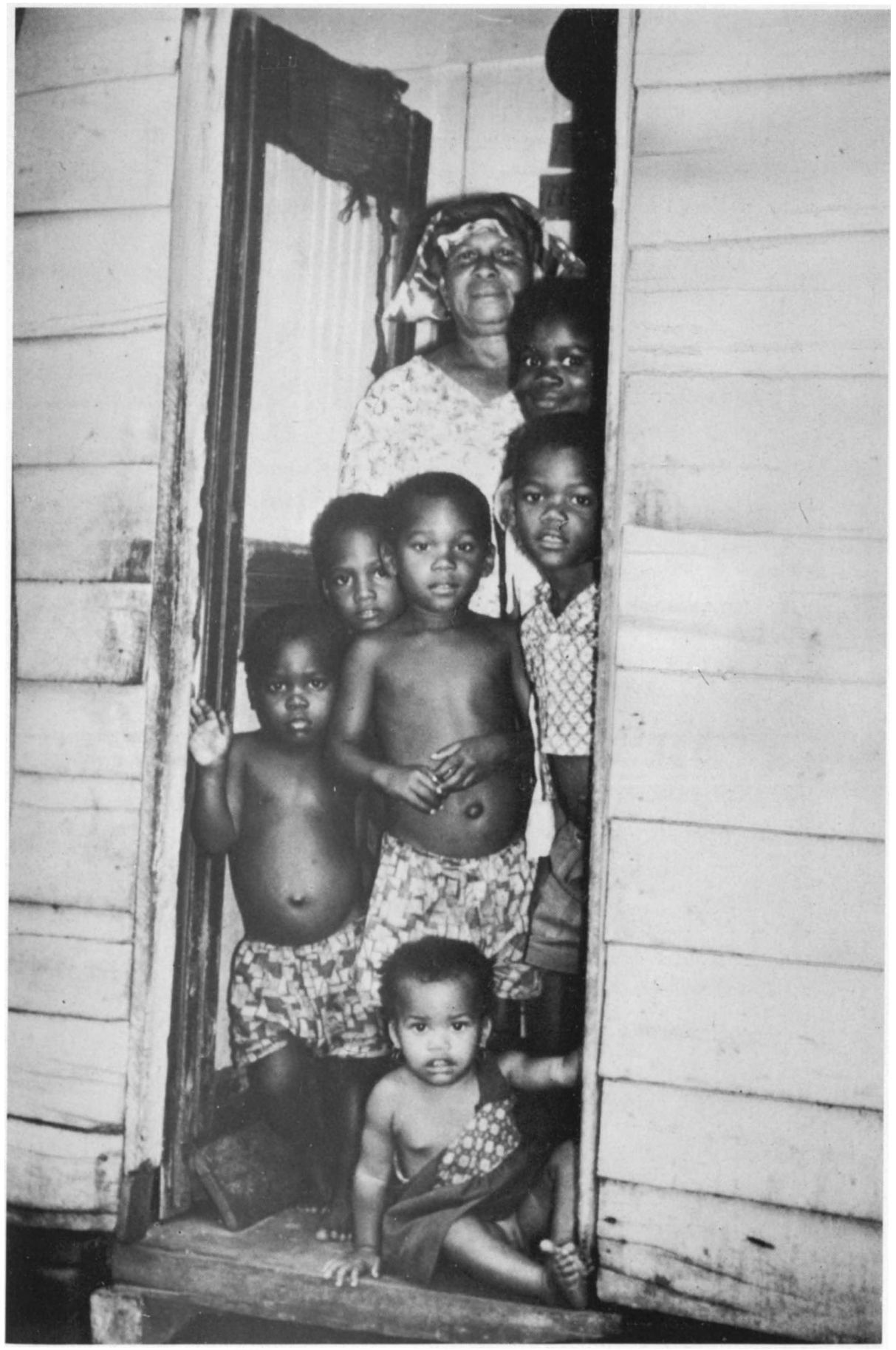

1. Manifest matrifocal household.

Female head, her daughter and five grandchildren. 


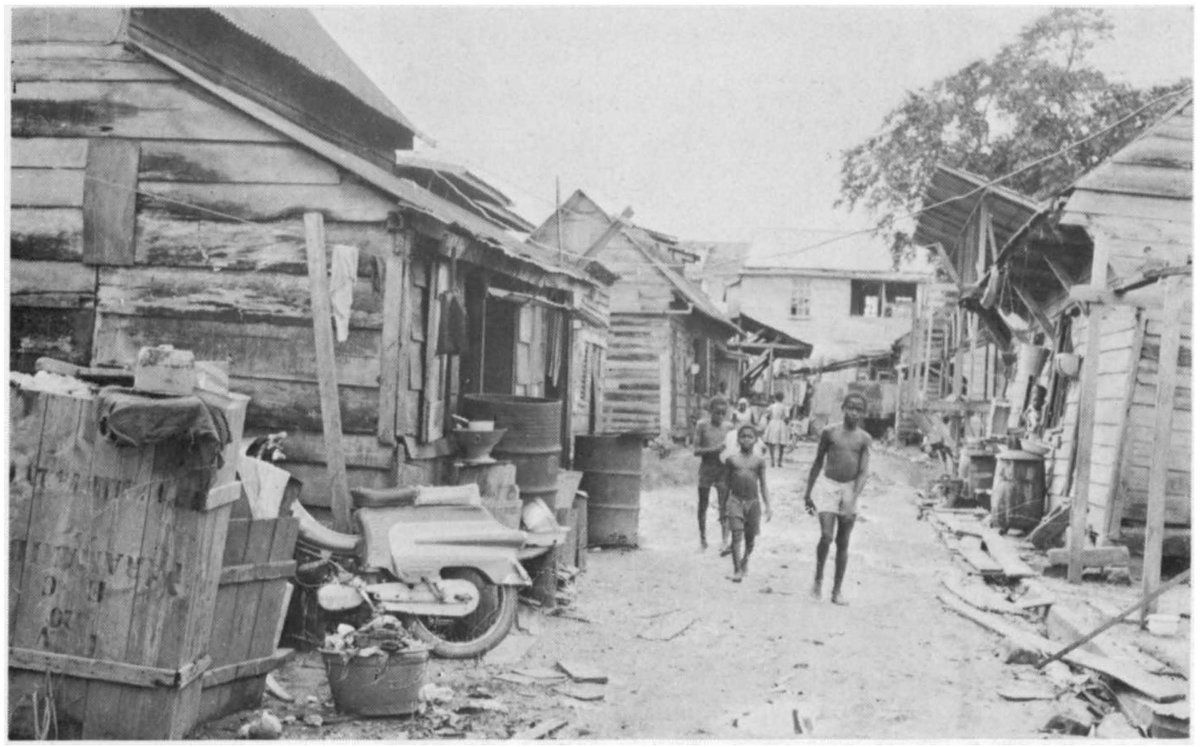

2. An example of the poorest yards.

Photo: G. A. de Bruijne

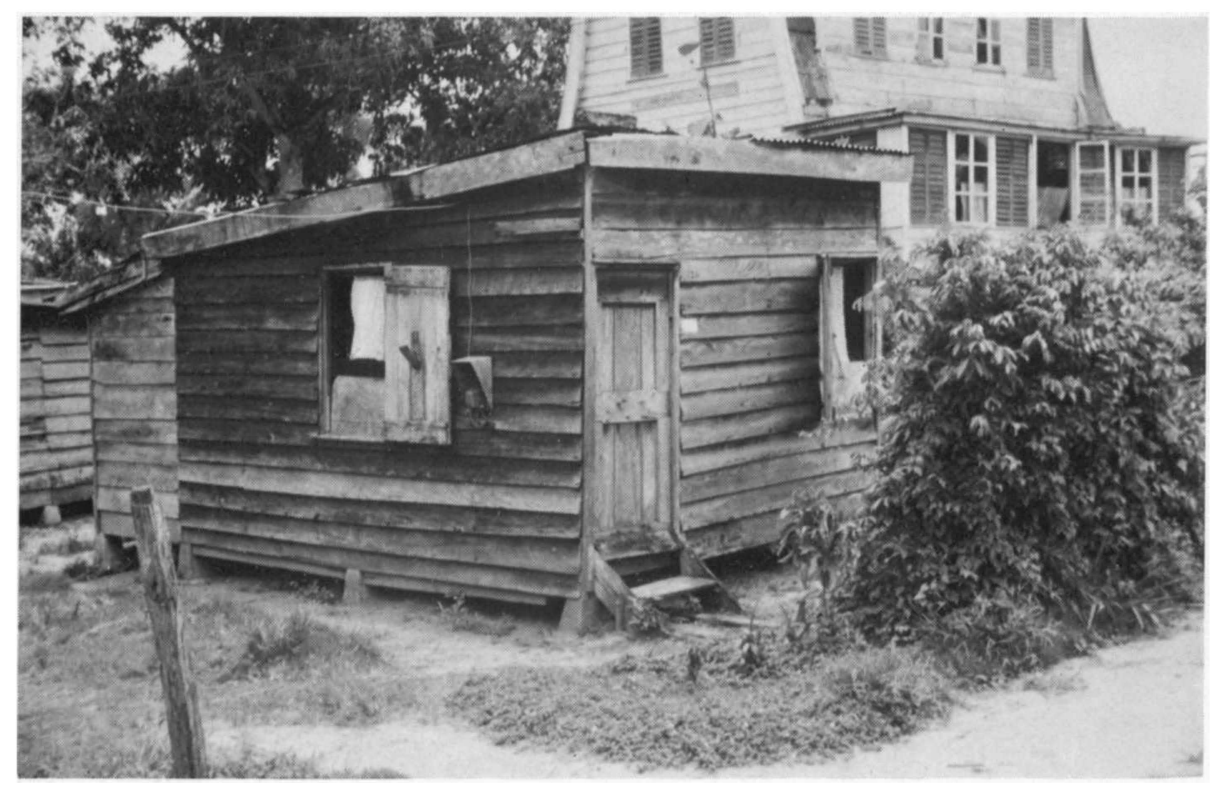

3. Lower-lower class house. 
This situation is doing much to intensify the lack of job security. The number of unemployed is reduced slightly by large numbers of Surinamers, most of them lower-class Creoles, moving to the Netherlands. There was a sharp rise in the number of Surinamers living in Holland from 1962-1966, increasing from 8,589 to 13,287 in those years, so that in this latter year $4 \%$ of the total population of Surinam was living in the Netherlands.

Of the households included in my sample, $22.2 \%$ were seen to be receiving aid from the poor relief scheme $(9.8 \%$ of the male-headed and $38.5 \%$ of the female-headed households). These figures indicate that many of the lower-class Creoles are reduced to utter poverty, as only the outright destitute qualify for aid under this scheme.

The table below shows how in Surinam, as in many other developing countries, efforts to eliminate unemployment by expanding the bureaucratic machine is resulting in the disproportionate growth of the latter. A large proportion of the working population of Paramaribo is working in government service.

Table 24. Working Population of Paramaribo, Classified according to Employment Sector and Sex (not including those seeking employment)

\begin{tabular}{lrrr}
\hline Employment Sector & Males & Females & Total \\
\hline The Civil Service & 7,049 & 3,203 & 10,252 \\
Agriculture & 352 & 41 & 393 \\
Mining & 1,488 & 75 & 1,563 \\
Industry & 2,427 & 658 & 3,085 \\
Building Trades & 980 & 19 & 999 \\
Electricity, gas/water supply & 418 & 78 & 496 \\
Trade and commerce & 3,853 & 1,767 & 5,620 \\
Transport, storage and traffic & 937 & 32 & 969 \\
Public Utilities & 1,178 & 2,654 & 3,832 \\
Not classified & 447 & 112 & 559 \\
& & & 27,768 \\
Total & 19,129 & 8,639 & \\
\hline
\end{tabular}

(Statistics derived from the 1964 Population Census.)

By appointing too many officials for too little work the government is creating latent unemployment. Much criticism is being levelled at the huge bureaucracy (counting 15,000 officials for the whole of Surinam) especially by foreign economic advisors. Although this is not entirely unjustified (many people become public servants through having connections with some minister or Staten member), it is even so much 
better, to my view, to employ a proportion of the group of unemployed as public servants and so keep them in work than to leave them out of work and dependent on unemployment relief benefits for years on end. In addition, many of these public servants are supporting destitute relatives, proletarianization of the population thus being partially prevented.

\subsubsection{The Occupational Structure}

What kind of occupations do lower-class Creoles usually exercise? I have set out in the table below the trades and callings followed by the heads of households of the sample. I have also indicated here those heads who are retired or jobless.

Table 25. The Occupations of the Heads of Households of the Sample

\begin{tabular}{|c|c|c|c|}
\hline Artisans & Males & Females & Total \\
\hline Baker & 2 & - & 2 \\
\hline Tinsmith & 1 & - & 1 \\
\hline Electrician & 3 & - & 3 \\
\hline Service station manager & 1 & - & 1 \\
\hline Gunsmith & 1 & - & 1 \\
\hline Tailor & 1 & 10 & 11 \\
\hline Frame-maker & 1 & - & 1 \\
\hline Bricklayer & 9 & - & 9 \\
\hline Joiner & 5 & - & 5 \\
\hline Motor mechanic & 13 & - & 13 \\
\hline Bicycle repairer & 1 & - & 1 \\
\hline Bootmaker & 1 & - & 1 \\
\hline Painter & 3 & - & 3 \\
\hline Chair plaiter & - & 1 & 1 \\
\hline Technician & 23 & 二 & 23 \\
\hline Carpenter & 27 & - & 27 \\
\hline Storekeeper & 2 & - & 2 \\
\hline Agricultural Workers & Males & Females & Total \\
\hline Farmer & 4 & 1 & 5 \\
\hline Gardener & 1 & - & 1 \\
\hline Livestock farmer & - & 1 & 1 \\
\hline Sailors and Fishermen & Males & Females & Total \\
\hline Boatswain Suriname Shipping Co. & 1 & - & 1 \\
\hline Skipper Suriname Aluminium Co. & 1 & - & 1 \\
\hline River- or sea-fisherman & 4 & - & 4 \\
\hline
\end{tabular}




\begin{tabular}{lccr} 
Traders & Males & Females & Total \\
\hline Door-to-door canvasser & 4 & 1 & 5 \\
Biscuit vendor & - & 1 & 1 \\
Lottery ticket seller & - & 1 & 1 \\
Market stall-holder & - & 10 & 10 \\
\hline
\end{tabular}

\begin{tabular}{lccr} 
Wage-workers & Males & Females & Total \\
\hline Labourer in the interior & 2 & - & 2 \\
Labourer under Unemployment Relief Scheme & 9 & 2 & 11 \\
Unskilled labourer & 24 & 2 & 26 \\
Baker's apprentice & 1 & - & 1 \\
Woodworker & 1 & - & 1 \\
Night-watchman & 11 & - & 11 \\
Assistant overseer Bruynzeel & 1 & - & 1 \\
Haulier/truck-driver & 17 & - & 17 \\
Typographer & 2 & - & 1 \\
Foreman concrete works & 1 & - & \\
\hline
\end{tabular}

\begin{tabular}{lccr} 
Civil Servants & Males & Females & Total \\
\hline Government office clerk & 34 & 2 & 36 \\
Drill master Geological Mining Engineering Service & 1 & - & 1 \\
Jail warder & 1 & - & 1 \\
Assistant Forester & 1 & - & 1 \\
Overseer Department of Traffic and Public Works & 1 & - & 1 \\
Policeman/serviceman/customs officer & 17 & - & 17 \\
Postman & 1 & - & 1 \\
\hline
\end{tabular}

\begin{tabular}{lccr} 
Teachers & Males & Females & Total \\
\hline Assistant teacher & 1 & 7 & 8 \\
\hline
\end{tabular}

\begin{tabular}{lccr} 
Hospital Workers & Males & Females & Total \\
\hline Hospital storeman & 1 & - & 1 \\
Nurse & 7 & 1 & 8 \\
Midwife & - & 1 & 1 \\
\hline
\end{tabular}

\begin{tabular}{lccr} 
Private Business Employees & Males & Females & Total \\
\hline Clerk & 6 & 1 & 7 \\
Waiter staff cafeteria Suriname Aluminium Co. & 1 & - & 1 \\
Storeman & 2 & - & 2 \\
Attendant & 1 & - & 1 \\
Shop assistant & 4 & 1 & 5 \\
\hline
\end{tabular}




\begin{tabular}{|c|c|c|c|}
\hline Domestic Servants & Males & Females & Total \\
\hline Manservant/charwoman-housemaid & 1 & 47 & 48 \\
\hline Cook & 1 & - & 1 \\
\hline Laundress & 一 & 40 & 40 \\
\hline Miscellaneous & Males & Females & Total \\
\hline Prostitute & - & 2 & 2 \\
\hline Retired & 22 & 5 & 27 \\
\hline No occupation & 13 & 85 & 98 \\
\hline Total & 294 & 224 & 518 \\
\hline
\end{tabular}

A small number of heads of households ( 7 male, 9 female) were seen to have extra jobs. One fisherman, who was earning around 50 Surinam florins a month, for instance, stated that he often went to work as wharf labourer in order to make some extra money. One charwoman sold "lemonade" (lemonjuice with sugar) in a stall in front of her house as a side line; another charwoman made syrup and biscuits to supplement her income. While one carpenter sometimes worked as pallbearer when he was short of work. Twelve male and three female heads owned a second house which they let to other people. There are hardly any instances of rooms in the house occupied by the household being let. Two male heads and only one female one were letting rooms.

There is a strikingly large number of female dressmakers among the Artisans. These are making a living by dressmaking. They are mostly female heads of households who have been deserted by their husbands.

Technical Occupations such as that of motor mechanic, electrician and technician (pipe-fitter, fitter and turner, welder, and so on) are extremely popular with Creole men. It is not surprising that the artisan group should include a large number of carpenters, as the majority of the houses in Paramaribo are of timber.

The number of agriculturalists among the Creoles is small. There are a number of lower-class Creoles living in town who own plots of ground outside Paramaribo, with the produce from which they supply urban consumers. This line of business is at present almost entirely monopolized by Hindustanis living on the outskirts of town, however.

The category of traders includes a strikingly high number of female market stall-holders. They are mostly elderly women with a regular turnover who, because they have spent the greater part of their lives in the market place, dispose over a large store of information and so are often seen to take a keen interest in politics. They are frequently to be 
found in the public gallery during Staten meetings, where they come to hear their political leaders. Their trade is coming to be dominated more and more by Hindustani women.

Unskilled labourers may be classed together with unemployment relief scheme workers, as in most cases the latter are also unskilled. These labourers have no regular income and they are often seen to be looking for a job. Thus a man may work as wharf labourer one day and as a factory hand the next. The category of wage-workers is seen to include a large percentage of hauliers and truck-drivers because of the Creole's technical orientation.

The Civil Service has of old been a major employer of Creoles. Where formerly mostly lighter-skinned Creoles of the middle class and elite were found in clerical jobs, we now come across many more darkskinned Creoles filling such jobs in government offices since the N.P.S., the lower-class Creole party, has come to power. These are poorly paid though highly coveted white collar jobs, which are often preferred to better paid jobs involving manual work by people with any education at all. It is to be expected that the white collar proletariat will grow steadily in the future. Jobs in the police force and the armed services are popular with younger Creoles on account of the good pay and the special nature of the work, as Creole men like to possess and be able to exert authority.

With regard to the teacher group we should observe that these are still partly classifiable with the lower classes, despite their education, because most of them have a lower-class background and usually go on living with their parents before setting up house themselves. The salaries drawn by young teachers, both male and female - not to mention assistant teachers - are lower than those of skilled labourers. There are also unmarried mothers acting as heads of households in the female teacher group.

The category of domestic servants includes a strikingly high number of women who are heads of households. These earn their living as charwomen, housemaids, washerwomen or laundresses. The latter are all eminently suitable occupations for single women compelled to work for their family's livelihood. They also offer an opportunity of earning some extra cash to concubines (but rarely married women). There were two women who told the interviewer quite openly that they were making a living by prostitution.

Not excluding old-age pensioners, the group of female heads of households included $81 \%$ who were following some occupation. This percent- 
age is in actual fact higher, if one takes into account the fact that there were a number of women looking for jobs among those who stated themselves to have "no occupation".

\subsubsection{The Family Income}

How much do the heads in question earn? Do they have to provide for the household alone, or are they assisted in this by members of their household or by persons outside it? Of the male-headed households comprising more than one member (types A, B and $\mathrm{C} ; 272$ in total) one or more members were seen to be earning incomes of which part was handed over to the head in 123 cases. Of the female-headed households consisting of more than one member (types E, F and G; 290 in total) one or more members appeared to be wage-earners handing over part of their wages to the head in 97 cases. Table 26 sets out the status within the household of the members concerned.

Table 26. Table showing the Status within the Household of the Members handing over Part of their Income to the Head of the Household

\begin{tabular}{lcc}
\hline $\begin{array}{l}\text { Relationship } \\
\text { to Head of the } \\
\text { Household }\end{array}$ & $\begin{array}{c}\text { Male-headed Households } \\
\text { Types A/B/G } \\
\text { (total = 123) }\end{array}$ & $\begin{array}{c}\text { Female-headed Households } \\
\text { Types E/F/G } \\
\text { (total = 97) }\end{array}$ \\
\hline Wife & 17 & - \\
Common law wife & 21 & - \\
Common law husband & - & 12 \\
Son & 33 & 32 \\
Daughter & 33 & 34 \\
Others & 55 & 41 \\
\hline
\end{tabular}

Of the male heads of households with legal or common law wives (254) there are 38 whose wives were going to work. Common law wives are employed for the greater part in more menial types of occupation (as charwomen, domestic servants, and so on), while married women, on the other hand, are found in more "professional" types of vocation (e.g., office and teaching jobs). Sons and daughters in some cases hand over part of their income to the head; more of ten, however, they are allowed to keep their entire salary for themselves and are not required to pay any board. The category of "others" contributing to the household's income comprises for the greater part brothers and sisters and children born of previous unions of either of the partners who are living in with their respective relatives. 
Of the total number of male (294) and female (224) heads, there are 15 and 78 respectively who are receiving financial assistance from persons who are not members of the household. Table 27 gives a summary of these.

Table 27. Table showing non-members of Households giving part of their wages to the head of the Household

\begin{tabular}{lcc}
$\begin{array}{l}\text { Non-members of } \\
\text { Household }\end{array}$ & $\begin{array}{c}\text { Male-headed Households } \\
(\mathrm{n}=294)\end{array}$ & $\begin{array}{c}\text { Female-headed Households } \\
(\mathrm{n}=224)\end{array}$ \\
\hline Husband/wife & - & 6 \\
Friend & - & 12 \\
Ex-husband/common law husband & - & 7 \\
Son & 6 & 28 \\
Daughter & - & 5 \\
Others & 9 & 20 \\
Total & 15 & 78 \\
\hline
\end{tabular}

The number of sons not living in who give their mothers money is fairly high. They are men who, according to the popular saying in Surinam, are conscientious enough to pay their "suckling fees". A mother expects her children, and especially her sons, to provide for her in old age. A "good boy" is someone who is scrupulous about supporting his mother rather than his family. "I have three sons; two of them are devils - they don't pay me a penny", stated one invalid, 70-year-old female informant. Twelve female heads stated themselves to be receiving money from a man who was an outsider to the household. The women in question were maintaining visiting relationships, constituting a household type about which it was exceptionally difficult to obtain quantitative data because of the secrecy in which it is normally shrouded. These visiting relationships are found in types $G$ (female heads without legal or common law husbands) and $\mathrm{H}$ (women living by themselves). Women maintaining this type of relationship are usually the mistresses of men who either already have a wife or concubine or are still living in the household into which they were born. Such relationships with mistresses may last for life, though they may also be of extremely short duration. A man may keep a mistress for years, regularly paying her fixed sums of money and taking the responsibility for the upbringing of any children born of the union. He will usually legitimate such children, especially if he is unmarried.

Table F, Appendix 3, sets out the amounts earnt by heads of house- 
holds, as well as the total monthly income over which they dispose, that is, the amount including contributions from members and/or nonmembers of the household and, where applicable, payments from the poor relief scheme received by them. These figures represent only a rough approximation of the actual situation, as the sources of the different incomes are in many cases dubious or uncertain, or they are kept secret, as in the case of a woman receiving money from some man friend. So one man stated the amount of his income to be lower in the presence of his wife than when she was absent - he had a mistress with whom he had to share part of his income. Conversely, some Creoles had a tendency to overstate the amount of their income, probably motivated by some urge to assert their own importance, to show that they were no mere "nobodies". Women, on the other hand, were seen to be inclined to understate the amount of their actual income.

Of the total number of households (518) there were $41 \%$ with incomes lower than 100 Surinam florins a month. This percentage comes to 21 for the 294 male-headed and 68 for the 224 female-headed households. Although conditions in the society of Surinam are such that female heads of households have the opportunity to engage in moneymaking activities, the latter's households are in a much worse position economically than those headed by males. The difference we observed between these was significant $\left(x^{2}=114.60, p<0.001\right)$. When one asks the local people to say what they believe to be a reasonable income for the average family, they usually mention an amount of around 150 Surinam florins a month. Social workers whose opinion I asked confirmed that this was an income that would enable a household of about five people to live comfortably, though not luxuriously.

The average monthly wage in 1961 was 176.17 S.fl. for Paramaribo (cf. Bedrijfs en Beroepstelling (Business and Occupation Census) 1961, Paramaribo district, p. 4). This is approximately the amount earnt by skilled labourers. Hence many lower-class Creoles are a long way behind with incomes of 100 S.fl. a month or lower. Large families in many cases have to make do with much lower incomes, as will become apparent from the table below (see p. 153).

It is obvious, therefore, that many households have to cope with chronic shortage of cash. They try to make up for such shortages by pawning valuables at a pawnbroker's, by borrowing from money-lenders or friends, usually at high interest rates, and by buying on credit. In many households the children even have to do odd jobs to supplement the family income. Small boys may make a little money by working as 
Table 28. Number of Members and Total Amount of Income of Households

\begin{tabular}{lrcccr}
\hline \multirow{2}{*}{$\begin{array}{l}\text { Number } \\
\text { Members }\end{array}$} & \multicolumn{5}{c}{ Total Monthly Income in Surinam Florins } \\
\cline { 2 - 6 } & $0-50$ & $50-100$ & $101-150$ & 151 and over & total \\
\hline 1 & 33 & 11 & 6 & 6 & 56 \\
$2-5$ & 54 & 48 & 49 & 88 & 239 \\
$6-10$ & 28 & 32 & 31 & 82 & 173 \\
$11-20$ & 2 & 8 & 15 & 25 & 50 \\
\hline & 117 & 99 & 101 & 201 & 518 \\
Total & & & & &
\end{tabular}

shoeblacks or by selling sweets in coffee-shops or outside cinemas. If they expect a certain film to draw capacity audiences, they will buy up all the tickets and sell them at a profit to late-comers. People may also try to get money by stealing and through other petty crimes, or by prostitution. The past years have witnessed a sharp rise in criminality. According to the N.O.S. (National Development Plan Surinam) criminality in Surinam increased by $52 \%$ over a period of five years (absolute figures: $1959-3949 ; 1963-14,273$ ) as against a population growth of $14.7 \%$ (N.O.S. 1965, p. 818). This rise is even sharper in Paramaribo and surroundings, and a more detailed analysis of these alarming figures seems called for. Possibly the dramatic increase in crime figures is explained partially by improved methods of registering criminal offences, however.

\subsubsection{The Pattern of Spending of the Household}

A government-sponsored investigation into the budgets of families in the lower income brackets in Surinam in 1952 has shed some light on the spending pattern among the lower-class Creole population of Paramaribo.

Table 29. Cost of Living for Creoles living in Paramaribo for the year 1952

\begin{tabular}{lr}
\hline Food and drink & $53.9 \%$ \\
Rent and water rates & $9.0 \%$ \\
Lighting and heating & $6.1 \%$ \\
Clothing and shoes & $12.3 \%$ \\
Other items & $18.7 \%$ \\
Total & $100.0 \%$ \\
\hline
\end{tabular}

(Information derived from Budgetonderzoek (Budgetary Research) 1953.) 


\subsubsection{Expenditure on Food and Drinks}

As we are able to see in table 29, food and drink constitute the major items of expenditure. In order to be able to determine how and on what the average housewife spent her money, I asked six housewives to keep a record of all expenditures for one week. These one of my interviewers visited daily in order to remind them of their task and to check on whether they had noted down all their expenses of the previous day. Table P, Appendix 3, gives a summary of these expenditures.

The housewife goes shopping for food at least once, and in many cases several times, a day. She buys fruit, vegetables, meat and fish at the market, which is an important social centre. The rest of the family shopping is done in shops, which are open several hours on Sundays as well. She usually makes purchases in small quantities only. This applies not only to such commodities as bread, meat and fish, which have to be bought fresh daily, but also to foods that keep for longer periods, such as rice, cooking-oil, sugar, tea, vetsin, maggi cubes, pepper and even salt. Housewife number II (cf. Table P, Appendix 3), for instance, bought 20 cents' worth of sugar seven times, 45 cents' worth of rice seven times, and 25 cents' worth of charcoal four times and 15 cents' worth once during the week of the investigation. Whenever something is needed, the woman or one of her children will pop across to the shop (usually a Chinese-owned one). The goods are of ten bought on credit. Because they are purchased in small quantities, the prices charged are as a rule exorbitant in proportion to the quantities supplied. This way the shopkeeper makes a much bigger profit than if he were to sell the same articles in larger quantities. Part of his profits he loses again through customers' failure to pay on time or their disappearing altogether. The housewife is compelled by chronic shortage of cash and the impossibility of obtaining credit on large amounts to buy in small quantities, however. For the shopkeeper is generally more disposed to let the credit for small quantities bought at high prices mount up.

Many women seldom receive regular housekeeping allowances from their husbands. It is sometimes said that many men will give their wives money only after the latter's imploring and begging them for it. For many men this constitutes a means of asserting themselves in the household. If a woman thinks she is receiving too little money she will usually make scenes in which she accuses her husband of spending his money on other women or squandering it with his friends.

One woman (25 years old) said that whenever she received too little 
money from her common law husband, she would throw a screaming fit at night. The neighbours, including several young girls, would thus be led to believe that the wife was repelling the husband's advances. In order to avoid losing face and to put an end to her screaming the husband would usually give in to her by giving her the money. Day-time screaming fits had no effect, according to this woman.

\subsubsection{Expenditure on Rent, Electricity, Gas and Water}

The next major expenditure after those on food and drink is that for accommodation. This is less true for the more than half the heads of households who are home-owners, as not as much money is spent on the maintenance of houses. For those renting a house $(48.1 \%)$ or purchasing a house on the hire-purchase system, however, the monthly amount spent on accommodation is definitely on the high side. Many people consider the rents they are required to pay high in proportion to the incomes they receive. Rents are steadily rising as a result of the housing shortage. Table 30 sets out the amounts of rent paid by the heads of households of our sample.

Table 30. Monthly Rent (in percentages)

\begin{tabular}{lccc}
\hline Amount of Rent Payable & $\begin{array}{c}\text { Male Heads } \\
(\mathrm{n}=136)\end{array}$ & $\begin{array}{c}\text { Female Heads } \\
(\mathrm{n}=120)\end{array}$ & $\begin{array}{c}\text { Total } \\
(\mathrm{n}=256)\end{array}$ \\
\hline Sfl. 1- 5 & 8.2 & 13.3 & 10.5 \\
Sfl. 6- 10 & 22.8 & 40.9 & 31.4 \\
Sfl. 11- 15 & 17.6 & 20.8 & 19.1 \\
Sfl. 16- 25 & 25.7 & 8.3 & 17.6 \\
Sfl. 26- 35 & 13.2 & 9.2 & 11.3 \\
Sfl. 36-50 & 8.8 & 5.8 & 7.4 \\
Sfl. 51-100 & 3.7 & 1.7 & 2.7 \\
Total & 100.0 & 100.0 & 100.0 \\
\hline
\end{tabular}

Of the female heads $74.9 \%$ are paying less than Sf. 15 . - rent a month. The same percentage for male heads is 48.5, indicating a significant difference $\left(\mathrm{x}^{2}=17.67, \mathrm{p}<0.001\right)$. As we might expect from this, it is principally female heads of households whom one finds living in the poorest types of home. In order to alleviate the housing shortage somewhat and to improve the unsatisfactory housing conditions, the Public Housing Foundation has built some attractive homes for lower-class Creoles. But the rents of these are over 26 Surinam florins a month, an amount which it is beyond the means of the bulk of the lower-class Creole population to pay regularly each month, so that these 
homes are at present occupied for the greater part by members of the middle class, chiefly junior government officials. These homes are also purchasable and may be bought on hire-purchase; $6.8 \%$ of the household heads of our sample were seen to be paying off homes built either by this Foundation or under some other arrangement. The monthly payments for these came to about 50 Surinam florins, an exorbitant amount for most people from the lower classes.

Apart from the expenditure on accommodation, the costs of light and heating are also regularly payable. Most houses $(90.7 \%)$ are connected up to the main power net. The rates payable for this are rather on the high side for many people.

Table 31. Electricity rates for Households connected to the Power Net (in percentages)

\begin{tabular}{lccc}
\hline Amount Payable & $\begin{array}{c}\text { Male-headed } \\
\text { Households } \\
(\mathrm{n}=274)\end{array}$ & $\begin{array}{c}\text { Female-headed } \\
\text { Households } \\
(\mathrm{n}=197)\end{array}$ & $\begin{array}{c}\text { Total } \\
(\mathrm{n}=471)\end{array}$ \\
\hline Sfl. $1-5$ & 25.5 & 40.6 & 31.8 \\
Sfl. $6-10$ & 38.7 & 36.5 & 37.8 \\
Sfl. $11-15$ & 25.9 & 17.3 & 22.3 \\
Sfl. 16 and over & 7.7 & 5.1 & 6.6 \\
exempted * & 2.2 & 0.5 & 1.5 \\
Total & 100.0 & 100.0 & 100.0 \\
\hline
\end{tabular}

* Government employees living in government homes.

Many households had had the power cut off on account of failure to pay the rates.

The costs of cooking (heating) either on gas, butane gas, kerosene or charcoal also constitute a major item of the total budget.

Table 32. The Costs of Fuel (in percentages)

\begin{tabular}{lccc}
\hline Amount Payable & $\begin{array}{c}\text { Male-headed } \\
\text { Households } \\
(\mathrm{n}=294)\end{array}$ & $\begin{array}{c}\text { Female-headed } \\
\text { Households } \\
(\mathrm{n}=224)\end{array}$ & $\begin{array}{c}\text { Total } \\
(\mathrm{n}=518)\end{array}$ \\
\hline Sfl. $1-5$ & 36.6 & 50.7 & 42.7 \\
Sfl. $6-10$ & 50.5 & 39.9 & 45.8 \\
Sfl. $11-15$ & 9.5 & 8.1 & 8.9 \\
Sfl. 16 and over & 1.7 & 0.4 & 1.2 \\
exempted * & 1.7 & 0.9 & 1.4 \\
\hline & 100.0 & 100.0 & 100.0 \\
\hline
\end{tabular}

* Government employees living in government homes. 
In addition to these there are the water rates, though these are not insurmountable for most people, even the poorest.

Table 33. Monthly Water Rates (in percentages)

\begin{tabular}{lccc}
\hline Amount Payable & $\begin{array}{c}\text { Male-headed } \\
\text { Households } \\
(\mathrm{n}=294)\end{array}$ & $\begin{array}{c}\text { Female-headed } \\
\text { Households } \\
(\mathrm{n}=224)\end{array}$ & $\begin{array}{c}\text { Total } \\
(\mathrm{n}=518)\end{array}$ \\
\hline Sfl. 1 & 18.0 & 24.7 & 20.8 \\
Sfl. 2 & 22.7 & 26.9 & 24.5 \\
Sfl. 3 & 22.0 & 19.3 & 20.8 \\
Sfl. 4-8 & 31.5 & 22.4 & 27.7 \\
Sfl. 9 and over & 2.4 & 2.7 & 2.5 \\
exempted * & 3.4 & 4.0 & 3.7 \\
Total & 100.0 & 100.0 & 100.0 \\
\hline
\end{tabular}

* Government employees living in government homes.

\subsubsection{Expenditure on Clothing and Shoes}

Fine clothes and good shoes are items on which the lower-class Creole usually spends a lot of money. Especially those with aspirations to rise on the social ladder go to uncommon lengths to make sure they are never seen in old or patched clothes. Men and women both normally wear European-style dress. Only on special occassions does one still occasionally see women dressed in the traditional costume, called koto yaki, which was formerly the normal dress for women. This costume is completed by a gaily printed, starched kerchief folded around the head in a special style (called tai-hede). ${ }^{3}$ This scarf is also sometimes worn with Western dress.

It is impossible, or scarcely possible, to tell by people's clothes - on which, as we saw in table $30,12.3 \%$ of the budget was spent in 1952 how much poverty there actually is among lower-class Creoles. One seldom comes across people in rags here.

\subsubsection{Costs of Illness and Funerals}

When a person is ill he or she will usually go to see a doctor or a popular healer. Although a visit to the doctor's and the purchase of the medicines prescribed by him may be almost beyond the means of the

3 For a description of the koto yaki and scarf see Herskovits and Herskovits (1936, pp. 3 ff.) and Morpurgo (1934-'35, pp. 393 ff.). 
working man, this is nevertheless a paltry sum compared to the amounts of money out of which some popular healers may try to swindle him.

The popular medicineman's status in the society requires a note of explanation. These healers are men or women who play an important part in and possess a considerable store of knowledge of the AfroAmerican religion to which a large number of lower-class Creoles still adhere. Although most of these Creoles are members of one or other of the Christian denominations, many have preserved some traces of the African religion of their slave ancestors, which to them has the same, if not a greater appeal than the Christian religions which they may profess (cf. Van Lier, 1971, p. 15). Herskovits (1936, pp. 44-111) gives a detailed description of this Afro-American religion of the lower-class Creoles. This religion includes a belief in a number of supernatural beings such as Massa Gran Gado, the Winti and the Yorka. Massa Gran Gado is the overlord of all the other gods, but does not take an active part in world affairs. He created the Winti, or the gods and spirits of nature, heaven and the earth who determine the fate of the universe. The latter reveal themselves to man by giving him a helping hand or by causing him harm. Each individual possesses his personal Winti one or more of them - passed on from father to son or mother to daughter. In addition to the Winti there is the (A) kra, or human soul. This lives on as a Yorka after a person's death. ${ }^{4}$ It is a manifestation which may cause its relatives on earth a great deal of trouble, such as, for instance, if a deceased person's descendants have not given him a proper burial (cf. Pollak-Eltz, 1970, pp. 176-177). When a person is having a spell of bad luck, such as when he is seriously ill or has met with an accident, for example, he can only be helped, according to popular ideas, if the cause of the disease or accident can be traced. It can usually only be explained by a specialist in magic or religious affairs, that is to say, a popular healer. These persons are capable of finding out

4 According to R. A. J. van Lier's unpublished observations among the lowerclass Creoles in Paramaribo, the Yorka may exercise a certain degree of social control in the families of his surviving relatives. If the family is experiencing setbacks in certain of its affairs the Yorka may make members of the family who have transgressed particular norms subject to corrective measures. The popular healer (Lukuman or Obiaman) often determines that the Yorka is causing a particular member of the family to be ill or even threatening him or her with death. The African belief that the displeased Yorka of a deceased member of the family is responsible in these cases functions in a corrective and preventive way. It would be interesting to devote a detailed study to this socio-psychological mechanism, which may possibly have its origin in West African religions of which ancestor worship constitutes an important element. 
why a person's (A) kra, ${ }^{5}$ a Yorka, a Winti or some other power is exercising an adverse influence on his affairs. He (or she) similarly has the ability to remove the cause of the evil and thus cure the person in question by going through a number of specific actions.

Various kinds of popular healer are distinguishable, though in actual practice their functions overlap. The Lukuman is the medicineman who is endowed with the ability to trace the reason for which a Winti, Yorka or (A) kra is causing a particular person trouble. The Wintiman in his practices takes recourse to the Winti, who help him to solve the problems of those who come to consult him. The Obiaman is a popular curer who uses "white magic" for the protection of his clients. While the Wisiman, furthermore, uses "black magic" for the purpose of attaining certain of his clients' objectives.

The popular healer derives considerable financial profit from his prescriptions for herb bath cures, from performing "ablutions" on his patients, and so on. But the most lucrative activity for most popular healers is the organization of a "Wintipree" - a mass religious gathering usually held out of town, at which some of the spectators as well as the participants are put into a trance by the beating of drums and in this state are entered by a Winti. The aim of these gatherings is to seek a cure for a patient, or to expel any evil powers of which he may be possessed. In many cases the first attempt is unsuccesful, so that another Wintipree then has to be held. Gatherings lasting anything up to three days may cost the patient as much as 300 to 1,000 Surinam florins. Hence it is not surprising that many people run into heavy debt by resorting to this kind of cure (cf. Pronk, 1962, pp. 100-103).

Not only the costs of treatments by popular healers, but undoubtedly also those of treatment by medical practitioners are much too high for many lower-class Creoles. A household may also often run into heavy debt as a result of the death of one of its members. The elaborate mortuary and funeral rites observed in the lower-class Creole subculture (see section 9.8.) involve disproportionately high costs. There have existed of old burial societies, which are usually at the same time medical benefit funds, with which people may insure themselves in part against

5 There is wide disagreement in the various views on the Akra concept. Some people believe that in addition to his (A) kra which resides within him during his lifetime, a man possesses a Djodjo, or "soul", which leaves him on occasion to go wandering about, in the course of which wanderings it meets with all kinds of adventures, of which the person concerned becomes aware in his dreams. Others consider (A) kra and Djodjo to be synonymous, however. 
the expenses arising from the death of members of their household. Even during slavery slaves would form "burial societies" for insuring themselves against funeral expenses. Expensive funerals were already the rule among town slaves who had attained some degree of prosperity. These societies were probably the first organizational structures on a more or less large scale among slaves. The 18th century writer Hartsinck mentions the existence of decrees prohibtiting excessive display at funerals among town slaves. He says: "Nor are they allowed to sing or have baljaaren (dances) on return from the burial (unless they have obtained special permission), stringent decrees having been promulgated against this as well as the use of ornate coffins and other extravagances." (Hartsinck, 1770, II, p. 912).

Lammens in his writings also points to the tremendous expense to which both white persons and slaves might be put by the death of a relative in the 19th century. "Funerals are rendered expensive affairs by the splendour of the coffin, which is made of costly wood, the fittings and the inside lining..." (Lammens, 1816-'22, XIII, p. 55). The funerals of freedmen, mulattoes and Negroes were "conducted with due propriety". His enumeration of the funeral expenses for these persons of "lower class", to which some privileged slaves also belonged, is as follows:

$\begin{array}{ll}\text { the coffin } & \text { fl. } 100 .- \\ 12 \text { pallbearers } @ \text { fl. 5.- } & \text { fl. } 60 .- \\ \text { a mute } & \text { fl. } 15 .- \\ \text { the rights of burial in the new graveyard } & \text { fl. } 59.15 \\ \text { shrouds } & \text { fl. } 100 .- \\ & \text { fl. } 334.15\end{array}$

The higher classes had even higher expenses to pay, those for "a corpse of the foremost rank, hence the uppermost class" coming to fl. 3,500.-, those for "a corpse of lesser rank, hence the second class" fl. 1.120 .

After Emancipation, when the ex-slaves had to bear the costs of at least an "inferior or third class" funeral themselves whenever there was a death in the family because their former owners were no longer paying these, they faced heavy expenditure at such times. This also applied to illness, as slaves now had to pay for their own medical care. For these reasons a large number of "Mutual Benefit Societies" were founded, many of these organizations soon disappearing again or being replaced by others. These functioned as burial societies and often simultaneously 


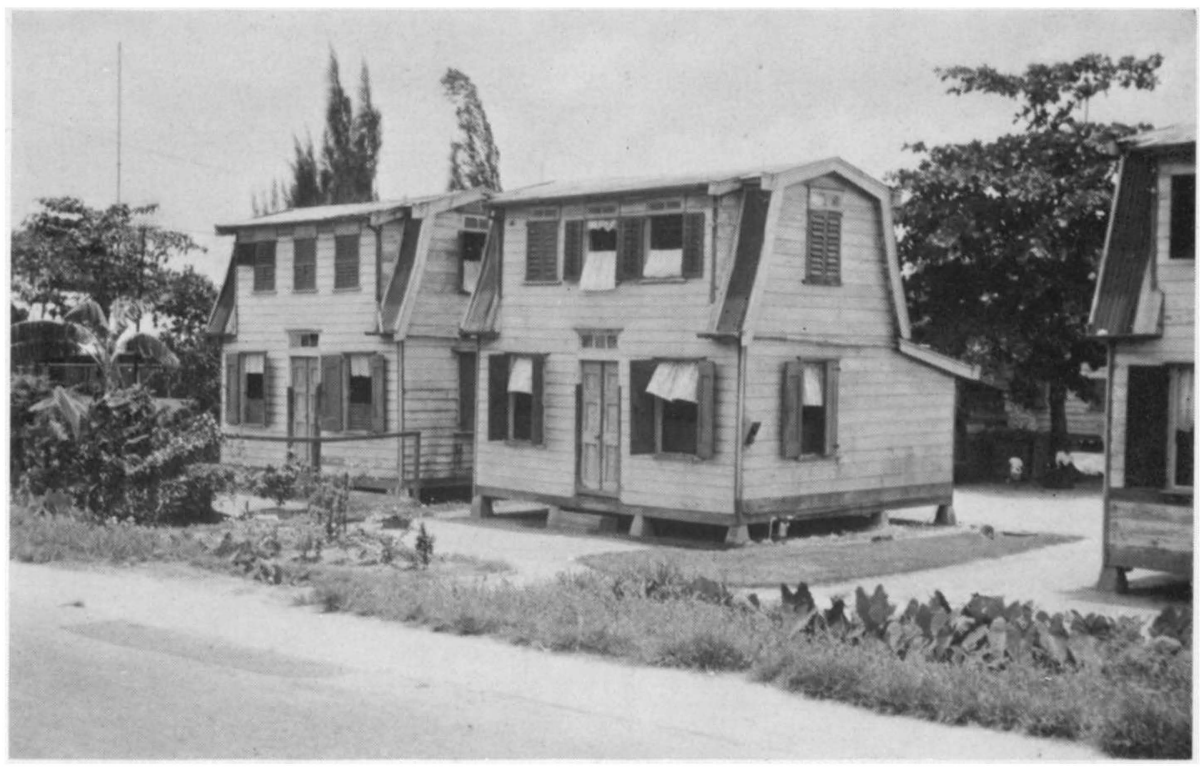

4. Upper-lower class houses.

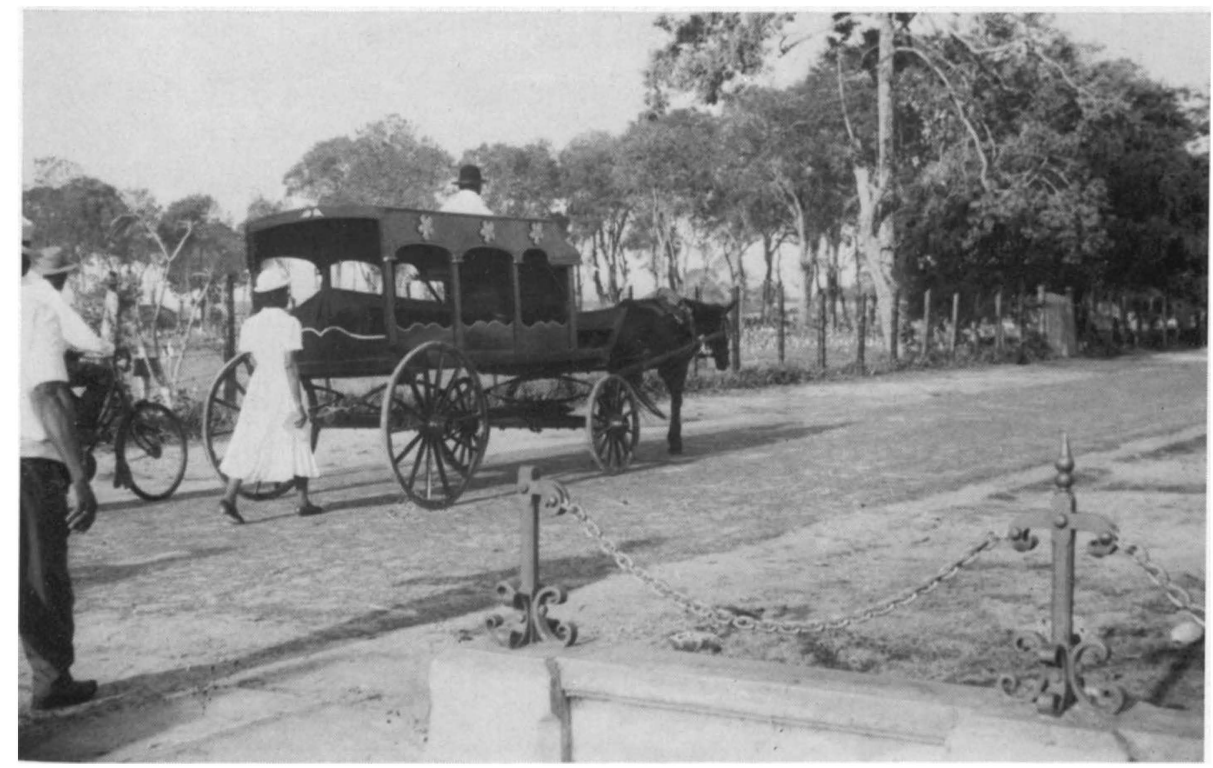

5. A very simple funeral. 


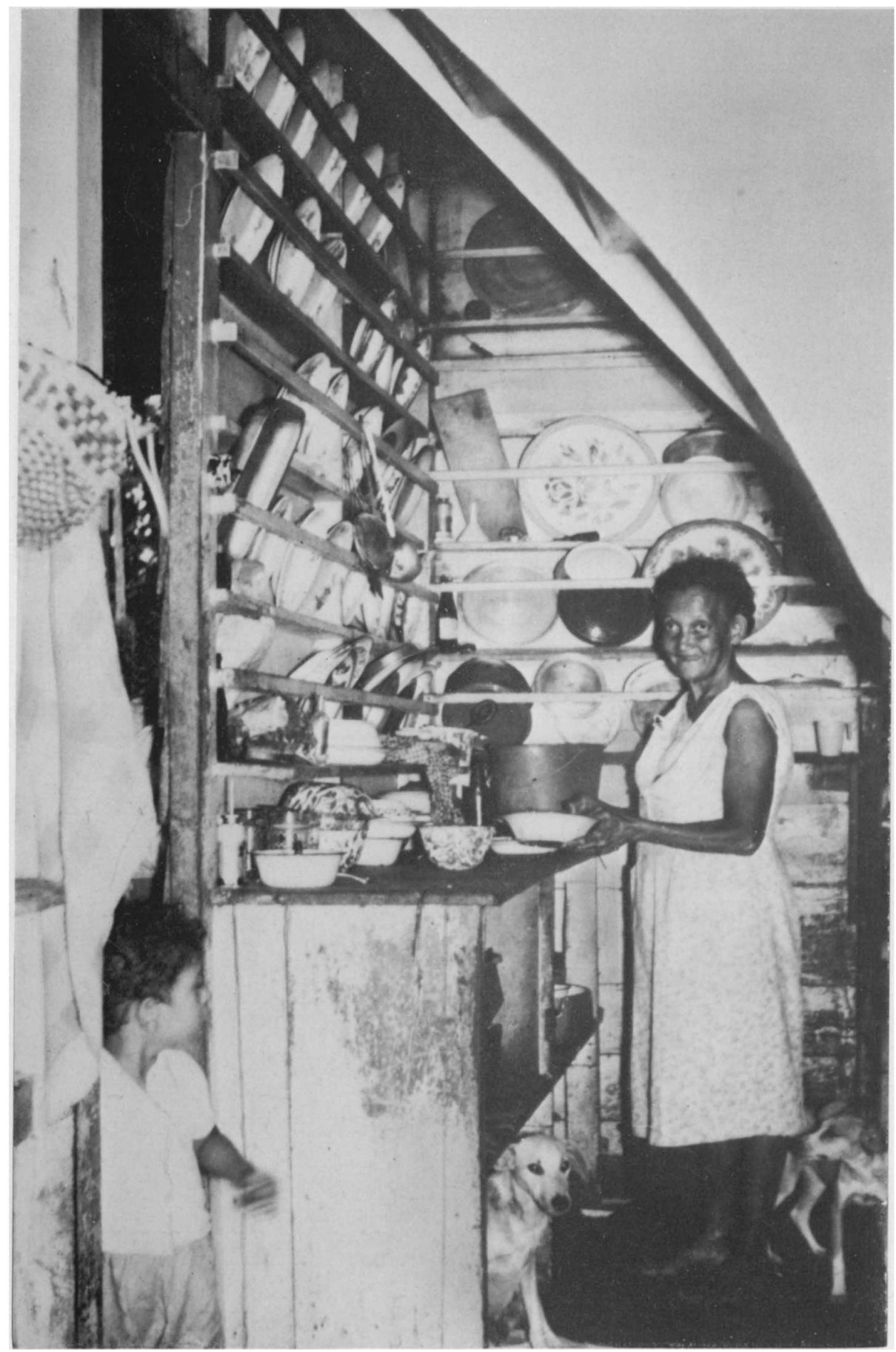

6. In the kitchen. 
as medical benefit funds. The best-known of these societies at present are the Moravian Jubileum Fonds, the Reformed Dutch Stuiversvereniging, the Lutheran society Vrede en Arbeid, and the medical benefit fund and funeral society Steun in Nood. There is also a special Marktfonds for market vendors.

After payment of an admission fee, members are required to pay a regular membership fee for each member of their family, the amount of which varies with age. Where formerly these amounts were on the low side, as the name Stuiversverenigingen (Penny Societies) implies, at present premiums are appreciably higher. The monthly membership fees of the medical benefit fund and funeral society Steun in Nood, for instance, are, under clause 180 of the articles of incorporation (undated, p. 15), for persons:

\begin{tabular}{lccc}
\hline & & $\begin{array}{c}\text { Medical } \\
\text { Benefit Fund }\end{array}$ & $\begin{array}{c}\text { Funeral } \\
\text { Society }\end{array}$ \\
\hline under 13 years of age & fl. 0.88 & fl. 0.63 & fl. 0.25 \\
from 14 to 17 & fl. 1.15 & fl. 0.90 & fl. 0.25 \\
from 18 to 59 & fl. 1.35 & fl. $1 .-$ & fl. 0.35 \\
from 60 to 65 & fl. 1.54 & fl. 1.09 & fl. 0.45 \\
\hline
\end{tabular}

The amount payable to this society each month by a large family is far from low. Despite these high regular payments, however, $49 \%$ of the heads of households were seen to have insured themselves against illness and/or funeral expenses. As these funeral societies are at present no longer exclusively funeral societies but also pay sickness and materny benefits, their usefulness should not be underestimated. In many cases they prevent households being reduced to dire financial straits. Although many people are behind with their premium payments to these societies, most people will guard against having their membership cancelled. The assurance of a "decent" funeral is a matter of prime importance to people of the lower-class Creole subculture, where mortuary and funeral rites play a key role. Although the Social Welfare Department sees to the funerals of the destitute, this is undergone as a "disgrace" by the relatives of the deceased. For the funeral in such cases takes place at Veldrust cemetery, the special burial ground for the poor. The coffin provided by the government on this occasion is of poor quality and lacks a "hood" or domed lid. To be buried in a coffin of this kind is considered as a degradation. 


\subsubsection{Other Expenses}

This heading covers, among other things, children's school fees and membership fees of clubs and societies. In addition, the expenses entailed in giving parties (such as at weddings and birthdays) are of ten so high that the household may run into long-term debts for this sort of thing.

The purchase on the installment plan of luxury articles (such as refrigerators, wireless sets, motor-cycles, and so on) which one would not otherwise be able to afford, is at present landing many households in greater financial difficulties than ever before. Some people are trying to obviate this by joining a kasmoni savings scheme. Especially women tend to do this in order to temporarily get rid of their financial worries. Such a kasmoni is usually run by a woman, and it involves her collecting a fixed sum of money from the members of her particular kasmoni group regularly each week or month. The participants are allocated the pool in turns at regular intervals, the turns being decided by drawing lots or by following a pre-arranged order. People use the proceeds from this to pay unusually high costs, such as those of giving parties, or the purchase of luxury items, or to pay off debts. Kasmoni members who have been allocated the total pool once often refuse to continue to participate in this scheme. In other cases the treasurer may be found guilty of embezzlement after appropriating kasmoni funds for personal ends without being able to refund the money in question. There is usually much friction and quarrelling in connection with the kasmoni schemes.

\subsubsection{The Degree of Poverty}

As is apparent from the above, the living standard of the bulk of the lower-class Creoles is low. However, there is virtually no dire poverty in the absolute sense of the word such as we find this in many Latin American, African and Asian countries among them.

Since Surinam is a relatively wealthy developing country because of the bauxite mining industry, it has been possible to save the urban proletariat from complete pauperization. Thus there is no evident starvation. A number of authors (such as Speckmann, 1963, pp. 76-92, and Van Renselaar, 1963, pp. 93-105) have pointed out that in his attitude to financial matters the lower-class Creole is the exact opposite of his Hindustani compatriot. Among the Hindustanis there is an obviously strong urge to save and invest, whereas among the lowerclass Creoles one tends to find a relatively more pronounced consumer- 
mindedness - they attach more importance to entertainment and relaxation, while most of them tend to concentrate less than their Hindustani compatriots on investing what money they have as profitably as possible (cf. Buschkens, 1965, p. 89). My observations tend to confirm that they seldom save money, live from hand to mouth, and often pretend to be better off than they actually are. Almost without exception they have a high level of ambition. But a great many of them are convinced that vertical social mobility is possible only through the factor of "luck", such as by enjoying the patronage of influential connections or winning a lottery prize. But in addition there are a not inconsiderable number among them who are trying to realize their ambitions by dint of sheer hard work; many of them try to advance to better positions by studying for diplomas.

There is a seignorial frivolousness observable among many lower-class Creoles; this becomes especially manifest in the pattern of consumption (e.g. the large sums of money spent on luxury items or on drinks for friends, which may be out of all proportion to the wages earnt by any given person), as well as in a certain defeatist attitude with respect to their chances of ever improving their social position. The latter attitude is being encouraged by the feeling that many of them seem to have that the economic and political dominance is certain to be taken over by the Hindustanis.

In the next chapter we shall discuss at greater length the effects of the socio-economic conditions outlined above on the family life of the lower-class Creole. 


\section{THE NATURE OF UNIONS AND THE HOUSEHOLD STRUCTURE}

\subsection{General}

We were able to see from the data supplied in the aforegoing chapter that the bulk of the lower-class Creoles are still living under unsatisfactory socio-economic conditions at the present day. In spite of Emancipation and decolonization, their economic position in the society of Surinam has improved little if anything.

There is a close connection between the uncertain employment situation which most men face and their defeatist attitude to life, in which there is no room for hope that their circumstances will ever change for the better. These circumstances are exercising a strong influence on the lower-class Creole family system, the characteristics of which are still distinctly "West Indian".

I shall now proceed first to discuss the presence in the current system of alternative unions between men and women, and after that to analyse the structure of the different household types, in order to examine next whether there is any correlation between the presence of such alternative unions, matrifocality and the various types of household.

\subsection{Alternative Unions between Men and Women}

Men and women may live together either as legal or as common law marriage partners. Looking at table B, appendix 3, in which the households of our sample are distinguished into eight types on the basis of the considerations enumerated in sections 3.2. and 7.2.1., we discover that of the heads of these households $29.4 \%$ (types $\mathrm{A}$ and $\mathrm{E}$ ) are married, while $22.6 \%$ (types $\mathrm{B}$ and F) are living in concubinage. As regards the total sample population over 16 years of age, $25 \%$ of the males are living in the one household together with a legal wife, and $19.9 \%$ with a common law wife, while for females over 16 years of age these percentages are 18.6 and 14.9 respectively. It is clear from these figures that legal marriage is the more prevalent of the two types of 
union, though the percentage of concubinage should by no means be overlooked. We shall discuss the motives impelling people to opt for either legal marriage or concubinage below.

\subsubsection{The Choice of one or other of the Alternative Unions}

Men and women who have made up their minds to share their lives (or part thereof) together have a choice out of three possibilities of realizing their ambition - they may marry at law, live in concubinage or visit each other regularly. In the latter case it is usually the man who comes to visit the woman in her residential unit. This comparatively sporadic type will be discussed further below. I shall attempt first to find an answer to the question of what reasons a man or woman may have for opting for either marriage or concubinage. It is essential in order to be able to answer this question at all satisfactorily to identify a number of characteristics of couples who are either legally married or living in concubinage, while at the same time the way in which certain unions are brought about should be examined.

\subsubsection{Age of the Partners and Nature of the Union}

Examining the distribution of the different types of union over the different age groups of the total sample population we discover (tables $\mathrm{C}$ and D, appendix 3) that the younger lower-class Creole shows a greater tendency to live in concubinage than to marry at law, while the reverse is true for the older age groups. Hence people generally marry fairly late in life. This hypothesis was confirmed by data supplied by the office of the Registrar of Births, Deaths and Marriages. It was evident for the year 1962, for instance, that a large percentage of Creole ${ }^{1}$ males (13.6) and females (12.0) married for the first time only past the age of 40 (table E, appendix 3 ). So men especially generally marry later on in life, after first living in concubinage either with the same or with another woman. Thus it similarly became apparent from our sample that of the 151 married male heads of households, $55.1 \%$ had lived in concubinage with the same partner prior to marrying. There was considerable divergency in the duration of these forms of premarital cohabitation, as is apparent from the table below.

1 It was difficult to establish from the marriage certificates who belonged to the lower classes. 
Table 34. Period of Time for which Married Male Heads of Households lived in Concubinage with their Present Partners prior to Marriage

\begin{tabular}{lr}
\hline No prior concubinage & 44.9 \\
Lived in concubinage for 1 year & 4.8 \\
Lived in concubinage for 1-2 years & 6.1 \\
Lived in concubinage for 2-5 years & 17.0 \\
Lived in concubinage for 5-10 years & 9.5 \\
Lived in concubinage for 10-15 years & 7.5 \\
Lived in concubinage for 15-25 years & 4.1 \\
Lived in concubinage for 25 or more years & 6.1 \\
Total & $100.0 \quad(\mathrm{n}=151)$ \\
\hline
\end{tabular}

Generalizing one might say that more than half the lower-class Creoles enter into concubinage at a fairly young age first, to convert their union into marriage later on. Slightly less than half marry direct, without first living in concubinage with their partner, however.

\subsubsection{Socio-economic Status of Married Persons and of Persons living in Concubinage}

I was struck immediately, in the course of my preliminary observations among the lower-class Creoles, by the fact that married couples on the whole seemed to create a more prosperous impression than those living in concubinage. This impression was confirmed by the figures supplied by the sample. Here the monthly incomes from work or pensions as well as the total incomes (i.e. incomes supplemented by payments received from members and/or non-members of the household and/or those received under the Poor Relief Scheme, and/or rent from houses or rooms) turned out to be considerably higher for married male heads of households than for male heads living in concubinage (see table $\mathrm{F}$, appendix 3). The married male heads of households were seen in $47.7 \%$ of the cases to be the owners of the houses occupied by them. This percentage was much lower for male heads of households living in concubinage, coming to $26.2 \%$ for this category. On the point of other material possessions, too, the married male heads of households appeared to be better off than those living in concubinage. Table G, appendix 3, shows plainly that the former have more possessions (such as refrigerators, washing-machines, gas or electric stoves) than the male heads living in concubinage.

Although there are a number of exceptions to this rule, one can state 
that on the whole marriage is the union of the more well-to-do and concubinage that of the less well-to-do lower-class Creoles.

\subsubsection{The Way in which Unions are Realized}

That men and women living in concubinage start thinking about marriage only after the male partner has acquired a certain socioeconomic status is also obvious from the ideal pattern of realizing unions. By asking a number of lower-class Creoles to state what was the "proper" way of concluding marriages and concubinages, we were able to form the following idea concerning this.

When a boy and girl have made up their minds to either marry or live in concubinage the boy asks his parents (often only his mother) to pay a visit to the parents of the girl of his choice to ask their consent for the proposed match. On the day appointed for this visit the girl gives her parents' home a thorough cleaning, explaining her behaviour by announcing that they may expect visitors in the evening. During the visit the boy's parents ask for the girl's hand - after first chatting about all kinds of unrelated matters. If the girl's parents give their consent (which is usually the case if they have invited the boy's parents to come inside), the parties may continue talking for a little while longer, the girl's parents teasing her, according to popular custom, by making slighting remarks about her, such as that at home she is "cheeky" and lazy, in short, that she is incapable of fulfilling the duties of a housewife. Politeness requires that the future parents-in-law duly express their strong doubts about this. (W. F. van Lier's description (1940, pp. 267270) of the way in which unions between men and women are realized among the Aucan Bush Negroes indicates that a number of the features described above are also to be found here.)

Usually the bridegroom or the common law husband-to-be does not come along to the girl's home on the occasion of the proposal. If he does, it is customary for the girl's brothers and sisters to tease her about him after his departure by making disparaging remarks about his looks, saying, for instance, that his nose is too big or there is something wrong with his ears. The husband-to-be usually buys two engagement rings with his and the girl's names engraved in them, and the couple prepares to set up house during an engagement period lasting sometimes more than a year. It is customary for couples to settle neo-locally when entering into marriage or concubinage. As soon as the husband has succeeded in renting or buying a home and has accumulated sufficient 
furniture the young people will move into this. Only after the arrival of a child will the couple in most cases start thinking about marriage eventually - provided the husband is earning an adequate income. "Build first and then get married", as the popular saying goes. Only socially successful men of the upper strata of the lower classes usually marry straightaway. They are the only ones able to offer their wives a "decent" home to live in at the outset. The wedding-feast is held in grand style.

This ideal pattern is now considered old-fashioned by the majority of young people, and is in fact seldom to be observed in reality. A not inconsiderable number of young people who consciously strive to be "modern" regard concubinage as a relic from the colonial past. They may enter into marriage without the slightest hesitation, but these marriages often turn out to be unstable. This procedure is followed especially by young people from the lower classes who have risen in the social scale and have secured some white-collar job or other. Their behaviour in this respect strongly resembles that of Negroes in the United States, who similarly tend to marry fairly young (see section 1.3.1.).

There are also many deviations from the ideal pattern as a result of forced marriages or concubinages in consequence of the arrival of a child. The following cases illustrate how a number of unions are effected in actual reality rather than according to the ideal pattern.

The 24-year-old girl G. came to Paramaribo from Coronie with her mother. Here she worked at first as a housemaid. At the age of 18 she became friendly with a man 10 years her senior, a bricklayer living in the same street. She soon became pregnant and gave birth to a son in her mother's home. A year after this birth, after she was pregnant by this same man for the second time, she went to live in concubinage with him. This her mother managed to bring about by making a number of scenes with this man.

The 36-years-old Miss N., a mother of nine children, was orphaned at a very early age, whereupon she came to live with her aunt. She went to work as a domestic servant. At the age of 17 she became pregnant by a Chinese who, on being told about this by her, left her. After that she went to live in concubinage with an unskilled labourer, without her aunt's consent, at the age of 20.

Mr. G. ( 59 years old), a bootmaker and rubber-tapper by trade, told me: "When my wife became pregnant, when I was 23 , I simply went to live with her without asking her mother's permission or having it asked. 
I did not marry her until after the birth of my children (four)." Mr. P. (aged 33) met his present concubine when visiting a female cousin of hers. After that he came to see her regularly at her home, and some time later asked the girl's mother for her hand. Initially he went on living at the home of a sister of his father's, whence he visited her regularly. He regularly slept with his wife-to-be with the consent of the girl's mother. After they had a child he moved in with his wife, who continued to live with her mother. He eventually became the head of this household as its breadwinner.

The old idea of not marrying until after the woman with whom one has lived in concubinage has had children and one is sufficiently well-off no longer holds true today either.

The 81 husbands of the sample who entered into legal marriage with their concubines after living in concubinage with them first were asked to state their motives for doing so. Although I am inclined to attach only relative importance to the answers to this rather intimate question given by the respondents to the interviewers, there are even so a number of interesting things to be discovered about them. No far-reaching quantitative conclusions should be drawn from the answers given, however.

Table 35. Motives of Male Respondents for converting their Concubinages into Marriages

$\begin{array}{lr}\text { 1. "love" } & 33 \\ \text { 2. for the sake of the woman's economic security } & 11 \\ \text { 3. for the children's sake } & 9 \\ \text { 4. for religious reasons } & 7 \\ \text { 5. to meet the requirements of the job (police force/armed forces) } & 5 \\ \text { 6. for the sake of living a "moral" life } & 5 \\ \text { 7. pregnancy of the concubine } & 2 \\ \text { 8. at the woman's request } & 1 \\ \text { 9. because we get on well together } & 1 \\ \text { 10. because it is the wife's right } & 1 \\ \text { 11. because the concubine insisted } & 1 \\ \text { 12. because the girl's parents desired it } & 1 \\ \text { 13. because it was the family tradition to marry } \\ \text { 14. because my wife treated my children of a previous marriage } \\ \text { as a real mother } & 1 \\ \text { 15. uncertain } & 81 \\ \text { Total } & \end{array}$

The answer stated under 1., "love", should not be taken too seriously, as in many cases it was no doubt merely a convenient answer considered 
appropriate for the occasion. Besides affective feelings, there appeared to be other motives as well which played a part in bringing a marriage about, however.

With the answer "for the sake of the woman's economic security" (2.) the men in question were alluding to the possibility of bequeathing their possessions to their wives after their death. Superannuation payments to the widow where the husband was in government employment or in the employment of a private firm with superannuation facilities for its employees also played an important role here. Thus Bruynzeel Suriname Houtmaatschappij N.V. urged its employees in a circular of 1955 to convert their concubinages into marriages because a man's common law wife and unlegitimated children were not entitled to insurance payments in the event of his meeting with a fatal accident. 'This situation had come into the full glare of publicity as a result of a fatal accident which an employee living in concubinage who had failed to legitimate his children had met with (cf. De West, 17th November, 1955, p. 2).

The reason "for the children's sake" stated under 3. probably has some connection with the circumstance that where the children have risen socially they may urge their parents to marry in the belief that this will enhance their social prestige. Children are also sometimes seen to try and get their parents to marry because they consider marriage an act of recognition of their mother by the father. Religious reasons were stated in seven cases (4), these being further specified as: "because the bible says so", and "the minister insisted", among other reasons.

Five men were obliged to marry because of their position in the police force or army. Evidently members of the police force and the military services are expected to set an example to their fellow citizens in private life. The remaining answers (6-15) are self-evident. It is worth noting that the man stating as reason "because it is the wife's right", under 10., had been living in concubinage with his present wife for thirty years before marrying her.

The question that remains to be answered now is why a substantial percentage of men and women continue to give preference to concubinage.

The main, and possibly most important factor here is that there are certain obstacles placed in the way of the less well-to-do which deter them from marrying. Among the majority of the Creole lower classes, and more especially in the lower strata, the idea is prevalent that it is impossible for a man to marry unless he enjoys a stable and relatively high income. If this is not the case, then, according to the common 
opinion among the lower classes, he is fit only for concubinage. According to this view, marriage entails moving into a home that is in reasonably good repair and being able to afford such more or less durable articles as refrigerators, gas or electric stoves, washing-machines and decent furniture (preferably including a lounge suite). Men and women marrying without fulfilling these conditions are accused of pretending to a social rank which they do not in fact have. Such couples are derided and made fun of. The woman will be scornfully referred to as "Madam", and satirical songs are made up about them which are sung or whistled whenever the couple is seen approaching in the street. This can be particularly vexing for people living in yards, where the social control exercised by the community may be extremely strong.

The above tendency is connected with the fact that in the view of many people marriages should be celebrated with much pomp and circumstance. The expenses of the festivities involved are high. If one marries without any festivities at all, however, one makes oneself the butt of scorn and ridicule as a person with social pretensions without the necessary economic backing. Especially if one has often been a guest at other people's weddings, it is virtually impossible to avoid marrying without giving an enormous party and hence reciprocating the hospitality of one's former hosts. For these reasons women are often reluctant to marry if this condition cannot be met. The expenses of a wedding are not inconsiderable. Besides the expenses of the wedding dress there are the fees to be paid at the townhall and the church. The party held after the church ceremony for all the couple's relatives, friends and acquaintances, and at which vast quantities of food and drink are consumed by the guests, makes up the lion's share of all the costs, however. The drinks served are mostly imported ones, such as champagne, brandy and whisky, while, moreover, a band is usually hired to provide music for dancing. The costs of such a party run into at least several hundred Surinam florins, while expenses of S.fl. 1,000 are not exceptional. Many people who enter into marriage seem to be laying the foundations for the failure of their marriage on their very wedding day itself because of all the expense they go to, forcing them to make debts which it may take them years to pay off. The husband tends to feel severely restricted in his freedom by this heavy indebtedness, which greatly increases the likelihood of conflict. Most ostentatious are the wedding parties given by older people who have lived in concubinage for years. These it is impossible for younger people to rival if they wish to marry young.

This widespread social expectation that weddings be attended with 
large-scale festivities is causing some people to marry in secret. This may happen in cases where a man wishes to give his partner the rights to a widow's pension, for instance.

Apart from these socially conditioned reasons for not marrying, personal reasons may also play a role. A man may refuse to marry because the social environment is often opposed to married women going out to work. If he marries in spite of this, a difficult situation will arise for him. For, as we have seen, marriage makes high demands on a man's financial resources, while, moreover, his wife will no longer be willing to go to work to make up for the financial setback thus sustained, at any rate not in the more "menial" kinds of job as charwoman or housemaid. Only $11.3 \%$ of the partners of legally married male heads of households were seen to have jobs, as against $20.4 \%$ of the partners of male heads living in concubinage. One married man who was head of a household told us that whereas his wife used to go to work when she was still his concubine, she was no longer willing to do so after he had married her. In addition, married women tend to demand more housekeeping money, according to him, and are not as easily satisfied financially as concubines. He said that his wife had become "lazier" at home, too. Another man, aged 40, complained that his wife refused to bring him his food at work any longer after becoming married to him. The latter case exemplifies one of the reasons why men in many cases refrain from marrying - because if they did they would lose all "authority" over their wives. The thought that men are required to pay alimony in the event of divorce is also deterring men from entering into this kind of union.

The Creole male, who has a strong tie with his mother, frequently marries only after his mother's death, so one informant told us. Men are in many cases advised against marriage by their mothers. Parents tend to look on their children as a kind of security for their old age. This attitude is causing many of them to oppose either consciously or unconsciously marriage on the part of their sons or daughters.

A number of the male heads living in concubinage were unwilling to convert their concubinage into marriage because they regarded their concubine rather as a temporary housekeeper than as their ideal partner for life. In consequence of the surplus of women it is not difficult for a man with a regular income to change partners. Lower-class Creole women, for their part, seldom insist on marriage. "A Creole woman would feel disgraced in asking a man to marry her", an elderly female informant said to us. This "modesty" stems partly from the weak 
bargaining position of women. A man with a good income can easily afford to say: "Ten others to take your place".

On the other hand one also finds women who have little inclination to marry. They feel they are able to enjoy a freer, more independent life as a concubine than as a legal spouse. They consider it quite inadvisable to marry a man with an irregular income, "because it is harder to get rid of a jobless husband than a jobless lover", as one female informant stated. Although women are prepared to go to work to support their children, they refuse to do so to provide for a husband. Women sometimes reject proposals of marriage from men they consider mentally immature for this reason. They do sometimes enter into concubinage "for as long as it works" with such men, who are in some cases younger than they, of ten regarding and treating them partly as sons, however.

In a large number of cases concubinage is favoured over marriage by the partners because the woman already has children by another man or other men. This has caused her value in the marriage market to drop sharply, as a result of which she often has to content herself with a concubinage. Young virgins or women without children or a "past" stand a much better chance of making a matrimonial match than women with children of earlier unions or affairs. We should look in this group for the fairly large percentage of marriages which are unpreceded by concubinages between the same partners $(44.9 \%$, cf. table 34$)$.

Some women living in concubinage rationalize their status by saying that they prefer this way of life to that of a married woman because they have more power over their husbands this way. They represent married women as their husbands' slaves.

\subsubsection{Views on Marriage}

Whenever in the course of an interview I asked respondents living in concubinage with whom I was fairly intimately acquainted whether concubinage or "Surinam-style marriage" possessed the same prestige as legal marriage, this question was invariably answered in the negative. Marriage is considered superior to concubinage as a union between a man and a woman. Similarly when one asks young girls to say which of the two they would prefer for themselves later on, marriage is mentioned as the normal union, while not a word is said about concubinage.

As far as I was able to judge they answered this way not because 
it was felt that a European sociologist liked hearing this kind of answer on account of his own social and moral attitudes, but rather because the bulk of the lower-class Creoles do in fact cherish the ideal of living in accordance with a number of Western norms and values, though in reality they are not able to live up to this "standard". Most lower-class Creole girls would ideally like to enter married life as virgins. But there is little to support this ideal in actual life. One factor contributing significantly to this is that girls are insufficiently protected inside the household. The father is often living away from the household, making it necessary for the mother also to be away part of the time in order to earn the family's livelihood. Hence daughters receive only scant supervision as a result of this situation.

It is the men's ideal to marry with much pomp and glitter only after a series of affairs in which they have given proof of their virility. For the former, however, men often lack the means as well as the necessary regular income in consequence of the prevailing structural unemployment. If a man marries without satisfying this condition he is ridiculed especially by his friends.

As regards the phenomenon of the ideal pattern which people would like to follow in their own lives being incapable of realization, the majority of the Creole lower classes has much in common with the persons from Lewis' "culture of poverty". The latter observes that: "People with a culture of poverty are aware of middle-class values, talk about them and even claim some of them as their own, but on the whole do not live by them. Thus it is important to distinguish between what they say and what they do. For example, many will tell you that marriage by law, by the church, or by both, is the ideal form of marriage, but few will marry." (Lewis, 1969, p. 51). Although there is a demonstrable gap between ideals and reality in virtually every culture, this can be said to be especially wide in the lower-class Creole subculture of Surinam. In the lower-class Creole group marriage has come to be regarded as the union of the socially successful, or as the obvious union for people of some consequence. Where people have advanced on the social ladder, such as after a successful political career, they are therefore of ten seen to convert their concubinages into marriages. Older people concluding a marriage after many years of concubinage are therefore inclined to regard this event as a serious step which will win them social prestige. Women in particular tend to view this as the crowning achievement of their sexual career. Both partners have in this case decided to perpetuate the bond between them until the death of either one of them. 
Progressive people of the younger age groups generally do not marry with this objective. They are inclined rather to enter into marriage "for as long as it will work". This leads us to the subject of the duration of the various kinds of union between men and women and to the question of whether these are in fact as instable as is generally asserted in Surinam.

\subsubsection{The Stability of Unions}

The American and Caribbean Negro family has been characterized as instable by Frazier (1939), Henriques (1953), R. Smith (1956) and many others. This is generally stated with reference to the fact that divorce and the termination of concubinages and visiting relationships are frequent.

When asked about this, my informants seemed to be unanimously of the opinion that unions tend to be extremely casual and short-lived among the lower-class Creoles. This opinion was put forward by both informants who themselves were lower-class Creoles and informants belonging to another class of Creole society or to a different ethnic group. The lower-class Creole informants stated the view that visiting relationships broke up very frequently, and concubinages often, though slightly less frequently than visiting relationships. According to them marriages were seldom dissolved, especially in the case of older people.

I have tried to collect some quantitative data on this subject with the object of discovering: (1) whether the above opinion, which is common among lower-class Creoles, can be confirmed statistically; and (2) whether it is possible to define accurately what exactly is meant by such quantitative value statements as "very frequent", "frequent" and "not so frequent", which are not in themselves very meaningful, in the lower-class Creole subculture.

Collecting statistics about the dissolution of the different types of union turned out to be no easy task. Of the three types of union, records are kept only of legal marriages at the Registrar's Office. It is relatively easier to collect data on legal and common law marriage among the people themselves, however, as people speak just as openly about the latter as about legal marriage. The position is not nearly so easy as regards the visting relationship, as one is able to obtain information about this only if one knows the persons in question fairly intimately. Relationships of this kind are usually kept secret from the outside world, as was observed above. The data collected by means of a number of 
case studies suggest that mostly men with a common law or legal wife elsewhere and with a sufficiently high income for them to be able to afford a regular mistress enter into visiting relationships. But these are comparatively rare. For this reason I shall leave them out of consideration.

Tables $\mathrm{C}$ and $\mathrm{D}$, appendix 3 , set out the nature of the unions of the total male and female population of the sample over 16 years of age. They show that of the male and female population above the age of 16 , $26 \%$ of the men and $21.3 \%$ of the women are married. The percentages of men and women who have divorced one or more times are 1.9 and 3.3 respectively. These latter figures seem to be rather on the low side. They give an exaggeratedly favourable impression of the stability of marriage, as it is not uncommon for married people to separate without obtaining a legal divorce. These persons, who have taken recourse to what is termed in the United States "the poor man's divorce" and are de facto divorcees, form part of the category specified in tables $\mathrm{C}$ and $\mathrm{D}$, appendix 3, as "married without a partner living in in the household". The figures concerned are $1 \%$ of the males and $2.7 \%$ of the females above the age of 16 . The number of persons divorced either by legal divorce or de facto separation constitutes only a small percentage of the population of the sample. The lower-class Creole belief that marriages are seldom annulled is therefore correct. Tables $\mathrm{C}$ and $\mathrm{D}$ of appendix 3 also show $19.9 \%$ of the males and $14.9 \%$ of the females above the age of 16 to be living in concubinage - hence these percentages are lower than those of married persons.

I have collected no data on the number of marriages and concubinages of the total sample population. As stated earlier on, only heads of households, and where possible their partners, were interviewed. Hence it was possible to record only the histories of the number of marriages and concubinages, divorces and desertions of these particular persons. For it did not seem right to get heads of households or their partners to give information on this point about other members of the household, as I did not always believe the former to be in possession of the full facts concerning the life history of all the members of their households.

Table $\mathrm{H}$, appendix 3 , sets out the number of unions concluded and the number dissolved by the heads of households and their partners. Of the total number of marriages concluded by men (185: $1 \times 161+$ $2 \times 9+3 \times 2)$ and by women $(235: 1 \times 217+2 \times 9), 13 \%$ and $15 \%$ respectively were dissolved through legal divorce or de facto 
separation. Of the total number of concubinages of men (216: $1 \times 120$ $+2 \times 36+3 \times 8)$ and of women $(267: 1 \times 186+2 \times 33+$ $3 \times 5) 41 \%$ and $45 \%$ respectively were terminated by desertion. Concubinages are dissolved more frequently than marriages -- they are, in fact, dissolved "frequently" as stated by the informants.

Looking at marriages and concubinages combined under the collective term "co-residential unions", $28 \%$ of the 401 unions of this type concluded by men and $31 \%$ of the 502 concluded by women were seen to have broken up. The Moynihan Report (1967, p. 52) observes that in urban environments in the United States almost a quarter of the marriages concluded by Negroes are dissolved. Regrettably so, Moynihan lists no percentages with respect to the concubinages dissolved. Although, as was stated earlier, these are less prevalent in the United States than in the Caribbean, a more correct representation of factual instability would be given by stating this percentage. We may reasonably suppose that if we proceed on the basis of an estimate of the percentage of "dissolutions of co-residential unions" (marriages and concubinages) in the United States, too, we shall arrive at a percentage that is higher than "almost a quarter", because in the United States, too, concubinages are more unstable than marriages. I am inclined to think that roughly estimated this will turn out to be around $30 \%$, thus corresponding closely with the above percentages of 28 and 31 of dissolved co-residential unions in Surinam. Thus there would seem to me to be close similarity between the urban American Negro population and the lower-class Creole population of Paramaribo town as regards the stability of coresidential unions. Of every three co-residential unions entered into by them one is dissolved through divorce or desertion. Speckmann (1965, p. 169), who in his study on the Hindustanis of Surinam supplies statistics with reference to the instability of marriages in this group (Nickerie $35 \%$, Saramacca $24 \%$ and Paramaribo $32 \%$ ), notes that: "Generally speaking, (...) one third of all marriages (common law and legal) in the Indian community are broken by an intentional dissolution. The group does in fact exhibit a high rate of matrimonial instability, even though it may be assumed, on the evidence of Pronk's figures, that the percentages are even higher among the Javanese (Pronk, 1962)." These figures would seem to give the lie to the popular view in Surinam according to which instability is highest by far among the Creoles.

\subsubsection{The Duration of the dissolved Marriages and Concubinages}

As we saw above, concubinages tend to terminate in larger numbers 
and within a shorter time than marriages. Hence it is to be expected that where concubinages are dissolved they will on the whole appear to have been of shorter duration than marriages.

Table 36. Duration of the dissolved Marriages and Concubinages of the Heads and their Partners (in percentages)

\begin{tabular}{lcc}
\hline & $\begin{array}{c}\text { Marriages } \\
(\mathrm{n}=44)\end{array}$ & $\begin{array}{c}\text { Concubinages } \\
(\mathrm{n}=208)\end{array}$ \\
\hline One years or less & 3 & 8 \\
1 to 3 years & 13 & 17 \\
3 to 5 years & 14 & 15 \\
5 to 10 years & 43 & 38 \\
10 to 15 years & 16 & 13 \\
15 years or more & - & 7 \\
unknown & 11 & 2 \\
Total & 100 & 100 \\
\hline
\end{tabular}

N.B. "De facto" separations are not included in these figures.

The percentage of concubinages dissolved within five years or less appeared to be higher than that of legal marriages dissolved within the same period. More concubinages than marriages are seen to break up, especially in the first year. Obviously common law marriage partners are less motivated "to give it another try" than are legal marriage partners. The percentages of marriages and concubinages dissolved between the fifth and the tenth year are strikingly high.

\subsubsection{Reasons for terminating Unions}

Now, what are the reasons why couples separate? From the case-study material collected by us the following three principal, mutually related reasons for terminating unions emerge:

(1) Inability or unwillingness of the husband to give his wife a reasonable housekeeping allowance;

(2) Absence of the husband for reasons of work or recreation;

(3) Adultery.

As was observed earlier on, in the discussion of unemployment in Paramaribo, there are a large number of unskilled labourers without any definite prospects of regular work. From the instant a man is turned out of his job, both partners will try to subsist on borrowed money and 
Poor Relief aid until such time as the husband finds another job. They soon discover that the credit extended by most (Chinese) shopkeepers and the landlord is definitely limited, while it is impossible to make ends meet on the money and food allowances supplied under the Poor Relief Scheme. In order to try and get some extra money pending the moment the husband will find another job, the female partner will usually start looking for work - that is to say, if she is not already earning her own income. If she succeeds in earning a cash income, she will become the dominant person in the household. She is often supported in this by her older children, who are in many cases the offspring of earlier unions of the woman. Life then becomes extremely dismal for the male partner, and this will prompt him to leave his wife or send her away. He will moreover suspect his wife - rightly or unrightly - of drawing her income from some relationship with another man. The following case of two concubinage partners who eventually left each other for good may serve as a partial illustration of the mechanism described above:

The 30-year old C. G. is living together with his 21-year old common law wife and three children in a one-room hovel of a house of $3 \times 4$ metres somewhere in a squalid, neglected yard. The husband has been out of work for three months. He was formerly working as an attendant in a government office, but was dismissed after getting involved in a fight with his boss. For the latter, he claimed, had grievously insulted him by casting aspersions on his mother's morals. This couple has no income other than food parcels from the Poor Relief. The husband owes three months' rent and thinks it likely that he will be evicted by his landlord soon. He hopes that his mother will take him and his family in. In order to ease their financial plight somewhat, the wife has had sexual relations with a fellow yard dweller while he himself was away from home. The husband was informed of this by friends living in the same yard. So as not to lose face he subsequently gave his common law wife a thorough beating with the leg of a chair.

Apart from the husband's inability to give his wife money, many conflicts arise from husbands' refusal to hand over a reasonable portion of their wages to their wives as housekeeping money. This may be a consequence of the husband's squandering his money with friends - it is not uncommon for people to gamble away all their money - or of his spending money on affairs with other women.

The informant N. I. G. (54 years of age) is living with her husband A. I. (56) and his three children of a previous union - including a 
daughter with three children and her foster-child - in a five-room dwelling. The husband makes a good living as a technician. The informant is unable to tell me how much her husband earns, as "husbands never tell their wives". The husband gives her little money, or sometimes none at all for weeks on end, which gives rise to quarrels. She suspects her husband of keeping mistresses. Husband and wife regularly organize square dance evenings partly as a hobby and partly to make some extra money. The husband had started a temporary affair with one of the members of the square dance club a year ago. When the informant came to hear of it she abused the woman in question at one of these dances, whereupon she had a fight with her. On coming home that same evening the husband gave his wife a sound beating for behaving this way. The relations between them have cooled off noticeably since this incident. In order "to have someone to talk to" at home - the other members of the family have taken their father's side the informant has adopted a child through the intermediary of the Social Welfare Department. A childless woman herself, she enjoys bringing up her children.

It is also not uncommon for a man to hand over a considerable part of his salary to his mother, which may become a cause of serious quarrels with his wife. Elderly people are sometimes entirely dependent on their children because there are few if any social benefits for the aged. I shall come back to this in the discussion of the relations between the members of households.

A woman receiving a reasonable share of her husband's pay packet is expected, according to the common opinion, to be absolutely faithful to him, provided he regularly fulfils his bedroom duties as well. If these conditions are not fulfilled, however, she has every right to look around for another partner.

A percentage of the male informants gave the fact that their wives were in the habit of spending money on their mother or on children of previous unions as an excuse for giving their wives so little money. Quarrels about this are most frequent.

As we saw above, many men are away from home for long periods at a time because of their work. This happened in the past in the balata and gold-mining days, while at present they go away to work in the bauxite fields at home or migrate to Holland. A man earning his living this way will sometimes omit to send his wife money, or fritter away all his money on his return to town. One woman informant told me the following story: 
The informant E. C. (36 years of age) makes up a household together with her 55-year-old mother and her seven children. She is living in concubinage with a man who is mostly absent. Like her mother's husband, he is a labourer working in the gold fields in the interior. He sometimes stays away for more than four months on end without sending any news of himself. When he is in town, he will often stay away from home for whole nights, going out to play cards or have drinking sprees with his friends. The mother's husband is away in the interior for periods of two to three years. Whenever the concubinary husband fails to send money - which is more often than not the case - his common law wife borrows money from the son of the owner of the concession on which he is working. The amount of this "loan" is deductible from the wages payable to the husband on his arrival in town. Violent quarrels arise about this on the husband's return home. The informant's fifth child is not by her concubinary husband but is the child of a man she was living with during one of the husband's absences. The latter has not left her on account of this adulterine child but has moved in with her again, after some initial quarrelling, on his return to town from work. During the interview there was a man in the house who was introduced as a family friend. From this man the woman receives money off and on in exchange for sexual services. The woman had received no news from her common law husband, who had meanwhile left again, for three months.

I was told the following story by a male informant.

The man, the 59-year-old J. K., married at the age of thirty after his wife became pregnant. He makes a living as shoe-mender and balatableeder. He told me he had lived with his wife for ten years, when he discovered one day that she was unfaithful to him during his prolonged absences in the bush (balata-bleeders sometimes spend three or more months away in the bush). According to him his son informed him of this. This in itself he did not take too seriously. But when it transpired that his wife continued these illicit relations even when he was at home for a longer period he left her (the husband having made this discovery from letters to his wife from her lover). They never obtained an official divorce.

Seeing that prolonged absences of husbands on account of work have constituted a structural feature for a long time now, an unwritten law has come into being which absolves women from any guilt normally attaching to adultery provided the offence has been committed during a protracted absence of their husbands. Husbands are as a rule inclined 
to be tolerant about or even condone adultery committed by their wives in these kinds of situation. A man who had been away working in the oil refineries in Curaçao for a few years discovered on his return home that his common law wife had had a child by another man. He glossed this over by putting it down to "nature". "Women are weak and no man is to be trusted," he said. His common law marriage was continued as though nothing had happened, and he recognized the child born of the affair. Another woman also had a child of an illicit affair during her husband's two years' absence in Curaçao. The child was entrusted to the care of a friend of the woman's soon after its birth "because she felt ashamed". The man heard of his wife's conduct while still in Curaçao and decided to return home. He considered his wife's adulterous affair normal, but thought she had acted correctly in giving the child away. The child occasionally visits his mother with his foster-mother. If the husband is away from home he is asked inside. But if the husband is at home the child is only greeted at the door.

It is exceptionally difficult to trace to what extent the husband's tolerance in this respect is connected with the old belief that pregnant women should have regular sexual intercourse if they are to bear healthy children. Apparently it was not uncommon in former days for husbands to ask a friend to replace them if they were obliged to leave their pregnant wives for a longer period of time. Serious conflict will arise between husband and wife if the wife has an adulterous affair in the husband's presence, however. Such behaviour on the part of the wife will cause the husband to suffer a serious loss of prestige, which it will be possible for him to make up for only by "giving the slut a trashing and sending her on her way". Adultery is least tolerated if a woman commits it with a man of lower status. In such cases the woman's partner is obliged to give not only her, but also her lover a trouncing if he is to save face.

A certain police constable comes home one day and catches his wife with the postman, which gives rise to a fierce fight with the intruder. The latter succeeds in running off with the woman, though battlescarred and still in a partial state of undress. The husband shouts after them that he will kill them both with the pistol his office entitles him to carry; but he has left the fire-arm behind at the office. He announces his intention to all the neighbours who have rushed to the scene of the quarrel, and continues broadcasting it around for another few weeks. Most of them adjure him to give up the idea. The exposed adulterers go into hiding so as to prevent him from carrying out his threats - 
which actually suits him perfectly well, as his sole aim in uttering them had been to prevent his losing prestige, this having been dealt a serious blow by a man of much inferior social standing seducing his wife. $\mathrm{He}$ tells us in a confidential conversation that he would not have been nearly so vindictive had the wife committed adultery with a man of higher status than himself, such as a Staten member, for example. In that case he would have contented himself with sending the intruder packing and giving his wife a beating. When three months later the incident had stopped being a subject of neighbourhood gossip the wife returned to her husband and was magnanimously "forgiven" by him.

Apart from being away from home frequently for reasons of work, there are quite a lot of men who are often away because they like to go out alone. Most lower-class Creoles seldom take their wives out, because they do not have enough money for this and because there are few inexpensive cafes or restaurants to take a woman to for drinks. Husbands and wives usually go out together only to go to church or to attend the birthday party of some relative or friend. In addition there are many men who refuse to take their wives out because their friends consider it ridiculous, or because they are carrying on an affair with another woman which they wish to keep secret from their lawful wife. Their husbands' absences enable some women to entertain their men friends at home in their turn. These practices reveal some parallels with those of the Negroid population of Anamat described by Freilich, though they are not as much a structural phenomenon in Paramaribo. Freilich says: "A certain man leaves his house on an evening to visit a girl friend or have a fete with the boys. His wife, now alone, can be visited by one of her admirers. The second male, by leaving his own house, provides a place for a third man, and so forth." (Freilich, 1961, p. 962.)

The majority of women do not take adultery on the part of their husbands over-seriously. Especially older married women do not frown too heavily upon their husbands having amorous adventures, provided the latter give them enough money and the outside world continues to regard them as the lawful partner, or "the missis". Some women are so tolerant as regards their husbands' extra-marital escapades as to be prepared to bring up the husband's illegitimate offspring if their own mother is unable or unwilling to support them. One married woman told us she had presented an illegitimate child of her husband's for baptism and later taken it into her own home "because she considered it her Christian duty". It is considered normal for illegitimate children to visit their fathers at home, where they are then received by the latter's 
wife or concubine. It would be false to suppose, however, that there is no jealousy among lower-class Creole women. If they suspect their husbands of adultery especially the younger women will try to catch the latter out by following him whenever he goes out. This may sometimes end in fights and quarrels between the wife and the husband's girl friend. This constitutes a source of entertainment and gossip for the entire neighbourhood in which such scenes take place. Apart from this the wife who has been thus deceived may make things very unpleasant for her rival by means of an institutionalized form of revenge, known as lobi singi, meaning literally "love song" (cf. Herskovits, 1936, pp. 23-32). Whenever the wife meets her rival she will sing a song hinting at the relationship between the latter and her husband. Formerly the wronged wife might go to the house of her rival accompanied by her woman friends and a number of specially hired musicians in order to sing such songs in chorus for hours on end with the aim of humiliating the woman in question.

Women sometimes resort to magic to try and bind a man to them. Some believe that the way to tie a man for good is by mixing some of their menstrual blood into his food or drink. It is for this reason that many men refuse all offers of food or drink in the homes of women with whom they have casual relations. Some men are obsessed by the fear of "never getting rid of such a woman" when entering into temporary visiting relationships.

That men in their turn may try to win the affections of certain women through magic is illustrated by the case of one of our informants. This man, a bonuman ${ }^{2}$ of lower-class origins, succeeded in making a lightskinned middle-class Creole girl with a secondary school education his wife. His story is as follows:

„I was carrying on my practice as bonuman when one day a wealthy lady came to see me with her mentally ill daughter, asking me to cure the girl. I succeeded in doing so and the girl became normal again after several visits. Because I wanted her for my wife I sent her a bunch of white roses which I had "treated" for her birthday. The girl promptly fell in love with me and married me. Her mother died of grief at her daughter's marrying such a poor man, who was socially unacceptable to her. A few years later, when the "potency" of the roses had worn off, she divorced me."

2 A Bonuman is a practitioner of popular medicine. He practises "white" magic. Sometimes he is at the same time Wisiman, or a practioner of and consultant on Wisi or "black" magic. 
On checking his story against the Registrar's records I discovered that this man had in fact been married to a girl of higher social rank for some three years. While I was further able to discover that his motherin-law had died shortly after her daughter's marriage. Domestic conflicts between husband and wife are sometimes imputed to a third party. It is believed that some people have the power to cause husbands and wives to drift apart through black magic (wisi). This happens when, for instance, a person manages to slip a twig of the Prati Lobi (literally: separate love) plant (Lycopódium cérnü̈m) into the house, preferably under the bed, of the couple concerned.

One further remark should be made concerning the stability of unions in the group under discussion. It is extremely difficult to give a definite "yes, lower-class Creole unions are unstable", or "no, lower-class Creole unions are stable" answer with respect to this problem. Applying a scale to the types of union found here, the following picture emerges:

stable |marriage - concubinage - visiting relationship - affair | unstable

Comparing the situation from an ethnocentric standpoint with that in the Western world it is reasonable to suppose (although we have little statistical information concerning the stability of concubinages in the Western world to go by) that unions between men and women are more unstable among the lower-class Creoles than they are among "us".

Murdock (1950, pp. 195-201), who studied the stability of marriage in forty randomly selected non-European societies in order to try and make a cross-cultural comparison of the situation in the United States with this, arrived at the conclusion that: "The cross-cultural evidence makes it abundantly clear that the modern American family is unstable in only a relative and not an absolute sense. From an absolute, that is comparative point of view, our family institution still leans quite definitely towards the stable end of the ethnographic spectrum." For of the societies studied, $40 \%$ were seen to have a lower and $60 \%$ a higher divorce rate than the United States. Evidently the lower-class Creoles of Paramaribo belong to this $60 \%$, that is to say, if we class dissolved concubinages as "divorces". (Cf. table $\mathrm{H}$, appendix 3.)

\subsubsection{Illegitimacy of Births}

Many authors have used illegitimacy figures as an indicator by which to demonstrate the "disintegration" of the West Indian family. Thus we are able to read in the Beschouwingen over den Oeconomischen en 
Financieelen toestand der Kolonie Suriname (Reflections on the Economic and Financial Position of the Colony of Surinam), for instance: "How deeply distressing the situation still is on the point of morality at the moment is indicated over-plainly by the number of illegitimate births over the past year. Of the total of 2776 births for that year, 2061, i.e. $74 \%$, were illegitimate. These figures speak volumes." (Beschouwingen 1911).

The anxious compilers of the Beschouwingen had the total population of Surinam in mind and probably derived their statistics from the Algemeen Verslag der Kolonie Suriname (General Report of the Colony of Surinam) which started publishing statistics of this nature at a fairly early stage. Thus it is apparent from the Verslag for the year 1855 (eight years before Emancipation), for instance, that illegitimacy was rampant among the "Free Population" of Surinam. Of the 352 births in this group 236 were illegitimate.

That this was of old a common phenomenon not only in the Creole lower classes but also among the ruling classes is apparent from the "Baptismal Registers" of the Reformed Dutch Church of Paramaribo. The majority of the members of this Church in the period under investigation were influential whites and free mulattoes.

Table 37. Baptisms in the Reformed Church of Paramaribo from 1845-1855

\begin{tabular}{ccc}
\hline \multirow{2}{*}{ Year } & \multicolumn{2}{c}{ Children Baptized } \\
\cline { 2 - 3 } & Legitimate & Illegitimate \\
\hline 1845 & 19 & 139 \\
1850 & 26 & 178 \\
1855 & 28 & 130 \\
\hline
\end{tabular}

The illegitimate children were probably for the greater part the progeny of Surinam-style marriages, or concubinages of whites or Mulattoes with Creole women. This pattern was maintained after Emancipation, too, both by the elite and by the freedmen making up the Creole lower class. In this latter group it has been preserved down to the present day, whereas in the upper social strata it became less prevalent after World War I, when marriage became more popular among this group.

In 1885, when Paramaribo was still almost exclusively inhabited by Creoles, the number of illegitimate births came to $78 \%$ (Schneider, 1893 , p. 174); Kruyer (1951, p. 23) reports that almost $58 \%$ of the Creole children born in Paramaribo in 1946 were born out of wedlock. 
Of the total population of my sample of lower-class Creoles, $67.3 \%$ appeared to have been born illegitimately. The following table setting out the nature of births among the three numerically most important ethnic groups in Paramaribo was compiled from the annual report of the office of the Registrar of Births, Deaths and Marriages for 1961 and 1962.

Table 38. Births in Paramaribo in 1961-1962

\begin{tabular}{|c|c|c|c|c|c|c|c|}
\hline & \multicolumn{2}{|c|}{ Creoles } & \multicolumn{2}{|c|}{ Hindustanis } & \multicolumn{3}{|c|}{ Indonesians } \\
\hline & Legitimate & Illegitimate & Legitimate & Illegitimate & Legit & imate & Illegitimate \\
\hline 1961 & $132136 \%$ & $232864 \%$ & $146680 \%$ & $387 \quad 20 \%$ & 315 & $73 \%$ & $11727 \%$ \\
\hline 1962 & $143038 \%$ & $236062 \%$ & $157281 \%$ & $368 \quad 19 \%$ & 355 & $78 \%$ & $98 \quad 22 \%$ \\
\hline
\end{tabular}

Compared with the Hindustanis and Indonesians, the percentage of illegitimate children among the Creoles ${ }^{3}$ is extremely high. To make for a better insight into these illegitimacy figures among the Creoles of Paramaribo ${ }^{4}$ the following two factors should definitely be taken into account:

(1) The Marriage Act for Asians of 1941, in consequence whereof all children born of customary law marriages between Hindustanis and Indonesians respectively are registered as legitimate in the Registers of Births, Deaths and Marriages.

(2) The fact that children born of concubinages - the common law marriage of the Creoles - are registered as illegitimate in the Registers of Births, Deaths and Marriages.

A discussion of these two factors will follow below.

\subsubsection{The Marriage Act for Asians and the Creoles}

As regards the government's regulation of their marriage system, the Asian immigrants - Hindustanis and Javanese - have made better progress than the Creoles. They have continued to conclude marriages according to their own customary law, before their own priests or other

3 By way of comparison I mention here the illegitimacy figure for Holland, which according to the statistical year book of 1968 was $2.1 \%$

4 The Creole illegitimacy figure for the whole of Surinam in 1961 and 1962 was $66 \%$ and $65 \%$ respectively. 
religious officials, in Surinam. Only very few have had marriages performed at the Registry Office. The customary law marriages of Asian groups possessed no legal force until 1st January, 1941, when the so-called Marriage Act for Asians came into operation. This Act stipulated that marriages concluded according to the Hindu or Muslim religious laws were thenceforward to be regarded as legally valid provided certain specific conditions, including registration, were fulfilled. The minimum age for such marriages was fixed at 15 for men and 13 for women, which contrasted with the minimum ages of 18 and 15 respectively prescribed for marriages performed at the Registry Office.

The promulgation of this Act met with considerable opposition in the Staten, which were Creole dominated at the time. Many Staten members believed this was flying in the face of the ideal of unity of the law in Surinam (cf. Speckmann, 1965, pp. 54-55, 120-125), and completely at variance with the assimilation policy hitherto pursued. Hence the bill was defeated - not surprisingly so - in the Staten of Surinam in March 1938 and March 1939. The Act was not promulgated until 1940, when Governor Kielstra did so on his own authority by virtue of the emergency existing as a result of the martial state declared under article 32 of the Constitution of Surinam (De Klerk, 1953, pp. 188, 189).

In Creole circles Kielstra's high-handedness in pushing through the Marriage Act for Asians is viewed as an act biased in favour of other groups over their own. People tend to wonder why a similar law has not been created with respect to concubinage, the common law marriage of the Creoles. According to this school of thought, concubinage developed from the "Alliance", which is historically the Creole's common law marriage. For it was after all sanctioned by the group through the instrumentality of the clergy of the Moravian Church.

This is a frequent subject of discussion especially in progressive Creole circles, whose efforts are directed at highlighting everything that can be at all regarded as characteristic or typical - hence also "Surinamstyle marriage". This is particularly true for the cultural and nationalistic movement Wie Eegie Sanie (Our Private Property) founded by Creole students in Amsterdam in 1950, the core of which shifted to Paramaribo in 1954 (cf. Van Renselaar, 1963, a, pp. 100-101).

In church circles, too, the marriage laws for Asians are considered biased, as it is now possible for marriages to be performed by Hindu priests and Moslem officials without any prior ceremony before a Registry Office official, whereas the clergy of Christian churches or 
rabbis are denied this right. For, as in Holland, members of the latter faiths cannot marry in church without a prior Registry Office ceremony.

What members of the Creole group object to most strongly, however, is that children born of Asian marriages are considered as legitimate by the law, whereas children born of concubinages, or Creole common law marriages, are registered as illegitimate and are only given their father's name if the latter makes a statement of recognition before an official of the Registrar's Office.

The promulgation of the Marriage Act for Asians has caused the number of illegitimate births to drop sharply for the total population of Surinam, falling from $70.8 \%$ in 1940 to $43.3 \%$ in 1945 (cf. Van Lier, 1971 , p. 287). So that if we look at the table published in a recent Jaarverslag van de Burgerlijke Stand en het Bevolkingsregister van Paramaribo (Annual Report of the Office of the Registrar of Births, Deaths and Marriages of Paramaribo) setting out the number of legitimate and that of illegitimate births per ethnic group for 1962, we see that the Creole group accounts for the lion's share of the illegitimacy figure of $44.2 \%$.

Table 39. Births in Paramaribo for 1962

\begin{tabular}{|c|c|c|c|c|c|c|}
\hline & \multicolumn{2}{|c|}{ Legitimate } & \multicolumn{2}{|c|}{ Illegitimate } & \multicolumn{2}{|c|}{ Total } \\
\hline & Absolute & $\%$ & Absolute & $\%$ & Absolute & $\%$ \\
\hline Europeans & 82 & 97.6 & 2 & 2.4 & 84 & 100.0 \\
\hline Creoles & 1,430 & 37.7 & 2,360 & 62.3 & 3,790 & 100.0 \\
\hline Hindustanis & 1,572 & 81.0 & 368 & 19.0 & 1,940 & 100.0 \\
\hline Indonesians & 355 & 78.4 & 98 & 21.6 & 453 & 100.0 \\
\hline Chinese & 148 & 89.2 & 18 & 10.8 & 166 & 100.0 \\
\hline Others & 9 & 100.0 & - & - & 9 & 100.0 \\
\hline Total & 3,596 & 55.8 & 2,846 & 44.2 & 6,442 & 100.0 \\
\hline
\end{tabular}

Of the 2846 illegitimate births, $2360(83 \%)$ were within the Creole group. However, not all of these children grow up without a father to look after them, as will be shown below.

\subsubsection{Aspects of Illegitimacy among the Lower-class Creoles}

As was discussed above, not only children born of civil marriages, but also those born of marriages performed by a Hindu priest or Moslem religious official are legitimate in Surinam. 
As regards the latter point, the Creoles are placed at an utter disadvantage vis-à-vis their Hindustani and Javanese compatriots, whose customary law the lawgiver has not ignored, incorporating their laws on marriage into the law of Surinam. This has not been done in the case of the Creoles. Neither the government, the churches, the Creole elite nor, more recently, Creole leaders have given any consideration to the "typical" lower-class Creole form of marriage, or concubinage, which formerly enjoyed church sanction under the term "alliance" for many years. The authorities have concentrated blindly since Emancipation on integrating the lower-class Creoles into the "Western"-type culture, and have thereby forced the legal system of the white colonists and the lighter-skinned Creole elite onto them. This attempt has been only partially successful, however, the Creole still living for the greater part within the context of his own distinctive culture, the pattern of the norms and values of which definitely differs from the more Western orientated type of culture of the ruling classes.

The system of norms and values of the Creole lower-class subculture, which also regulates relations between the sexes, evolved on the plantations during the period of slavery. It has survived down to the present day, particularly in Creole agrarian communities of the type found in Coronie and Para. In these kinds of community relations between the sexes are regulated by social control. Any man abandoning his wife or children lays himself open to severe criticism and ostracism, especially on the part of the female members of such a community. In Paramaribo town, where social relations have become subject to the effects of commercialism, also among the lower-class Creoles, since World War II, this social control has mostly disappeared. As a result of the population increase the individual has become much more anonymous and it has become easier than ever before for men to shirk their responsibilities with regard to wives and children, among other reasons because it has become extremely easy to go to Holland. Only in certain older quarters of Paramaribo, such as the "Land van Van Dijk" district, is social control still strong, particularly among the older generation.

This vacuum has so far not been filled in by the law in Surinam, which lacks the necessary sanctions to force fathers of illegitimate children to support these. Though it is possible for the mother of a child by a man who refuses to provide for it to try via the Child Welfare Department and by securing an order of the court to get the father to pay a certain monthly allowance for the child, this is by no means an easy course for her to follow, as there are only two such Departments in 
the whole of Surinam, one in Paramaribo and one in Nickerie. The jurisdiction of that in Nieuw Nickerie extends over the entire district of Nickerie, and that of the one in Paramaribo over all the other districts.

The Department's duties include the supervision of all minors entrusted to its guardianship by order of the court as well as those committed to its care by the Attorney General (cf. clause $382 \mathrm{~b}$. of the Civil Law Code of Surinam). The Department further sees to it that all funds paid to it by persons with court injunctions to pay allowances for their children's upkeep and education are properly administered. These funds comprise mainly allowances which men are ordered to pay to the mothers of their illegitimate children. This latter has become virtually the Department's principal task in view of the large numbers of such cases, so that it seems to have degenerated into a kind of collecting office.

During the period of research the Department had the supervision of approximately 12,000 such cases in Paramaribo alone, half of which were still before a court. The Department was behind with its work because of shortage of staff, lack of funds and inadequate accommodation. The majority of the cases, both those already settled and those still awaiting a court decision, concerned Creoles, and only a small percentage Hindustanis, while only a fraction of the Javanese population had referred cases to the Department.

It became apparent from an interview I had with the Department's Secretary as well as from interviews with a number of lower-class Creoles that although most women were aware of the possibility of obtaining a court injunction through the intermediary of the Child Welfare Department against the fathers of their children to pay them an allowance, many of them refrained from doing so. The reason why they fail to approach the Department is that the latter is known to be sluggish in the handling of cases. They are aware that there is a long waiting-time before one is able to have one's case dealt with by the Department. Most women cannot afford such long periods of waiting, because they are for the greater part obliged to go to work in order to be able to support their children. Moreover, most women also realize that the monthly allowance the court is likely to award them for each child is a very paltry sum, varying from 25 Surinam florins to less than five. The usual amount allocated is Sfl. 10. They do not consider this sum worth all the trouble and effort, while moreover it of ten remains to be seen whether the allowance will in fact be paid, because there is no way of forcing 
a man who is out of work to pay up. A further reason why women may refrain from going to the Department is that their husbands may threaten to "give up their job" or to get a job in which it will be impossible to keep a check on their income. In some cases a man may also threaten to do the woman in question harm by using physical force or black magic, or Wisi. Many women feel humiliated after a trip to the Department as a result of the fact that in the interviews to which they are forced to submit there they have to answer questions they feel to be indiscreet, such as where, when and under what circumstances the child was conceived.

Even where a court injunction for the payment of an allowance through the Child Welfare Department has been imposed, many men evade regular payment of the amount in question. In order to provide for legal prosecution of defaulters two new clauses were added to the Surinam Criminal Code in 1957, according to the first of which:

"Any male person sentenced by an irreversible verdict of a court of law to payment of alimony to another person or of an allowance for the support and education of a minor, who deliberately fails to comply with this wholly or in part for a period of at least two months shall be punishable with a maximum term of imprisonment of one year or a maximum money fine of 1000 florins." (Clause 314a).

It was not until eight years later, in August 1965, that a judgement under this article was pronounced for the first time in Surinam, namely by the District Judge of the Third District. Hereby a man who had failed to pay an allowance of fl, 4.-- a week per child to the Child Welfare Department for the support and education of two minors was sentenced to two months' imprisonment and three years' probation, in addition to a money fine of fl. 25. - commutable to ten days' confinement in case of failure to pay. The only possible effect of this verdict will probably be that Child Welfare Department actions for payment of alimony may be taken somewhat more seriously by fathers of illegitimate children in future.

We should be careful not to jump to the conclusion, however, that all lower-class Creole children registered as illegitimate in the Registers of Births, Deaths and Marriages are abandoned by their fathers. My observations showed $67.3 \%$ of the sample population to have been born out of wedlock. Now, if one were to use this figure for demonstrating the enormous degree of disintegration of the family life, one would run the risk of drawing a false conclusion from this. A large percentage of the people born thus out of wedlock is socially accepted. This is 
particularly the case where a child is born of a concubinage, which, as we saw above, is a socially sanctioned form of union between men and women. A child born of such a union definitely does possess a father who contributes financially to his upbringing. The latter is usually not the case where a child is born as a result of a casual affair, however. Children whose fathers reject their paternal role are mostly the issue of affairs which young women still living in with their parents or female heads of households without a legal or common law husband may have with men who are unable to set up a household of their own or who intentionally desert the woman in question as soon as she becomes pregnant. Many children born of common law marriages are recognized by their fathers before the Registrar of Births, Deaths and Marriages (cf. table $\mathrm{K}$, appendix 3 , household type $\mathrm{B}$, male head with common law wife). The fathers of children born of casual affairs usually fail to legitimate them, however, except where they plan to marry the mother of the child or enter into a common law marriage with her. Hence the illegitimacy figure assumes a different dimension if one distinguishes the illegitimate into those legitimated and those not legitimated by their fathers.

Table 40. Table showing the Nature of Births among the Sample Population

\begin{tabular}{ll}
\hline Legitimately born & $32.7 \%$ \\
Illegitimately born but legitimated by the father & $38.8 \%$ \\
Illegitimately born and not legitimated by the father $\begin{array}{r}28.5 \% \\
\text { Total }\end{array}$ & $100.0 \% \quad(\mathrm{n}=2827)$ \\
\hline
\end{tabular}

Generally speaking, the $38.8 \%$ of illegitimate children legitimated by their fathers are persons born of common law marriages. They have been born into families with a mother and a father to look after them. The only difference between them and legitimate children is that their parents are not married before the law. Such persons enjoy only slightly less social prestige than the legitimate.

Of lower social status are the $28.5 \%$ illegitimately born not legitimated by their fathers, among other reasons because they bear their mother's family name. They are mostly persons born into families where the fathers are not living in and for the greater part reject their paternal role. In most cases these men give the mothers of the children in question no regular financial support except where there is a regular visiting relationship between them. 
The percentage of 28.5 of illegitimately born persons not legitimated by their fathers gives a more accurate picture of the actual illegitimacy, or in other words, of the number of children without fathers to share the responsibility of bringing them up with their mothers. (A small percentage of the mothers of such children may receive irregular financial assistance from the children's fathers.) Though the above percentage is still of course high, one should bear in mind that a fatherless child here is not at as great a social disadvantage as illegitimate children in the Western world. They may be at an economic disadvantage, but are by no means exceptional cases. The circumstance that a person does not bear his father's name is considered "normal", and is something to which one gives no further attention. Only persons climbing to higher social positions may sometimes experience some slight disadvantage from being illegitimate. Thus one Creole woman who had become a teacher stated herself to have apprehended public exposure of the fact that she was an illegitimate and unlegitimated child in the course of the reading out of the marriage certificate when she was about to be married.

\subsection{The Structure of Households}

After our discussion of the alternative unions between men and women and their implications, I now wish to give attention to the structure of the different types of household found in Paramaribo. This is all the more important since the lower-class Creole household constitutes the principal social unit, based on kinship, within which people's most basic needs, such as eating, sleeping and social contact, are satisfied for the greater part. In a measure the household constitutes the chief reference group for the individual as a result of this.

The lower-class Creole household is primarily a kinship group which includes only few non-relatives. Of the members of households consisting of more than one member, only $2.1 \%$ were seen to be non-relatives (Table I, Appendix 3, categories 69 and 70).

The lower-class Creole's kinship terminology is simple, with little differentiation. The 64 kinship terms listed in Table I, Appendix 3, are not for the greater part used by the lower-class Creoles themselves, but have been summarized by myself for the purpose of analysis of the composition of households. As in the Western world, the number of terms actually used in day to day life is small. The most common ones are: father, mother, foster-father, foster-mother, son, daughter, stepson, stepdaughter, brother, sister, grandfather, grandmother, uncle, aunt, 
cousin (male and female), son-in-law, daughter-in-law, brother-in-law, and sister-in-law. Most old women are respectfully addressed as "grandmother", even by people other than their actual grandchildren. Nonrelated friends of ego's parents may also sometimes be addressed as "aunt" and "uncle". (See also Pierce, 1971, pp. 78-105.)

There is no unit organized on the basis of kinship operative over and above the social unit of the household. Mutual relations between households are determined by kinship to only a slight degree and are based for the greater part on friendship or neighbourhood ties. That is not to say, however, that the persons regarded as relatives by the lower-class Creole must necessarily be members of his household. Those regarded as relatives are siblings, parents and grandparents as well as their descendants insofar as one is acquainted with them. The latter is usually not the case with paternal kin. With these one is usually unacquainted because the relationship between one's father and mother is often of short duration, so that as a result one does not bear one's father's family name unless one is born of a marriage or has been legitimated by one's father. Hence the persons one most looks to as one's next of kin are as a rule one's matrilineal relatives, acquaintance with whom does not usually extend beyond the sixth degree, however.

For the discussion of the problems in connection with the household the following plan would seem to me most feasible. First a summary will be given of the different types of household found in Paramaribo, with special attention being given to their composition. Here we shall also discuss what kind of person acts as head, what kinds of person are members of the different types, how many members each of the different types comprises, and how many generations they embrace. After that I shall go into the economic factors affecting the structure of the household. Subsequently the different types will be compared with each other, and following this we shall try to determine whether they constitute part of a cycle or should be considered as mutually independent.

\subsubsection{The Prevalent Types of Household}

In sections 3.2. and 7.2.1. I indicated what I took the concept "household" to mean and who should be considered the head and who the members of a household. The concept of "head of household" is used not as a juridical but as a sociological term in the present study. The head of a household is the man or woman acknowledged as such by the other members on the basis of actual relations within the household. 
The following types of household were distinguished on this basis as well as on that of the type of relationship, which we summarize once more here for convenience sake:
A male head with legal wife
B male head with common law wife
C male head without legal or common law wife
D single man
E female head with legal husband
F female head with common law husband
G female head without legal or common law husband
$\mathrm{H}$ single woman.

The distribution of the different types of household (mostly indicated both in the text and the tables simply by the relevant letters) is shown in Table B, Appendix 3, while Table R, Appendix 3, sets out which persons of the sample population over the age of 26 are heads or otherwise of households. I shall now first discuss the structure of the different types individually, after which their mutual connectedness and the problem of the authority of the different types of head of household will be discussed.

\subsubsection{Type A: Male Head with Legal Wife}

This is the most prevalent type among the male-headed households (coming to $51.4 \%$, cf. table B, appendix 3). Not much more need be said about the way in which this type is realized, as I have already discussed this at length in the description of marriage and concubinage. The type under discussion here comes about as a result either of a man and woman not previously living together concluding a marriage, or of a man and woman previously living in concubinage converting this union into a legal marriage in which the husband acts as head. Of the 152 married couples sharing the same domicile, 151 were seen to belong to type A, where the husband is the head of the household. Table J, appendix 3 , shows that the majority of this type $(69.5 \%)$ comprises two generations, mostly parents and children. As table I, appendix 3 , shows, these children are for the greater part the offspring of the head and his spouse. There are few children of previous unions of the head found in this category (categories 16 and 17 of table I, appendix 3). They make up $0.6 \%$ of the total number of members of this type of household. Table $\mathrm{K}$, appendix 3 , illustrates that the majority of the children 
of the head and his partner are legitimate. The illegitimate, born prior to the marriage, are for the greater part legitimated. It is further apparent from table J, appendix 3, that $25.2 \%$ of this type embraces three generations, and $2.0 \%$ even four generations. This latter is a consequence of the fact that this type may include both parents, children and grandchildren of the head. Most of the latter are children of daughters living in with their fathers (table $\mathrm{I}$, appendix 3 , categories 43 and 45), the majority of whom are illegitimate. Only a small proportion of these illegitimate children are recognized by their fathers (table $\mathrm{K}$, appendix 3). Children of sons living in (table I, appendix 3, categories 39 and 41) are found only sporadically. Eight of the thirteen non-related members (table I, appendix 3, categories 69 and 70) are foster-children or de facto adopted children; all eight are younger than 15. As regards parents living in with their children, the majority are seen to be mothers of the head or of his wife (table I, appendix 3, categories 56 and 58). Only two fathers of wives are found in this type of household (table I, appendix 3, category 57). The average number of members of this type of household is 6.5 (table $\mathrm{L}$, appendix 3 ).

\subsubsection{Type B: Male Head with Common Law Wife}

This type is less frequent than the above among the male-headed households ( $35 \%$, cf. table B, appendix 3). Of the 117 household heads living in concubinage, 103 were males. The type discussed here is structurally very much akin to that dealt with above. It results where a man and a woman go and live together without entering into legal marriage and where the male partner acts as head.

Table J, appendix 3, shows that the majority of this type (68.9\%) comprises two generations.

It is apparent from table I, appendix 3 (categories 16-19) that these households include a large number of children not by the head and his common law wife together. Especially the number of children brought into the household by the female partner is considerable, comprising $11.2 \%$ of the total number of members of this kind of household group (table I, appendix 3, categories 18 and 19). Comparing this percentage with that of such children in the above type of household $(2.9 \%$, table I, appendix 3, categories 18 and 19), this suggests that men are more inclined to live in concubinage than marry with women with children of previous unions.

It is apparent from table $\mathrm{K}$, appendix 3 , that the children of the 
head and his common law wife are - naturally - all illegitimate. It is similarly obvious from this table that $229(88 \%)$ of these children have been legitimated by their father and hence bear his name. The fact that a substantial percentage of this type of household $(17.5 \%)$ comprises more than two generations (table J, appendix 3) stems to a fairly high degree from the circumstance that this type of household includes the children of children of the head and his common law wife or of either one of them (table I, appendix 3, categories 39-50).

Resident parents are infrequent in this type, as in the preceding type (male head with legal wife). They are mostly mothers of the head or his common law wife. Only one father of the head (table I, appendix 3, category 55) was found to be living in with this type.

Non-related members, including foster-children (table I, appendix 3, categories 69-70) are infrequent - we discovered only two. People indulge less frequently in the luxury of adopting an extra child in this type of household, as this is on the whole less prosperous than the type discussed above, which we did see to include a large number of fosterchildren (cf. table I, appendix 3, categories 69 and 70).

The average number of persons making up this type of household is smaller than in the case of the preceding type, coming to 5.7 (table $\mathrm{L}$, appendix 3). This is probably due to the fact that the households in question are "younger", thus counting fewer children than the preceding type.

\subsubsection{Type C: Male Head without Legal or Common Law Wife}

This type is fairly infrequent among the male-headed households $(6.1 \%)$. The type results chiefly from the desertion or death of the female partner, as is apparent from the table below.

Table 41. Marital Status of Heads of Households of Type C

$\begin{array}{lr}\text { Married, not coresiding with wife } & 1 \\ \text { Divorced } & 3 \\ \text { Widower } & 5 \\ \text { Deserted by common law wife } & 3 \\ \text { Widower of common law wife } & 3 \\ \text { Unmarried } & 3 \\ \text { Total } & 18\end{array}$

It may also result from two friends, mostly young men, going to live together (cf. table I, appendix 3, category 69). Young men with an 
income of their own usually leave their parents' household to rent a dwelling together with a friend "so as to be free". I have the impression that they are under-represented in the sample because these independent young men are more negligent than any of the members of the other types of household about having their households registered in the civil registers. We see a large number of sisters (table I, appendix 3, category 6) of the head living in with this type. They run the house for their brothers, looking after any children who may have remained with the latter. This latter role may also be filled by the mother of the head (category 56). As is apparent from table I, appendix 3, categories 14 and 15, there are thirteen sons and only four daughters living in in this type of household. Evidently men are more inclined to take their sons than their daughters with them on separating from their partners. The average number of persons living together in this type of household is 3.9 (table L, appendix 3).

\subsubsection{Type D: the Single Man}

In our survey $7.5 \%$ of the male heads of households were seen to be living by themselves (table $\mathrm{B}$, appendix 3 ). Of the 22 men in question, three appeared to be widowers, one married but separated from his wife, and 18 unmarried, including eight living by themselves because the concubinage in which they had been living had been terminated through either the desertion or death of their partners.

\subsubsection{Type E: the Female Head with Legal Husband}

The female heads of households include only one of this type (i.e., $0.4 \%$, cf. table $\mathrm{B}$, appendix 3 ). The woman in question belongs to the 76-80 age-group, and is looking after her invalid husband. Their daughter is living in with them with her three children. This daughter earns the family income, but did not appear to be the head of the household, as her mother considered herself the "owner" of the house, since her invalid husband had had its ownership transferred to her (without having a notarially executed deed drawn up to this effect, for the rest).

\subsubsection{Type F: Female Head with Common Law Husband}

This type (cf. table B, appendix 3) makes up $6.3 \%$ of the femaleheaded households. It may come about in two different ways, viz.: 
(1) where a man and woman go and live together without being legally married, with the female partner acting as head; and

(2) where in the type of household headed by a male with a common law wife the male partner loses or resigns the management of the household to his concubine for any number of reasons (unemployment, invalidity, marginality or psychological condition).

In this type we come across 27 children of the head and her partner, and 23 of the head alone (table I, appendix 3, categories 14-17). What strikes us here is that we find no children of the male partner alone in this category (table $\mathrm{I}$, appendix 3, categories 18 and 19). The average number of members of this type is 7.2.

\subsubsection{Type G: Female Head without Legal or Common Law Husband}

This type constitutes $78.1 \%$ of the category of female-headed households and $33.7 \%$ of the total number of households studied (cf. table B, appendix 3). It is the type of household that has attracted most attention in investigations into the family life of the Negro of the New World.

This type evolves in two different ways, viz.:

(1) where the partners of a marriage or concubinage separate through legal divorce, desertion or the death of the male partner; and

(2) where a woman with children who has hitherto remained a member of her parents' household settles independently in a residential unit without a legal or common law husband.

In order to give the reader some idea of how this type may come about I relate below the histories of three households of this type.

(1) The informant G. L. (35 years old, a domestic servant by occupation) is living in, together with her son C. H. (aged 14) and her daughters M. V. (12) and E. D. (10), with her sister J. L. and her son J. L. (3 years old) in a one-room dwelling with a kitchen and attic. At the age of 19, when still living in her parents' home and making a living as housemaid, G. L. became pregnant by the carpenter G. H., who was two years her senior. She gave birth to their child in her parents' home. The child was legitimated by the father. Plans were made for setting up house together, but the informant's father was opposed to a marriage between them as there were religious differences between the two, G. L. coming from a Moravian background (her parents had 
entered into an "Alliance"), while G. H. was a Roman Catholic. In order to try and find out "whether it would work" the partners went to live in concubinage in a rented dwelling some months after the baby's birth. This union broke down two years later as a result of the intrigues of the husband's elder sisters. For these sisters would constantly borrow money from their brother without ever paying him back. This situation gave rise to major conflicts between husband and wife, so that as a result the husband left the conjugal home and moved back in with his mother and sisters. Following this, the informant became the girl-friend of the skilled labourer W. V., a man who was living in concubinage and making a good living, and who regularly visited her and gave her money. Of this relationship her daughter M. V. was born, who was legitimated by her father. Because the latter had more girl-friends besides our informant - according to her three other women were pregnant by him at the same time -- quarrels arose between the partners, so that the visiting relationship was terminated. Some time later G. L. had another short visiting relationship with K. M. D., a timber-feller who spent the greater part of the year away in the bush. Of this relationship the child E. M. D. was born, who was similarly legitimated by her father. The relationship was broken off because the man sent no news of himself whatever after a trip into the bush lasting several months.

None of the three men is paying any allowance for the child fathered by him. G. L.'s sister J. L. has a young son who has not been legitimated by his father J. P. L. She and her son sleep in the attic. The informant sleeps down-stairs in a part of the lower-floor room that is screened off at night from the part in which her children sleep. When she goes to work her sister, who has been looking for a job for years, looks after the house and minds the children. Apart from her wages as a domestic servant the informant receives a monthly food parcel from her mother and from the poor relief fund of the Social Services Department.

(2) The 21-year-old informant Y. G. is living together with her four-year-old son S. G. and her two daughters L. G. (2) and C. G. (8 months). She had her first child when she was 17 and was still living with her grandmother. The father of the child was 23 years her senior. According to her he raped her on a building-site on the outskirts of Paramaribo. Half a year after the birth of her baby she set up house on her own in a tiny dwelling in her grandmother's yard, for which she pays a nominal rent of 2.50, and sometimes 5 Surinam florins. Here she met a man who left for Holland when she was two months' pregnant by him. Of this affair - a visiting relationship - L. G. was born. Next 
she became friendly with a married man who left his family for a year on her account and moved in with Y. G. This one-year concubinage, of which C. G. was born (it was impossible for her to be legitimated as her father was already married) was converted into a visiting relationship when the man went back to live with his wife. He still supports the informant irregularly by giving her "money for the child" or paying her for sexual favours.

(3) The 36-years-old informant J. D., who is head of a household, lives with her ten children, a younger brother (of 27) and her mother in a yard dwelling consisting of two rooms (one of 3 by 4 metres, and the other 2 by 3 metres) and an attic. Her two eldest children, twins, were fathered by a Chinese when she was still living at home with her mother. This man vanished into thin air as soon as he found out she was pregnant. When she was about 16 she went to live in concubinage with a man by whom she had three children. She said she left this man on discovering that he was suffering from a serious illness and was turning invalid. Of the visiting relationship she thereupon had she had another five children. This relationship is proving stable, the man paying her fl. 28. - a week. The woman herself earns a living as cook with a family she has served for years, where she is paid good wages (S.fl. 120 a month). She is supporting her unemployed brother and her mother. The latter has been living in with her for five years.

\subsubsection{Type H: the Single Woman}

This type comprises $6.6 \%$ of the female-headed households. The majority are elderly women (table $\mathrm{B}$, appendix 3 ). Of these, $85.3 \%$ are over the age of 56 (cf. table $\mathrm{M}$, appendix 3 ). Of the 34 women belonging to this type seven appeared to be widows, one a divorcee, and one a married woman who had separated from her husband. The remaining 25 were unmarried. They included common law widows and deserted common law wives. The life of these women is generally extremely hard in a country where contributions from the children or from the poor relief fund constitute the only old-age benefits. Hence these women as a rule live in dire poverty.

\subsubsection{The Inter-connectedness of the Different Household Types}

In the initial stages of the research into the West Indian family the prevalent household types were approached primarily from a static 
perspective. Simey's (1947) and Henriques' (1953) pioneering work, for instance, was restricted to the classification of the types of household and types of man-woman relationship found. Only in Raymond Smith's work (1956) on the Guyanese rural Negro family was attention given for the first time to the fact that the existing household types should be regarded not as isolated, independent types, but rather as phases in a developmental cycle. This approach has led to a deeper insight into the effects of the various circumstances and forces in the society at large reflected in the structure and functioning of the family.

The developmental cycle distinguished by Smith consists of different phases, each phase evolving from a preceding one, to develop into a succeeding one in its turn, all in a fixed sequence. Each phase represents an organizational form of the household type at a particular point of the cycle. This organizational form of the household in a particular phase, as well as how and why the various phases are subject to transmutation, are products of the interaction between certain forces generated by both the organizational form of the household at a particular phase and the organization of the total society of which the household of that particular phase constitutes part at that particular moment.

In the following paragraphs I shall compare the mechanism described by Raymond Smith (1956, pp. 108-141) with respect to the rural Negro family of Guyana (where, it goes without saying, different variables are operative from those in an urban setting) with the situation in Paramaribo (a Guianese urban area). Such a comparison seems feasible to me since Guyana and Surinam are neighbours displaying marked cultural affinities.

\subsubsection{Smith's Cycle Theory}

The theory developed by Raymond Smith may be summarized as follows. According to him most lower-class Negroid youths and girls have sexual relations out of which parenthood without coresidence with the partner concerned ensues when still living with their family of orientation.

The first phase opens with the young woman leaving her household of orientation and setting up a new household with the father of her children in either (sometimes, but not always) a marriage or a concubinage. In this phase she is extremely dependent on her partner and subjected to his authority because she is economically dependent on him by reason of the fact that she has young children, preventing her from going out to work. Some women take their children with them from 
their household of orientation, others don't. The latter is especially the case where the man with whom she sets up a household is not the father of these children. These children of previous relationships are then brought up by their grandmother.

The second phase begins where the woman takes over as head of the household in consequence of her partner's desertion or death, or of his inability or refusal to contribute sufficiently towards the household's financial upkeep. In this phase the woman is the de facto head in her status as mother. The husband-father, although he is the de jure head - provided, that is to say, he is still present -- occupies a marginal position in the complex of internal relations within the household. The household is kept going financially by the woman's going out to work, while her children may also begin to earn an income part of which they hand over to their mother.

The children of such households in their turn have sexual relations with partners with whom they do not coreside. The offspring of such relations in their turn come to form part of their mother's household of orientation. As soon as the daughter leaves the household, with or without her children, to settle independently with a man, the cycle commences anew.

The matrifocality of the second phase is explained by Smith from the father's marginal role in the domestic group. He says: "In the lowest status group the only basis for male authority in the household unit is the husband-father's contribution to the economic foundation of the group, and where there is both insecurity in jobs where males are concerned, and opportunities for women to engage in money-making activities, including farming, then there is likely to develop a situation where men's roles are structurally marginal in the complex of domestic relations. Concomitantly, the status of women as mothers is enhanced and the natural importance of the mother role left unimpeded." (R. Smith, 1956, pp. 227-228).

Smith establishes a link here between the organization of society at large and the organization of the household. There is a correlation between the nature of the husband-father role and men's roles in the economic system and the system of social stratification (which is determined by colour and class) in the total society of Guyana.

I shall now endeavour to discover how relevant Smith's theory is to the situation obtaining in Paramaribo by investigating whether the cycle described by him is found there and what social forces determining the functioning of the cycle operate in Paramaribo. 


\subsubsection{The First Phase of the Household}

Of the household types described above, A and B (i.e., male head with legal spouse and male head with common law wife respectively) are the types in which the first phase of the developmental cycle should be studied. In these types the husband is classifiable as the head as he makes the principal economic contribution to the household's survival.

In these types of household women in Paramaribo - as in rural Guyana, though not to an equally high degree (Smith, 1956, pp. 75, $112,113)$ - are tied to the house and dependent on men. As an urban environment offers women all kinds of opportunities to engage in moneymaking activities they are less dependent on men here than in rural areas. There have of old been large numbers of washerwomen, charwomen, seamstresses and female market-stall keepers in Paramaribo. I was able to discover traces of an ideal pattern of the kind found in Guyana, whereby the husband is solely responsible for the household's economic upkeep, only in the case of households based on marriage. Married women may go to work only in "the better kinds" of jobs (section 8.2.1.3.), whereas concubines may do almost any kind of work.

Hence the number of wage-earning women was found to be considerable. Of the 151 wives from type $\mathrm{A}$ seventeen (i.e., $11 \%$ ), and of the 103 concubines from type B 21 (20\%) were seen to be following some kind of occupation. These percentages might be higher still if we took into consideration the fact that a proportion of the women was looking for work. Many women go to work to earn an income quite soon after establishing a household, while a number even keep the job they had or occupation they pursued before entering into marriage or concubinage.

As there are two crèches in Paramaribo women are able to have quite young infants looked after by other women for part of the day against payment of a nominal fee; in this respect they have become less dependent on female relatives and friends. It is quite common still for a mother, sister or elder daughter to mind the children, however.

Although the wages earnt by women are reasonable, they are mostly lower than those of their husbands, so that the balance of authority in the household tips in favour of men, even in the case of working women, as men are the principal contributors to the household's economic survival. It is the husband whose voice is decisive in important matters, such as choosing a place for the family to live, deciding who may be invited to come inside the home, what purchases to make, and so on. 
Despite the women's dependence, most households can be characterized as latently matrifocal in this phase. Women play a key role as regards internal relations and other internal domestic affairs (cf. section 1.3.2.). This is mostly a consequence of the fact that men are often absent for reasons of work and spend their spare time for the greater part out of the house. Many men come home only to eat and sleep, in fact. It is not customary for husbands to take out their wives, because, as they maintain, the latter are supposed to look after the children. The real reason, however, is that a man is usually made fun of by his friends, with whom he retains close contact after marriage or concubinage, for taking his wife out to places where men gather to drink (usually Chinese-owned shops). The fact that men may spend their spare time with other women also encourages this tendency. As in Guyana (R. Smith, 1956, p. 114), women are seldom unfaithful, on the other hand, except if their partners stay away for long periods of time and stop sending them money. Another factor causing most men to be away from home much of the time would seem to be the overcrowded conditions in most houses, so that these seldom provide a congenial atmosphere for relaxation after work. The situation in Paramaribo very much resembles that described by Raymond Smith for rural Guyana on the point of male behaviour. He says: "They (men) rarely play with their children, and they spend a considerable portion of their time outside the home in the company of other men. There are no tasks allotted to a man in his role as husband-father beyond seeing that the house is kept in good repair, and providing food and clothing for his spouse and the children." (R. Smith, 1956, p. 113).

In view of this situation women are for the most part the key figures in the household. It is the woman who has the closest ties with the children, and not the man. Men are nevertheless led to believe that they are the head of the household. They are submissively welcomed by their wives on coming home. They hardly speak to the latter except to give them orders to bring in something to eat or drink, or the newspaper, for example; they are served their meals, which they usually enjoy at a separate table by themselves, with their wives waiting on them; and the quality of the food for men is often better than that for the other members of the household. The children - usually not only the husband's children - are expected to behave respectfully and not make any noise when the man is at home. When reprimanded by their father they must answer him with cast down eyes. He seldom plays with them. After eating his meal he usually goes out without saying where 
he is going or when he will be back. The domestic situation in this phase has been represented as follows in the figure below.

Figure 1. Household Type A or B, The latently matrifocal Household
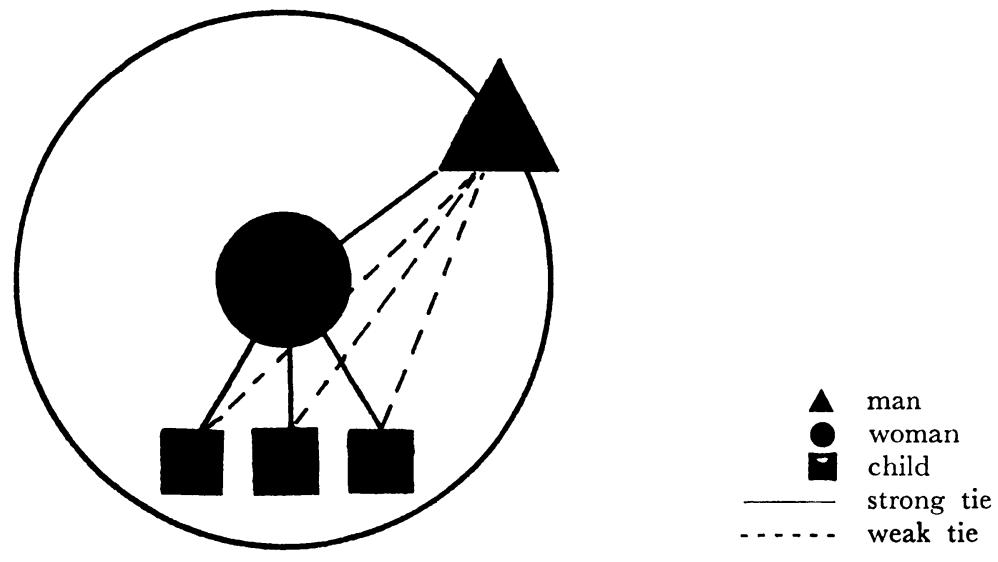

Here the husband's position is only partly inside the household (represented by the circle), while that of the wife is central. The broken lines indicate that his ties with the children are weak, in contrast to those of the wife, which are strong (continuous line). It goes without saying that there are also some fathers who have a strong tie with their children. The tie between husband and wife is still strong because the wife is economically dependent on the husband and because there is in many cases a close sexual tie and/or strong affection between them. We are able to see that apart from the husband, wife and children, other persons as well may join households of the types A and B (cf. table I, appendix 3). The mother or a sister of the wife's may move in with them, which, as we shall see below, will make it easier for the wife to become more independent of her husband.

This phase may continue for a long period of time. As table M, appendix 3, shows, there are a large number of men in the older agegroups still heading households of types A and B.

The household may also undergo a different sort of development, however. Because of the shorter life expectancy of men and the instability of relationships, the woman of ten comes to occupy the position of head of the household quite early on, either in type $F$, female head with common law husband, or $\mathrm{G}$, female head without legal or common law husband. I have left type $\mathrm{E}$, female head with husband, of which there 
is only a single instance in our sample, out of further consideration. Type G, the most prevalent one, in fact develops for the greater part from households the husband of which has been lost either through death or desertion. If such desertion has been occasioned by instability of the relations between the partners, most female heads belonging to type $\mathrm{G}$ will have behind them a period of conflict with their ex-partner, the former male head. In this transitional phase between types A and B on the one hand and $\mathrm{G}$ on the other we are able to observe the phenomenon of the husband's increasing marginality in the household, for which virtually always the fact that he is unable to earn an income as a result of unemployment is responsible. The children, including those who have reached or are approaching adulthood, usually take their mother's side in the ensuing conflict. The father is seldom home, and is only just tangent to the circle representing the household (see figure 2).

Figure 2. The Household in the Period of Transition from Types $A$ or $B$ to Type G
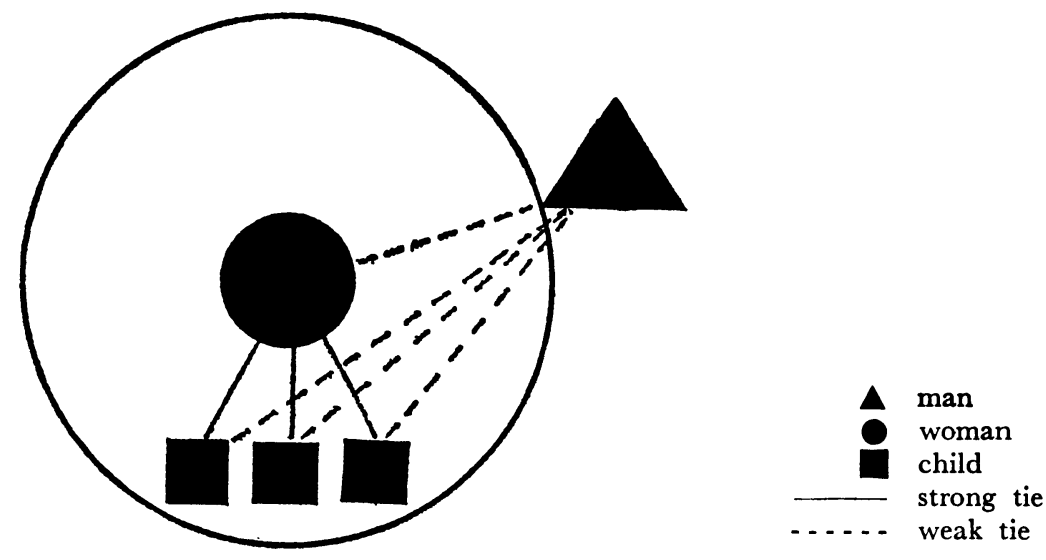

His ties with each of the members, this time also including the wife, are weak. It is exceptionally difficult to determine whether the husband or the wife is the head in this transitional situation; the household is almost manifestly matrifocal, as the wife, apart from occupying the central position within the household, is obliged to manage all its external affairs as well. She often finds herself constrained to go out to work during this transitional phase because the husband has stopped giving her money, either because he is unable or unwilling to. Women are usually in a position to go to work because they receive help from 
relatives from their matrilineal kinship group (sisters and mothers). The latter are sometimes already a member of the household, or become one after the husband's definitive departure (cf. table I, appendix 3, categories 8 and 58 for types $A$ and B; categories 6 and 56 for type G). In the transitional phase from types $\mathrm{A}$ and $\mathrm{B}$ to $\mathrm{G}$ the husband is sometimes seen to be living no longer in the same house, but in some small building in the vicinity of the house.

In both this initial phase of the development of the household and the transitional phase we see daughters still living in give birth to children by men with whom they have as yet no permanent relationship.

Types $A$ and $B$ in this phase may also be transformed into types $\mathrm{C}$ or $\mathrm{D}$ (male head without legal or common law wife) as a result of the death of the wife or her desertion of the household.

\subsubsection{The Second Phase of the Household}

In this phase the household is manifestly matrifocal, or in other words, the mother is the person who controls both the internal and external affairs of the household. It is household types $\mathrm{E}$, female head with legal husband, F, female head with common law husband, and G, female head without legal or common law husband, which should be studied in this phase of the developmental cycle. Single women (type H) also have some connection with it.

Although the female heads are mostly women past their menopause both in Paramaribo and in the situation described by Smith (R. Smith, 1956 , p. 65), the percentage of women under 45 who are heads of households is significantly higher in Paramaribo than in the villages described by Smith.

Table 42. Female Heads of Households grouped according to Age

\begin{tabular}{llll}
\hline & \multicolumn{2}{c}{ Age } & \\
\cline { 2 - 3 } & -45 & $45+$ & \\
\hline Paramaribo & $28 \%$ & $72 \%$ & $(\mathrm{n}=224)$ \\
August Town & $22 \%$ & $78 \%$ & $(\mathrm{n}=108)$ \\
Perseverance & $16 \%$ & $84 \%$ & $(\mathrm{n}=18)$ \\
Better Hope & $13 \%$ & $87 \%$ & $(\mathrm{n}=30)$ \\
\hline
\end{tabular}

N.B. Including single women.

Cf. R. Smith, 1956, p. 63, and table M, appendix 3, of the present book. 
The factor responsible for this is probably the lower stability of relationships between men and women in Paramaribo than in the rural areas described by Smith. This is causing a higher number of marriages and concubinages to break up and forcing more women to set up house on their own direct from their household of orientation without living together with a man first. Also the fact that men die younger than women (table A, appendix 3 ) results in many elderly women becoming heads of households.

Of the female heads of households comprising more than one person, 190 in all, 15 turned out to have a partner living with them. There was only one woman acting as head of a household of this type which was based on marriage (type E), while fourteen were heads of households based on concubinage. This type $\mathrm{F}$ (we shall not take $\mathrm{E}$ into further consideration on account of its numerical insignificance) was also observed by Smith, who says with reference to it: "We have not felt it necessary to designate this kind of union by a separate term, as it is not of very frequent occurrence, nor does it seem to constitute a generically different type of family. It is really a marginal case of the normal development of household groups and will be treated as such. It may be that in Jamaica or in urban areas of the West Indies generally, it occurs with much greater regularity but there are not enough adequate data to assess this, though if it could be established that the regularity of its occurrence under urban conditions is very high it would perhaps throw interesting light on the whole problem of the relations between development of household groups and other factors." (R. Smith, 1956, pp. 113, 114.)

Although the occurrence of this type of household in Paramaribo is not spectacularly frequent, it seems important to give some attention to this type because my material tends to show that, as Smith expected, it occurs more frequently in urban areas. Its percentage of the sample population was seen to be 2.7 (table B, appendix 3). In only two of these fourteen households was there question of a direct development from type $B$, male head with common law wife. In these two cases the "power" in the household had been seized by the concubine because she was the person earning the larger income. The two husbands were out of work and were merely "tolerated" in the household. They were both elderly men.

The remaining twelve cases concern types which have developed from types A or B via type G. This happens as follows: a married woman or a woman living in concubinage has become head of her household as a 
result of her husband's death or his deserting or divorcing her (type G). She has begun a relationship with another man who has eventually moved in with her as her common law husband. It is not this man who is head of the household, but she who has continued as such. Table I, appendix 3 , shows that these households include 27 children by the head and her common law husband, 23 by the head alone, and none by the common law husband alone. The woman is able to remain head of such a household because her (older) children of previous unions support her in this. In the majority of cases she provides the household's livelihood. Even so, her partner is not to be regarded as a sponger. For of the fourteen common law husbands twelve were seen to be earning wages, of which they handed over part or all to the head of the household. What we were struck by was that they were for the greater part younger than their partner, the head of the household.

In a number of cases studied by us these men created the impression that they were "married to their mother". This was apparent from, among other things, their being treated as "elder brothers" by their wife's children of previous unions. The lower-class Creole male, who is often born into a female-dominated household, sometimes perpetuates this situation after his mother's death by choosing a partner who, like his mother, dominates him. Having a concubinary relationship on this basis is one way of doing so, as far as I am able to judge.

The lower frequency of this household type in rural areas (R. Smith, 1956, pp. 113, 114) probably springs from the fact that there is stronger social control here than in urban areas. In Paramaribo, where the individual possesses greater anonymity than in rural areas, there is greater opportunity for this kind of relationship. There is no strong censure against younger men cohabiting with women older than themselves. Households of this type are in fact not much more than a variant of type $G$, in which a large number of heads of households have relationships with men who are not members of their household.

In type $\mathrm{F}$ the woman does not expect the man to live with her for good or to marry her. These women have concubinary relationships for as long as these will last.

The structure of this type is as follows: the female head occupies a central position and her common law husband a marginal one. There is a fairly strong tie between the woman and the man, based primarily on sex. The man may have either no relation at all, a weak or very weak relation or a fairly strong one with his partner's children. The latter may be the case where the children concerned are by him and the head 
Figure 3. Household Type F, Female Head with Common Law Husband
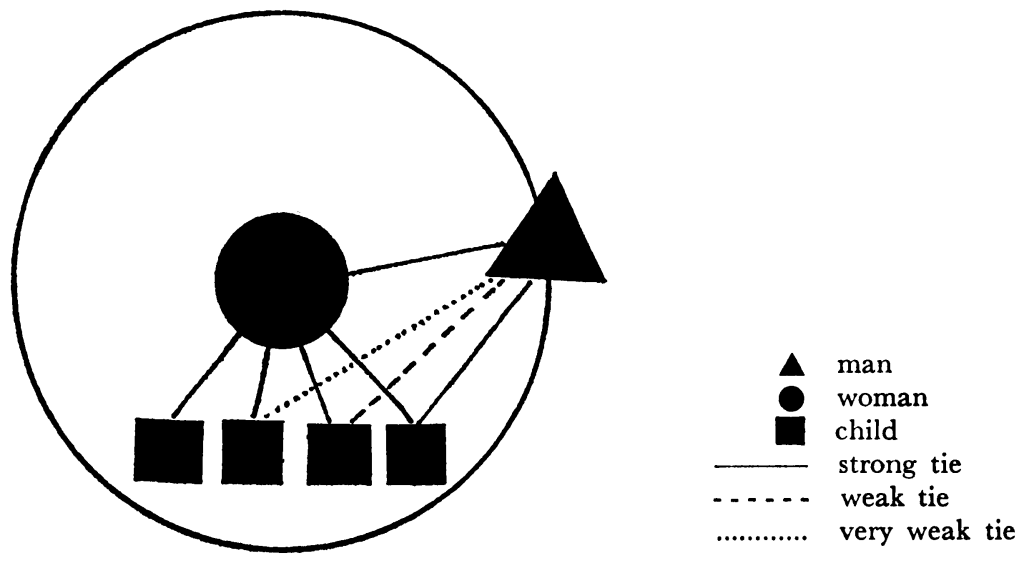

together. This type is manifestly matrifocal. Although the woman consults her partner concerning most domestic affairs, she is nonetheless the one who regulates these affairs both internally and externally.

Type $\mathrm{G}$ is similarly a manifestly matrifocal household type, (figure 4, variants 1 and 2). It is at the same time the most prevalent type (female head without legal or common law husband (cf. table B, appendix 3)). Here the woman has no partner living with her. A number of these women (variant 2) have relationships with men who are non-members of the household. It is impossible to say exactly how many of these 175 heads of households have relationships of this kind, as people usually tend to be secretive about them. For the visiting male is in many cases the head of some other household, so that the relationship has to be kept secret from his legal or common law wife. For this reason it did not seem very tactful to include direct questions about this in the questionnaire. It is even so possible to draw a few conclusions about the relationships of these women with male non-members of the household from our material. Twelve of the 175 women concerned were seen to receive monthly payments of money from male friends. These they receive from men with whom they have a visiting relationship of a stable nature. Although possibly the sample includes more than these twelve, I do not believe that this number will turn out to be a multiple of the abovementioned figure, as a man wishing to have a regular visiting relationship must have a relatively high income, since he will then be required to support the family of his "mistress" in addition to his own. Men belonging to the Creole lower class as defined by me are seldom 
Figure 4. Household Type G, Female Head without Legal or Common Law Husband

variant 1: without visiting male
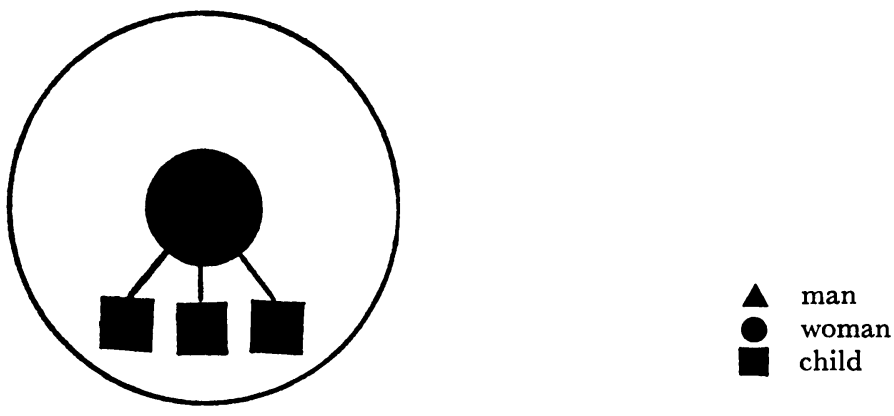

variant 2: with visiting male

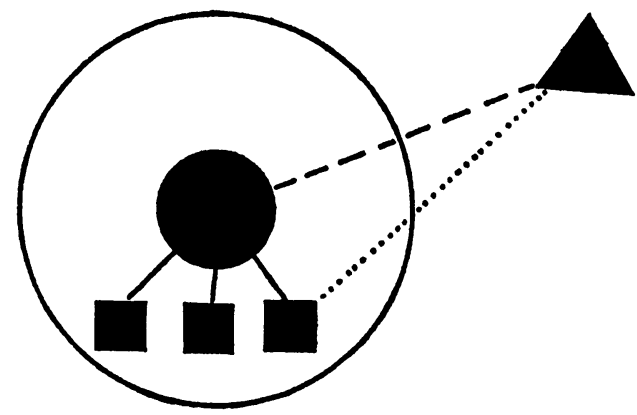

$\begin{array}{ll} & \text { strong tie } \\ \ldots \ldots \ldots & \text { weak tie } \\ \ldots \ldots \ldots \ldots . & \text { very weak tie }\end{array}$

financially capable of doing so. One may well ask, however, whether there are possibly non-members of this group supporting Creole lowerclass women, such as Europeans or middle- or upper-class Creoles.

Although this does sometimes happen, it is no longer as much a common rule as formerly (cf. section 4.5., the family life of the free citizens). Even prior to World War II it was considered improper in the European group for a man to support a permanent Creole mistress in addition to his legal wife. As more married whites were now coming to the colony, this group was inclined to form a clique which, as in so many colonial areas, evolved a style of life which as far as the pattern of consumption is concerned far exceeded anything to which the majority of people in the mother country were used. There was little room for anonymity in this group, where people knew one another from being members of social, tennis or swimming clubs - the membership of which was fairly exclusive as a result of the ballot system, which made it possible only for whites and socially prominent Creoles to be admitted 
as members. The female members of this clique kept a close watch on the doings of its members to ensure that it remained as endogamic as possible. Their newly acquired status made them susceptible to all kinds of false notions about the life of the indigenous population, which they formed almost exclusively on the basis of their observations of the stewards at the club or their own domestic servants. So as to underline their own exclusiveness they evolved the idea that they belonged to a higher human order than the non-white population of Surinam, whom they tended to regard as one undifferentiated mass (of servants). All non-whites came to be treated by them as beings who were utterly devoid of the capacity to become adult persons, so that they felt obliged to be patronizing towards them. One of the consequences of this infantilization process was that these people came to be referred to with the diminutive "Creooltjes", "Chineesjes", "Javaantjes" (meaning literally "little Creole people", and so forth), which tendency was also observable in the former Dutch East Indies. Many white as well as Creole middle-class women closely guarded the accepted standards of "common decency" through an almost over-subtle gossip system, thus making it more difficult for white men and well-to-do Creoles to support lower-class Creole mistresses openly - that is to say, if they did not want to "spoil their career". So it is to be supposed that the mass arrival of white women anything but improved communications between the whites and other ethnic groups. For the system of keeping housekeepers and mistresses prevailing before their arrival made for rather more frequent and better contact and understanding between whites and Creoles, so that there were far fewer "stereotyped" ideas in circulation about the life of the latter at the time.

The way of life held up as the ideal by the whites was imitated by many Creoles who had climbed to higher positions on the social ladder, so that at present it is rare among the Creole elite, too, for a man to keep a regular mistress openly. It is not uncommon for white men as well as socially successful Creoles to have secret relationships with lowerclass Creole women, however, though these seldom take the form of a relationship with a mistress living in her own residential unit. The girls they have affairs with at present are mainly Creole, Javanese or Hindustani girls still living in their household of orientation who are socially mobile (such as typists, nurses, etc.). These affairs seldom end in unwanted pregnancies as a result of the use of contraceptives. Female heads of households of type $\mathrm{G}$ under discussion here who have visiting relationships have these principally with middle-class Creoles or highincome lower-class Creoles. 
I am also inclined to believe on the basis of a number of observations that Chinese, most of them shopkeepers, have relationships of this kind with lower-class Creole women. These men, the majority of whom are newly arrived in Surinam, sometimes have concubinages with lowerclass Creole women. But the majority send for brides from China once they are rich enough. They then have the lower-class Creole woman with whom they have children (mostly legitimated children) move into a separate living unit, which they will sometimes continue to frequent as a visitor.

Apart from the relatively infrequent visiting relationships the heads of households of type $G$ may have sexual relations with men in the form of casual affairs. Such relations are not on the whole of long duration, although naturally there are exceptions to this rule. They often end in pregnancy because lower-class Creole women are unfamiliar with contraceptives except where they have vertical social mobility, and, moreover, are of ten unable to afford these. We are able to see from table $\mathrm{K}$, appen$\operatorname{dix} 3$, that the heads of households of type $G$ have 336 illegitimate as against 76 legitimate children. Of the illegitimate children more than half, or 180, have not been legitimated by their fathers, which might be an indication that the relationship between the head and the father was an extremely short-lived one. For I find it difficult to believe that all these children are by fathers married to other women, for whom it is hence impossible to legitimate them. Few affairs are begun on the basis of the expectation that they will last for very long. A woman may have this kind of affair because it offers her a brief spell of diversion with a man who favours her (and sometimes her children) with presents and money, thus enabling her to pay off her debts. Usually the man concerned will make all kinds of promises, such as that he will marry the woman, provide for her, and so on. But as soon as the woman tells him she is pregnant by him he will in most cases stop seeing her. According to one informant most men never turn up again once they hear that a woman is pregnant. Unfortunately women are inclined to believe men again and again, according to her. The number of women who have children by a succession of fathers in this way is not inconsiderable.

In non-Creole circles the fact that these women keep on having children is usually spoken of in a slightly amused and pitying tone. In Surinam, too, more well-to-do women are inclined to think that women who do not enter into legal or common law marriage act irresponsibly in having children. This is a false notion in a society in which there are no government sponsored and supervised social benefits for the aged 
such as in a country like Holland, however. It is impossible for an old person to survive unless he or she has children to depend on and move in with on reaching an age at which he or she can no longer work. Viewed in this light, even children born of casual affairs are definitely not always unwelcome. Hence childless women or women with too few children often adopt children or "foster-children" with a view to this. We can see a large number of male and female non-related members living in households of type G (table I, appendix 3, categories 69 and 70). All these persons were later seen to be "foster-children" of the head or of the latter's mother living in with the latter. This brings us to the question of the relationship between the various members of the household type under discussion here. In a large number of these households the head will delegate part of her authority to her eldest son or daughter or to her brother. Table I, appendix 3, category 5 , shows that in this household type $\mathrm{G}$ fifteen brothers of heads are found. These are usually living in with their (mostly elder) sister, whom they give financial support in her task of bringing up her family. The latter actually tend to regard their uncle as an "elder brother", a position the significance of which should not be under-estimated in the manifestly matrifocal lower-class Creole household. The eldest son of the head of such households (or her younger brother) represents the male element in the household, which involves his using or threatening to use physical force in name of the head to compell the other members to behave as she wishes them to. For example, they will punish any of their sisters with a sound beating for coming home late, while they will also try to keep their younger brothers in line by means of thrashings. It is they who decide who is to be allowed to frequent the household, and so on.

These sons usually have an exceptionally strong tie with their mother, who thoroughly spoils them for being her prop and comfort. The psychological background behind this is probably that she regards them as a kind of substitute husband. Many of these young men are jobless and live at their mother's expense. Eldest sons are given more opportunities by their mothers to follow some kind of training than are the other children; they are given better clothes, better food and luxury articles (usually bought on the hire-purchase system) such as motor-bikes, record-players, and so on. Mothers spoil them so because they consciously or unconsciously expect these sons to look after them in old age. We note that in general sons are favoured over daughters. One of the consequences of this is that many of them experience great difficulty in tearing themselves free from their mother when a woman enters their 
lives with whom they wish to marry or live in concubinage. Thus often conflict will arise between mothers and sons once the latter begin to make plans for marriage. There are a number of men who only realize such plans after their mothers have died.

Table I, appendix 3, shows how rarely male-headed households include the head's mother (category 56). Evidently daughters-in-law won't tolerate them in their household.

If there are no sons the mother usually has strong ties with the eldest daughter. So we see from table I, appendix 3, that daughters quite frequently allow their mothers to live with them (for household types A, $\mathrm{B}$ and $\mathrm{C}$ see category 58 , for types $\mathrm{E}, \mathrm{F}$ and $\mathrm{G}$ see category 56 ). Especially many mothers of heads are found in households of type G. In this latter case it is often essential for the mother to live in with the household, as the head is obliged to go to work, in which case the mother will do the housework and mind the children. Sons are seen to have their mothers live in with them to a lesser degree (table I, appendix 3 ).

\subsection{Unmarried Women and Women not Living in Concubinage and their Children}

We should look for the principal reason why unmarried women or women not living in concubinage have children in the necessity for a large proportion of these women to adapt themselves to the prevailing socio-economic conditions. These oblige them to have children as a guarantee for their future and more particularly their old age. These conditions also normally oblige women to take the responsibility for the children's upbringing, moreover, as it is only ton of ten impossible in the entire complex of socio-economic and cultural relations of lower-class Creole society to rely permanently and depend effectively on the father to take care of his offspring.

We should not overlook the important reason for the phenomenon just outlined, besides the above factor, however, that many lower-class Creole women have children even though they are not married or living in concubinage because they derive pleasure from motherhood, because they wish to prove themselves as women and because their religious attitude makes them reject contraception as sinful, as we shall see in the next chapter.

Hence household type G, the female head without a legal or common law husband, should be considered as an alternative form of family 
organization in which society perpetuates itself. The way in which women accomplish this will be discussed below. One question we may try to answer in this connection is how and if such female heads of households are capable of bringing up children who will be fit to occupy whatever places are open to them in the society of Surinam when they grow up with little or no support from a man.

By way of conclusion of our present chapter we would make one more remark. The reader may have been able to conclude from the aforegoing that a cyclical development is observable in the lower-class Creole household in Paramaribo as much as in the rural societies studied in British Guyana by R. Smith. There appeared to be a number of differences with the societies analysed by Smith, however. The principal ones are:

1) In the first phase of the household women in Paramaribo are less dependent on men because urban conditions offer them more opportunities to engage in money-making activities. As a result, the urban household displays matrifocal traits at an earlier stage than does the rural household of British Guyana.

2) In Paramaribo many women become heads of households at a younger age (cf. table 42).

3) In Paramaribo there is one household type in which women act as heads and their partners are common law husbands (type F). This type is not distinguishable in the villages studied by Smith.

The supposition that the differences listed above may be corollaries of the fact that there is much less social control in an urban area than in rural Guyana and that town offers women greater opportunity for independence is merely hypothetical.

These factors similarly contribute to the development of the household cycle in Paramaribo being less regular than that in the villages described by Smith, or the sequence of the phases distinguished by him being less regular. 


\section{THE FUNCTIONING OF THE FAMILY SYSTEM}

\subsection{General}

In the following pages we shall describe the functioning in actual reality of the West Indian family system in Paramaribo, as this determines to a large extent the behaviour of the lower-class Creoles from all age-groups with regard to such matters as childbirth, child-rearing, dealings with members of the opposite sex, old age and attitude towards death. For the discussion of the functioning of the family system in this connection a description of the life-cycle seems the most appropriate approach.

\subsection{The Desire for Children}

Lower-class Creole women are aware that they will in all likelihood not be supported by either a legal or a common law husband in later age. The instability of man-woman relationships, the unfavourable employment situation and the uneven sex ratio are all of them factors which render a woman's chances of having a legal or common law husband to look after her to the end of life low. As there are no government benefits for the aged (no such thing as old-age pensions are known in Surinam, and there is poor-relief only for the really destitute) people tend generally speaking to be wholly dependent on the generosity of their children when they grow older. Hence children (or foster-children) are on the whole regarded as people's sole security for old age.

In this connection the following notes on women's attitudes as regards the ideal size of families are of interest. I have collected the data on this as well as on behaviour with respect to contraception, which will be discussed further down, through interviews with lower-class Creole women at the Public Health Office (Bureau voor Openbare Gezondheid, from here on abbreviated as B.O.G.). For a description of the method followed here the reader is referred to section 3.2.3., while the interview form used is reproduced in appendix 4 .

The B.O.G. sample comprised 180 women from nine different agegroups. Twenty women from each group were interviewed. The age- 
groups selected were: 16-20, 21-25, 26-30, 31-35, 36-40, 41-45, 46-50, 51-55, and 56 and over. Of the women interviewed 141 were natives of Paramaribo, 38 were born elsewhere in Surinam, and one in Curaçao. They described their occupations as follows:

Table 43. Occupations of Women from the B.O.G. Sample

\begin{tabular}{lr}
\hline Housewife & 62 \\
Charwoman & 38 \\
Laundress & 11 \\
Market Vendor & 3 \\
Milliner & 11 \\
Housekeeper & 2 \\
Agricultural Worker & 1 \\
Saleswoman & 1 \\
Assistant Teacher & 5 \\
Female Clerk & 3 \\
Laboratory Assistant & 1 \\
School Girl & 5 \\
No Occupation & 37 \\
Total & 180 \\
\hline
\end{tabular}

Of the women interviewed 48 were married, 40 were living in concubinage and 24 had a sexual relationship with a man who was neither a legal nor a common law marriage partner. The remaining 68 women, including widows of both legal and common law husbands, stated themselves to have no sexual relationships with men at the time.

The religious distribution of the respondents was as follows:

Table 44. Religious Distribution of the Women of the B.O.G. Sample

\begin{tabular}{lrr}
\hline Moravian & 90 & $50 \%$ \\
Roman Catholic & 63 & $35 \%$ \\
Reformed Dutch & 13 & $7 \%$ \\
Lutheran & 9 & $5 \%$ \\
Other Religions & 5 & $3 \%$ \\
\cline { 2 - 3 } Total & 180 & $100 \%$ \\
\hline
\end{tabular}

Furthermore, $147(82 \%)$ of the women were discovered to have children. They had their first child at the following ages: 
Table 45. Age at Birth of First Child of Women of the B.O.G. Sample

\begin{tabular}{cc}
\hline Age in Years & Number of Women \\
\hline $14-15$ & 5 \\
$16-20$ & 83 \\
$21-25$ & 29 \\
$26-30$ & 18 \\
$31-35$ & 11 \\
$36-38$ & 1 \\
Total & 147 \\
\hline
\end{tabular}

So $67 \%$ of the women interviewed were seen to have had at least one child before their 22nd year. The following answers were given to the question of "How many children should a woman have in her lifetime?":

Table 46. Desired Number of Children of the Women of the B.O.G. Sample

\begin{tabular}{cc}
\hline Number of Women & Desired Number of Children \\
\hline- & 0 \\
- & 1 \\
7 & 2 \\
15 & 3 \\
58 & 4 \\
46 & 5 \\
20 & 6 \\
5 & 7 \\
4 & 8 \\
9 & 9 \\
16 & No opinion \\
\hline 180 & \\
\hline
\end{tabular}

The implication of this is that the average number of children desired is 4.8. Of the sixteen women who stated no opinion, 7 (including 5 of 56 and over) were in favour of letting the number of children depend on "the will of God" and one on "the dictates of nature", while two wished to let this depend on their financial circumstances. The remaining six women who stated no opinion gave no reason for withholding their answer. 
The average number of children desired did not appear to vary greatly per age-group.

Table 47. Average Number of Children Desired by the Women of the B.O.G. Sample

\begin{tabular}{llc}
\hline Age-group & & $\begin{array}{c}\text { Average Number of } \\
\text { Children Desired }\end{array}$ \\
\hline $16-20$ & $(\mathrm{n}=20)$ & 4.6 \\
$21-25$ & $(\mathrm{n}=20)$ & 4.7 \\
$26-30$ & $(\mathrm{n}=20)$ & 4.7 \\
$31-35$ & $(\mathrm{n}=20)$ & 5.3 \\
$36-40$ & $(\mathrm{n}=18)$ & 4.4 \\
$41-45$ & $(\mathrm{n}=18)$ & 5.2 \\
$46-50$ & $(\mathrm{n}=17)$ & 5.0 \\
$51-55$ & $(\mathrm{n}=12)$ & 4.9 \\
56 en ouder & $(\mathrm{n}=164)$ & 4.4 \\
& & 4.8 \\
\hline
\end{tabular}

Nor did the average number of children desired differ significantly according to whether a woman was legally married, was living in concubinage or was having some other kind of sexual relationship with a man at the time of investigation.

Table 48. Average Number of Children Desired by Women of the B.O.G. Sample According to Marital Status

\begin{tabular}{lcc}
\hline & Number & $\begin{array}{c}\text { Average Number of } \\
\text { Children Desired }\end{array}$ \\
\hline Legally Married Women & 44 & 4.6 \\
Women Living in Concubinage & 37 & 4.9 \\
Women with Men Friends & 24 & 4.8 \\
Women without Men Friends & 59 & 4.8 \\
\cline { 2 - 3 } Total (180-16 who stated no opinion) & 164 & 4.8 \\
\hline
\end{tabular}

Nor was there any substantial difference observable with respect to this number between the two principal religious groups, coming to 4.9 in the case of Moravian women and 4.7 for Roman Catholic women.

Although we should definitely handle the validity of the answers to the question about the number of children desired with caution, the above data do seem to warrant the conclusion, as far as I am able to judge, that there is relative homogeneity on the point of the desired 
number of children among lower-class Creole women, irrespective of age, marital status or religion. Parenthood is held in high esteem. Besides their normal value as children - because, among other reasons, they are company for the women in question and are objects of affection with whom the latter have strong emotional ties - they also represent economic value, as they offer their mothers a kind of insurance against old age. Added to this there is the popular belief that the woman who is childless is unhealthy. People generally believe that every woman is predestined to bear the number of children God has fated her to bear. If a woman interferes with this, such as by using contraceptives, God will surely punish her with disease, especially "cancer". For some women the number of "knots" in their first-born's navelstring is an indicator of their reproductive "destiny". This popular belief was also observed by Judith Blake (1961, p. 194) in Jamaica. Apart from the belief that it is unhealthy for a woman to remain childless, many lower-class Creole men and women are inclined to feel that sexual abstinence is unhealthy and may cause insanity. Having children is regarded as a logical consequence of living a "natural life". Although this view would seem to preclude the possibility of children being undesired, this is nevertheless not always so. According to the table below the sample included 43 women who would have liked fewer children than they actually possessed.

Table 49. Table Showing the Number of Women of the B.O.G. Sample who would have liked More or Fewer Children than they Actually Possessed or were Satisfied with the Number they had

\begin{tabular}{cccccc}
\hline $\begin{array}{c}\text { Number } \\
\text { of } \\
\text { Women }\end{array}$ & $\begin{array}{c}\text { Present } \\
\text { Number } \\
\text { of } \\
\text { Children }\end{array}$ & $\begin{array}{c}\text { Average } \\
\text { Number } \\
\text { of } \\
\text { Children } \\
\text { Desired }\end{array}$ & $\begin{array}{c}\text { Would like } \\
\text { more than } \\
\text { the present } \\
\text { Number of } \\
\text { Children }\end{array}$ & $\begin{array}{c}\text { Is satisfied } \\
\text { with the } \\
\text { present } \\
\text { Number }\end{array}$ & $\begin{array}{c}\text { Would like } \\
\text { fewer than } \\
\text { the } \\
\text { present } \\
\text { Number }\end{array}$ \\
\hline 31 & 0 & 4.6 & 31 & - & - \\
14 & 1 & 4.5 & 14 & - & - \\
23 & 2 & 4.3 & 21 & 2 & - \\
18 & 3 & 5.4 & 15 & 3 & - \\
16 & 4 & 4.5 & 5 & 10 & 1 \\
14 & 5 & 5.2 & 4 & 6 & 4 \\
15 & 6 & 5.5 & 2 & 5 & 8 \\
13 & 7 & 4.9 & 1 & 1 & 11 \\
3 & 8 & 5.3 & 1 & - & 2 \\
17 & 9 & 4.6 & - & - & 17 \\
\hline 164 & & 4.8 & 94 & 27 & 43 \\
\hline
\end{tabular}


I would have expected these to be chiefly women without legal or common law husbands, which circumstance would seem to make a large family an economic burden. This did not in fact appear to be the case, as table 50 shows.

Table 50. Marital Status of Women of the B.O.G. Sample who would like Fewer Children than they Actually Possess

\begin{tabular}{lccccc}
\hline Age & $\begin{array}{c}\text { Legally } \\
\text { Married } \\
(\mathrm{n}=44)\end{array}$ & $\begin{array}{c}\text { Living } \\
\text { in Con- } \\
\text { cubinage } \\
(\mathrm{n}=37)\end{array}$ & $\begin{array}{c}\text { Woman } \\
\text { with } \\
\text { Man Friend } \\
(\mathrm{n}=24)\end{array}$ & $\begin{array}{c}\text { Woman } \\
\text { without } \\
\text { Man Friend } \\
(\mathrm{n}=59)\end{array}$ & Total \\
$(\mathrm{n}=164)$ \\
\hline $16-20$ & - & - & - & - & - \\
$21-25$ & - & 1 & - & - & 2 \\
$26-30$ & 2 & 2 & - & - & 4 \\
$31-35$ & 1 & - & - & 3 & 7 \\
$36-40$ & 3 & - & - & - & 7 \\
$41-45$ & 6 & - & - & 2 & 7 \\
$46-50$ & 5 & -3 & - & 2 & 4 \\
$51-55$ & 1 & - & - & 15 & 43 \\
$56+$ & 2 & 7 & 1 & & \\
\hline Total & 20 & &
\end{tabular}

We are struck by the large number of married women who would have liked to have had fewer children than they actually possessed. The difference among them between the desired and the actual situation is probably due to the fact that: (1) unions between legally married people are generally speaking of longer duration than those between common law marriage partners, as we saw above, so that on the whole more children tend to be born of this type of union than of concubinages; and (2) married couples belong by and large to a higher level of lowerclass society, many members of which cherish ambitions of rising to a higher social position. There is a general impression that many married couples realize too late that a large family constitutes a handicap in their struggle for social advancement. It is in connection with this second point that the reactions to pregnancies of unmarried daughters still living in differ between the higher and the lower lower classes. In the higher strata of lower-class society (as in the Creole middle class) this kind of event results in a loss of prestige. As soon as the girl is discovered to be pregnant she may be chastised or even turned out of the house. In these cases she will usually seek refuge with a befriended woman, 
either a neighbour or an aunt, who a few days later will go and talk to the girl's mother. The mother will then usually persuade her husband to admit their daughter to the household again and to raise her child for her. The fate of these unmarried mothers who have been pardoned is not as a rule an enviable one. Their fathers will usually adopt a hostile attitude towards them, while in some cases they are treated as domestic servants and charged with the most menial of household tasks. This happens much less in the lower strata. Here there is usually no fuss if unmarried daughters still living in become pregnant. Nor is there question of any considerable loss of prestige here. The fact that a woman who is capable of bearing children does so is accepted as something quite matter-of-course here. For girls from the lower lower classes the birth of a child constitutes the rite de passage marking her transition from childhood to adulthood. Accordingly we sometimes find girls who have not yet entered motherhood treated as persons of much inferior standing by their girlfriends. One of the questions a childless young woman is commonly asked is: "Who will look after you when you are old?" The tendency to prove themselves as women induces many young women to have sexual relations with men who are in many cases financially incapable or who have no intention of entering into marriage or concubinage with them. As a result there are large numbers of girls who bear children while they themselves still belong to their natal household. For boys, too, the rule holds good that they have not proven themselves as men until they have fathered a child.

Categories 43 and 45 of table I, appendix 3, show the various types of household to include 234 children (126 sons and 108 daughters) of resident daughters. Of these 234 children $78 \%$ appear to be illegitimate. The ties between these children and their mothers are usually very loose. Such children are in most cases reared by the parents, and in many cases the mother only, of the girl. These children will often address their grandmother as "Ma", while calling their real mother by her Christian name.

The 40-years-old widow K. V., who is head of her household, is living together with her daughter R. A. (19) with her two children (of 4 and 2) and her own two sons ( 7 and 3 ) in a small dwelling in an outer suburb of Paramaribo. One afternoon four years ago, when the head of the household was away from home, a man from the neighbourhood came and dropped in for a visit, and begot a child with the then 15-yearold R. A. After that she had another child by a Dutch soldier stationed in Surinam. Neither of these fathers does anything for the support of 
their children, gives their mother any money for them or visits them. R. A. goes to work as a housemaid and this way brings money into the household. The head looks after both her own two children and those of R. A., who call her "Ma". They call their natural mother by her Christian name and regard her as an elder sister. The head views R. A.'s having these children as part of the natural course of things. She has never reproached her daughter with her escapades, and never makes any attempt to stop her from seeing other men. She believes that every woman is predestined to bear the number of children God has decided to grant her. She considers it a sin to interfere in this course of events, as one must resign oneself to it.

If women with such "premarital" children later on enter into marriage or concubinage they will sometimes refrain from taking these children with them into their new household. Though this is sometimes because the husband refuses to adopt these children, it is mostly a result of the grandmother's refusing to part with these grandchildren, which she has come to regard entirely as her property. Categories 44 and 46, table I, appendix 3, reveal that the sample includes 44 "children of non-resident daughters". Of these, 32 are included in households of type $\mathrm{G}-$ female head without legal or common law husband. Of these 44 children, 36 appeared to be of illegitimate birth.

The informant C. P. (28), who is living in concubinage and has two children by her common law husband, told me she had a "premarital" child who is living with her mother. Her mother refuses to give the child up to her because she thinks C. P. gives it too many "thrashings" and would leave it in a crèche all day, as the informant has a part-time job as housemaid. When she goes to work she drops her two children in at the crèche. C. P. 's premarital child comes to stay the weekend with her once a fortnight.

It is an evitable consequence of the system that many premarital children change households during childhood. If their grandmother, with whom they are living, dies their real mother is then compelled to take them into her household, which of ten arouses much opposition from her partner. One solution that offers itself in these cases is to have the child adopted as foster-child by some other person, mostly a female relative. This latter is done often and without much ado by women who feel they haven't enough children of their own. They usually bring these (foster-)children up as their own. One of the more objectionable features of this practice is that foster-children tend sometimes to be used as unpaid domestic servants. Especially in the old days it was common 
for people to adopt a child, mostly from a plantation, into their household so as to have the benefit of its services. As boys are generally less useful for housework these were mostly girls (cf. Encyclopaedie, 1914-'17, p. 436). This system of adopting foster-children is sometimes condemned as a form of "slavery in disguise".

\subsection{Birth Control}

Although it may be posited as a general rule that the lower-class Creole woman wants children and in most cases eagerly looks forward to their arrival, there are nonetheless also women who try to prevent or terminate pregnancies. These are often women who realize that, as their family disposes over insufficient income, it would be economically irresponsible to have more children. Or they may be girls from the upper lower classes who want no children for the time-being because they wish to finish their education first, because they have a job or because they are afraid of reducing their chances on the marriage market by having children.

In spite of the high growth rate in Surinam (almost $4 \%$, see section 2.5.) no systematic government effort has so far been made to promote family planning. This may have something to do with the interests of the different political parties, mostly formed along ethnic lines, being served best by increasing the number of their voters. It is more particularly the Creoles who are afraid of being numerically eclipsed by the Hindustanis, as we saw above.

An interest is being shown at present by the churches, especially the Moravian Church, in the study of social problems in connection with the family of their (chiefly Creole) members, with the possibilities of responsible family planning also coming under consideration.

There was also a special work group, composed of private citizens, set up to study this problem in 1965. But this interest on the part of the churches and private initiative has not so far led to a systematic, in-depth study being made of the problems in connection with family planning. I would suggest that if this problem should ever be studied at greater depth at some future time, the fact that it will be far from easy to convince lower-class Creole women that smaller families are economically more feasible unless adequate old age benefits are introduced should definitely be taken fully into account. Some women go as far in their anticipation of such a provision for their old age as to refuse to accept any payments for their children's upbringing from the latter's fathers 
from fear lest this will put the children under an obligation to look after their father as well when he grows old.

As is the case in virtually every culture, the Creole subculture of Surinam has also possessed of old its own methods of preventing or terminating unwanted pregnancies. Kuhn (1828, pp. $30 \mathrm{ff}$.) reports in his work on the conditions among plantation slaves in Surinam that female slaves were acquainted with methods of procuring abortion. As for the popular methods of inducing abortion and preventing conception in practice at the present day, I was given information on these by a number of men and women.

A woman wishing to terminate a pregnancy will try to do so in the first place by taking one of a variety of draughts and potions. The drinking of boiled stout mixed with Epsom salts is well-known in this connection. This is taken together with the pulp of certain unripe fruits, such as pineapples, avocados, bananas or pumpkins. Women sometimes also experiment with the concentrated extract of the leaves of the Azadiráchta indica tree, which though native to Asia is planted widely in the compounds of Hindustanis (cf. Ostendorf, 1962, p. 137). Other well-known methods include the drinking of lemon juice mixed with extra strong coffee, or vinegar with orange juice. The juice extracted from the seeds and leaves of the Chenopódium ambrosioides is also sometimes used; this is also taken as a medicine against worms, according to Ostendorf (1962, p. 25). I was further told of the practice of taking quinine and phenol. Karbaat (1964, p. 112) mentions the use of Apiol, a herb that is sold in the market. These concoctions, or variations thereof, are either prepared by the women themselves or administered to them by men or women making their living by this. The latter may also provoke abortions by mechanical means. The method of Javanese women, who possess the art of inducing abortion through massage, is well-known in this connection. There are also rumours about doctors, midwives and nurses in Paramaribo who are prepared to procure abortions against payment. It was hardly feasible for me to gather statistics concerning these phenomena within the scope of my research. A number of doctors assured me that illegal abortion is on the increase, however. They are being consulted more and more by women who have sustained serious injury as a result of the practices of illegal abortionists or their own attempts to induce abortion.

Apart from popular medicines for provoking abortions, Creole women have been familiar of old with a number of supposed contraceptive medicines. The best-known of these is the abovementioned extract from 
the leaves of the Azadiráchta indica. This should be swallowed either just before or just after copulation. According to one informant this made conception impossible as it "turned the blood bitter". Another well-known method is that of douching the vagina with the juice of the leaves of the aloe after coition. Other women wishing to prevent pregnancy may consult Javanese dukuns -- i.e., men or women practising popular medicine. Many dukuns possess the art of causing prolapsus of the uterus by external massage, which makes conception practically impossible. This method has been imported by Javanese immigrants. It is not free from danger, as it commonly causes menstrual disorders, coupled with severe back-aches. Annemarie de Waal Malefijt (1963, pp. 127 and 128), who mentions the method in her book on the Javanese in Surinam, states that according to doctors in Paramaribo it usually causes permanent sterility. The dukuns claim to be able to cause the uterus to revert to its normal position through further massage, however, thus making it possible for the patient to have children again if she wishes. Only one informant from the B.O.G. sample stated herself to have undergone this form of treatment. However, 59 of the women interviewed (i.e., $33 \%$ ) were aware of its existence.

Although many lower-class Creoles still take recourse to popular medicine from lack of money or ignorance, there is also a marked tendency especially among the younger generation to show greater faith in modern medicine, also with respect to the use of contraceptives. Information on the availability of such devices is still scanty, however. There is a more or less illegal traffic in such popular contraceptives as condoms, foam tablets and jellies, but many women (and men) do not know their way to the shopkeepers trading in these, or are embarrassed about approaching them. In addition the prices of these articles are too high for many people to use them regularly. Furthermore, it is not uncommon for members of the medical profession to be uncooperative when approached by lower-class Creole women wishing to adopt family planning. One woman from the B.O.G. sample, a mother of seven, told me that when she once asked a Creole doctor for contraceptives he had refused to help her. He justified his refusal to her by asking whether she wanted Surinam to be taken over by the coolies (Hindustanis). There are on the other hand also doctors who are willing to lend their cooperation, mainly through the sterilization on a fairly wide scale of women who wish no more children.

In order to check on how conversant lower-class Creole women are with the various methods of preventing conception I asked women from 
the B.O.G. sample to state with which of the contraceptives devices and methods listed below they were familiar. Of the 180 respondents, 157 stated themselves to be acquainted with one or more of the methods listed in the following table.

Table 51. Conversancy of Women of the B.O.G. Sample with Contraceptive Devices and Techniques

\begin{tabular}{lcccc}
\hline & \multicolumn{5}{c}{ Age } \\
\cline { 2 - 5 } & $\begin{array}{l}16-30 \\
(\mathrm{n}=54)\end{array}$ & $\begin{array}{c}31-45 \\
(\mathrm{n}=54)\end{array}$ & $\begin{array}{c}45+ \\
(\mathrm{n}=49)\end{array}$ & $\begin{array}{c}\text { Total } \\
(\mathrm{n}=157)\end{array}$ \\
\hline The Rhythm Method & 12 & 22 & 3 & 37 \\
Coitus Interruptis & 14 & 17 & 1 & 32 \\
Douching & 9 & 18 & 4 & 31 \\
Condom & 48 & 36 & 28 & 112 \\
Pessary & 11 & 23 & 5 & 39 \\
Foam Tablets & 30 & 29 & 8 & 67 \\
The Contraceptive Pill & 31 & 30 & 23 & 84 \\
Female Sterilization * & 38 & 37 & 38 & 113 \\
Male Sterilization & 5 & 4 & - & 9 \\
Contraceptive Jellies & 23 & 20 & 5 & 48 \\
Other Methods & 1 & - & - & 1 \\
\hline
\end{tabular}

* As distinguished from the abovementioned Javanese method of female sterilization by massage.

Upon further questioning only 37 of the women stated themselves to be using or to have ever used in the past one or more of these methods. Their distribution according to age was as follows:

Table 52. Table Showing the Number of Women of the B.O.G. Sample who had at Some Time used Contraceptive Devices and Techniques and those who had no Past or Present Experience with these, set out According to Age

\begin{tabular}{lccc}
\hline Age & $\begin{array}{c}\text { Has Experience with } \\
\text { Contraceptives }\end{array}$ & $\begin{array}{c}\text { Has no Experience } \\
\text { with Contraceptives }\end{array}$ & Total \\
\hline $16-30$ & 16 & 44 & 60 \\
$31-45$ & 18 & 42 & 60 \\
$45+$ & 3 & 57 & 60 \\
\hline Total & 37 & 143 & 180 \\
\hline
\end{tabular}

These 37 women who had used contraceptives were seen to have adopted the following methods on one or more occasions. 
Table 53. Table Setting out According to Age the Women from the B.O.G. Sample who had used one or more Contraceptive Devices or Techniques

\begin{tabular}{|c|c|c|c|c|}
\hline & \multicolumn{4}{|c|}{ Age } \\
\hline & $\begin{array}{c}16-30 \\
(n=16)\end{array}$ & $\begin{array}{c}31-45 \\
(n=18)\end{array}$ & $\begin{array}{c}45+ \\
(n=3)\end{array}$ & $\begin{array}{c}\text { Total } \\
(\mathrm{n}=37)\end{array}$ \\
\hline Rhythm Method & - & 4 & 一. & 4 \\
\hline Goitus Interruptis & - & 2 & - & 2 \\
\hline Douching & - & 1 & - & 1 \\
\hline Condom & 7 & 1 & 2 & 10 \\
\hline Pessary & - & 2 & - & 2 \\
\hline Foam Tablets & 1 & 1 & - & 2 \\
\hline The Pill & 8 & 5 & - & 13 \\
\hline Contraceptive Jellies & 1 & - & - & 1 \\
\hline Female Sterilization & - & 7 & - & 7 \\
\hline
\end{tabular}

Condoms and the pill appear to be the most widely used devices among women from the 16-30 age-group. The pill constitutes a method that is popular in the middle and upper classes, but is now also gaining ground among the lower classes, mostly as a result of women employing domestic servants advising their female servants to start taking it. Some of them even pay the costs involved "if they have a reliable maid". The price of the pill is in most cases too high for women from the lower classes.

The number of women between the ages of 31 and 45 who have had themselves sterilized is relatively high ( 7 of the 60 , i.e., $11.7 \%$ ). As elsewhere in developing countries, the surgical method of sterilization is the most widely used in Surinam. But, as a spokesman for the Public Health Service informed me, the operation is usually performed for medical rather than social reasons, such as in cases where a woman's health would make it dangerous for her to have more children.

As only 37 of the 180 women stated themselves to be adopters, we might well ask what is preventing the many others from using contraceptive devices or techniques. The following reasons were stated by the group of non-users (see table 54).

The view that one shouldn't use contraceptives because it is bad for one's health and/or because God forbids it was the most frequently stated.

As we are able to infer from the table, it is chiefly elderly women who have religious objections to the use of contraceptives. This in turn influences the behaviour of younger women, as older women are virtually the only persons they can turn to for advice on such matters. Because 
Table 54. Reasons against Using Contraceptive Devices or Techniques stated by Women of the B.O.G. Sample, listed According to Age

\begin{tabular}{lcccc}
\hline & \multicolumn{5}{c}{ Age } \\
\cline { 2 - 5 } & $\begin{array}{l}16-30 \\
(\mathrm{n}=44)\end{array}$ & $\begin{array}{c}31-45 \\
(\mathrm{n}=42)\end{array}$ & $\begin{array}{c}45+ \\
(\mathrm{n}=57)\end{array}$ & $\begin{array}{c}\text { Total } \\
(\mathrm{n}=143)\end{array}$ \\
\hline $\begin{array}{l}\text { Wanted children } \\
\text { Husband was against it }\end{array}$ & 6 & 12 & 7 & 25 \\
$\begin{array}{l}\text { Bad for health } \\
\text { Religious grounds }\end{array}$ & - & 2 & 2 & 4 \\
$\begin{array}{l}\text { Religious grounds and } \\
\text { bad for health }\end{array}$ & 4 & 5 & 6 & 22 \\
$\begin{array}{l}\text { Too much fuss } \\
\text { Too expensive }\end{array}$ & 2 & 1 & 7 & 35 \\
$\begin{array}{l}\text { Don't know how to go about } \\
\text { getting contraceptives }\end{array}$ & 1 & - & - & 10 \\
Other reasons & 1 & - & - & 1 \\
Not interested & 1 & 5 & 1 & 7 \\
\hline
\end{tabular}

they are badly informed it is not very likely that there will be any dramatic increase in the use of contraceptives as long as there is no official body to supply adequate free counselling, as long as the West Indian family system, according to which children constitute a form of insurance for old age, remains in force, and/or as long as the government fails to provide old-age benefits in Surinam.

I have given no attention in this tentative exploration among lowerclass Creole women as regards their attitudes to contraceptives and the idea of family planning to the extremely important role of men in taking decisions in this connection. If a further study is ever made of this subject, this aspect should most certainly be given full attention (cf. Blake, 1961).

\subsection{Traditional Practices in Connection with Pregnancy and Childbirth}

It is extraordinarily difficult to indicate any fixed pattern with respect to practices observed in connection with pregnancy and childbirth. The group under study is an urban one, which generally implies the existence of a wider range of alternatives than in rural areas. Added to this, the group in question is resident in a plural society the different ethnic groups of which are prone to mutual cultural influencing, thus increasing the number of alternatives, including those with respect to childbirth 
and pregnancy, still further. In many of these customs traces of African and European popular beliefs, or a mixture of both, are discernible. A number of data concerning these customs will be furnished in the pages below. I should stress at the outset, however, that they are no longer observed by all lower-class Creoles.

In general pregnant women are treated with great consideration by their environment here. Every effort is made to ensure that mothers-to-be are as comfortable as possible. This stems from fear lest the unborn child be adversely affected by quarrels, reproaches and excessive physical exertion. The pregnant woman is also given whatever foods she fancies, where possible. This is done partly in connection with the prevalent belief that, in order to protect the unborn child, the mother must observe the father's taboos with regard to food as well as her own. There are still many lower-class Creoles who believe that it is possible to prevent certain skin diseases, including leprosy, by abstaining from eating certain foods which are taboo to them. These taboos vary from person to person. The forbidden foods are referred to as a person's trefu (cf. Simons, 1959, p. 53). This trefu is inherited exclusively from one's paternal kin, although it may sometimes occur for a person's trefu to be revealed in a dream to some relative or friend, mostly a woman, at his birth. It is further possible for a person to be forced to abstain from eating certain foods as a result of wearing particular amulets, and thus acquire a trefu during his lifetime. Herskovits and Herskovits (1936, p. 37) observed that if a woman has a child with persistent skin disorders in spite of its observing its father's trefu, this is taken as a sure sign that the woman has had the child by a man other than her acknowledged husband. Such a woman is doing her child a grave harm by not enquiring about its father's trefu, as it will then have to grow up in ignorance of the food taboos of its real father (cf. Lampe, 1928, pp. $545 \mathrm{ff}$.).

In order to protect the foetus against black magic (wisi), some women may consult an obiahman (medicineman), who will supply them, against payment, with some charm or other (tapu) with which to effect this. This $t a p u$, usually a bottle filled with some liquid, is placed by the woman above the entrance to the house (cf. Herskovits and Herskovits, 1936 , p. 35). Belief in this practice is rapidly disappearing, as far as I am able to judge. I came across only a few instances of pregnant women who had "placed a charm" in the course of my field work.

Extra expenses have to be made in order to give the new arrival a suitable welcome. Where money reserves are scarce this often entails 
having to raise a loan with relatives or friends or at the pawnbroker's. Because of these financial sacrifices which have to be made, the birth of a child is not always an event looked forward to with unmixed joy. Common law (and sometimes also legal) husbands may sometimes abscond on hearing that their partner is pregnant or at the approach of the birth. The poorest may as a result give their infants away to people desiring to adopt a "foster-child". This is done especially frequently by female heads of households without a legal or common law husband, who are therefore their household's breadwinner. It will of ten be impossible for them to exercise this latter function if they have another infant to take care of. So they may give away their infants to other people to prevent their other children being reduced to utter poverty.

Paramaribo counts a large number of well trained midwives and women with experience in attending women in childbirth. Many women prefer to go to hospital for the birth of their first baby. It has long been the custom for women not to have their children at home - this being a corollary also of the overcrowded conditions in most homes. Benoit observed as early as the beginning of the 19th century: “. . . on a établi à Paramaribo des maisons tenues par des sages femmes et où les négresses esclaves qui sont enceintes, vont faire leurs couches aux frais de leurs maîtres" (Benoit, 1839, p. 54). A woman will only have her first child at home if there is absolutely no money at all for a hospital delivery.

The mother-to-be will get in touch with a midwife or the consultation bureau at a fairly advanced stage of her pregnancy, usually after the sixth or seventh month. In the old days, and sometimes even today, some elderly woman, usually a female relative with experience in such matters, was placed in charge of affairs at childbirth. These women upheld all kinds of customs and practices in connection with birth and pregnancy. That they have not disappeared altogether is illustrated by the observance of the customs described below in connection with many - though definitely no longer all - pregnancies and births. Midwives trained according to modern methods are helping to suppress many of these customs, but their influence is not always strong enough to effect their complete elimination.

As probably everywhere in the world, the mother-to-be in Surinam is bombarded with all kinds of advice and admonitions. Thus a great many people believe that sexual intercourse during pregnancy is conducive to an easy birth and will make the new-born infant stronger and 
healthier than if the mother has been abstinent. Some women even continue to have sexual intercourse right up to the moment just before the birth in order to induce labour. Similar behaviour was observed by Kerr (1963, p. 29) among the Negro population of Jamaica. In order to accelerate parturition, women may also drink herb extracts, swallow traditional brews or take steam-baths by sitting atop a tub of steaming water mixed with herbs.

There exists a belief as regards the child's appearance that if it is conceived before its mother's menses it will be dark-skinned at birth. If it is conceived after menstruation, "when all is clean", it will have a light skin at birth and keep this all its life. Women who have had a series of miscarriages or stillbirths may "sell" their unborn infants for a token sum to a man who is not the father in order to avoid a recurrence. The objective of this is to avert wisi or the malevolence of some wrathful Yorka, for instance. Although such a child will become the rightful "property" of the buyer after birth, it will usually remain with its mother. The owner of the child - mostly some good friend will spoil it in childhood, such as by giving it occasional presents. Male children born after being thus "purchased" formerly had their earlobes pierced like female children. This symbolized the fact that they had actually died, but had "come back". On the plantations such men in former times used to wear earrings.

It is interesting to note what Herskovits observes with regard to a group of Negroes in the U.S. in this connection, viz.: "A technique of tricking the malevolent spirits, described as occurring among these Georgia Negroes, is equally African: 'If you wish to raise your newborn child, sell it to someone for 10 or 25 cents and your child will live" " (Herskovits, 1964, p. 189).

Expectant mothers having their babies at home duly make the necessary preparations. They make up a lying-in bed out of old rags or newspapers, as some choose to lie on the floor during the birth so as to save what is in many cases the only bed in the house. This custom is not approved of by all midwives, but sometimes there is no other alternative because of the total absence of a bed. The other children are sent to stay with friends or relatives before the birth is due. If the woman in question has a husband he is usually present at the birth, as is her mother or some other female relative.

Some women in labour will scream at the top of their voice, as this is believed to reduce the pain. This belief is slowly disappearing at present, and there are women who are ashamed to make so much noise. After 
parturition the child is wrapped in a cloth, whereupon the mother is attended to first. The umbilical cord and placenta are rolled up in a newspaper and later buried near the house in a special pit, usually behind the privy. It is believed that if this is not done the child may become feeble-minded. The new mother, or the female relatives present, subject the navelstring to a close scrutiny, as the number of "knots" in it is supposed to foretell the number of other children to which the woman will give birth, as was mentioned above. There is also a belief that the deeper the pit in which the navelstring and placenta are buried, the longer it will be before the woman has another child. So as to make sure she will have more children a woman may in some cases desire the navelstring to be buried on top of the placenta, with a coin placed on top of it or some salt scattered over it. The burial usually takes place with the assistance of the midwife. These customs in connection with the afterbirth are still so much alive as to cause some women who have had hospital deliveries to ask to be given the navelstring and placenta to take home in order to be buried there. If a child is born with its navelstring twisted around its neck or if a newborn infant's placenta leaves its mother's body immediately after the birth, a sapling may be planted on top of its buried afterbirth by way of commemoration of such an unusual event. The end of the umbilical cord that remains attached to the infant's body for a few days after birth before dropping off also possesses a specific function. Some mothers dry it in the sun and then keep it rolled up in a piece of cloth. Six to eight months later it is burnt on top of a tin and the remaining ashes are mixed in minute quantities through the child's food. Popular belief has it that this prevents infantile convulsions.

Herskovits (1964, p. 189) observes that "The care used in disposing of the placenta and the treatment of the navelcord are also largely African". He further reports that, "Certain Negro attitudes reported from the United States toward abnormal births are highly specific in their African reference. Twins, the child after twins, children born with teeth or with a caul or other peculiarities are, among African folk, regarded as special types of personalities whose spiritual potency calls for special treatment." In Paramaribo, too, these beliefs prevailed. Twins are believed to be clairvoyant. According to the popular belief they dream more frequently than ordinary people.

One informant, a man in his sixties who claimed to be endowed with second sight, told me he was born immediately after three sets of twins. He was therefore a dosu, i.e., a person born after twins, who is also 
supposed to possess clairvoyant powers, though to a lesser degree than actual twins (cf. Bastien, 1961, p. 495). As his mother's youngest child or tapu bere, moreover, he was thoroughly spoilt during childhood, as is customary here, and this had according to him strengthened his powers still further.

New mothers take daily herb baths for about six weeks after their confinement. The herb used is called jara-kopi, or sometimes faja pau (Siparuna guianénsis). It is supposed to make the vagina "like that of a young girl". Modern mothers, or women without relatives in the country, whence this herb has to be imported, use Dettol for these baths.

So as to be able to breast-feed their children properly many women drink an extract of Fini bita (Phyllánthus amárus) leaves for some length of time; this plant is sold in the market. It is supposed to promote the baby's growth, especially because it reputedly ensures that it has regular motions. Women sometimes also drink stout to boost their milk supply. Sometimes female relatives or friends will massage the new mother inorder to get her abdominal muscles back in shape.

\subsection{Childhood}

On its first day of life the infant is given molasses and water to drink. This old-fashioned practice is at present replaced largely by that of giving the baby water with sugar and milk, on the advice of the collective midwives. If the mother is able to breast-feed the infant it will usually be put to the breast quite soon. The admonitions of midwives to feed children according to a fixed time schedule are usually ignored, and most mothers feed their infants as soon as they begin to cry. Midwives try to persuade mothers to stop breast-feeding their infants after 8-9 months, but many women try to extend this period in the belief that they are preventing pregnancy this way. Sometimes a child is not weaned until its second year. But the majority of women reject this as a "Javanese" practice. Children are not put onto solids until their fourth month, when they are fed on porridge consisting of shredded cassava cakes, or patent baby foods if there is enough money. As soon as a mother wishes to start weaning her infant she will rub her breasts with bitter aloe or the hot "Madame Jeanette" species of cayenne pepper. A child is supposed to be completely weaned after one or two attempts to feed from its mother's breasts after they have been rubbed with this. This rather abrupt method of weaning is connected with the custom that forbade nursing mothers to have sexual intercourse in former times. 
At the present day this is usually resumed "as soon as possible", according to one female informant.

As soon as the new mother rises from childbed she will carry the baby around the house to show it where it has come to live. To ward off the evil eye (ogri ai) she will rub the child behind the ears with blue dye by way of counter-charm. She may also attach a safety pin with a blue bead to its clothing for this purpose. Whenever a mother has cause to suspect that the evil eye has fallen on the child despite these precautions she will bathe it in water mixed with blue dye or lick the child's face clean, spitting out the substance she has licked up far away from her.

Baby girls have their earlobes pierced with a red-hot needle at 10 days. A red thread is passed through the hole to keep it from closing. This is done in order to enable them to wear earrings when they are older.

Most children are christened in one of the Christian churches. The godparent who sponsors the child at baptism - usually a woman - is under an obligation to bring up the child if anything should happen to its parents. In town this vow is no longer taken as seriously as it was in former days. Not all children have as close relationships with their godparents as was the case formerly, when it was customary for godchildren to visit their godparents often.

In order to cut down on the family washing, lower-class Creole mothers often dress their younger children in clothes that cover only the upper part of their bodies in and around the house. Little boys commonly run around stark naked. Children are subjected to quite rigourous toilet-training, attended with many spankings. The child is taught to urinate on the ground outside the house in the daytime; and it is brought to the privy in the yard or put on a pot to defecate. In the more prosperous households, where there is usually an indoor toilet, children are not as a rule trained to urinate or defecate outside.

A child that is late with its toilet-training is ridiculed and derided by its brothers, sisters and playmates. A form of punishment used to correct this in the 19th and even at the beginning of the 20th century is described as follows by Lammens (1816-'22, p. 102): "If a little boy or girl is caught soiling its bed it has a kurekure, a long tapering basket with long feathers stuck in it, placed on its head. In addition a number of live toads are tied around the culprit's body and a pot to its back. It is then conducted along several streets amid constant banging on the latter and the jeering of its playmates." Such spectacles are supposed to have occurred right up to the 1930's.

Child-beating is resorted to a great deal, not only during the toilet- 
training of infants but also during the rest of the children's upbringing, this disciplinary method in some cases being pursued until the age of seventeen. Corporal punishment, or threats thereof, constitute the most common form of disciplining youngsters. People responsible for bringing up children are often heard uttering threats of thrashings or whippings. And these do not always remain mere threats, for fathers and mothers are often seen to inflict painful punishments by striking children with the hand or with any suitable object that happens to be ready at hand, such as a clothes-hanger, brush, belt or stick, when angry. No part of a child's body is safe from blows, although these are mostly aimed primarily at the legs and buttocks. In some of the yards it is not uncommon even for older children (especially boys) to be suspended naked by the arms from the branch of a tree and given a thrashing with a stick, as was done during slavery.

Corporal punishments are not confined solely to beatings. A girl of 17 told me that the serious burns she had on her legs had been caused by her mother's throwing hot oil from a frying-pan at her in the middle of a violent quarrel.

Instances of such extreme forms of punishment, which are not very far short of bodily assault and cruelty, seem to be fairly frequent. I was told that some mothers burn their children with hot clothes irons "to make them feel". One boy who had been caught pilfering had a crosswise incision made in his fingers. The pedagogical logic behind this was that the scars would remind him of the sinfulness of stealing for the rest of his life.

Although most fathers and elder brothers do not seem to be inclined to spare the rod, it is chiefly mothers who mete out punishments. Most beatings are inflicted by female heads of households without legal or common law husbands. These women, who usually have to go out to work in the mornings, are as a rule tired and irritable on coming home. As a result the strain of running the household and having to put up with naughtiness from the children will simply become too great. These mothers will work off their feelings of vexation on the children by punishing the latter often and severely, even for the slightest offences. The notion that regular beatings are essential for a child's normal development is widespread. When I asked one woman why she beat her 10-year-old son with a leather strap every day (the boy's legs displaying infected weals) she replied that he always refused to do his homework and wanted to do nothing but play outside all the time. A daily beating was necessary for him, although it seemed to have little effect, according 
to her. A young woman who once lashed out to slap a toddler stated the opinion that "beating is good, since then you don't have to forbid the youngster anything".

Lower-class Creole women tend to feel that the right to beat their children is reserved strictly to themselves and their husbands (or eldest sons and mothers). If a mother catches any stranger beating her child she will react most aggressively. This provided a frequent source of conflict wit teachers. Although corporal punishment in schools has been prohibited for some time, many teachers still consider it the most effective form of chastisement and hence have continued to use it.

Boys and girls usually play together until the age of puberty. Boys who go around with girls too much are called "sissies" by their friends. Hence there is some division according to sex observable in groups of playing children, though this is rather vague and arbitrary.

Parents seldom give their children an adequate sex education. Boys are told not to masturbate because it purportedly causes insanity or because, according to the prevailing belief, it can cause ejaculatio praecox in later life. But boys are ridiculed sooner than punished if caught masturbating, in which case the emphasis is put on their acting "like a little boy". Girls are seldom informed about menstruation beforehand. A number of female primary school teachers informed me that it is not uncommon for girls to undergo their first period as a deeply shocking experience because of fears that they may bleed to death. The only information a mother is likely to impart to her daughter after this event is that she is thenceforth to shun all physical contact with boys. But she will seldom go into greater detail and inform the child of the secrets of procreation. Lower-class Creole women tend to feel extremely embarrassed at discussing such matters with their children. An important factor in this - apart from certain Christian religious notions - is fear lest the child may stop respecting its mother. In contrast, grown-ups tend to discuss the most intimate aspects of the manwoman relationship with surprising frankness and facetiousness as a subject of amusement among themselves, in the presence of members of both sexes.

Hence boys and girls have to rely for the greater part on what they can find out from their friends or are able to infer from certain goings-on at home as far as their sex education is concerned. So the ideas they form in this respect are of ten entirely false.

Despite the inadequate information and the embarrassment at discussing sex with children, a girl's first period is even so not allowed to pass 
altogether unnoticed. Many girls receive presents of such things as a tiny gold ring or pendant or earrings to mark the occasion. This is supposedly good for a girl's soul or (A) kra, which is believed to demand some such offering.

There are a great many magical beliefs associated with menstruation. A woman is avoided as much as possible by her environment during her menses - it is especially the men who try to avoid all contact with her at this time. No lower-class Creole male will have sexual intercourse with a woman having her period. This is carried to such lengths as to cause many men to refuse to let a woman cook for them during this time, because they believe she will contaminate the food. They will do anything - have their meals at a Chinese restaurant, cook their own meals or eat bread - to avoid this. There are also many women who refuse to eat food prepared by a menstruating woman. Women who make a living by selling food, such as biscuit vendors, for example, are mostly women in their menopause. This way their customers may be sure that the food they buy has not been prepared by a woman in her menses. Among the Bush Negroes, too, it is forbidden for a menstruating woman to cook her husband's meals (cf. Van Wetering, 1966, p. 53). Among the Saramaccans women having their period are placed in a hut by themselves (Datta wosu). As was observed earlier, menstrual blood may be used for certain magic purposes. A woman wishing to engage a man's affections, for instance, will mix some of this blood into his food or drink. Blood is believed to contain considerable "vital essence", as it is called, while this is believed to be present in even stronger concentration in menstrual blood. Quite possibly there are traces of Jewish belief, in addition to African elements, in the prevailing taboos with regard to menstruation. After all, many of the former plantation owners were members of this faith. As Leviticus 15, verse 19, ordains, a menstruating woman "shall be put apart seven days: and whosoever toucheth her shall be unclean until the even."

As regards a young person's first sexual experiences we would make the following observations. Boys are on the whole allowed greater freedom than girls. They usually gang up with boys from the same neighbourhood or the same school. These gangs play an important role during a boy's early life as well as the rest of his adult life. With the members of this gang the boy, and later on the grown-up man, goes to the cinema, soccer matches, parties and so on. These gangs are as a rule very heterogeneous on the point of age. The younger boys try to imitate their older friends, usually the leaders of the gang, in every way. These 
gangs usually have fixed meeting-places, such as outside the house of one of the members, or in one of the local Chinese stores, where there are often a few benches offering patrons seating while enjoying a drink or a snack. It is in these stores that the boy has his first taste of alcohol and cigarettes. Here he sits listening with rapt attention to the tales told by the older boys about their - real or imaginary - sexual experiences. He begins to realize that if he wishes to count for someting with his friends he, too, must be able to tell stories of his "experiences". The latter circumstance may prompt some boys to go to one of the prostitutes whose addresses are known in the gang. While in other cases a boy may start an affair with an older woman - usually someone who has been abandoned by her husband - who will "initiate" him. First sexual experiences with girls of the same age are much rarer.

The latter is true also with respect to girls. Although parents and elder brothers will try to protect their daughters or sisters against the advances of men, they are not always equally successful. Girls are kept at home as much as possible so that all their actions may come under strict surveillance. They are usually allowed to go out only if accompanied by a specific girlfriend. There is no rigid chaperonage system as in the Latin countries among the lower-class Creoles. Because of the absence of a father who might help keep an eye on them, it is easy enough for many young girls to escape the watchful eye of their mothers. This is further encouraged by mothers being regularly away from home to earn the family's livelihood, so that a girl is often alone in the house or is able to go out without her mother's knowledge.

Most young girls have their first sexual experience with older men who are already married or living in concubinage. The following reasons seem to suggest themselves for this:

(1) Older men are on the whole better off financially than younger men, who in many cases earn lower wages or are out of work altogether. Furthermore, as less money is normally spent on daughters than on sons, as was observed above, an affair with an older "patron" is likely to be more attractive, since he will be able to give a girl the necessary money to buy the clothes and shoes she so eagerly desires. $\mathrm{He}$ is further able to take her to places where she most likes to be seen. The older man's spending pattern far exceeds the financial capacities of the younger man.

(2) An older married man, or man with a common law wife, may reasonably be expected not to make their affair too public. This 
consideration carries special weight with girls who have improved their social position, such as office girls, for instance, since young men are well-known to brag about their conquests to their friends.

(3) Older men are more likely to promise a girl to give her the necessary money for an abortion "if anything goes wrong", while younger men are mostly unable to afford this.

(4) Young girls are in addition often defenseless against the advances of older men for psychological reasons. Because she is brought up to the idea that she is inferior to men, a girl will often find it difficult to resist a man, who is likely to be quite domineering and may furthermore in many cases be her boss.

The loss of virginity does not cause as sharp a drop in a girl's market value as in many Latin American countries. Although it was formerly the custom (and may still sometimes be today) to display the bloodstained bedsheet after the wedding night, there is no strongly developed virginity complex here. Admittedly the girl who is still a virgin has better prospects of making a legal rather than a common law marriage than her "fallen" sister, but there is no hard and fast rule regarding this. It is not uncommon for men marrying a woman with a child of a previous union to adopt the latter into his household. Men marrying women who already possess such children do not suffer any appreciable loss of prestige.

\subsubsection{Social Relations During Childhood}

\subsubsection{With the Parents}

The mother or the woman who fills her role (mostly mother's mother) is the more important parent for the lower-class Creole child. It generally has a weak tie with its father, who is either absent altogether or is often away for work or pleasure.

If the mother has to go out to work the child will be committed to the care of a female relative or neighbour. As a very young child at school it will often be brought up by a female teacher. Hence it is not surprising that the lower-class Creole man or woman should be more dependent emotionally on women than on men for the rest of his or her life, since it is mostly women who give children security and guidance and who dominate them. Married men or man living with a common law wife often still visit their mothers daily, in which case the latter will prepare their sons' favourite dishes for them. Many men marry only 
after their mother has died, as was observed earlier. Women experiencing difficulties in their love life or going through some other crisis go to their mothers for help and advice. The maternal figure is looked upon as someone on whom one can always rely, as the constant factor, whereas the child is uncertain about the place the father figure occupies in his life, although it does know that it must treat the latter with due respect where present.

\subsubsection{With Brothers and Sisters}

Girls are charged with the responsibility of looking after their younger brothers and sisters during their mother's absences from a fairly early age. The tie with the elder sister is often exceptionally strong, the more so since the latter generally takes over the running of the household from the mother if she turns invalid or dies. There is a general tendency to spoil the youngest child of the household thoroughly, especially if it is a boy. As has been stated earlier, boys are on the whole favoured over girls, which gives rise to frequent tension in the brother-sister relationship. The eldest brother, who of ten fills the part of the father, is the man of the house who raises the other children together with their mother. Much attention is given to, and money spent on, the education of the eldest child, especially if this is a son. In return he is expected to support his mother (and where present, father), brothers and sisters financially if he finds a good job later on in life. Mothers also expect this of daughters, usually the eldest, though little money is generally spent on the education of girls. The level of ambition of mothers with respect to their sons is often unrealistically high, tending chiefly in the direction of the learned professions. As was said above, the youngest children are thoroughly spoilt - also by their brothers and sisters though this may come to an abrupt end at the birth of a new brother or sister. As a result of the fact that boys are economically and emotionally favoured over girls, a certain rivalry remains between brothers and sisters for the rest of their lives.

\subsubsection{With Other Persons}

Many lower-class Creole children are entrusted to the care of grandmothers, aunts, neighbours, and at present also nurses at crèches, among others, from babyhood as a consequence of the absence of a father and hence by necessity the daily absence of their mother. Crèches are 
meeting an extremely strong need for the working mother. Before their introduction, young children sometimes had to be locked into the house if their mother had to go out to work and was unable to find someone to mind them. Foundlings were formerly quite common. At the time of research there were two crèches operating in Paramaribo (Foundation Crèche on Gemenelandsweg, and Queen Juliana Crèche in Gravenstraat). The former of these had been in operation for about fifteen years. The lady in charge told me that her crèche was looking after about 240 children between the ages of 3 months (minimum) and 6r/2 years (maximum). This Foundation Crèche is a semi-government childminding centre run on subsidies from the Social Services Department. Of the children admitted to this crèche around $80 \%$ are lower-class Creole. Admission is not unrestricted, as both crèches are filled to capacity. The opening-hours are adjusted to the working-hours of the mothers, extending from 6 a.m. to 5.30 p.m. The fees payable are calculated on the basis of the mother's income. The children are given food and clothing at the crèche. The idea of having one's children looked after by strangers at a crèche is not foreign to the pattern of life of the lower-class Creole. Thus the Creole youngster has interaction with persons not belonging to his household from early infancy. It is partly as a consequence of this that the Creole from this class is fairly unhibited in his contacts with strangers, being used from early childhood to having people other than his mother (mostly women) look after him. Especially in the yards, where people are in the habit of walking in and out of each other's houses, one frequently comes across children in households where they do not belong but where they are nevertheless "at home". For the lower-class Creole woman it is the most natural thing in the world to look after the children of other women. Sometimes the tie with such children will grow so strong as to cause the woman in question to adopt such a child and raise it as her foster-child. On asking one woman with two children and one foster-child how she had come to adopt the latter she told me that before she got the child to live with her she used to look after it regularly whenever her brother went out with the child's mother, who according to her was a whore and neglected the child, for several days at a time. The child became so attached to her that the mother allowed her to keep it after discussing the matter with her. It should be noted that the informant's brother (who had meanwhile broken off relations with the woman in question) was not the father of the child. 


\subsection{Adulthood}

\subsubsection{Man-Woman Relationships}

The principal reason for the termination of a union between a man and a woman listed in section 8.2.2.2. was the inability or refusal of the husband to give his wife a reasonable housekeeping allowance. For a proper insight into man-woman relationships in the West Indian family system a more detailed discussion of the connection between a man's income and his relations with women seems called for.

A man earning a low income or none at all will find it impossible to dominate his wife and maintain his position as head of the household. Women only have "respect" for men who make enough money to support the household. For as long as a man is able to fulfil this obligation (and it should be borne in mind here that this may be the case with many lower-class Creole men, especially skilled labourers, for many years of legal or common law marriage) he will be treated with the utmost respect, consideration and submission in the household by his wife and children. He then has a patriarchal role. As soon as he begins to fail in his role as breadwinner, however, his wife will show him increasingly less respect and her loyalty to him will gradually disappear. She will in the end generally tell the man to leave the house or will herself move out with the children. Where possible she will try to find a better breadwinner. It is rare for a man to continue living in the household after the woman has taken over from him as head. There was only one instance of a female head of a household with a (invalid) husband in our sample (type $\mathrm{E}$ of table $\mathrm{B}$, appendix 3 ). In the case of the 14 female heads of households with common law husbands (type F, cf. table B, appendix 3) these common law husbands were discovered to have moved in with the female head after the latter's breaking off an earlier relationship with a legal or common law husband, rather than had the headship "seized" from them by the woman in question.

For the lower-class Creole male who is aware that his failure as his family's breadwinner implies the loss of the respect of his wife and children there presents itself a way of abandoning the field in time without loss of dignity to himself. Besides the "French leave" tactic there is also that of starting an affair with another, preferably younger, woman so as to provide his wife with an excuse for giving him notice to leave the household.

In that case he will not lose his friends' respect for being "a man 
turned out of his home by his wife". His masculine pride then remains intact, especially if the woman with whom he has the new affair has a child by him. As was observed earlier, young women usually have their first child by an older man, the West Indian family cycle beginning with this phase (see sections 9.5.1. and 8.3.2.1.).

Because of the shortage of "unattached" males with a reasonable income, many women who have lost their husbands through death, "infidelity" or desertion are seen to be unsuccessful in finding a new partner to support them. Their experiences with the opposite sex have moreover in many cases proved so disappointing as to incline them to have recourse solely to members of their own sex. This has led to a high incidence of Lesbianism.

\subsubsection{Homosexual Relations between Women}

Intimately connected with the West Indian family system, whereby women's reliance on men as permanent breadwinners is often undermined, is the high prevalence of Lesbianism among lower-class Creole women.

Whereas the lower-class Creole tends to strongly condemn and ridicule homosexuality in men, he is relatively tolerant towards homosexual relations between women. There are comparatively few signs of homosexuality among men, and most lower-class Creoles believe that it hardly occurs among them. Many of my informants expressed the opinion that this phenomenon is rather widespread among their Hindustani and Javanese compatriots, however, as well as among the Creole population of Curaçao - these categories, excepting that of the Javanese, being the ones to which people are most inclined to be antagonistic in Surinam.

Lower-class Creole society makes little secret of the widespread occurrence of Lesbianism, on the other hand. The Lesbian female (mati or kompe) is an extremely common phenomenon. Every person knows of at least one couple of Lesbian women living together, and is likely to proffer the view that Lesbianism is on the increase, in particular also among younger women at present. People are inclined to be so open about this as to render it quite normal for women to send radio stations requests for records for their "mati".

Lesbianism has been a familiar phenomenon in the lower-class Creole subculture for quite a long time. There are reports of its occurrence in the writings of some relatively early observers of the society of Surinam. So Baron A. J. Schimmelpenninck van der Oye, for instance, refers in 
a report of a committee instituted by Government Resolution of 1910 to "Sexual relations between women (the so-called matie game), which immoral behaviour has increased markedly over the past decade, so I am told, and has, alas, already infiltrated deeply into the public morals. Not only are young girls and single women of different classes - the poorest of whom often go and live together in pairs so as to reduce the costs of rent and food for each - prone to it, but women cohabiting with men and even mere school-girls are becoming involved in it as well, after the example of their elders." (Ambacht, 1912, pp. 98, 99). Almost a quarter of a century later Melville J. and Francis S. Herskovits described the customs in connection with birthday parties given by Lesbian women for their mati that were popular at the time (Herskovits and Herskovits, 1936, p. 32). Van Lier (1971, p. 289) has also pointed to the existence of Lesbian practices among lower-class Creole women.

In the course of my fieldwork I came into contact with a number of matis after being introduced by one of my female informants at a party given by a women's club. Elderly matis may in some cases form social clubs, mostly for dancing, which meet regularly. Such clubs may on occasion arrange parties. The occasion for such parties is usually provided by the birthday of one of the members. Relatives and friends of both sexes are usually invited to these gatherings, and there is little to distinguish them from the usual dances which one may attend in Paramaribo. There is dancing to the music provided by a band or recordplayer and amplifier and there is the normal share of eating, drinking and merrymaking. The only difference is that here one may observe a somewhat larger number of women dancing in slightly closer embrace than at regular parties, it being not unusual for women to dance together at "normal" parties, too, if there are not enough men present. The club members are anything but promiscuous - on the contrary, the women are reportedly extremely jealous of their partners. The party I attended was given by twelve women friends. There was nothing secretive or mysterious about it, being held in a house the French doors of which were flung wide open onto the street. Inside there was dancing to the music of a hired band. Neighbours without invitations came to watch the dancing from the street without making any comments or showing any signs of disapproval. There is nothing unusual about such interest being shown in a party by on-lookers in the street, although the mati party drew slightly more attention from the people in the street than an "ordinary" party would, because there is still something slightly curious about such an event to the public at large. Three of the members of the 
club had dressed in men's clothes especially for the occasion, while the others wore koto yaki.

Lesbianism is not a condition for admission to the membership of such a club. Women may join these clubs for the companionship they offer and to benefit from the mutual moral support and financial assistance the members give one another. Elderly women without husbands are often dependent on these clubs for their social contacts, although sometimes also women who are still married may become members. But by and large the members of the clubs are women in their menopause who in many cases have a heterosexual career behind them but now no longer have a male partner.

The existing uneven sex ratio in the higher age-groups is only partly responsible for older women entertaining sexual relations with members of their own sex. Unpleasant experiences with members of the opposite sex are also an important factor in this.

A number of utterances of matis which I recorded seem to point in this direction, viz.: "Men only want young girls these days", "My husband left me years ago and is living with someone else now", "After my fourth child I wanted to have nothing more to do with fellows", "G. A. is a member because her husband is impotent and his jealously is stopping her from going around with other men; but he does not object to this".

Sometimes these clubs include one or two men among their members. This is because it is not uncommon in some neighbourhoods for the members of such a club to be molested by a group of local inhabitants after a meeting. These latter may shout obscenities at them, and so on. It is the task of the male members of the club to prevent such incidents, by force if necessary. They are in most cases rather brawny or even tough characters whose physical strength inspires awe. According to some informants they fulfil this function on account of the financial reward offered them for their services by the women - one informant said something about money and free sexual access to the club members.

Although most Creoles are inclined to be tolerant about the existence of matis, there are evidently also a number among them - mainly women - who object most strongly to Lesbian women. Their objections, which they sometimes vent in aggressive behaviour, are illustrated by the following statements.

A common law widow of 47 with 6 children stated the opinion that the matis should be exterminated, as there were too many of them around. She has accordingly strictly forbidden her children to have 
anything to do with two matis living together in the same yard as she. She is afraid lest the women try to win over her young daughters to the mati game. She is anxious to prevent this, as she believes that the mati game can cause cancer and tuberculosis. A married woman of 35 tended to think that only vulgar persons engaged in this. According to her there are many prostitutes among them. "You have to pester them to get rid of them if they come and live near you", she contended. One 54-yearold woman explained to me why the mati game causes illness. Intercourse with a man causes the body "to discharge all its fluids", thereby keeping a person healthy. But because this does not happen in the mati game, all kinds of diseases may develop, especially cancer. A common law wife of 38 told me she had threatened her 17-year-old daughter with branding her private parts with a hot iron if she ever found out she was involved in mati nonsense.

Matis often set up house together. One of the partners, mostly the more dominant one, will provide the household's livelihood, while the other stays at home to do the housework and look after the children or grandchildren where present. One also often finds two partners living in separate households and visiting each other daily. Some are in the habit of dressing exactly alike. Though formerly non-Lesbian women friends also used to do this, the fear of being taken for a mati is at present putting an end to the practice.

There is usually an economic reason for matis living together. Two girlfriends who find themselves in a difficult economic position may join their respective households together so as to economize on such items as house rent and rates, for instance. One also comes across women without any income and without hope of ever finding (another) husband to look after them being compelled to find some girlfriend as a last resort and getting the latter to take them into their home and support them in return for sexual favours.

Besides the unequal sex ratio as a factor, this behaviour is at present also being encouraged by the difficulty experienced especially by women with vertical social mobility in finding a male partner of equal social status. This may lead them to give preference under the circumstances to a Lesbian relationship rather than a series of casual affairs with men, which may furthermore result in unwanted pregnancies. Thus Lesbianism is reportedly quite common among hospital nurses, policewomen and girls who are following or have completed some form of secondary education, for instance. So one female informant told me that one of her friends, who was a teacher, had confided to her that she preferred 
the mati game to intercourse with a man, "who will only give you a baby and go". Hence there seems to me to be a definite correlation between the instability of unions between men and women and the frequent occurrence of homosexuality among women.

\subsubsection{Contacts with Other Persons}

The lower-class Creole tends to have a great variety of social relations with persons outside his household. Especially the inhabitants of some of the older neighbourhoods all seem to know one another, and, as we have already said above, regularly walk in and out of each other's houses. The relations a woman may have with her next-door neighbours are often very close. Men maintain close relations with their regular friends, some of whom may even be childhood friends. Men who are often out of a job will in many cases take refuge with these friends, who form the only group in which they may still enjoy some prestige, by being an authority on soccer, or being a great drinker or seducer of women, for instance. Such groups of men are found everywhere, usually endlessly talking politics or soccer, in cafés, Chinese shops or on the doorstep of the house of one of the group of friends. Apart from such unorganized contacts quite a large number of lower-class Creoles are members of organized clubs and societies, ranging from sports clubs to political party associations and secret fraternities. As regards these latter, there is the International Secret Order of the Foresters and that of Mechanics, of which 28 and 13 household heads of my sample, mainly from the higher income groups, were members respectively. The Foresters and Mechanics (originally English societies; the Mechanics separated from the Freemasons in 1757 , becoming predominantly a society for the ordinary man) fulfil an important social function, lending their members assistance in the event of illness or death. They furthermore assist the widows and orphans of their members. Members of the Mechanics - which is accessible only to men - help each other to find jobs. Both brotherhoods possess secret rites. The Mechanics refuse to admit anyone living in concubinage as member; some men may enter into legal marriage with their concubines especially to qualify for membership. The membership fees of both orders are relatively high. As a result it is mostly lower-class Creoles from the higher income brackets who are members.

The sample was discovered to include 36 women (21 female heads of households and 15 female members of households) who were members of so-called prayer groups (begi). Three male heads of households were also discovered to be members of such groups. The members of these 
groups hold prayer meetings at the home of one of them in the afternoons or evenings. At these meetings there are communal prayers and religious singing. Some of the members, mostly men, may give sermons - which may be very long-drawn - in the course of the hymn-singing. The begis, which are not affiliated with any particular Church, are viewed with due distrust by the clergy, as these admit the followers of every Christian denomination as members, and as the proceeds from collections held at the meetings are often spent on some lavish feast rather than being handed over to the Church (information given by $\mathrm{J}$. Voorhoeve). In the 19th century participation in these begis was forbidden to Roman Catholics on pain of excommunication because the Church authorities believed they displayed a number of pagan traits. At present most members of these societies are elderly women. Members of these groups, too, may assist each other financially. Such assistance may be especially welcome to old people, as most people in this phase of their life cycle live in dire straits.

\subsection{Old Age}

The most difficult phase of the life of the lower-class Creole often sets in when he or she grows old. Economically speaking a great many old people are exceedingly badly off. Unless a man or woman has been successful in building up some reserves for approaching old age - in the form of some property, such as a house, or some superannuation arrangement - he or she will be completely dependent on the children, the poor relief fund, or total strangers. So it is not uncommon for elderly women to move in with their children and fulfil a function in connection with the upbringing of their grandchildren (cf. table I, appendix 3, categories 56 and 58). We see old men doing this less of ten (cf. table I, appendix 3, categories 55 and 57). Hence many old men and women who have no relatives to take them in are found to be living alone (cf. table M, appendix 3). They of ten live in dire poverty. Because of the social isolation in which many are living, the death of quite a few of them may not be discovered until days afterwards.

This brings us to the subject of the customs observed in connection with death and burial which is of such prime importance to the lowerclass Creoles.

\subsection{Death}

The lower-class Creole spends the utmost care on the preparation of the dead for burial and on the funeral itself. At the death of a member of the household, his or her relatives face the task of arranging a 
"decent" funeral and organizing a wake and special memorial gatherings, all of which entail considerable expense. As we have already discussed above (section 7.3.4.4.) many people insure themselves against these costs by joining medical and burial societies. The sums refunded by these cover only part of the expenses that have to be incurred for the proper care of the dead, however. As for weddings, the expenses for funerals are extremely high. They are often unforeseen, moreover, so that people may get into heavy debt for this. As we saw above, the degree of lavishness and extravagance of a wedding feast may enhance or diminish the prestige of families. The same is true also for funerals, and the environment is bound to cry shame upon people who have failed to pay their dead the proper last honours.

The existence of elaborate rites in connection with the burial of the dead is a cultural trait that is found in most Negro cultures in the New World. So Métraux (1957, pp. 100-102, 1959, pp. 243-256) and Courlander (1960, pp. 30-40) have described the rites in connection with death in Haiti. With respect to the United States, Frazier (1965, pp. 375-376) pointed out the existence of burial societies particularly among rural Negroes. The latter author places strong emphasis on the importance attached by them to a "decent funeral", saying, "However destitute of worldly goods the rural Negro has been, he has often borne his lot patiently as long as he was consoled by the prospect that he would be 'put away right', i.e., given a decent burial".

Herskovits pointed out that the emphasis Negroes in the New World put on proper burial should be regarded as a survival of African cultural elements, in which ancestor worship plays an important role. He says: "The elaborateness of funeral rites in the area is cast in terms of the role of the ancestors in the lives of their descendants, and because it is important to have the assurance of the ancestral good will, the dead are honored with extended and costly rituals. In all this region, in fact, the funeral is the true climax of life, and no belief drives deeper into the traditions of West African thought. For the problem of New World survivals this is of paramount importance, for whatever else has been lost of aboriginal custom, the attitudes toward the dead as manifested in meticulous rituals cast in the mold of West African patterns have survived." (Herskovits, 1964, p. 63). He further defines the importance of this as follows: "For the dead are everywhere regarded as close to the forces that govern the universe, and are believed to influence the wellbeing of their descendants who properly serve them" (Herskovits, 1964, p. 197). 
As we shall see below, this concept has become mixed up with Christian views on life after death.

The elaborate, costly ritual is not, therefore, provided solely from prestige considerations, but rather testifies to the existence of a characteristic complex of ideas concerning survival after death (cf. section 7.3.4.4.).

No thorough investigation was conducted by us into the influences of the African religion on the family life. We purposely refrained from going into this subject at any great depth, as in many lower-class Creole families the significance of African processes is either a negligible quantity or it is latent.

So many people are seen to be averse to what they term "paganistic" matters, though some of these "agnostics" — and not all of them persons from the lower classes only - may be discovered in major crises to revert to the African religion. Hence the customs in connection with death described below are not observable in a uniform degree in all lowerclass Creole families.

\subsubsection{Description of the Customs observed in Connection with Death}

When a person dies his mortal remains must be interred between 18 and 36 hours after his death, according to the law of Surinam. Hence a great many things have to be attended to within a period of 36 hours in order to be able to give the deceased a fitting burial.

In the first place the deceased person's relatives and friends must be notified of his death by the members of his household, neighbours or friends. It is customary to have the death of a relative announced by radio. The regular programme will then be interrupted, funeral music played and an announcement to the following effect made by the announcer: "The relatives of ... announce with deep regret the passing away of their... (specification of the relationship of those making the announcement to the deceased and name of the deceased)". The age at which he or she died and the time of death are also stated. The announcement is concluded with more funeral music, after an expression of the wish that the deceased may rest in peace. As the majority of the lower-class Creoles have their wireless sets turned on most of the day an obituary via this medium constitutes the most effective way of communicating the news to a wide public, so that many people may then be able to attend the funeral and/or the wake, if held.

The deceased's relatives get in touch with his parish minister or priest, 
if the latter was not present at the death-bed. Then they approach the burial society of which the deceased was a member with a death certificate issued by a medical practitioner or a statement signed by a cleric. The best-known burial societies are affiliated with the different religious denominations. The principal ones are the Moravian "Jubileumfonds", the Roman Catholic "Verbond", the Reformed Dutch "Stuiversvereniging" and the Lutheran "Vrede en Arbeid". The Stuiversvereniging and Vrede en Arbeid are the only ones which admit non-members of the affiliated religious denomination to their membership. The death also has to be registered at the Registrar's Office by the deceased's relatives.

Most burial societies extend facilities for borrowing the necessary equipment for a wake to the relatives of deceased members. This includes palls, candelabras, candles and a bier on which to place the corpse. The so-called "corpse-washers" are called in to lay out the body. These persons are mostly members of the same church as the deceased. They devote themselves to laying out and dressing bodies for burial as an "act of charity". These persons are said to do this work for the glory of God, and are consequently rewarded with good health. They are organized into a brotherhood of "corpse-washers" which possesses its own code of honour. The members of these brother (or sister-) hoods are admitted under oath. The brotherhoods are affiliated with both the Churches and particular burial societies.

These corpse-washers possess a number of secrets concerning principally techniques in connection with the preparation and embalmment of corpses, which they refuse to divulge to the uninitiated. This kind of work is done by both men and women. Usually a member of the same sex as the deceased is charged with the task of laying out the body. One of the taboos they must observe strictly is that prohibiting them from performing this task if they have had sexual intercourse in the past 24 hours. Although the corpse-washers are treated as respectable members of their religious communities by their fellow-members of society, they are responsible for the preservation of a number of practices, through the advice they pass on to the relatives of deceased persons, of which the church authorities disapprove and which they label as "paganistic". This is especially true of the corpse-washers of the popular churches, namely the Moravian and Roman Catholic Churches, as they try to put themselves across to outsiders as repositories of specific esoteric knowledge and supernatural powers. One such corpse-washer of the Moravian Church claimed he "knew" when someone whose body he had to lay out had died, for example, as he could hear the "spirit" of 
the deceased "knocking" at his door. His colleagues who usually accompany him in his work also received such signs. After being thus warned they assemble at a pre-arranged point from which they proceed to the house of death together. Other corpse-washers said they were simply notified by the deceased person's relatives of the latter's death. Corpsewashers never work alone - there should be at least two present at the preparation of a body for burial, though it is not uncommon for seven or eight to work together.

When they arrive at the house of death the corpse-washers are left alone with the body and the hired funeral equipment in a separate room. None of the relatives is allowed to be present at the laying out and the washers make sure that no-one is able to spy on them while they are at work.

It is their task to make the body as presentable as possible, and to preserve it from decay long enough to delay the process of decomposition until after the funeral. This no easy task in a humid, tropical climate. They go about this by pouring half a litre of formalin into the dead person's mouth, washing the body with formalin and wrapping it in a sheet moistened with the same chemical, which process is referred to as "embalming". The orifices are plugged with tobacco moistened in rum or cotton wool soaked in formalin. The mouth is tied shut with the so-called chin-cloth.

Some old people may state the wish before they die to be laid out according to the old-fashioned method, involving the use of the juice of the "zure oranje" (sour orange, Citrus aurantium). This was mixed with dram (a kind of rum), tobacco, salt and camphor. A lot of dram was needed for these "orange jobs", much of which the corpse-washers consumed rather than using it all on the body, to help them to build up a resistance to the odour of the corpse and thus remain "healthy". It is because of this that they are regarded by many as tipplers.

As I observed in the course of my field-work, many of these corpsewashers appeared to be slightly intoxicated after finishing their work. All of the males as well as a few of the female washers interviewed by me constantly asked for alcoholic drinks during the interview (which request I readily complied with as they claimed this helped them to think more clearly!).

At present, since the virtually exclusive use of formalin for this work, the deceased person's relatives usually give the corpse-washers a bottle of brandy or wine to take in with them during their work of preparing the body. It is also customary to serve them sandwiches or breadrolls. 
The relatives may later give them presents in reward for their services. The corpse-washers sing religious songs during the preparation of the corpse. They lay it out in a kind of trough placed on a stand, in which old rags are placed to catch any of the moisture spilt. Meanwhile the relatives give the house a thorough cleaning - if this has not already been done before - and prepare it for the reception of the guests expected to take part in the wake. Mirrors ${ }^{1}$ and pictures are covered with a sheet or hung back to front. Chairs and couches for seating the guests are borrowed or hired. Everyone dresses in white, which is the colour of deep morning here. Most Creole men who are at all able to afford one possess a white suit. Women, especially the older ones, tie a white kerchief around their head and throw a white shawl around their shoulders. They also wear white dresses. This deep mourning they wear until the day of the memorial gathering held on the eighth day after the death (aite de). The colour of light mourning is mauve. People who have climbed socially now also may wear black for mourning.

Food and drink have to be prepared for the expected guests. In addition to coffee, tea and cocoa, alcoholic beverages are served. The drinks are served with rusks, wheat roasted in burnt sugar and roasted peanuts. Well-to-do people serve their guests a complete meal, usually consisting of boiled bananas with meat and rice.

When the corpse-washers have finished their work they leave the room with the wet rags from the bier. Everyone rises respectfully to their feet when they pass and then all go in to inspect the result of their work. The body is usually placed on ice-blocks covered with black draping. Beside the bier are placed candelabras with candles. One of the corpsewashers remains in the house to look after the body and assist the relatives with advice. He also takes action if decomposition sets in too soon. If the body begins to "sweat", for instance, he will pour a strong brine solution into its mouth.

The relatives assemble around the bier to await the guests between seven and eight o'clock in the evening. The guests - most of them also dressed in white - go around expressing their condolences to the deceased's close relatives assembled around the bier. This is often accompanied with loud weeping and wailing. Everyone has the right to

1 De Rek (1967, pp. 374-375) observes in his cultural history of the Netherlands in the 17 th and 18th centuries that in the house in which a death had occurred "The mirror was reversed, as a person's reflection was his soul, and the soul of the dead person might be tempted to carry off the souls of the living". 
visit a house of death, called "dede oso", including strangers. It is a known fact that there are a number of poor people who make the rounds of all dede oso and collect all the food and drink served around here. They even take bottles with them in which to collect the cocoa served to take home. They are popularly designated "dede oso alatta", or "mourning-house rats".

At eight o'clock a prayer is said and hymns are sung. This prayer and hymn session lasts until about ten o'clock, when the official part of the ceremony ends. The late arrivals among the guests then have an opportunity to offer their condolences to the relatives seated around the bier.

Snacks and drinks are not served until after ten - before that time only glasses of water are passed around. More hymns and chorales are sung. Usually only the men sing, led by a cantor who knows the words well and runs them quickly through before each verse for the others to repeat. The guests help themselves to generous servings of the food and drink. Some may drink more strong drink than they can hold. There is no smoking inside, as this is supposedly uncomfortable for the deceased's spirit. Despite this slight inconvenience, the atmosphere here becomes quite excited and boisterous, though everyone feigns grief. Usually there is too little room to seat all the guests inside, so that they often have to be seated on chairs and benches outside the house. I observed a number of the female guests stretched out fast asleep on such benches late at night during one such dede oso.

A wake normally lasts until five o'clock in the morning. Though some of the guests may leave earlier, most of them remain present throughout the entire wake out of courtesy. According to popular belief a deceased's spirit abandons the body at five in the morning. There is some final hymn singing, after which the guests take leave of the relatives, and the latter are left alone.

In the course of the day the corpse-washers come once more to place the boy in the coffin 3-4 hours before the funeral is scheduled. They unwind the corpse from its shroud, wash it once more and dress it in its good clothes and lay it in the coffin, placed on two chairs or a stand. They remove the chin-cloth from the body, as otherwise its spirit will be unable to speak, and the relatives take care to see the cloth does not fall into the hands of people who might commit evil with it - in order to prevent black magic. ${ }^{2}$

2 Cf. W. F. van Lier (1940, pp. 276-291) for a detailed description of Bush Negro customs in connection with death and burial. 
When the washers have done they call in the relatives to say goodbye to the dead person. It is most important that this is done in order to prevent the deceased's spirit from returning. Hence it is imperative that one take proper leave out of respect for the spirit. Usually the first question asked the relatives by guests at a funeral or other outsiders is whether this has in fact been done with due propriety. It is one of the corpse-washers' chief functions to counsel the relatives correctly in this matter. So it is customary for the latter to step three times across the coffin in this connection. The coffin is placed on the floor especially for this purpose. Small children are lifted across. Alternatively, the deceased's relatives may place their hands on his or her forehead and utter the words "rest in peace". Wives comb their husband's hair for the last time on this occasion. The dead person is given certain of his personal belongings to which he was especially attached in his lifetime to take with him in his coffin, such as his spectacles, tobacco jar or comb. Wives are usually advised by the washers or some of their women friends to place one of their possessions in the coffin as well, so that their husband's spirit will not be tempted to visit them. For this purpose they will place a wad of cotton wool in their mouth or armpit, thereupon to put it in the coffin. According to the popular belief the spirit of the deceased man will now no longer try to visit his wife, as her odour is with him. Some women even place a sanitary napkin they wear during menstruation in the coffin as a precaution against this. To safeguard the children of the deceased against visitations from his spirit, the height of the children under four (some informants said seven) is measured from top to toe with a piece of string. This string is then rolled up and placed in the coffin. But the most effective safeguard is provided by tying a blue ribbon around the children's arms as well.

Both wives and husbands of deceased persons may take due precautions to ensure that the spirit of their deceased partner does not come and visit them in order to have sexual intercourse with them at night. The consequences of this are believed to be especially unpleasant for widows, as it supposedly causes their abdomen to swell enormously. In order to avoid this some women may tie a dark-blue cotton cloth before their private parts before going to sleep every night for six weeks. In this cloth pins are stuck with their sharp points turned away from the body. This is believed to make it impossible for the spirit to carry out its intentions. Men may sometimes wear jockstraps at nights to discourage the spirits of their wives in a similar way.

The coffin is usually closed one hour before the funeral. Before the 
lid is screwed on, a handkerchief is spread over the dead person's face. As soon as the hearse (horse-drawn or motorized) and the bearers arrive all the chairs in the house are moved against the walls. The bearers sing hymns as they lift the coffin with some ceremonial display. They carry the coffin once around the room while making shuffling dance-steps. It is customary for the women to burst out in loud wailing and lamenting as the coffin is borne out of the house. Some may even have a fit. In lower- as well as middle-class families it is not uncommon for the wife, mother or daughters of a deceased person to have a hysterical fit, which has an almost institutionalized character and is popularly referred to as "convulsions". In former days the bearers used to carry the coffin all the way to the cemetery, making shuffling steps at all the street-corners on the way. But at present the coffin is conveyed in a coach or motorcar which the guests follow on foot. Close relatives and, where present, distinguished guests, follow immediately behind the hearse. If the deceased was a man, the women will follow after that, and then the men, while the reverse order is observed if the deceased was a woman.

The ceremonies at the graveyard are dependent on the deceased's religious affiliation. There is usually a speech by a priest or minister. A collection is taken, the proceeds of which are spent, if the family is Roman Catholic, on special Masses for the soul of the dead person. The burial society usually provides guarantees to pay for one or two Low Masses. For members of the Moravian community a special memorial service is usually held in church, that is to say, if the relatives have not already arranged a special aite de gathering. The Church is strongly opposed to the latter practice as it purportedly also possesses definite paganistic traits.

On their return home from the graveyard the relatives are still not left alone, as friends and other relatives drop in once more to offer their condolences. The week following the funeral is filled with visits from people prevented from attending the wake and funeral.

\subsubsection{The Memorial Gathering on the Eighth Day}

A special memorial gathering is arranged in honour of the dead person on the eighth day after his death. ${ }^{3}$ His relatives again have to hold open house to all who wish to come and commemorate the deceased person.

3 For a description of the eighth-day meeting in Curaçao see E. E. Abrahamvan der Mark (1969, p. 180). 
As on the occasion of the dede oso, the relatives are again constrained to go to great expense. There is even more eating and drinking at these aite de gatherings than at the dede oso. They also begin in the evening and continue all through the night. The deceased is remembered in a short prayer, while this, too, is accompanied by the singing of hymns and chorales. The guests tell each other Anansi-tori or animal fables of which the spider Anansi is mostly the hero. In former days there were professional story-tellers who were specially commissioned to divert mourners assembled at the house of deceased persons by narrating these stories (Encyclopaedie 1914-'17, p. 44). At the aite de celebration an oblation is poured for the spirit of the deceased outside his house. Some food from the meal is also put out for it at the rear of the house. One rather skeptical informant told me that this is usually eaten by dogs.

The aite de gatherings sometimes degenerate into purely festive affairs or "true orgies", as one Moravian clergyman qualified them. It is for this reason that the Moravian Church has tried to ban them and has begun by way of reaction to institute special memorial services for deceased members on condition that the relatives of the deceased forgo all aite de celebrations.

Where a deceased person was an active member of some club or society, such as a prayer group or dancing club, the members of these may also organize special memorial meetings for their late member. This is usually done before the gathering on the eighth day.

If the relatives of a deceased person wish to uphold all the traditions they will organize another meeting similar to that just described six weeks after the death. This will then be repeated once more one year after the death.

Not an equal amount of trouble is taken over every dead person. The death of a child, for instance, receives much less attention. According to Herskovits and Herskovits (1936, p. 38), for women who have died in childbirth only a perfunctory wake is held, which is attended only by close relatives or a few older persons, or none is held at all. I was unable to verify whether this is still the custom. The indigent are also buried with little ceremony. The Social Welfare Department provides a plain coffin without a "dome" for such persons, as well as a plain hearse with an ununiformed driver and bearers for its conveyance.

Persons who have advanced socially and who have some of them left the Moravian Church to become Reformed Dutch or Lutheran, follow the customs described above to a much lesser extent. Although they may hold a wake for friends, this is kept very austere. There is usually 
no singing at these, nor are alcoholic beverages served. The guests leave the house of mourning before midnight. The Churches, which are opposed to wakes and memorial gatherings, have welcomed the construction of a mortuary, which was inaugurated in January 1965. The authorities believe that this will produce a reduction in the number of wakes, since it will be possible for the bodies of deceased persons to be kept here.

All these customs centering around death are illustrative of the arguments set forth by Malinowski $(1948$, p. 47) in the chapter entitled "Death and Reintegration of the Group" of his work Magic, Science and Religion. He points out that in all funeral rites there is side by side with the desire to preserve the ties with the deceased person a parallel tendency to break these. This is also borne out by my observations. On the one hand people seek to break off all relations with the deceased by taking "proper" leave of them and taking all kinds of precautions to ensure that those surviving will not be in any way troubled by their spirits, while on the other they tend to try by means of Wintiprees or through the intermediary of an obiaman to get in touch with the spirits of the ancestors to help set matters right especially in major crises. Malinowski pointed out in the work cited above that the community becomes disintegrated by the death of one of its members. The principal function of the funeral ritual, in his opinion, is to effect the reintegration of the group. This is doubtless also true with regard to the mortuary rituals of the lower-class Creoles of Surinam. A person's death implies a loss not only to his relatives but also to the community as a whole. The latter will become reintegrated by the holding of wakes and memorial gatherings to which everyone, even people who are total strangers to the surviving relatives, is welcome. The presence of a large number of people at these occasions is a source of comfort and consolation to the relatives, who are thus made aware that they are an integral part of a society which sympathizes with them (cf. Henriques, 1953, p. 185). 


\section{FINAL REMARKS}

\subsection{General}

In the preceding pages the family system of the lower-class Creoles of Paramaribo, ${ }^{1}$ past and present, was described and analysed. In this connection we discussed in detail the far-reaching changes to which their way of life and culture have been subject over the years. In the course of this historical development a family system which has preserved certain constant traits throughout the various phases of their history evolved among them from quite an early stage. It shows definite correspondences with the characteristics of what is termed the "West Indian family system", namely: the presence of institutionalized alternative man-woman relationships and the prevalence of female heads of households connected with matrifocality (cf. sections 1.3., 1.3.1. and 1.3.2.).

It was underlined that the development of the system was essential to provide the slaves and their descendants the lower-class Creoles with the means of surviving as a group in a society confronting them with major problems in the social, economic, legal, religious and political spheres. Hence this institutionalization should also be regarded as a process of adaptation, or adjustment to totally new and almost invariably adverse circumstances, as a refined instrument whereby the slave/lower-class Creole was able to go on living, multiplying and perpetuating his particular subculture in the society of Surinam. It is a flexible system, as it proved effectual as an instrument of survival under the various social systems which Surinam has known in the course of its history.

So we see that despite the major changes in the economic structure of Surinam, extraordinarily enough the nature of the family system, and more particularly the structure of the limited family, of the slaves and their descendants the lower-class Creoles remained virtually unchanged (cf. section 1.4., hypothesis A). The colony of Surinam, where plantation farming constituted the chief sector of the economy, grew into a self-governing province of the Kingdom of the Netherlands, with

1 Similar research was conducted in the same period in Curaçao by A. F. Marks (1973). 
mining and some secondary industry and intensive farming at present constituting the principal economic sectors. The drastic changes involved, which gave rise to a radical change in the social structure as well, have not, however, effected a change for the better in the socially inferior position of the Creole proletariat. In the past the slaves, and later the bulk of their descendants the lower-class Creoles, lived under conditions of steady "Verelendung", or progressive deterioriation and pauperization, as plantation labourers, subsequently to live a life of poverty as an urban proletariat to the present day. Efforts to stimulate Surinam's economic growth in recent years have not so far succeeded in promoting the emergence of an energetic Creole lower class maintaining a reasonable social and economic standard of living.

The lower-class Creole male, who during slavery was of virtually no importance economically to his wife and children, and thereafter became a figure occupying an uncertain, precarious position on the labour market (as he still does today), is a person whose ability to permanently support a family the whole of society discounts. As a result he has come to have a mentality, forced upon him by the social conditions, that has in turn engendered to a large extent the lower-class Creole's defeatist attitude with respect to his ability to improve himself socially. Any future socio-economic development scheme for Surinam should therefore give considerable attention to ways of broadening the economic perspectives for the Creole from this group. Where the past held mostly a succession of missed opportunities for him, future measures should be aimed at transforming the socio-economic climate in such a way as to open up to him in his pattern of expectations with regard to his life lasting prospects of being able to fulfil a role and possess a status enabling him to assume permanently the position of effective head of his household.

The continued failure of the authorities to frame appropriate policies is compelling women even today to make certain arrangements to ensure their own and their children's economic survival after the man of the family has stopped bringing in money. The basis for the concomitant independence and self-sufficiency of women was laid as early as the period of slavery, when the master used to provide for his slave families, irrespective of whether or not there was a man present. The resultant independence of women of their husbands continued after Emancipation, too, because most men, although they were now "free", were incapable of exercising an occupation that provided them with the necessary stable income, and thus the indispensable socio-economic basis for supporting 
a family. The nature of many of the callings followed by men was such, moreover, that they were of necessity absent from home for long periods of time (e.g. the balata and gold industries and oil refineries in Curaçao). Because of this unfavourable situation only a small minority of the lower-class Creoles were in a position to earn a stable income and accumulate material possessions of any significant worth. These developed into a rather puny Creole middle class. We shall discuss in the section below the way in which the family system that developed in this context functions as an adaptation model.

\subsection{The West Indian Family System of Paramaribo as an Adaptation Model}

The lower-class Creole subculture of Surinam is the outcome of an acculturation process whereby individuals of primarily West African cultural origin were forced by the bearers of a Western culture to accept a subordinate, inferior position. The resultant culture displays marked traits of what Spicer has termed the fusionistic type of acculturation. "The essentials of fusion are that elements of two or more distinct cultural traditions be involved, that they combine into a single system, and that the terms of which they combine not be the same as those governing the cultural system from which they come." (Spicer, 1961, p. 532; Locher, 1963, p. 127.)

African cultural elements played a significant part in this process, and the aggregate of cultural traits the Negro brought with him to Surinam from Africa should by no means be undervalued. Basing himself on the observations of the sociologist U.G. Weatherley (1923, pp. 290-304), Van Lier writes that even if the Negro did not perhaps possess a great deal of "objective cultural equipment" on arrival in America, his mind was at any rate no tabula rasa. He had a number of specific interests, propensities and capacities when he came here. The direction he was able to give these in the slave society determined his entire subsequent culture (Van Lier, 1951, p. 293). Hence the West Indian family system might quite conceivably have developed in a different direction altogether if, for instance, marriage in Africa had been not only economically but also religiously sanctioned.

The family system within this culture evolved by way of a restructuring of particular socio-cultural elements, developing into a mechanism composed of interlinked and interacting elements, with the interaction between affinal and consanguineal relations being regulated by collec- 
tive rules of behaviour. The following aspects of lower-class Creole culture can be considered as preconditions for the functioning of this system:

(a) the possibility for men and women to make a choice out of several types of union that are socially accepted within their own social stratum;

(b) the possibility of breaking off such unions without much ado (in particular common law marriages and visiting relationships);

(c) women's predisposition and preparedness to become the head and breadwinner of their household (matrifocality).

$A d$. (a). The possibility of making a choice out of different kinds of manwoman relationship as dictated by a given social, economic and demographic situation was seen to exist as early as the period of slavery. The shortage of women on the plantations which resulted from a larger number of male than female slaves being put to work as field labourers here and from the possibility for men of prominent rank - both freemen and slaves - to have more than one wife, prevented large numbers of men from having co-residential relationships with women on their own plantations. They had to adjust to this situation either by having extraresidential or visiting relationships on a different plantation or by resigning themselves to having casual affairs on their own.

In Paramaribo, too, the visiting relationship received considerable impetus during the period of slavery. Here the principal factor responsible was the shortage of male slaves, however. Many men could afford to have more than one wife by reason of the substantial surplus of women, thus upholding in some measure the West African polygynous system. These women they visited in the latter's own residential units. After Emancipation the visiting relationship slowly disappeared in Paramaribo, to become primarily a "luxury" for more well-to-do men who were able to afford more than one wife. Co-residential unions in the form of legal and common law marriages became the most frequent type of union in the family life of the lower-class Creole. Concubinage became socially accepted and has remained prevalent down to the present day.

One of the corollaries of slavery and its aftermath was that for many lower-class Creoles a prosperous style of life, which most of them were unable to attain, was a precondition for legal marriage. Because the expenses involved in marrying before the law and the attendant administrative red tape also deterred many from marrying thus, common 
law marriage is to be viewed as a form of adjustment to a social system wherein the lower-class Creole occupied a socially and economically inferior position both during and after slavery. The institutions of the "alliance" and the Roman Catholic form of marriage (for which marriage at law was not preconditional), which had come to be accepted as adaptive forms of marriage for Christianized slaves - enabling them to meet their ecclesiastical obligations in a society in which they were officially debarred from legally marrying - remained in force for some time after Emancipation without, however, having the chance to develop into the customary law marriage of the lower-class Creole. The shortsighted policies of the Government and the Moravian Church were chiefly to blame for this. Notwithstanding the fact that Registry Office discrimination with respect to the conclusion of legal marriages has at present been eliminated and the costs for this no longer constitute an insurmountable obstacle even for the less prosperous, common law marriage has not given ground. This is because the notion that legal marriage is a form of union which only the socially successful - or more particularly, people who are able to give evidence of this by holding a lavish wedding feast, being able to afford a comfortable home and furnishings, and arranging their lives in such a way as to obviate the necessity of the wife going to work in the category of menial jobs (at the very least as teachers or clerks) - may enter into is still very much alive in broad groups of the lower-class Creole population.

Although a number of progressive members of the younger generation are abandoning this viewpoint and marrying even if the above conditions are not fulfilled, the majority of lower-class Creoles continue to adapt to their social environment mostly by living in concubinage in the most austere material circumstances, with most of the women earning extra money in some socially low-rating job as charwoman, laundress, and so on.

If the trend whereby younger people marry without fulfilling the set "norms" continues, the lower-class Creole family system is likely to develop in the direction of the present-day family system of the (lowerclass) Negro in the United States, which is more assimilated to Western culture (cf. section 1.3.1.).

Ad. (b). The possibility of breaking off (some) man-woman relationships with ease (instability) is generally held to be "dysfunctional" for a given society. Though I in no way wish to deny that there are definite dysfunctional aspects attaching to instability of the relations between 
men and women, in my view it also possesses an obvious functional aspect with regard to the West Indian family. For if we view the phenomenon of instability as part of the process of adaptation to specific socio-economically unfavourable circumstances (in particular unemployment), this will be seen to constitute a means of somehow providing the household with a breadwinner on the one hand, and of obviating too painful an accentuation of the marginality and lack of function of males who do not fulfil any role or possess any status as regards the outside world on the other. ${ }^{2}$ In section 9.6.1. we described how men who fail in their role als breadwinner are compelled to break off their relationship in due course. Women on the whole refuse to provide for men. Because of this men are forced to leave their wife and children as soon as they are no longer able to provide for them. In this situation the wife will as a rule accuse her husband of having an affair with another woman. Although this is not always true, it is seized on by women as an excuse for getting rid of their husbands. It similarly provides the male with an opportunity of preserving his prestige as a "macho", especially among his friends, and, moreover, leaves the woman free to take another man and provider into her house or herself to move in with another man, if she has the opportunity, within a relatively short space of time without any great loss of prestige to herself. If she is not successful in this, she will be able to keep her household in continuance in some other way, such as by taking up a full-time job herself, in which case she will usually get an elderly female relative (mostly her mother) to move in with her to mind the children, or - and this, too, should be viewed as an element of the adaptation model - by having a homosexual relationship, either co-residential or extra-residential, with a woman who will support her economically. Hence the high frequency of Lesbianism in Surinam is to be regarded rather as a function of the dislocation of the socio-economic structure than of any individual psychological disturbances.

$A d$. (c). In connection with (b), women's predisposition and preparedness to act as heads and breadwinners of their households where necessary should also be regarded as an element of the adaptation model. This predisposition, the foundations for which were laid quite soon after

2 A very important question that remains to be answered is what the consequences of such a family system are likely to be for the future personalities of children. To date virtually no research has been done on this aspect of the West Indian family system in Surinam. 
the abolition of slavery, has survived among a large number of women down to the present day. Even where a woman has a husband-breadwinner (especially if she has entered into a common law marriage with him) she will make sure as a rule not to be entirely dependent economically on him. She does so by going out to work, whereby she may place herself in a more or less economically independent position with respect to her husband. This practice has made some women so independent as in some cases to lead them to refuse to enter into a legal marriage (which is more difficult to terminate) and to give decided preference to concubinage.

The arguments brought forward under (a), (b) and (c) imply that the characteristics of alternative man-woman relationships, namely instability and matrifocality, should also be viewed as functional elements necessary for the continued existence of the lower-class Creole group in Surinam, as well as for any other group that is commonly considered socially inferior, living in circumstances preventing men from earning a sufficient living to enable them to support a household on a permanent basis. This gives such a family system an extremely flexible character (cf. section 1.4., hypothesis B.). So we see the so-called "West Indian family system" occurring not only in the Caribbean area but also in urban centres in North America and the rest of South America, and in Africa and Asia, as well as in those of the rural areas of these continents where the same conditions obtain (cf. Lewis, 1969).

It should, however, be regarded as a "solution", evolved by people who have lived under these specific socio-economically unfavourable conditions for prolonged periods of time. The nature of these conditions, which has not fundamentally improved for the slaves and their descendants the lower-class Creoles in Surinam since the foundation of the colony, has as a result made for the continuance of this family system to the present day. We did, however, observe certain modifications in the course of time, such as the changes in the essential nature, social status and spread of the alternative man-woman relationships, and the fluctuations in the prevalence of female heads of households and the connected phenomena surrounding matrifocality (latent and manifest).

In conclusion we wish to make the following remarks with respect to hypotheses B and C, set out in section 1.4. Although the lower-class Creole subculture of Paramaribo is moving in the direction of greater assimilation to the culture of Western industrialized society, it is doubtful whether the family system will in the end become a variant of the Western family system. Even if employment opportunities for men do 
improve decidedly, it is even so unlikely that a Western-type middle-class family system will evolve among the lower-class Creoles within the next few generations, because the characteristic family system of the Creole lower classes has become so deeply rooted here. It is furthermore very much open to question whether the family system evolved in the West will prove after all the most ideally suited to conditions in an industrialized society, let alone those in a post-industrial one. For the values and norms underlying it in the West are displaying obvious cracks and strains everywhere, while their relevance is being constantly challenged by both internal and external forces and influences in an ever more rapidly changing society. These developments aside, I have attempted in the present study to analyse the lower-class Creole group's response to the challenges of both the historical and contemporary social forces which have left their imprint on this group from the perspective of lower-class reality. 
Letter of Introduction

APPENDIX 1

\title{
WOSUNA
}

Netherlands Foundation for the Advancement of Research in Surinam and the Netherlands Antilles

PARAMARIBO, March 1965.

Commewijne St. 18,

Zorg en Hoop.

\section{Dear Sir/Madam,}

I would ask your attention for the following:

I have been in Paramaribo for some time doing preliminary work in connection with a sociological study of the family life of the Creoles living in this town. This study will form part of a series of research projects conducted in Surinam under the auspices of WOSUNA, the object of which is to gain an insight into the life of the people of Surinam.

For the success of my study it will be necessary for me to gather information about the domestic life, problems, attitudes and beliefs of a large number of Creoles. In order to obtain this information I have drawn up a questionnaire to the questions of which I would like to ask about 500 Creole men and women who are heads of households to supply the answers.

As either yourself or one of the members of your household are one of the 500 heads of households I have selected by the random method for this purpose, I would ask you to be so kind as to receive one of my interviewers in your home in the course of one of the next few days and to give him the answers to a number of questions he will ask you.

Of course the information given by you will be treated as confidential and kept strictly private by myself and my assistants.

Trusting that you will lend your cooperation,

\author{
Yours sincerely, \\ (signed) W. F. L. Buschkens.
}


The Questionnaire

APPENDIX 2

\section{WOSUNA}

Research on the Creole family in Paramaribo

Name of interviewer:

No.:

Date:

Examiner's initials:

Length of interview:

Codifier's initials:

Address of household:

Note: Before commencing the interview inform the respondent that the information given will be treated as confidential and that you are neither a Taxation Officer nor a Poor-Relief official. Show your letter of introduction from WOSUNA.

Ask to be shown any of the family documents present. 
APPENDIX 2*

\begin{tabular}{|c|c|c|c|}
\hline & Head of Household & & \\
\hline & Column No. 1 & Golumn No. 2 & Column No. 10 \\
\hline $\begin{array}{l}\text { 1. Names of members } \\
\text { of household } \\
\text { a. surname } \\
\text { b. first name }\end{array}$ & , & , & p. \\
\hline 2. Place of birth & $\begin{aligned} & \text { 1. } \text { Paramaribo } \\
& \text { 2. } \text { Suriname Distr. } \\
& \text { 3. } \text { Commewijne ", } \\
& \text { 4. } \text { Marowijne ", } \\
& \text { 5. } \text { Brokopondo " } \\
& \text { 6. Saramacca ", } \\
& \text { 7. } \text { Coronie ", } \\
& \text { 8. Nickerie ", } \\
& \text { 9. } \text { French Guiana } \\
& \text { 10. } \text { British Guyana } \\
& 11 . \text {...................... }\end{aligned}$ & $\begin{aligned} & \text { 1. } \text { Paramaribo } \\
& \text { 2. Suriname Distr. } \\
& \text { 3. Commewijne ", } \\
& \text { 4. Marowijne " } \\
& \text { 5. Brokopondo " } \\
& \text { 6. Saramacca " } \\
& \text { 7. Coronie " } \\
& \text { 8. Nickerie " } \\
& \text { 9. } \text { French Guiana } \\
& \text { 10. } \\
& \text { 11. } \\
& \text {........................ }\end{aligned}$ & $\begin{aligned} & \text { 1. } \text { Paramaribo } \\
& \text { 2. Suriname Distr. } \\
& \text { 3. Commewijne ", } \\
& \text { 4. Marowijne ", } \\
& \text { 5. Brokopondo ", } \\
& \text { 6. Saramacca ", } \\
& \text { 7. Coronie ", } \\
& \text { 8. Nickerie }, \\
& \text { 9. } \text { French Guiana } \\
& \text { 10. British Guyana } \\
& \text { 11. .................. }\end{aligned}$ \\
\hline 3. Date of birth & & & \\
\hline 4. Sex & $\begin{array}{l}\text { 1. male } \\
\text { 2. female }\end{array}$ & $\begin{array}{ll}\text { 1. } & \text { male } \\
\text { 2. } & \text { female }\end{array}$ & $\begin{array}{l}\text { 1. male } \\
\text { 2. female }\end{array}$ \\
\hline $\begin{array}{l}\text { 5. Year of settlement } \\
\text { in Paramaribo }\end{array}$ & & & \\
\hline $\begin{array}{l}\text { 6. Relationship to } \\
\text { head of } \\
\text { household } \\
\text { (cf. list of possible } \\
\text { relationships) }\end{array}$ & & & \\
\hline $\begin{array}{l}\text { 7. Present marital } \\
\text { status }\end{array}$ & $\begin{array}{ll}\text { 1. } & \text { married } \\
\text { 2. } & \text { single } \\
\text { 3. } & \text { divorced } \\
\text { 4. } \text { widow } \\
\text { 5. } \text { widower }\end{array}$ & $\begin{array}{ll}\text { 1. } & \text { married } \\
\text { 2. } & \text { single } \\
\text { 3. } & \text { divorced } \\
\text { 4. } & \text { widow } \\
\text { 5. } & \text { widower }\end{array}$ & $\begin{array}{ll}\text { 1. } & \text { married } \\
\text { 2. } & \text { single } \\
\text { 3. } & \text { divorced } \\
\text { 4. } \text { widow } \\
\text { 5. } \text { widower }\end{array}$ \\
\hline $\begin{array}{l}\text { 8. Concubinage } \\
\text { (i.e., coresidence } \\
\text { of a man and } \\
\text { woman who are } \\
\text { not legally married } \\
\text { in same domicile) }\end{array}$ & $\begin{array}{l}\text { 1. at present living } \\
\text { in concubinage } \\
\text { 2. not at present } \\
\text { living in } \\
\text { concubinage }\end{array}$ & $\begin{array}{l}\text { 1. at present living } \\
\text { in concubinage } \\
\text { 2. not at present } \\
\text { living in } \\
\text { concubinage }\end{array}$ & $\begin{array}{l}\text { 1. at present living } \\
\text { in concubinage } \\
\text { 2. not at present } \\
\text { living in } \\
\text { concubinage }\end{array}$ \\
\hline
\end{tabular}

* Columns 3-9, which are identical with columns 2 and 10, have been omitted from this reduced reproduction of the questionnaire. 
APPENDIX 2

\begin{tabular}{|c|c|c|c|}
\hline & Column No. 1 & Column No. 2 & Column No. 10 \\
\hline $\begin{array}{l}\text { 9. Duration of } \\
\text { concubinage }\end{array}$ & $\begin{array}{l}\text { have been living in } \\
\text { concubinage with } \\
\text { present partner, } \\
\text { column no. ........., } \\
\text { for ........ years. }\end{array}$ & $\begin{array}{l}\text { have been living in } \\
\text { concubinage with } \\
\text { present partner, } \\
\text { column no. ........, } \\
\text { for ........ years. }\end{array}$ & $\begin{array}{l}\text { have been living in } \\
\text { concubinage with } \\
\text { present partner, } \\
\text { column no. ........., } \\
\text { for ........ years. }\end{array}$ \\
\hline $\begin{array}{l}\text { 10. Duration legal } \\
\text { marriage }\end{array}$ & $\begin{array}{l}\text { have been married to } \\
\text { present partner, } \\
\text { column no. ........, } \\
\text { for ......... years. } \\
\text { Date marriage: }\end{array}$ & $\begin{array}{l}\text { have been married to } \\
\text { present partner, } \\
\text { column no. ........, } \\
\text { for ......... years. } \\
\text { Date marriage: }\end{array}$ & $\begin{array}{l}\text { have been married to } \\
\text { present partner, } \\
\text { column no. ........, } \\
\text { for ......... years. } \\
\text { Date marriage: }\end{array}$ \\
\hline 11. Legitimacy & $\begin{array}{l}\text { 1. born in wedlock } \\
\text { 2. born out of } \\
\text { wedlock } \\
\text { a. recognized } \\
\text { by father } \\
\text { (date: ......) } \\
\text { b. not recognized } \\
\text { by father }\end{array}$ & $\begin{array}{l}\text { 1. born in wedlock } \\
\text { 2. born out of } \\
\text { wedlock } \\
\text { a. recognized } \\
\text { by father } \\
\text { (date: ......) } \\
\text { b. not recognized } \\
\text { by father }\end{array}$ & $\begin{array}{l}\text { 1. born in wedlock } \\
\text { 2. born out of } \\
\text { wedlock } \\
\text { a. recognized } \\
\text { by father } \\
\text { (date: ......) } \\
\text { b. not recognized } \\
\text { by father }\end{array}$ \\
\hline 12. Religion & $\begin{array}{l}\text { 1. Moravian } \\
\text { 2. Roman Catholic } \\
\text { 3. } \ldots \ldots \ldots \ldots \ldots \ldots\end{array}$ & $\begin{array}{ll}\text { 1. } & \text { Moravian } \\
\text { 2. } & \text { Roman Catholic } \\
\text { 3. } & \ldots \ldots \ldots \ldots \ldots \ldots\end{array}$ & $\begin{array}{l}\text { 1. Moravian } \\
\text { 2. Roman Catholic } \\
\text { 3. } \ldots \ldots \ldots \ldots \ldots \ldots\end{array}$ \\
\hline $\begin{array}{l}\text { 13. Ethnic affiliation } \\
\text { (to be filled in } \\
\text { only where this is } \\
\text { not Creole) }\end{array}$ & $\begin{array}{ll}\text { 1. } & \text { Hindustani } \\
\text { 2. Javanese } \\
\text { 3. Amerindian } \\
\text { 4. Chinese } \\
\text { 5. European } \\
\text { 6. Bush Negro } \\
\text { 7. } \ldots \ldots \ldots \ldots \ldots \ldots \ldots\end{array}$ & $\begin{array}{ll}\text { 1. } & \text { Hindustani } \\
\text { 2. } & \text { Javanese } \\
\text { 3. } & \text { Amerindian } \\
\text { 4. } & \text { Chinese } \\
\text { 5. } & \text { European } \\
6 . & \text { Bush Negro } \\
\text { 7. } & \ldots \ldots \ldots \ldots \ldots \ldots \ldots\end{array}$ & $\begin{array}{ll}\text { 1. } & \text { Hindustani } \\
\text { 2. } & \text { Javanese } \\
\text { 3. } & \text { Amerindian } \\
\text { 4. } & \text { Chinese } \\
\text { 5. } & \text { European } \\
6 . & \text { Bush Negro } \\
\text { 7. } & \ldots \ldots \ldots \ldots \ldots \ldots\end{array}$ \\
\hline
\end{tabular}


APPENDIX 2

14. (To be answered only if the head of the household is at present married.) How long did the head of the household live in concubinage with his/her wife/husband before marrying?

15. What was the principal reason for marrying at the time?

16. Has the present marriage of the head of the household been confirmed by a church ceremony?

If the answer is yes, in what Church?

17. Has the head of the household ever been married to or lived in concubinage with a different partner?

No. From...... to...... Nature of union
1.
1. mar. 2. conc.
2.
1. mar. 2. conc.
3.
1. mar. 2. conc.
4.
1. mar. 2. conc.

18. (To be answered only if the head of the household of the preceding question is a male.)

Has wife or concubine at present living with the head of the household ever been married to or lived in concubinage with another man before?

No. From to Nature of union
1.
1. mar. 2. conc
2.
1. mar. 2. conc.
3.
1. mar. 2. conc.
4.
1. mar. 2. conc.

* We distinguish between three types of termination, viz.:

a. divorce (in the case of legal marriage)

b. desertion (in the case of botr legal and common law marriage;

c. death
1. yes

2. no

1. Moravian

2. Roman Catholic

3.

1. yes (see table below)

2. no

No. of children Nature of termination *

1. yes (see table below)

2. no

No. of children

Nature of termination * 
APPENDIX 2

19. Does the female head of the household or the wife or concubine of the male head have any children not born of a legal marriage or concubinage?

1. yes

2. no

If the answer is yes, how many and when were they born?

No.

Name

Date of birth

1.

2.

3.

4.

5.

6.

7. 
N.B. Only the head of the household to be interviewed.

1. Chief occupation of respondent (Note: if running a private business this should be mentioned explicitly. If retired, this should also be mentioned.)

2. What is the respondent's monthly income from this?

S fl.

2. a. How much Child Endowment does this include?

S fl.

3. Does the respondent have any extra jobs?

4. What is the respondent's monthly income from these?

S fl.

5. Does the respondent have any additional sources of income?

1. rent of house $\mathrm{S}$

2. rent of rooms $\mathrm{S} \mathrm{fl}$

a month

rent of land

4.

a month

a month

6. Which other members of the household earn an income?

Name Occupation Monthly

1. Income

2.

$S$ fl.

3.

S fl.

4.

S fl.

5.

$\mathrm{S}$ fl.

S fl.

1. $\mathrm{S} f \mathrm{fl}$.

2. $\mathrm{S}$ fl.

3. $\mathrm{S}$ fl.

4. $S$ fl.

5. S fl.

8. Are you satisfied with the kind of work you are doing?

1. yes

2. moderately

3. no

If the answer is no, why not?

9. Is this household able to make ends meet on its total income?

1. yes

3. no 
APPENDIX 2

If the answer is no, what do you economize on?

10. Type of accomodation

11. How many rooms are there? (Only enclosed rooms to be included.)

12. Type of residence

13. The house is constructed mainly of

14. Age of house

15. Conditions of tenure of house

16. What is the amount paid by you for
1. food
2. clothing
3.

1. a detached residential unit

2. in tenement building or flat building (no. .........) specify number of apartments in the building)

No.

1. fronting street

2. yard dwelling

3. dwelling with shop fronting street

4. dwelling with workplace fronting street

5. yard dwalling with shop

6. yard dwelling with workplace

1. timber

2. stone, brick, concrete

1. $0-5$ years

2. 6-10 years

3. $11-20$ years

4. 20 years or older

5. age unknown

1. private property on privately owned land

2. private property on hereditary leasehold land

3. private property on leased land

4. rented

5. purchased on hire-purchase scheme

6. other

1. rent of house $\mathrm{S} f$

a month

2. ground rent $\mathrm{S} f$

a month

3. land rent

S fl.

a month

4. hire-purchase instalment

S fl. 
APPENDIX 2

17. What do you think of your accommodation?

18. What is the water supply like?

19. What amount do you spend on water a month?

20. Is the house connected up to the electricity network?

21. How much a month do you spend on electricity?

22. What do you cook on?

23. How much a month do you spend on this?

24. Bathroom facilities

In the case of 2 , outdoor bathroom or shower, how many other families do you share this with?

25. Sewage disposal

26. Which do you prefer to live in, a yard dwelling or a street frontage dwelling?

In the case of 1 . or 2., why?

27. Appliances in the house

8. How many beds are there in the house?
1. good

2. indifferent

3. bad

1. running water inside

2. running water outside

3. well, cistern, pump, tank

4. other

S fl.

1. yes

2. no

S fl.

1. gas (from main)

2. porta-gas

3. charcoal or wood

4. kerosene

5. electricity

S fl.

1. Inside bathroom or shower

2. Outside bathroom or shower

1. indoor water closet

2. outdoor privy

3. other

1. yard dwelling

2. dwelling with street frontage

3. no preference

1. refrigerator

2. sewing machine

3. washing machine

4. wireless set

5. gas or electric stove

6. record player

7. tape recorder

No. 


\section{APPENDIX 2}

29. Do adults and children over 10 years of age sleep together in the same room?

30. Vehicles

31. Are you satisfied with your accommodation?

If the answer is no, why not?

32. Do you expect your financial position to improve?

If the answer is yes, when?

33. Are you a member of a medical benefits fund or burial society, or do you have an insurance policy?

If the answer is yes, which one?

How much a month do you spend on this?

34. Would you like to live in the country?

35. Would you like to do agricultural work?

35. a. Which of the members of your household are looking for work?
1. yes

2. no

1. bicycle

2. motorized bicycle

3. motor cycle

4. scooter

5. car

6. van

1. yes

2. no

1. yes

2. no

3. no opinion

1. in the next year

2. in the next 5 years

3 . in the next 10 years

4. no idea

1. yes

2. no
S fl.

1. yes

2. no

3. no opinion

1. yes

2. no

3. no opinion

36. How long have they been looking for work? 
APPENDIX 2

37. Does this household receive any payments from the Poor Relief Fund or the Social Welfare Department?

1. yes

2. no

1. $\mathrm{S}$ fl. a month in cash

2. $\mathrm{S} \mathrm{fl}$. a month in food

38. If the female head of the household or the wife of the male head has a job, who looks after the children (from $0-12)$ when she goes to work?

1. an older female member of the household

2. a female neighbour

3. a crèche

4. no-one

5. are locked into the house

6.

39. Do you think corporal punishment is a necessary part of the children's upbringing?

1. yes

2. no

3. no opinion

If the answer is yes, why?

40. Is there a quiet place in the house where the children can do their homework?
1. yes
2. no
3. no opinion
1. Sranan
2. Dutch

41. Which is the most commonly spoken language in this house?

42. Do you ever pray with your children?

1. yes

2. no

43. When?

44. How often do you go to church? times a month times a year

45. If you are a Roman Catholic, how many times a year do you go to Holy Communion? times

46. Does a clergyman (minister, priest, and so on) ever visit you at home?

1. yes

2. no

47. If the answer is yes, how many times a year? times

48. Is anyone here a member of a prayer circle?

1. yes

2. no

If the answer is yes, who?

Name:

49. Is anyone here a member of the Foresters?

If so, who?

1. yes

2. no

Name: 
APPENDIX 2

50. Is anyone here a member of the Mechanics?

If so, who?

1. yes

2. no

Name:

51. Do you ever go to a cinema with your

1. yes children?

2. no

52. Do you ever go to a popular theatre performance with your children?

1. yes

2. no

53. Who is a member of a dancing club or fan club?

1.

2.

3. 
TABLE A Distribution of the Total Sample Population According to Sex and Age

\begin{tabular}{|c|c|c|c|c|c|c|}
\hline \multirow{2}{*}{ Age } & \multicolumn{2}{|c|}{ Male } & \multicolumn{2}{|c|}{ Female } & \multicolumn{2}{|c|}{ Total } \\
\hline & abs. & $\%$ & abs. & $\%$ & abs. & $\%$ \\
\hline $0-5$ & 197 & 7.0 & 184 & 6.5 & 381 & 13.5 \\
\hline $6-10$ & 233 & 8.2 & 232 & 8.2 & 465 & 16.4 \\
\hline $11-15$ & 194 & 6.9 & 193 & 6.8 & 387 & 13.7 \\
\hline $16-20$ & 159 & 5.6 & 140 & 5.0 & 299 & 10.6 \\
\hline $21-25$ & 106 & 3.7 & 119 & 4.2 & 225 & 8.0 \\
\hline $26-30$ & 73 & 2.6 & 87 & 3.1 & 160 & 5.7 \\
\hline $31-35$ & 48 & 1.7 & 78 & 2.8 & 126 & 4.5 \\
\hline $36-40$ & 41 & 1.5 & 70 & 2.5 & 111 & 3.9 \\
\hline $41-45$ & 54 & 1.9 & 79 & 2.8 & 133 & 4.7 \\
\hline $46-50$ & 36 & 1.3 & 59 & 2.1 & 95 & 3.4 \\
\hline $51-55$ & 40 & 1.4 & 56 & 2.0 & 96 & 3.4 \\
\hline $56-60$ & 37 & 1.3 & 49 & 1.7 & 86 & 3.0 \\
\hline $61-65$ & 25 & 0.9 & 57 & 2.0 & 82 & 2.9 \\
\hline $66-70$ & 27 & 1.0 & 38 & 1.3 & 65 & 2.3 \\
\hline $71-75$ & 17 & 0.6 & 32 & 1.1 & 49 & 1.7 \\
\hline $76-80$ & 12 & 0.4 & 24 & 0.8 & 36 & 1.2 \\
\hline $81-85$ & 3 & 0.1 & 17 & 0.6 & 20 & 0.7 \\
\hline $86-90$ & 3 & 0.1 & 5 & 0.2 & 8 & 0.3 \\
\hline $91+$ & 一 & - & 3 & 0.1 & 3 & 0.1 \\
\hline Total: & 1,305 & 46.2 & 1,522 & 53.8 & 2,827 & 100.0 \\
\hline
\end{tabular}




\section{TABLE B Types of Household Found in the Sample}

\begin{tabular}{|c|c|c|c|c|}
\hline \multicolumn{5}{|c|}{ MALE HEAD } \\
\hline A & with legal wife & 151 & $51.4 \%$ & $29.2 \%$ \\
\hline B & with common law wife & 103 & $35.0 \%$ & $19.9 \%$ \\
\hline C & without legal or common law wife & 18 & $6.1 \%$ & $3.5 \%$ \\
\hline \multirow[t]{2}{*}{ D } & single & 22 & $7.5 \%$ & $4.2 \%$ \\
\hline & Total & & $100.0 \%$ & \\
\hline
\end{tabular}

\section{FEMALE HEAD}

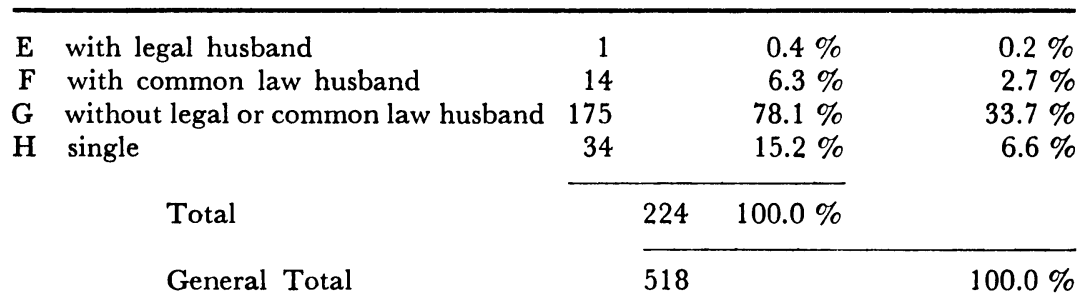

APPENDIX 3

TABLE C Males over the age of $\mathbf{1 6}$ according to marital status

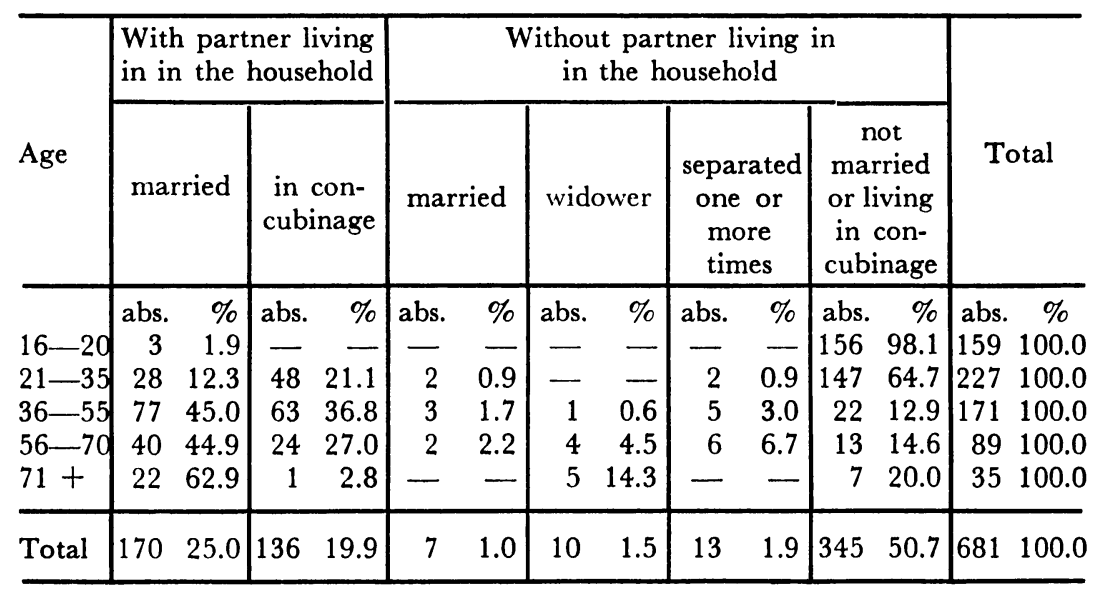


党

ஃ

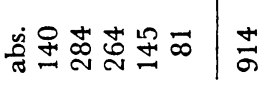

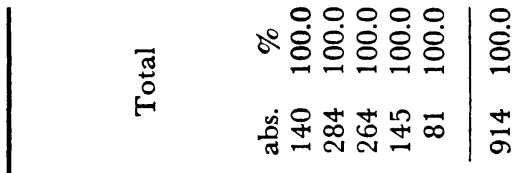

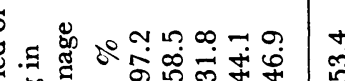

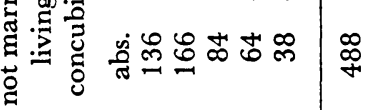

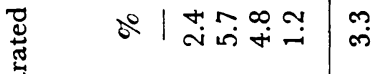

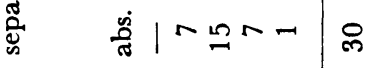

वी

त ह

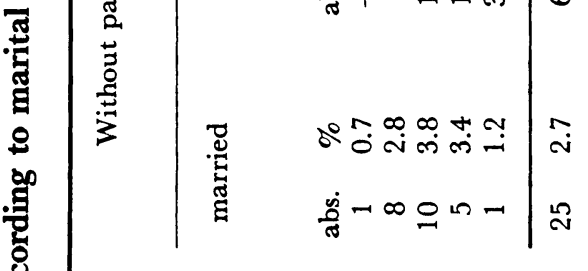

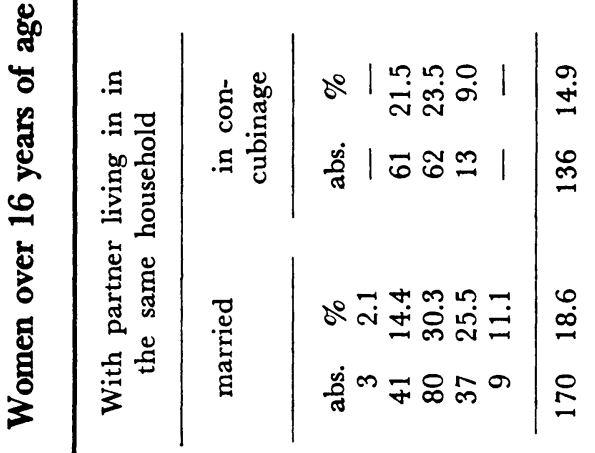

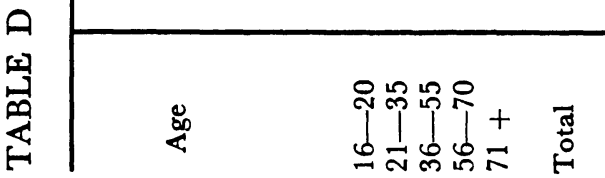


APPENDIX 3

TABLE E Age at time of first marriage of the Creole population of Paramaribo for the year 1962

\begin{tabular}{lccclllllll}
\hline Age & & -20 & $21-25$ & $26-30$ & $31-40$ & $41-50$ & $51-60$ & $61-70$ & $71+$ & Total \\
\hline Males & abs. & 22 & 134 & 86 & 65 & 24 & 17 & 5 & 2 & 355 \\
& $\%$ & 6.1 & 37.7 & 24.3 & 18.3 & 6.8 & 4.8 & 1.4 & 0.6 & 100.0 \\
Females & abs. & 107 & 126 & 56 & 48 & 27 & 15 & 4 & - & 383 \\
& $\%$ & 27.9 & 32.9 & 14.7 & 12.5 & 7.1 & 3.9 & 1.0 & - & 100.0
\end{tabular}

Statistics derived from the Marriage Registers in Paramaribo. 
照

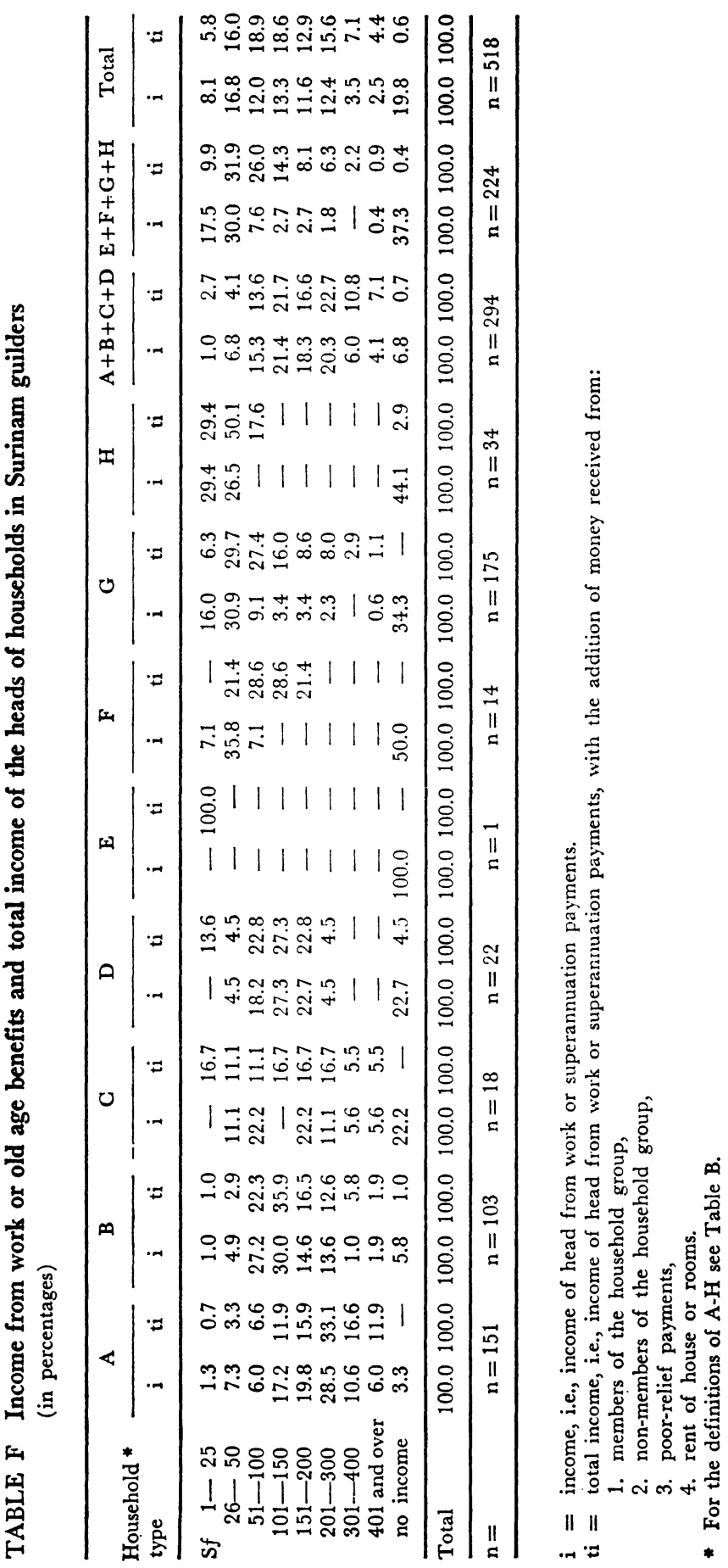


APPENDIX 3

TABLE G Material possessions of households (in percentages)

\begin{tabular}{|c|c|c|c|c|c|c|c|c|}
\hline $\begin{array}{l}\text { The household * } \\
\text { possesses one or } \\
\text { more of the } \\
\text { following items }\end{array}$ & $n=151$ & $n=103$ & $\mathrm{n}=18$ & $\mathrm{n}=22$ & $\mathrm{n}=1$ & $n=14$ & $\mathrm{n}=175$ & $\mathrm{n}=34$ \\
\hline Refrigator & 61.6 & 27.2 & 11.1 & 13.6 & 0.0 & 21.4 & 25.1 & 2.9 \\
\hline Sewing machine & 68.9 & 55.3 & 22.2 & 9.1 & 100.0 & 42.9 & 52.0 & 5.9 \\
\hline Washing machine & e 72.8 & 42.7 & 22.2 & 4.5 & 100.0 & 42.9 & 41.1 & 0.0 \\
\hline Radio & 94.0 & 89.3 & 66.7 & 63.6 & 100.0 & 85.7 & 76.0 & 50.0 \\
\hline Gas/electr. stove & 62.3 & 18.4 & 16.7 & 22.7 & 100.0 & 21.4 & 34.9 & 8.8 \\
\hline Record player & 13.9 & 1.0 & 0.0 & 0.0 & 0.0 & 0.0 & 1.1 & 0.0 \\
\hline Tape recorder & 6.0 & 1.0 & 0.0 & 0.0 & 0.0 & 0.0 & 0.6 & 0.0 \\
\hline Bicycle & 72.8 & 46.6 & 61.1 & 40.9 & 100.0 & 64.3 & 44.6 & 0.0 \\
\hline Motorized bicycle & e 21.9 & 21.4 & 22.2 & 18.2 & 0.0 & 7.1 & 12.6 & 0.0 \\
\hline Motor cycle & 1.3 & 0.0 & 0.0 & 0.0 & 0.0 & 0.0 & 1.7 & 0.0 \\
\hline Scooter & 2.0 & 0.0 & 0.0 & 4.5 & 0.0 & 0.0 & 1.1 & 0.0 \\
\hline Car & 5.3 & 2.9 & 5.6 & 0.0 & 0.0 & 7.1 & 1.1 & 0.0 \\
\hline Van & 0.7 & 1.0 & 5.6 & 4.5 & 0.0 & 7.1 & 0.6 & 0.0 \\
\hline
\end{tabular}

* For the definitions of A-H see Table B. 
APPENDIX 3

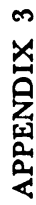

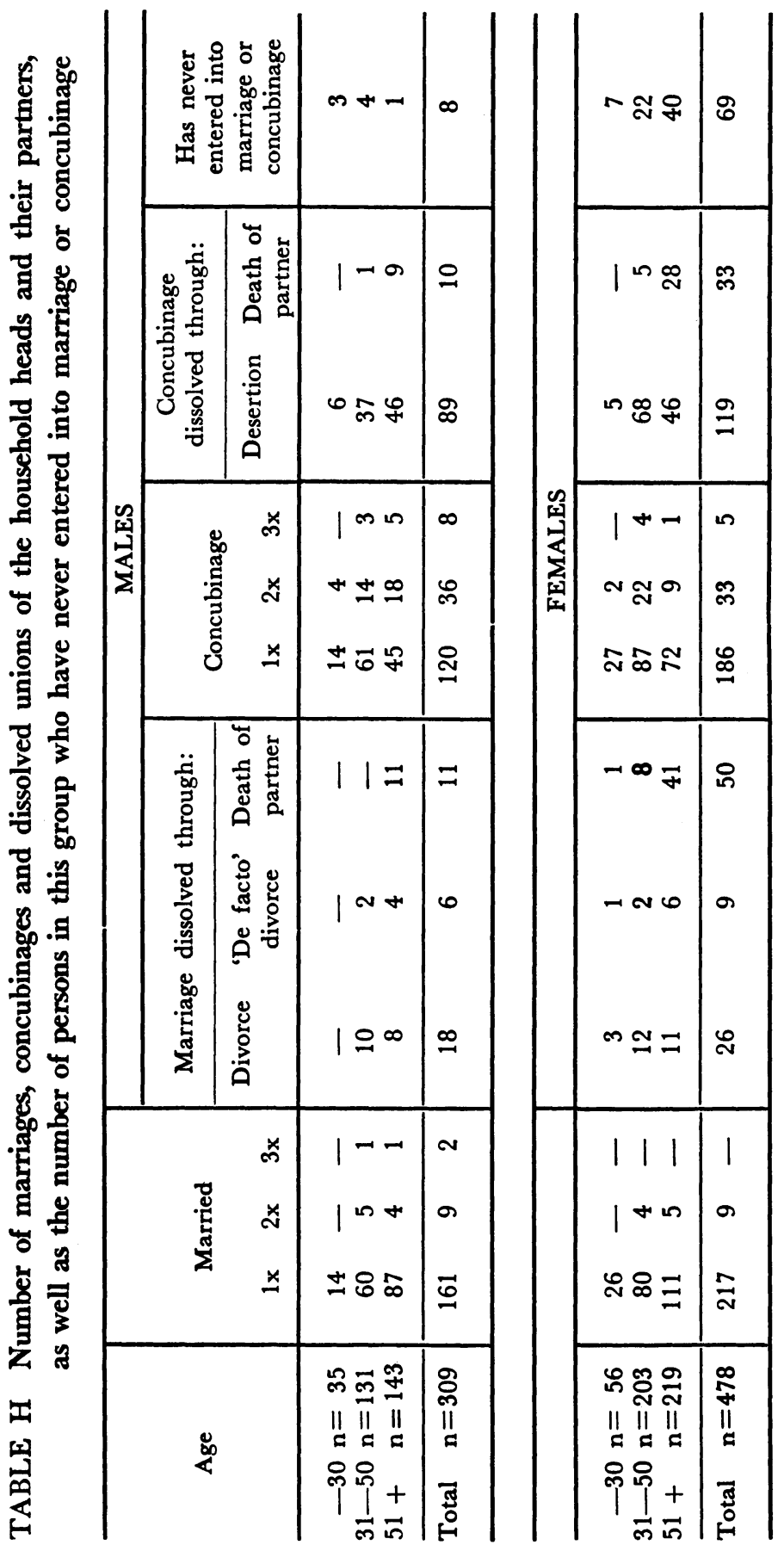




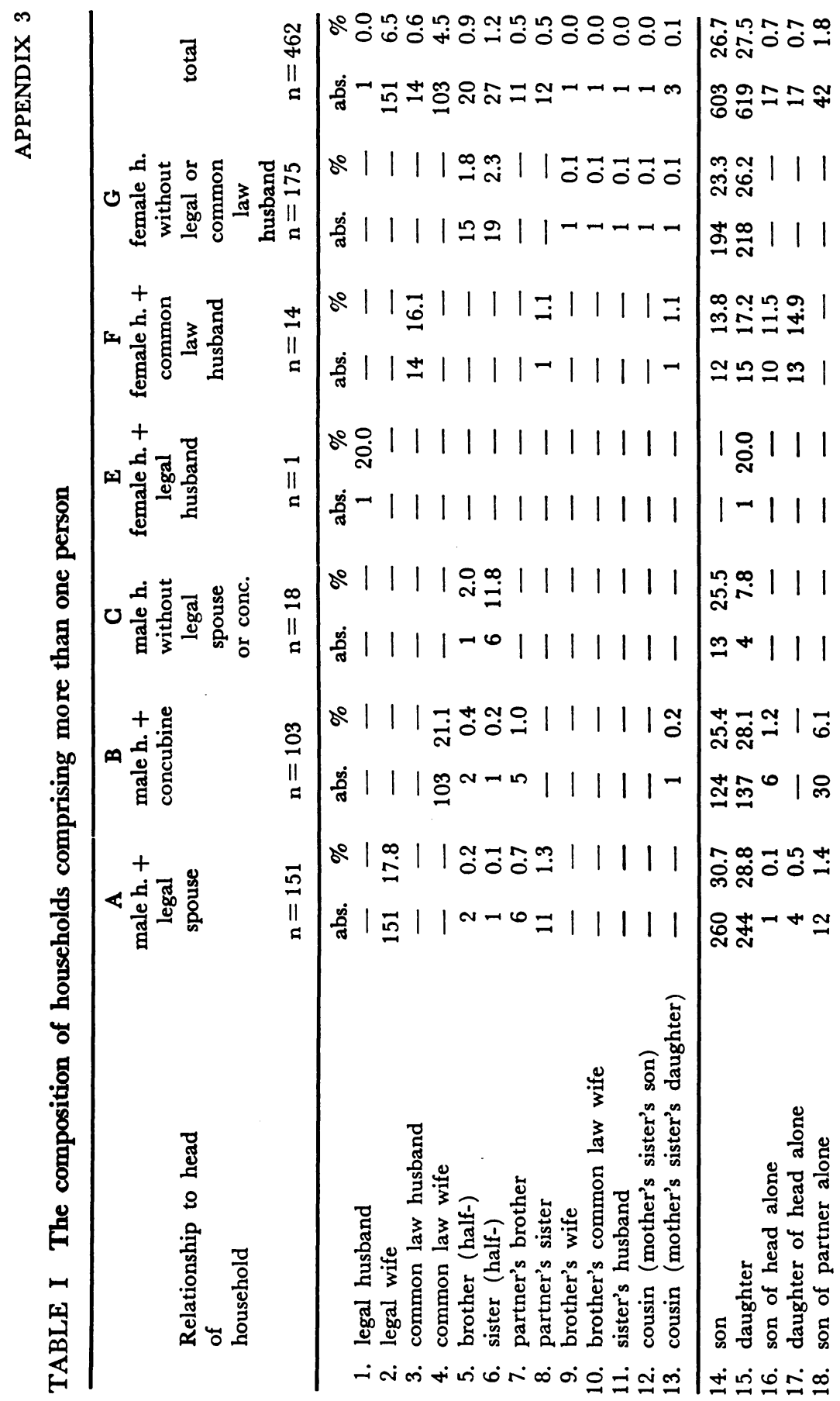




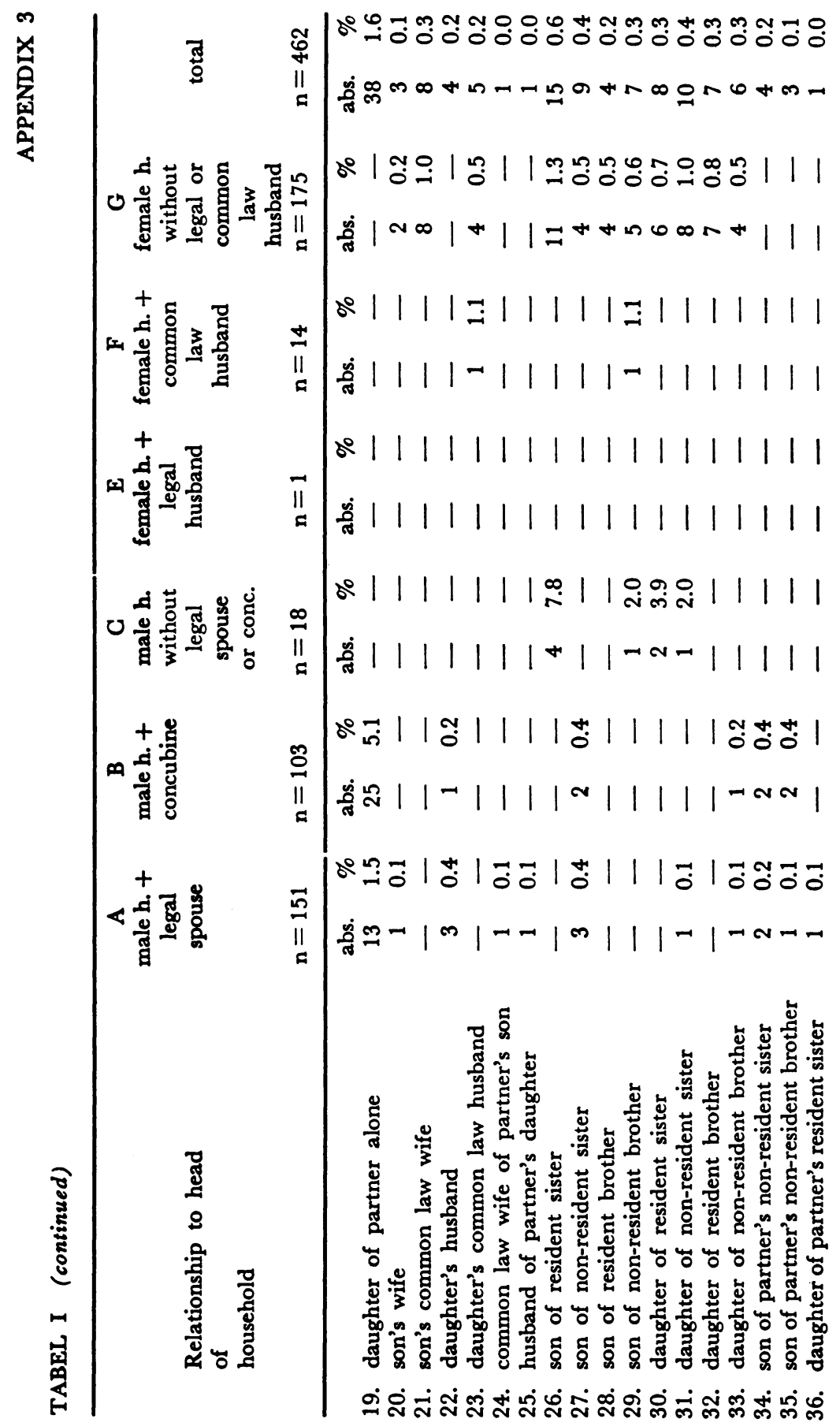


瓷

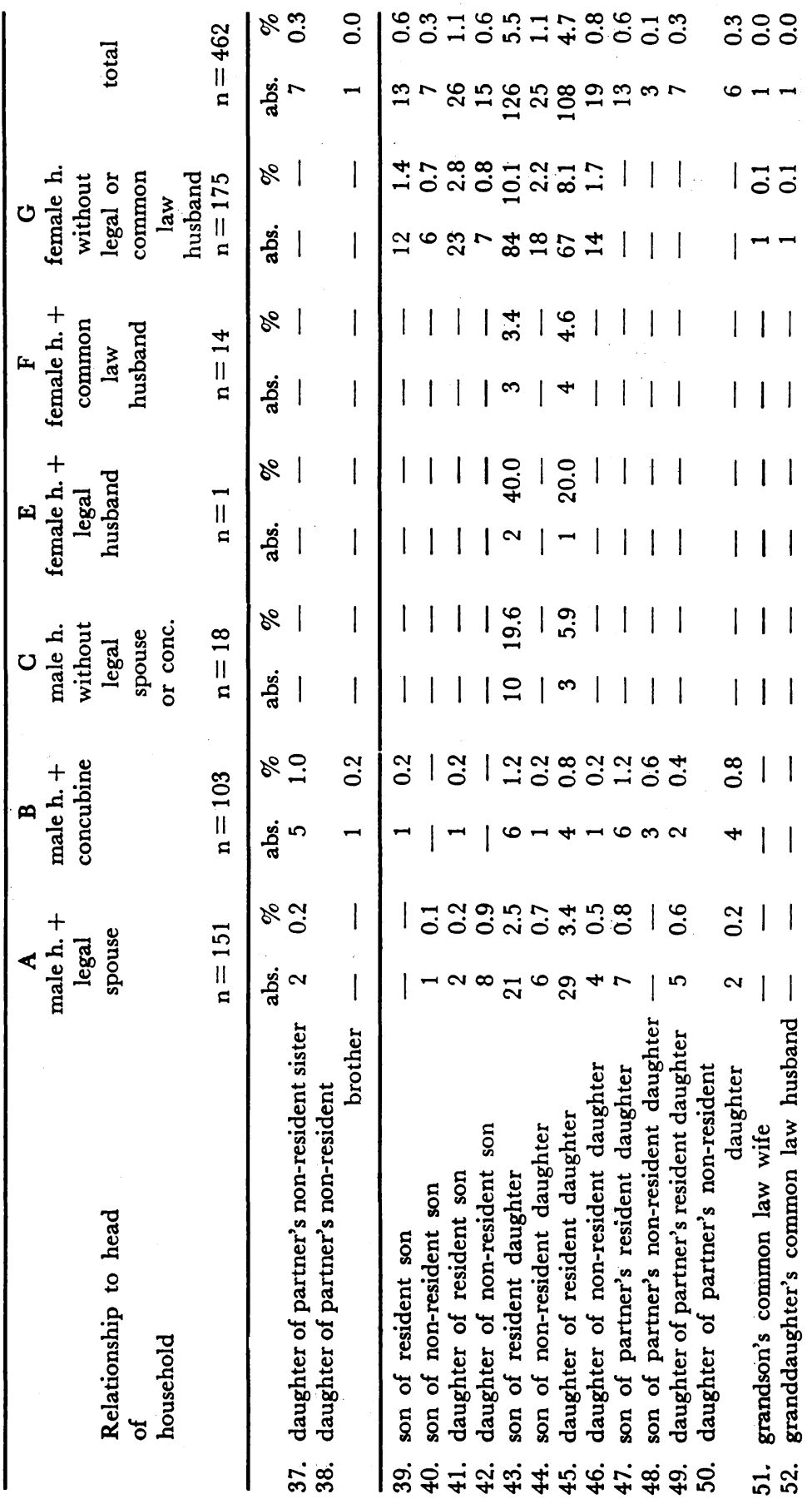


釜

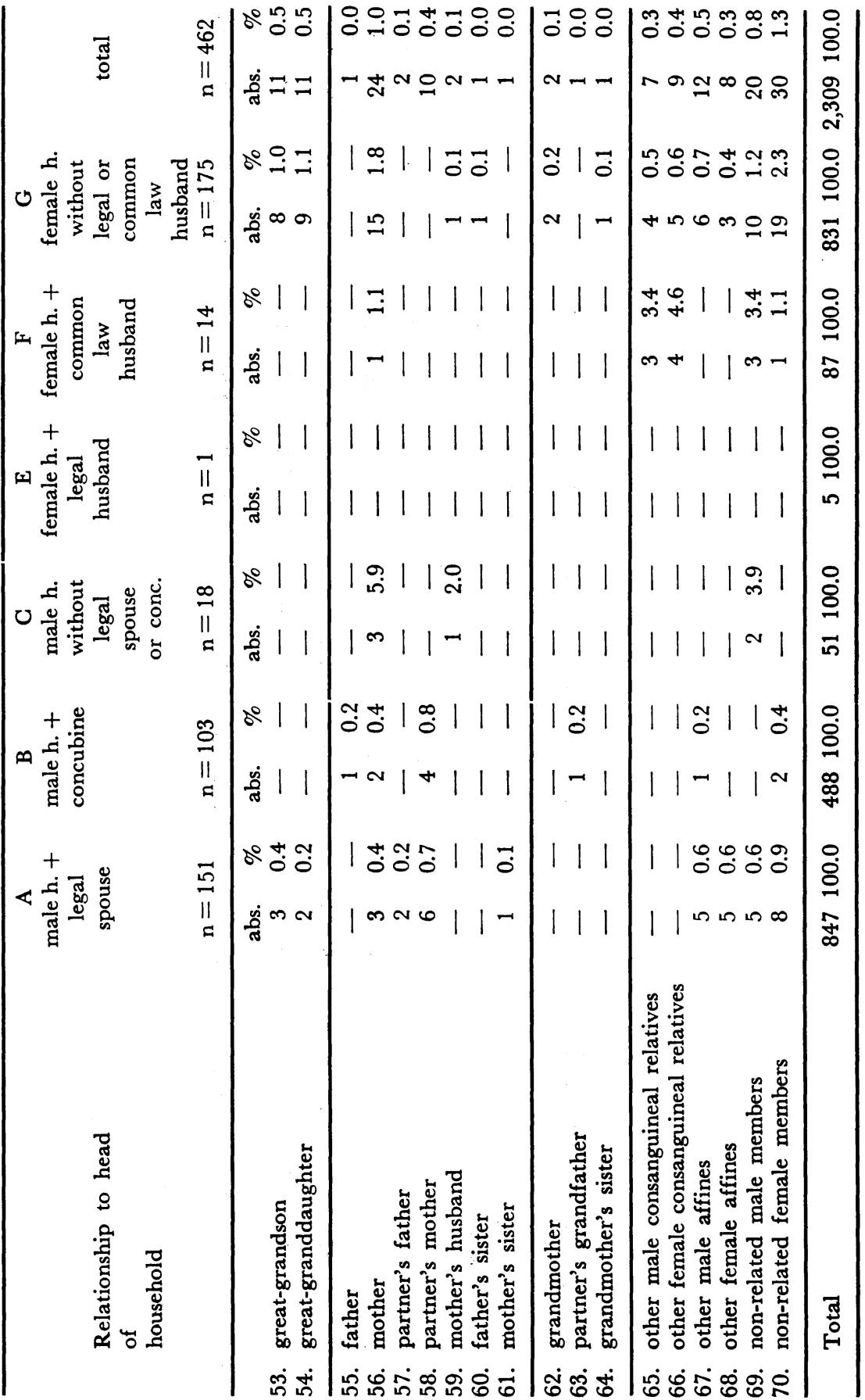




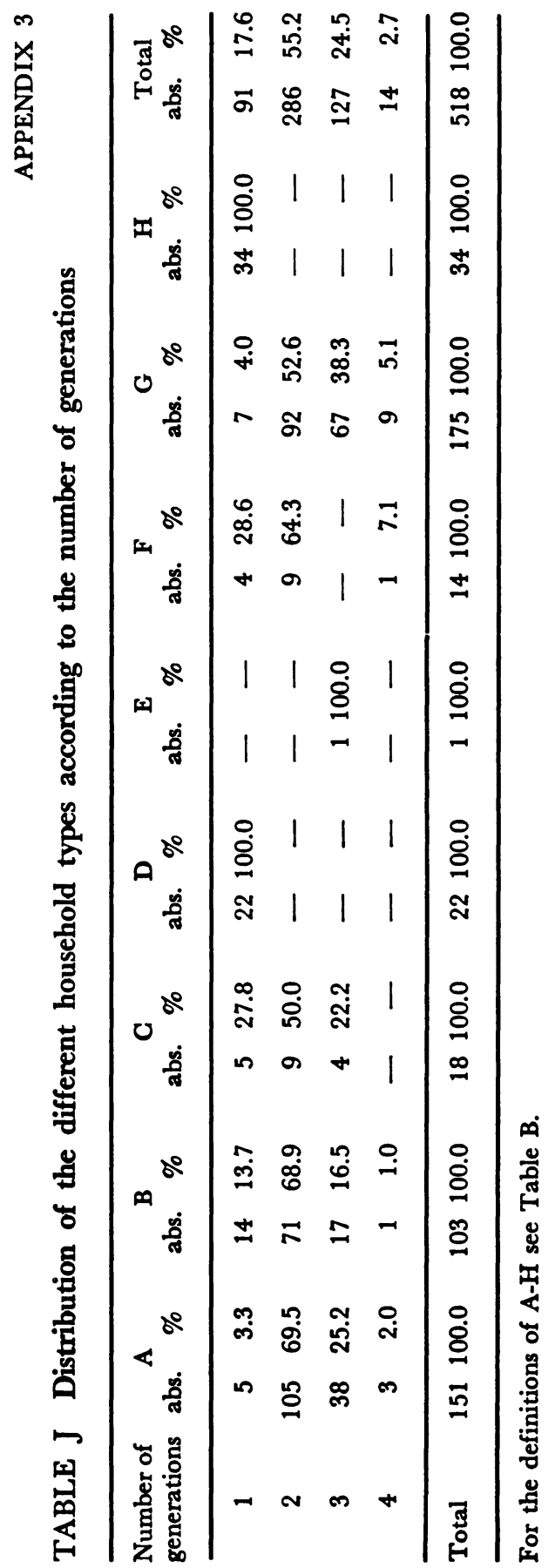


党

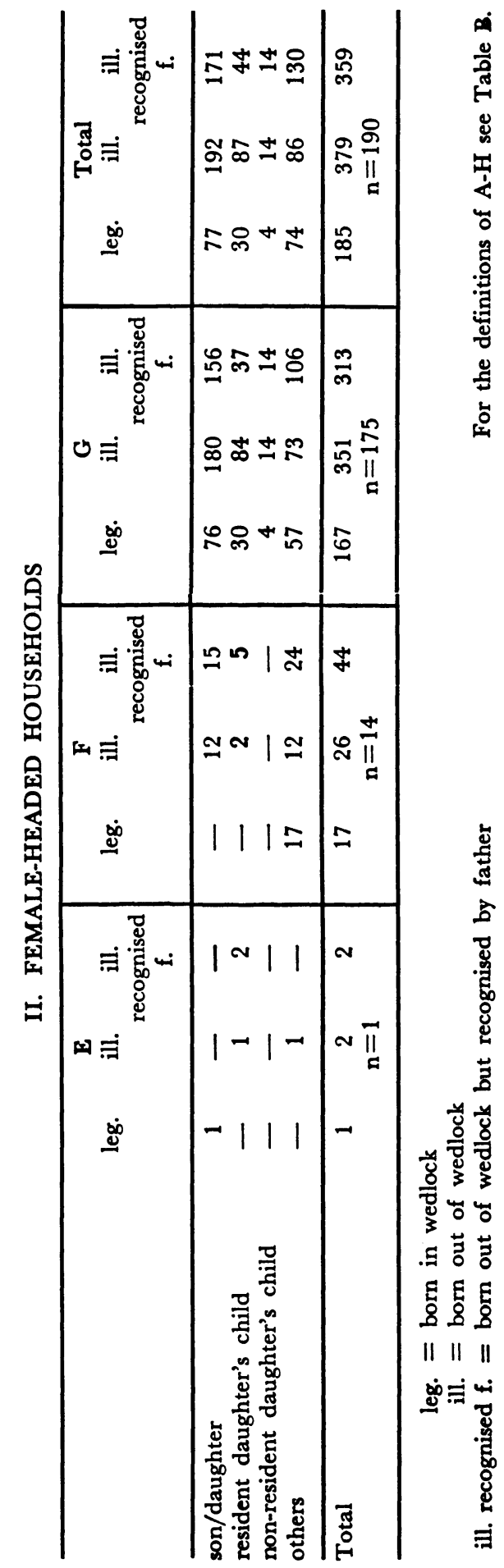


APPENDIX 3

TABLE L Households of the sample according to type and number of members

\begin{tabular}{crrrrrrrrr}
\hline $\begin{array}{c}\text { Number of } \\
\text { members }\end{array}$ & A & B & G & D & E & F & G & H & Total \\
\hline 1 & - & - & - & 22 & - & - & - & 34 & 56 \\
2 & 4 & 13 & 8 & - & - & 4 & 38 & - & 67 \\
3 & 25 & 16 & 2 & - & - & 2 & 25 & - & 70 \\
4 & 18 & 20 & 2 & - & - & 2 & 21 & - & 63 \\
5 & 17 & 3 & 1 & - & - & - & 18 & - & 39 \\
6 & 21 & 16 & - & - & 1 & - & 14 & - & 52 \\
7 & 15 & 6 & 4 & - & - & - & 10 & - & 35 \\
8 & 15 & 11 & 1 & - & - & 1 & 11 & - & 39 \\
9 & 9 & 5 & - & - & - & - & 12 & - & 26 \\
10 & 10 & 4 & - & - & - & - & 7 & - & 21 \\
11 & 5 & 5 & - & - & - & 1 & 6 & - & 17 \\
12 & 4 & 2 & - & - & - & - & 3 & - & 9 \\
13 & 2 & 1 & - & - & - & 1 & 2 & - & 6 \\
14 & 1 & - & - & - & - & 1 & - & - & 2 \\
15 & - & 1 & - & - & - & 1 & 4 & - & 6 \\
16 & 4 & - & - & - & - & - & 2 & - & 6 \\
17 & - & - & - & - & - & - & - & - & -1 \\
18 & 1 & - & - & - & - & 1 & - & - & 1 \\
19 & - & - & - & - & - & - & - & - & 1 \\
20 & 151 & 103 & 18 & 22 & 1 & 14 & 175 & 34 & 518 \\
\hline Total & 6.5 & 5.7 & 3.9 & 1.0 & 6.0 & 7.2 & 5.7 & 1.0 & $5.5 *$ \\
\hline Average & number & 6.5 &
\end{tabular}

* The average number, not including men or women living by themselves, comes to 6.0.

For the definitions of A-H see Table B. 
APPENDIX 3

TABLE N Number of rooms per household, male- or female-headed

\begin{tabular}{|c|c|c|c|c|c|c|c|c|c|c|c|c|c|c|}
\hline \multirow{3}{*}{$\begin{array}{l}\text { Number of } \\
\text { members of } \\
\text { household }\end{array}$} & \multicolumn{7}{|c|}{ Male heads } & \multicolumn{7}{|c|}{ Female heads } \\
\hline & \multicolumn{5}{|c|}{ number of rooms } & \multirow{2}{*}{\multicolumn{2}{|c|}{ total }} & \multicolumn{5}{|c|}{ number of rooms } & \multicolumn{2}{|r|}{ total } \\
\hline & 1 & 2 & 3 & 4 & 5 & & & 1 & 2 & 3 & 4 & 5 & 6 & \\
\hline 1 & 8 & 6 & 5 & 3 & - & - & 22 & 11 & 12 & 7 & 2 & 2 & - & 34 \\
\hline 2 & 5 & 11 & 6 & 2 & 1 & - & 25 & 6 & 13 & 13 & 6 & 3 & 1 & 42 \\
\hline 3 & 1 & 13 & 12 & 14 & 3 & - & 43 & 4 & 8 & 9 & 5 & 1 & - & 27 \\
\hline 4 & 5 & 10 & 12 & 9 & 2 & 2 & 40 & 2 & 3 & 11 & 5 & - & 2 & 23 \\
\hline 5 & - & 5 & 7 & 3 & 3 & 3 & 21 & - & 7 & 6 & 3 & 1 & 1 & 18 \\
\hline 6 & 6 & 8 & 9 & 6 & 6 & 2 & 37 & 1 & 8 & 2 & 4 & - & - & 15 \\
\hline 7 & 1 & 3 & 9 & 9 & 3 & - & 25 & - & 3 & 4 & 1 & 2 & - & 10 \\
\hline 8 & 2 & 7 & 3 & 11 & 3 & 1 & 27 & 3 & 6 & 3 & - & - & - & 12 \\
\hline 9 & - & 2 & 4 & 6 & 2 & - & 14 & 1 & 2 & 1 & 5 & 3 & - & 12 \\
\hline 10 & - & 2 & 3 & 5 & 1 & 3 & 14 & 1 & 1 & 3 & 1 & 1 & - & 7 \\
\hline 11 & - & 2 & 1 & 6 & 1 & - & 10 & - & 3 & 1 & 3 & - & - & 7 \\
\hline 12 & - & 1 & 2 & 1 & 1 & 1 & 6 & - & 1 & 1 & 1 & - & - & 3 \\
\hline 13 & - & - & 1 & 1 & 1 & - & 3 & - & 1 & - & 1 & 1 & - & 3 \\
\hline 14 & - & - & - & - & 1 & - & 1 & - & 1 & - & - & - & - & 1 \\
\hline 15 & - & 1 & - & - & - & - & 1 & - & 1 & 1 & 3 & - & - & 5 \\
\hline 16 & - & 1 & 1 & 2 & - & - & 4 & - & 1 & 1 & - & - & - & 2 \\
\hline 17 & - & - & - & - & - & - & - & - & - & - & - & - & - & - \\
\hline 18 & - & - & - & - & - & - & - & - & - & - & - & 1 & - & 1 \\
\hline 19 & - & - & - & 1 & - & - & 1 & - & - & - & 一 & - & - & - \\
\hline 20 & - & - & 一 & - & - & 一 & - & - & - & 一 & 1 & - & 1 & 2 \\
\hline & 28 & 72 & 75 & 79 & 28 & 12 & 294 & 29 & 71 & 63 & 41 & 15 & 5 & 224 \\
\hline
\end{tabular}


APPENDIX 3

蕞

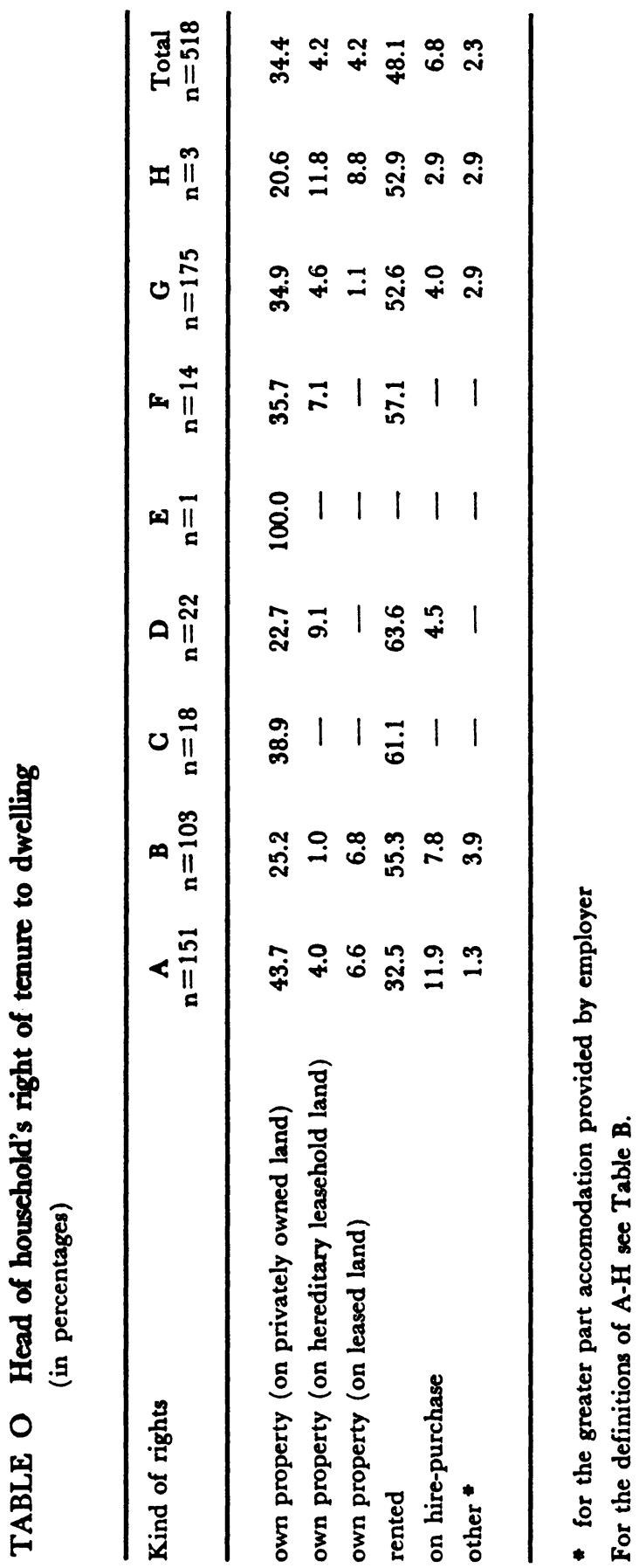


党

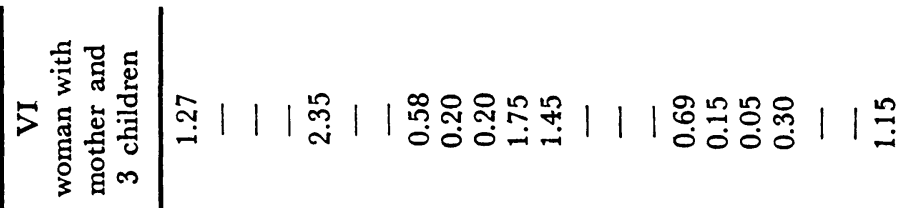

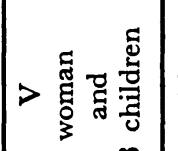

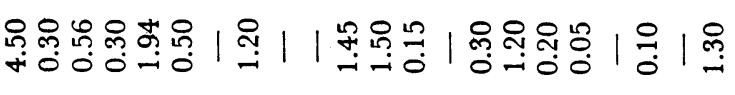

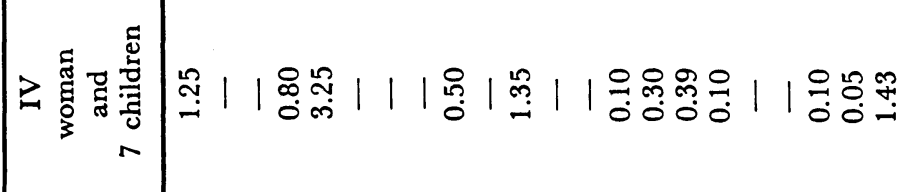



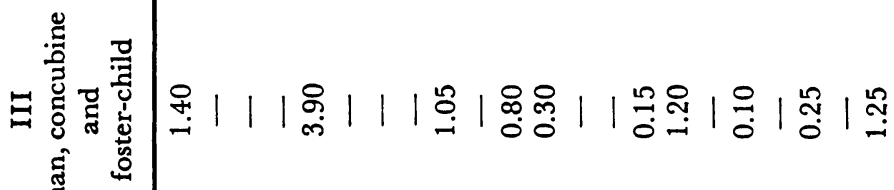
สำ

导 营

䆜

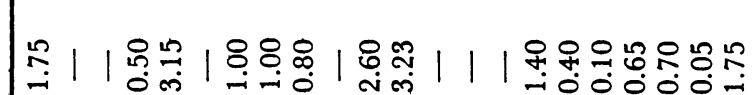
๘ี

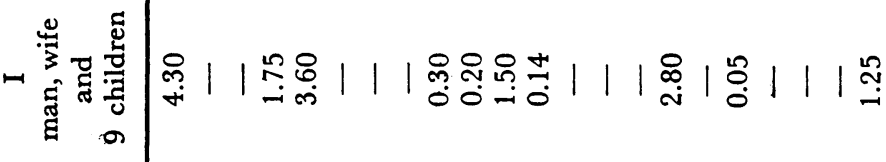

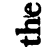

宕

.

远

荧

焉

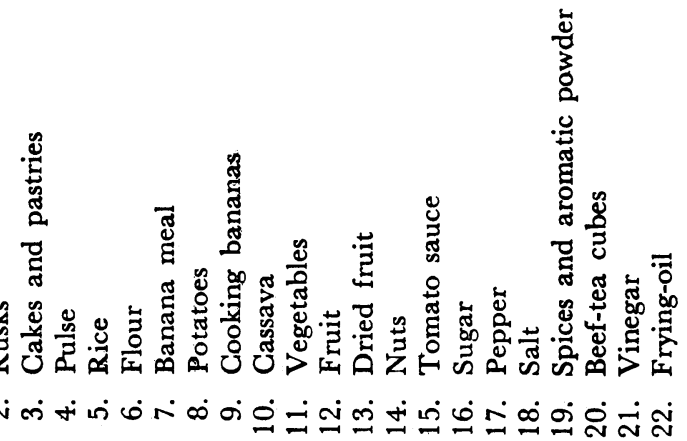




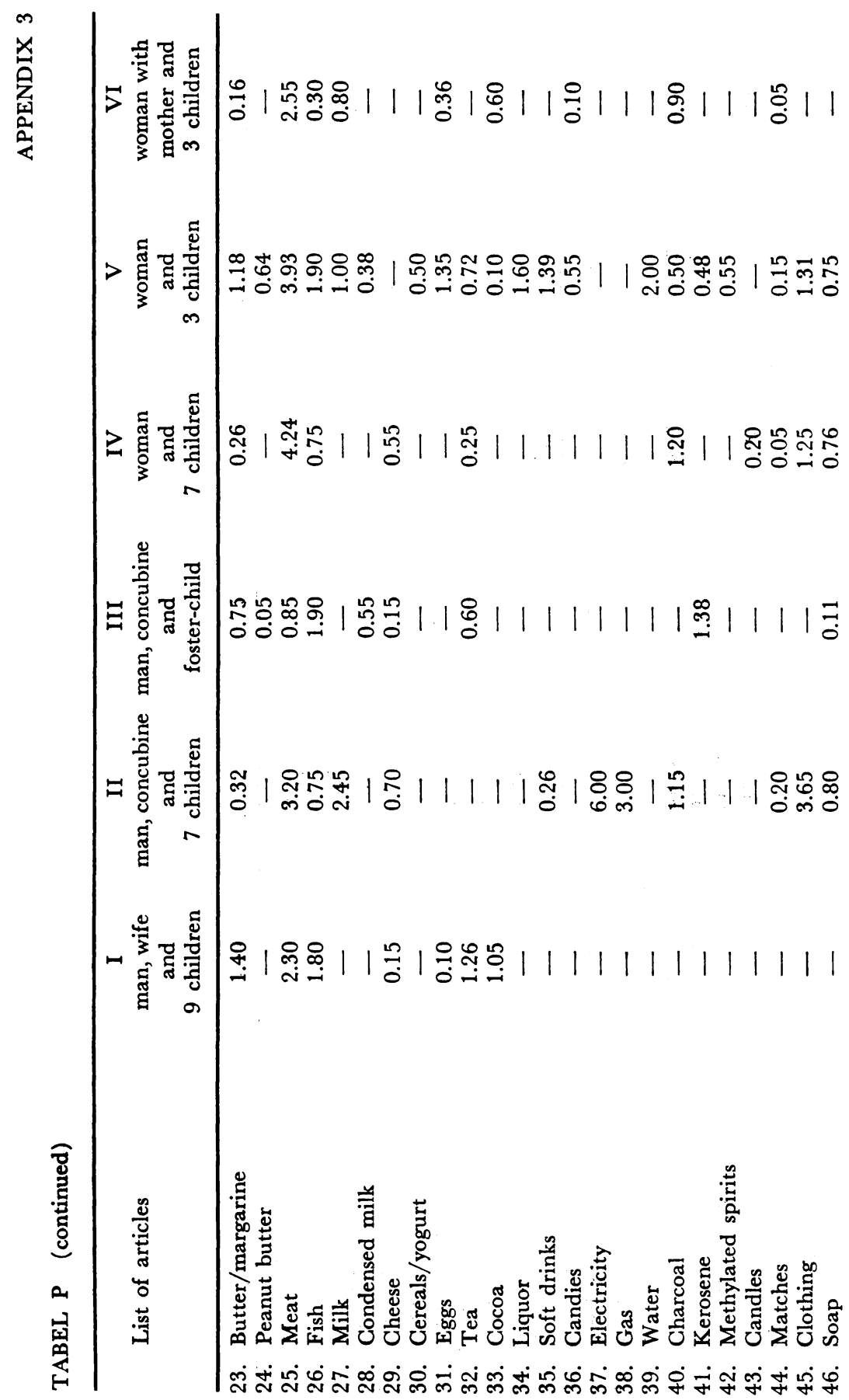




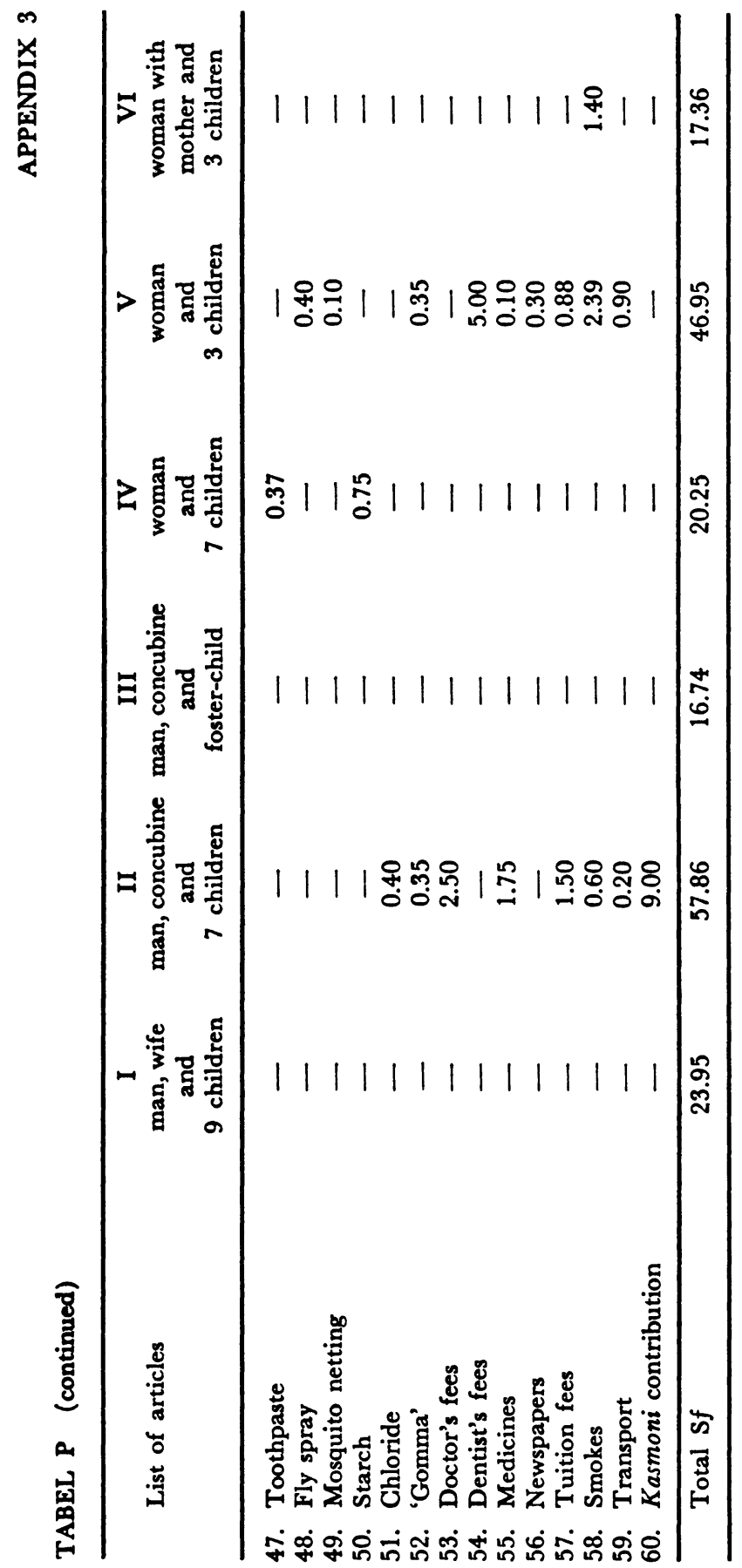




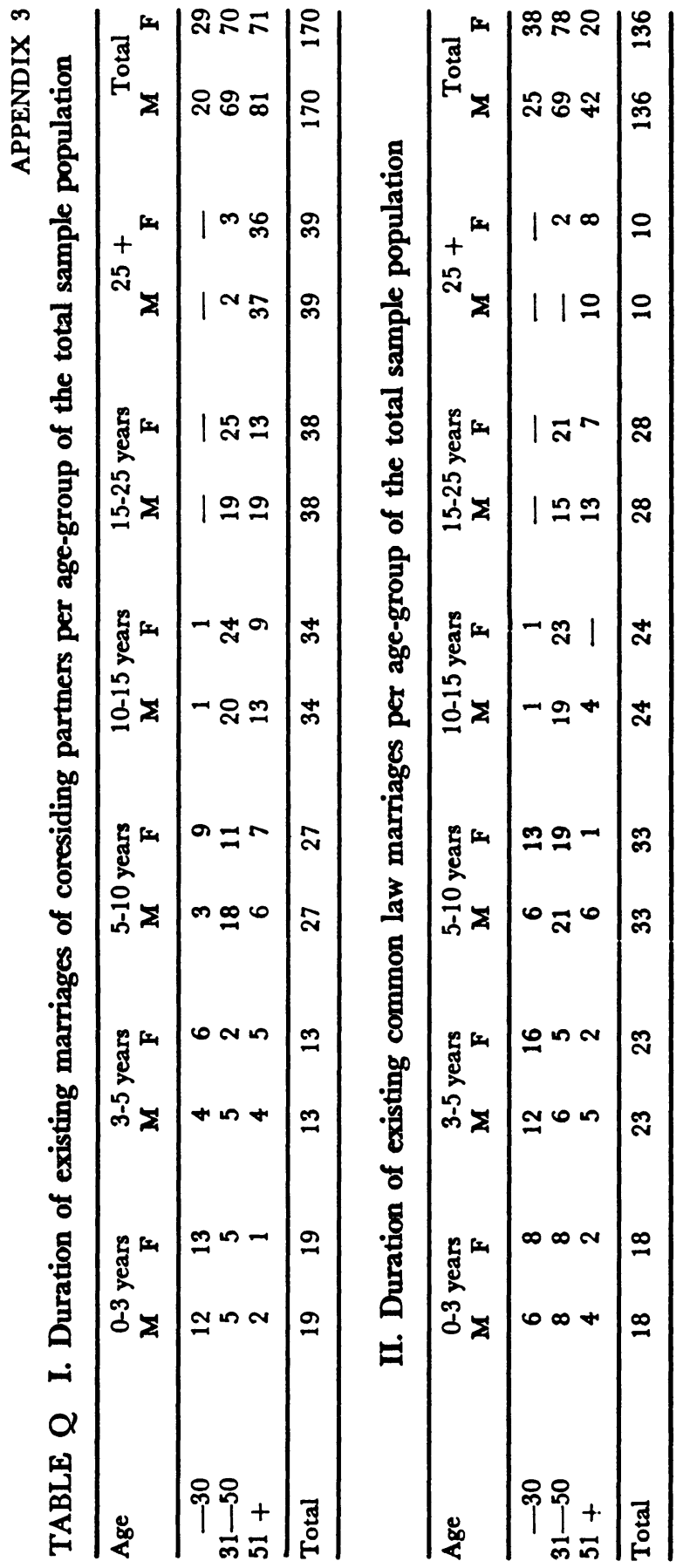




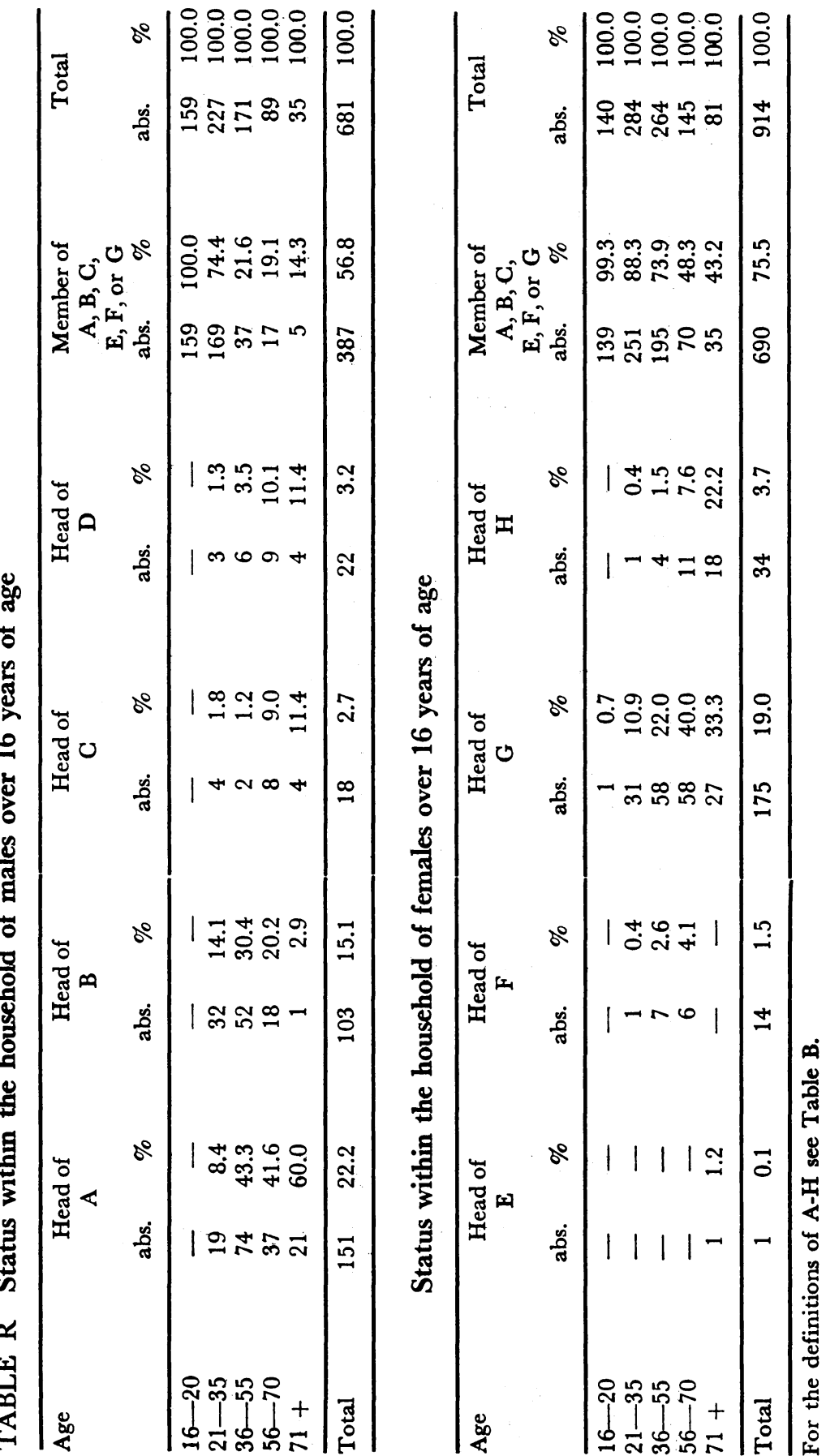




\section{WOSUNA \\ The Creole family of Paramaribo}

1. Place of birth

2. Age

3. Occupation

4. Religion

5. a. legal marriage; b. common law marriage; c. man friend;

d. no husband or man friend

6. Number of children

7. Age at birth of first child

8. Age at birth of youngest child

9. Is the population of Surinam: a. too large; b. too small; c. just right?

10. How many children should a woman have during her entire life?

11. How many children should a woman of your age have?

12. Have you ever heard of the existence of techniques and devices a man and woman may use in order to prevent conception?
a. yes
b. no

If the answer is yes, what methods are used?

13. Which of the following methods and devices are you familiar with?
a. the rhythm method
g. the pill (Lyndiol, Annoflar)
b. withdrawal of the male
h. contraceptive jelly
c. douching
i. male sterilization
d. condom
j. female sterilization
e. pessary
k. massaging (to induce prolapsus
f. vaginal tablets of the uterus)

14. Have you ever used any of these methods and devices? a. yes b. no

15. Which one?

16. When did you first start using it?

17. If the answer is no, why have you never used any such methods?
a. husband is against it
f. would like children
b. unhealthy
g. not interested
c. religious reasons
h. too expensive
d. they reduce pleasure
i. don't know how to get hold of
e. too much bother them

j.

\section{Remarks:}


Willem F.L. Buschkens - 978-90-04-28702-๑ Downloaded from Brill.come4/26/2023 12:01:51PM via free access 


\section{BIBLIOGRAPHY}

Abbreviations used:
A.A.:
American Anthropologist
B.T.L.V.: Bijdragen tot de Taal-, Land- en Volkenkunde
M. en M.: Mens en Maatschappij
N.O.S.: Nationaal Ontwikkelingsplan Suriname
(N.) W.I.G.: (Nieuwe) West-Indische Gids
S.E.S.: $\quad$ Social and Economic Studies

Abbenhuis, M. F.

1943 Volksplanting, Paramaribo.

1946 Suriname: De slavernij in de 17 e en 18 e eeuw - Verhalen en Schetsen uit de Surinaamse geschiedenis, Vol. 4, Paramaribo.

1953 De requesten van Pater Stöppel en Prefect Wennekers in 1817 en 1819, in: W.I.G. 34, Vol. 1.

1956 De Katholieke Kerk in Suriname, in: Vox Guyana, Vol. II, no. 3.

Abraham-van der Mark, E. E.

1969 Yu'i Mama, Enkele facetten van de gezinsstructuur op Curą̧ao, doctoral dissertation Amsterdam.

Ambacht in Suriname, Het

1912 Rapport van de commissie benoemd bij Gouv. Resolutie van 13 Jan. 1910, no. 13, Paramaribo.

Amersfoort, J. M. M. van

1968 Surinamers in de Lage Landen, 's-Gravenhage.

Back, Kurt W.

1962 Slums, projects, and people. Social Psychological problems of relocation in Puerto Rico, Duke Univ. Press, Durham N.C.

Bastien, Remy

1961 Haitian Rural Family Organization, S.E.S., 10, 4 dec., 478-510.

Bayer, A. E.

1965 Surinaamse arbeiders in Nederland, Assen.

Bedrijfs en Beroepstelling 1961

1962 Distrikt Paramaribo - published by Algemeen Bureau voor de Statistiek: Suriname in cijfers, no. 20.

Benoit, P. J.

1839 Voyage à Surinam, Brussel. 
Beschouwingen

1911 Beschouwingen over den Oeconomischen en financieelen toestand der Kolonie Suriname, aangeboden door de R.K. Mannenvereeniging van Paramaribo, Paramaribo.

Blake, Judith

1961 Family Structure in Jamaica, the Social Context of Reproduction, (in Collaboration with J. Mayone Stycos and Kingsley Davis), New York.

Brons, J. G.

1952 Het Rijksdeel Suriname, Haarlem.

Budgetonderzoek

1953 Budgetonderzoek gehouden in Suriname in februari-maart 1952, Nota no. 1 'de kosten van levensonderhoud', Stichting Planbureau Suriname, Paramaribo-'s-Gravenhage.

Buiskool, J. A. E.

1954 De Staatsinstellingen van Suriname, 's-Gravenhage.

Buschkens, W. F. L.

1965 De Opkomst van de Pochteca, een handelsklasse in het Rijk der Mexica, B.T.L.V., Vol. 121, pp. 77-102, 's-Gravenhage.

1973 Het Familiesysteem der Volkscreolen van Paramaribo. Doctoral dissertation, Leiden University.

Buschkens, W. F. L. and A. F. Marks

1966 Sociology of the lower-class Creole family in Surinam and Curaçao. In: WOTRO - Netherlands Foundation for the advancement of tropical research, report for the year 1966, The Hague, pp. 32-36.

Butt, A. J.

1966 The Shaman's Legal Role. Revista do Museo Paulista N.S. 16.

Buve, $\mathbf{R}$.

1963 Surinaamse slaven en vrije negers in Amsterdam gedurende de achttiende eeuw, in: B.T.L.V., Vol. 119, pp. 8-17, 's-Gravenhage.

Calker, Th. C. van

1858 Nota van de hoofdvoorstander van de zending der Evangelische Broedergemeente in Suriname Th. C. van Calker aan de gouverneur d.d. 17 juli 1858 - , in: Centraal Archief Paramaribo, lett. B. no. 9/96, Resoluties 1858 (869-900).

Clarke, Edith

1957 My Mother who Fathered Me, London.

Cotran, Eugene

1968 The Changing Nature of African Marriage, in: Family Law in Asia and Africa, School of Oriental and African Studies, London.

Courlander, Harold

1960 The drum and the hoe, Life and lore of the Haitian people, Berkeley, Los Angeles.

Cumper, George E.

1961 Household and Occupation in Barbados, S.E.S. Vol. 10, Jamaica. 
Davenport, William

1961 The family system of Jamaica, S.E.S.

Davis, Kingsley

1965 Illegitimacy and the Social Structure, in: Readings on the family and society, pp. 21-32, William J. Goode, editor, New Yersey.

Durward Badgley, L., Peter C. Logtens and Henry B. Schechter

1962 Housing Mission to Suriname, Report of September 1962, U.S. A.I.D., Suriname.

Dusseldorp, D. B. W. M. van

1963 Geografische Mobiliteit en de ontwikkeling van Suriname, in: B.T.L.V., Vol. 119, pp. 18-55.

Encyclopaedie van de Nederlandse Antillen 1969 Amsterdam.

Encyclopaedie van Nederlandsch West-Indië 1914-1917 's-Gravenhage/Leiden.

Fermin, Philippe

1769 Description générale, historique, géographique et physique de la Colonie de Surinam (two vols.), Amsterdam.

Ferrier, Johan H. E.

1950 De Surinaamse samenleving als sociaal-paedagogische opgave, Groningen.

Frazier, E. Franklin

1939 The Negro Family in the United States, Chicago.

1965 The negro in the United States, revised edition, New York.

Freilich, Morris

1961 Serial Polygyny, Negro Peasants and Model Analysis, in: A.A., Vol. 63, pp. 955-975.

Gemmink, Joh.

1966 Reproductie-patronen binnen een Raciaal en Cultureel heterogene Bevolking. Socio-demografische studies, publicatie I, Utrecht.

Glick, Paul C.

1957 American Families, New York.

Goetze, Dieter

1971 'Culture of poverty' und Soziale Wirklichkeit: Nachruf auf eine Theorie. Sociologia Ruralis, Vol.XI, no. 3, pp. 223-245.

Goslinga, C. Ch.

1956 Emancipatie en emancipator, doctoral dissertation Nijmegen, Van Gorcum en Comp. N.V., Assen.

Goode, William J.

1965 Readings on the family and society, New Yersey.

Goveia, Elsa V.

1960 The West Indian Slave Laws of the Eighteenth Century, in: Revista de Ciencias Sociales, Vol. IV, no. 1, pp. 75-105. 
Groot, Silvia W. de

1963 Van Isolatie naar Integratie, Verhandelingen Taal-, Land- en Volkenkunde, 's-Gravenhage.

1969 Djuka Society and Social Change, Assen.

Hartsinck, Jan Jacob

1770 Beschrijving van Guiana of de Wilde Kust in Zuid-Amerika (two vols.), Amsterdam.

Henriques, Fernando

1953 Family and Colour in Jamaica, London.

Herlein, J. D:

1718 Beschrijvinge van de Volk-plantinge Zuriname, Leeuwarden (Meindert Injema).

Herskovits, M. J. and F. S. Herskovits

1934 Rebel Destiny: Among the Bush Negroes of Dutch Guiana, New York.

1936 Surinam Folklore, New York.

Herskovits, M. J.

1937 Life in a Haitian Valley, New York.

Herskovits, Melville J.

1964 The Myth of the Negro Past, Beacon Paperback edition, third printing.

Hoetink, $\mathbf{H}$.

1961 Gezinsvormen in het Caribisch gebied, M. en M., Vol. 36, no. 1.

Hostmann, F. W. R.

1850 Over de beschaving van negers in Amerika door kolonisatie met Europeanen (two vols.).

Ismael, Joseph

1949 De immigratie van Indonesiers in Suriname, Leiden.

Jaarcijfers voor Suriname, 1958-1962

1965 Algemeen Bureau voor de Statistiek, Paramaribo.

Kappler, A.

1854 Zes Jaren in Suriname (two vols.), Utrecht.

Karbaat, J.

1964 Sociaal-Geneeskundige Beschouwingen over de personeelsleden van de troepenmacht in Suriname en hun gezinnen, doctoral dissertation Leiden, Broos, Amsterdam.

Kerr, Madeline

1963 Personality and Conflict in Jamaica, London.

Klerk, C. J. M. de

1951 Cultus en ritueel van het orthodoxe Hindoeisme in Suriname, Amsterdam.

1953 De immigratie der Hindostanen in Suriname, Amsterdam.

Kloos, P.

1971 The Maroni River Caribs of Surinam, Assen. 
Köbben, A. J. F.

1967 Unity and Disunity: Cottica Djuka Society as a kinship system, B.T.L.V., 123, 's-Gravenhage.

1968 Continuity in change: Cottica Djuka Society as a changing system, B.T.L.V., 124, 's-Gravenhage.

Kool, Rudolf

1964 Agricultural planning in Surinam 1950-1960, Wageningen.

Kruijer, G. J.

1951 Suriname en zijn buurlanden, Meppel.

Kuhn, F. A.

1828 Beschrijving van de toestand der Surinaamse plantageslaven, Amsterdam.

Kunstadter, Peter

1963 A survey of the Consanguine or Matrifocal Family, in: A.A., Vol. 65.

Kuyp, E. van der

1958 De voeding van de slaaf en de betekenis daarvan voor zijn nakomelingen, in: Het emancipatieblad, Paramaribo, July.

Kuyp, E. van der, W. Chr. Walvis and R. A. J. van Lier

1959 Report on the demographic problems of Surinam, in: Vox Guyana, Vol. III, no. 3 .

Lammens, A. F.

1816-'22 Bijdrage tot de kennis van de kolonie Suriname dat gedeelte van Guiana het welk bij Traktaat ten Jare 1815 aan het Koningrijk Holland is verbleven door Mr. Adriaan François Lammens, tijdvak 1816 tot 1822, Manuscript in library of Surinaams Museum in Paramaribo, cat. no. 868 - VI, Vol. XIII.

Lampe, P. H. J.

1928 Het Surinaamsche treefgeloof, Een volksgeloof, betreffende het ontstaan van melaatsheid, W.I.G. $545 \mathrm{ff}$.

Lamur, H. E.

1973 The demographic Evolution of Surinam, Verhandelingen Taal-, Landen Volkenkunde, Vol. 65, 's-Gravenhage.

Lewis, Oscar

1959 Five Families: Mexican case studies in the Culture of Poverty, New York.

1961 The Children of Sanches, New York.

1966 The Culture of Poverty, in: Scientific American, Vol. 215, no. 4.

1969 La Vida, A Panther Book, reprinted London.

Lier, R. A. J. van

1949 Samenleving in een Grensgebied, Een sociaal-historische studie van de maatschappij in Suriname, Martinus Nijhoff, 's-Gravenhage. (Second impression Deventer 1971; English translation: Frontier Society, The Hague 1971).

1950 The development and nature of society in the West Indies, Amsterdam. 
1951 De Sociale Wetenschappen van de neger in Amerika, B.T.L.V., 1951, 279-303.

1971 Frontier Society, a social analysis of the history of Surinam, Martinus Nijhoff, The Hague.

Lier, Willem F. van

1940 Aantekeningen over het geestelijk leven en de samenleving der Djukas (Aukaner Bosnegers) in Suriname, B.T.L.V. 99, pp. 129-295.

Locher, G. W.

1963 Nieuwe perspectieven in de studie van de acculturatie, in: B.T.L.V., Vol. 119.

Malinowski, Bronislaw

1948 Magic, Science and Religion (and other essays), A Doubleday Anchor Book, A 23, New York.

Marks, A. F.

1973 Man, vrouw en huishoudgroep, de Afro-Amerikaanse familie in de samenleving van Curaçao, doctoral dissertation Leiden.

Matthews, Dom Basil

1952 Crisis of the West Indian Family, Extra Mural Department of the University College of the West Indies, in the Series 'Caribbean Affairs', Trinidad.

Metraux, Alfred

1957 Haiti. La terre, les hommes et les dieux, Neuchâtel.

1959 Voodoo in Haïti, New York.

Morpurgo, A. J.

1934-'35 De kótómisi, W.I.G., Vol. XVI, pp. 393 ff.

Moynihan Report, The

1967 In: Rainwater, Lee and William L. Yancey, The Moynihan Report and the Politics of Controversy, M.I.T. Press.

Murdock, George Peter

1950 Family Stability in Non-European Cultures, in: The Annals of the American Academy of Political and Social Science, Vol. 272, Philadelphia.

Nepveu

1765 Annotatien van Jean Nepveu in manuscript, Algemeen Rijksarchief 's-Gravenhage.

N.O.S. (Nationaal Ontwikkelingsplan Suriname 1965)

1965 Stichting Planbureau Suriname, Paramaribo, 3 vols.

Ostendorf, F. W.

1962 Nuttige planten en sierplanten in Suriname, Landbouwproefstation in Suriname, Bulletin 79.

Otterbein, Keith F.

1964 Review of M. G. Smith's West Indian Family Structure. In: Caribbean Studies, Vol. 4, no. 3, pp. 74-76. 
1965 Caribbean Family Organization: A Comparative Analysis, in: A.A., Vol. 67, no. 1.

Panday, R. M. N.

1959 Agriculture in Surinam 1650-1950, Amsterdam.

Panhuys, L. C. van

1898 De vrouw in Nederlandsch West Indië, Amsterdam.

Pierce, Benjamin Edward

1971 Kinship and Residence among the Urban Nengre of Surinam: a reevaluation of concepts and theories of the Afro-American Family, Tulane University, doctoral dissertation.

Pollak-Eltz, A.

1970 Afro-Amerikaanse Godsdiensten en Culten, Roermond.

Pronk, B.

1962 Verkenningen op het gebied van de Criminaliteit in Suriname, 's-Gravenhage.

Quintus Bosz, A. J. A.

1954 Drie eeuwen grondpolitiek in Suriname, Assen.

1964 De ontwikkeling van de Rechtspositie van de vroegere plantageslaven in Suriname, in: Emancipatie Biografieën 1863-1963, Edited by de Surinaamse Historische Kring, Paramaribo.

Rainwater, Lee and William L. Yancey

1967 The Moynihan Report and the Politics of Controversy, M.I.T. Press.

Registers der Vrijgemaakten

1863 Manuscript in Archief Burgerlijke Stand en Bevolkingsregister, Paramaribo.

Rek, J. de

1967 Prinsen, Patriciërs en Patriotten, Baarn.

Renselaar, H. C. van

1963a De houding van de Creoolse Bevolkingsgroep in Suriname ten opzichte van de andere bevolkingsgroepen, B.T.L.V., Vol. 119, 's-Gravenhage.

1963b Het sociaal-economisch vermogen van de Creolen in Suriname, in: Tijdschrift van het Koninklijk Nederlandsch Aardrijkskundig Genootschap, Amsterdam, Second Series, Vol. LXXX, no. 4.

Rivière, P. G.

1966 A Policy for the Trio Indians of Suriname. In: N.W.I.G., Vol. 45, pp. 95-120.

1969 Marriage among the Trio, A Principle of Social Organization, Oxford.

Sack, Albert von

1821 Reize naar Surinamen, two vols., Haarlem.

Schimpf, Gh. P.

1858 Nota van gouverneur Schimpf aan zijn hoofdambtenaren betreffende de missive van de Minister van Koloniën d.d. 10 april 1858, letter B, no. 9/96, Resoluties 1858 (869-900), Centraal Archief, Paramaribo. 
Schneider, H. G.

1893 Foto; een bezoek in Paramaribo. Nijmegen.

Schvaneveldt, Jay D.

1966 The interactional Framework in the study of the Family. In: Emerging Conceptual Frameworks in Family Analysis, F. Ivan Nye and Felix M. Berardo, New York.

Simey, T. S.

1947 Welfare and Planning in the West Indies, Oxford Univ. Press, London.

Simons, R. D. G. Ph.

1959 Bijgeloof en Lepra in de Atlantische negerzônes, in: Vox Guyana, Vol. III, no. 5 .

Smith, M. G.

1962 West Indian Family Structure, Univ. of Washington Press, Seattle.

Smith, Raymond $\mathrm{T}$.

1956 The Negro Family in British Guiana. Family Structure and Social Status in the Villages, London.

1963/'64 Culture and Social Structure in the Caribbean: some recent work on family and kinship studies, in: Comparative Studies in Society and History, Vol. VI, Den Haag.

Solien de Gonzales, Nancie L.

1961 Family Organization in Five Types of Migratory Wage Labor, in: A.A., Vol. 63, 1264-1280.

Speckmann, J. D.

1963 De houding van de Hindostaanse bevolkingsgroep in Suriname ten opzichte van de Creolen. B.T.L.V., Vol. 119, pp. 76-92.

1965 Marriage and Kinship among the Indians in Surinam, Van Gorcum, Assen.

1967 De sociologie van de niet-Westerse volken. Inaugural speech Leiden, Assen.

Spicer, Edward H.

1961 Types of contact and Processes of Change, in: Perspectives in American Indian Culture Change, edited by Edward $\mathrm{H}$. Spicer, The University of Chicago Press.

Staal, G. J.

1928 Uit den Slaventijd, W.I.G., 168-173.

Statuten en Huishoudelijk Reglement van het Zieken en Begrafenisfonds n.d. 'Steun in Nood', gevestigd te Paramaribo.

Stedman, J. G.

$1813 A$ narrative of a five years expedition against the revolted negroes of Surinam, two vols., London.

Steinberg, H. G.

1933 Ons Suriname; de zending der Evangelische Broedergemeente in Nederlandsch Guyana, 's-Gravenhage. 
Sypesteyn, C. A. van

1854 Beschrijving van Suriname, 's-Gravenhage.

1866 Afschaffing der slavernij in de Nederlandsche West-Indische koloniën, uit officiële bronnen samengesteld. Sep. supplement of the Economist, Amsterdam.

Teenstra, M. D.

1835 De landbouw in de kolonie Suriname, two vols., Groningen.

Thoden van Velzen, H. U. E.

1966 Politieke beheersing in de Djuka maatschappij, two vols, doctoral dissertation, Amsterdam.

Traa, A. van

1946 Suriname 1900-1940, Deventer.

Tweede Landbouwtelling Suriname

1959 Uitgave Ministerie van Landbouw, Veeteelt en Visserij, Paramaribo.

Tylor, E. B.

1913 Primitive Culture, two vols., London.

Unger, S. W.

1956 Bijdragen tot de geschiedenis van de Nederlandsche Slavenhandel, in: Economisch Historisch Jaarboek, Vol. 26, 's-Gravenhage.

Verslag Centrale Bank van Suriname 1964 and 1965 Paramaribo.

Vierkandt, Alfred 1928 Gesellschaftslehre, Stuttgart.

Volkstelling Suriname 1964

Voorhoeve, J. and H. C. van Renselaar n.d. Het ontstaan van de Creoolse taal en cultuur (manuscript).

Waal Malefijt, Annemarie de 1963 The Javanese of Surinam, Assen.

Wagley, Ch.

1960 Plantation America: a culture sphere. Caribbean studies, a symposium, edited by Vera Rubin, University of Washington Press, Seattle.

Weatherley, U. G.

1923 The West Indies as a Sociological Laboratory, American Journal of Sociology, 29, pp. 290-304.

Wengen, G. D.

1963 Tajoeb, een prestige-feest bij de Javanen in Suriname, in: B.T.L.V., Vol. 119.

West, De

a Paramaribo daily newspaper. 
Wetering, W. van

1966 Conflicten tussen co-vrouwen bij de Djuka, in: N.W.I.G., 45, 52-59.

Winkels, W. E. H.

1856 Slavernij en Emancipatie. Eene beschouwing van den toestand der slavernij in Suriname, Utrecht.

Wit, Y. B. de

1966 Is Paramaribo te groot? in: N.W.I.G., 44, 77-93.

Wolbers, J.

1861 Geschiedenis van Suriname, Amsterdam. 


\section{INDEX}

Abbenhuis, M. F., 50, 52-53, 57-58, 8687,92

Abolition, of the slave trade, 21, 30-31, $41,49,74,81-82,86$; of slavery, 17 , $80,96,108,109,124,128,269$

Abortion, 66, 82, 228, 229, 243

Abraham-van der Mark, E. E., 260

Absentee ownership, 30, 49, 92, 93

Absenteeism of the male, $7-9,16,18$, 178-179, 181-182, 243, 265; effect on sexratio of, 16; social reasons for, 183184, 206, 243

Acculturation, fusionistic type of, 265; policy, 41 ; process of, 40,265

Adaptation, 12, 20 (def.) , 41, 136; flexibility of, 23; model of, 265, 268; process of, 1, 263, 268

Adoption of children, 180, 197, 198, 216, 226-227, 234, 245

Adultery, 178-184, 202, 206

Aerssen van Sommelsdijck, C. van, 54, 70,86

Aerssen van Sommelsdijck, family Van, 26

Administrateurs, 30, 49, 54, 68, 69, 92

Affairs, casual, 5, 179, 180, 182, 183, 242, 246-247, 266, see Illegitimacy

African, cultural elements, 2, 10-13, 40, 233, 235-236, 241, 265; culture, 2, 11, $40,51,60,265$; family system, 12,60 , 63 ; cultural traits, 13 , 265 ; Negro, 38 , 57 ; survivals, 11, 13-14, 253

Afro-America, 3

Afro-American, Caribbean family, 1, 3, $6,13-18,20,175$; cultures, 3 ; religion, $11,40-41,158-159,254$

Aite de, 257, 260-261

(A) Kra, 158-159, 241

Alliance, 85-86, 92-93, 96, 98, 124-125, $129,188,190,201,267$; abolition of the, $127-129$

Amerindians, 2, 25, 34, 57-58, 117; christening of, 83, 86; culture contact with, 40 ; population of, $1,36,38,50$, 135 ; slaves, $28,40,51$

Amersfoort, J. M. M. van, 124
Anamat, 183

Anansi-tori, 261

Ancestor worship, 158, 253-254

Asiatic Marriage Act, see Marriage Act for Asians

Assimilation, 13, 36, 40-41, 190, 267

Authority, of female heads of households, $6-7,107,121$; of male heads of households, 203-205, 246

Back, K. W., 137

Bakra Kirki, 135, see Masters

Bakstoelen, 142

Balata industry, 32, 34, 113, 115-118, $122,180,265$

Bastien, R., 237

Bauxite mining, 34-35, 118-120, 132, 162,180

Bayer, A. E., 124

Begi, 251-252

Benoit, P. J., 79, 82, 234

Bigi jari, 138

Birth control, see contraceptive methods, see family planning

Blake, J., 3, 223, 232

"Bleeders", 116-117, 181

Blom, planter, 58

Blommesteinmeer, Prof. Dr. Ir. W. J. van, 35

Bonuman, see popular healer

Bosch, J. Count van den, 83

Brons, J. C., 34, 117

Bruyning, J., 88, 92, 106

Buiskool, J. A. E., 27

Burial societies, 159-161, 253, 255, 260

Buschkens, W. F. L., 23, 163

Bush Creole, 39

Bush Negro, 1, 39, 117, 118, 143, 241, 258; Aucan, 167; christening of, 83, 129 ; and lumbering, 34, 120; population, $36,38,50,135$; raids/attacks, 29, 54; research among, 2, 10-11, 258

Butt, A. J., 2

Buve, R. Th. J., 124 
Calker, Th. C. van, 59, 62, 95, 128

Calvinist Church, 38, 66-67, 82, 92, 96, $128,134,186,220$; with regard to social mobility, $134-135,261$, see Churches

Caribs, 11

Catharina Sophia, government plantation, 93

Child(ren), lower-class Creole, birth of, 219, 232-237; desire for, 47, 217-218, 219-227; legitimation of, 192-194; premarital, 226-227; punishment of, 238-240; rearing, 219, 237-243; sexeducation of, 240-241; sexual experiences of, 241-243; toilet training, 238 ; weaning of, 237

Chinese, 39, 45, 202, 214, 241; culture contact with, 11; and illegitimacy, 189 ; immigration of, 31 ; population, $1,27,36,38,135$; visiting relationships with lower-class Creole women, 215; credit, 154, 179; social life centred around shops of, 206, 242, 251

Churches, 37- 38, 92, 95-96, 125, 132, $158,220,255$; activities of the Missions to improve family life of slaves, 65-67, 82-88, 96; and Asiatic Marriage Act, 188-189, 190; conversion of slaves, 41, 66-67, 82-83, 92; disapproval of Afro-American religious pratices by, $41,252,260,261,262$; encouragement of legal marriage by, 125-129; and family planning, 227; popular, 67, 134, 255, see Masters

Civil service, 120,149 ; as a means of relieving unemployment, 123, 145-146

Clarke, Edith, 3, 6, 16

Class, middle, lower, upper, concept of, 40

Clinic, helminthiasis outpatients', 48

Cocoa-growing, 32, 111-112

Coconut-growing, 112

Colour-class system, 15, 40, 104, 204, 214

Commission for the Affairs of the Protestant Churches in the East and West Indies, 92, 106-107

Common law marriage, 124, 144, 164, $175,177-178,187,189,193,215,220$, 224, 246, 266, 267, 269; common law husband, 136, 144, 181, 196, 199-200, 209, 211, 218, 226, 246; common law wife, 179, 181-182, 196, 197-198, 202, 205 , see concubinage
Comvalius, Staten member, 137

Concubinage, 3(def.) $-5,8,9,12,16$, $104,108,125-127,131,136,165,173$, $196,203,206,215,220,222,226,251$, 266, 267; conversion of into marriage, $5,169-171,174,196$; and customary law, 190, 267; faithful, 4; and illegimacy, 186-194; norms governing entry into, 167-169, 171-173; socio-economic status of persons living in, 166-167; termination of, $175,176,185,199$, 200, 201, see Surinam-style marriage and instability

Confucianism, 38

Contraceptive methods, 47, 217; with regard to social mobility of women, 215,227 ; use of various, 228-232; women's attitude towards, 219,223 , 227, 231-232

Contract-labourers, 21, 29, 31, 33, 36, 109

"Coolies", 112, 229

Coresidential union, 17, 55, 56, 57, 64

"Corpse-washers", 255-259

Cotran, Eug., 60

Courlander, H., 253

Cramer, J., 87

Crèches, 205, 226, 244-245

Creole, 38-40 (def.), 50, 69, 136-137, $143,188,189$; Mammy, 65 ; population, $1-2,21,36,37,42,108,123-$ $124,187,189,227$; upper and middle classes, 38, 40-41, 123-124, 137, 149, $175,185,190,213-214,224$, see Negroes and Bush Creoles

Creole, lower-class, 7, 40-41, 44, 45 (def.), 133-135, 212, 270; (sub) culture, $8-9,11,23,40-41,159,161,174$, $175,190,217,247,263,265-266,269$; economic position of, 105-107, 108$124,132,136-137,144-153,200,219$, 264-265; mortuary rites, 252-262 ; defeatism, 136-137, 163, 164, 264; denominational affiliations of, 38,87 , 134, 255; family life, 1-2, 17, 41, 43, $67,132,140,163,254,266$; legal marriage, 107, 125-131, 144, 164-175, $194,196,217,224,234,242-243,246-$ 247, 266; political affiliations of, 27, 39, 148-149; pol.-econ. competition between Hindustani and, 37, 118, 121 $122,136,148-149,163,227,229,247$; proletariat, $46,107,121,146,149$, 162, 264, see kinship 
Creole lower-class family system, 20-23, 42, 47, 124, 269-270; West Indian character, 1, 107-108, 132, 164, 263

Crijnssen, A., 26

Cumper, G. E., 17

Customary law marriage, $60,127,187-$ 188, 190, 267, see Asiatic Marriage Act

\section{Datta wosu, 241}

Daughters, 216-217, 244; differentiation in reactions to pregnancy of unmarried, 224-225, 243

Davenport, W., 17

Davidson, L., 4

Dede oso, 258, 261

Desertion, of men, 9, 190, 201-202, 204, $208,211,215,234,246-247$; of the women, 198-199, 202

Developmental cycle theory of R. T. Smith, 15-16, 195, 203-204, 205; as applied to lower-class Creole household in Paramaribo, 205-218

Divorce, 172, 181, 198, 200, 202, 211, 175-177; poor man's, 176

Differentiation, among Mulattoes, 103104; between alternative unions, 173175 ; between Negroes and Mulattoes, $50-51,105,131$; between whites and (ex-) slaves, 69, 70-71, 131; ethnic, $15,27,40,104,135,213-215,227$; among (ex-) slaves, 40-41, 50, 55; within the Creole group, 40-41, 51, 103, 104-105

Djodjo, 159

Dosu, 236

Dukun, 228-229, 230

Durward Badgley, L., 139

Dusseldorp, D. B. W. M. van, 113

Emancipation, 21, 32, 34, 41, 74, 164; campaigns in favor of, 80, 95; and family life of ex-slaves', 17, 97, 107$108,124,132,160,190,264,266-$ 267 ; and family life of slaves, 85, 93, 96, 99; and small-scale farming, 32 , 112 ; and plantation system, 109-110, $118,121,160,186$, see Alliance, abolition of and State Supervision

Europeans, cultural contact of slaves with, $11,40-41,67,70,101$; popula- tion, $1,36,39,50,54$; family life of, 102, 213-214, see Masters, Surinamstyle marriage

Ex-slaves, see slaves, emancipated

Family, Companiate, 4; Christian, 4; Disintegrate, 4 ; -planning, 47-48, 227, 229, 232

Family system, flexibility of, 21, 263, 269 ; of U.S. Negroes, 5

Father-child relationships, 7, 64, 98, 206-207, 211, 242, 243-244, 246

Fermin, Ph., 1, 57, 60

Ferrier, J. H. E., 2

Foresters, International Secret Order of the, 251

Frazier, E. F., 4, 7, 10, 12-14, 62, 175, 253

Freedmen, see free Mulattoes and free Negroes

Freilich, M., 183

Funeral rites, see Creole, lower-class and Mortuary

Gefken, W. J., 95

Glick, P. C., 5

Goetze, D., 19

Gold-mining, 33, 34, 113-115, 122, 180181,265

Goslinga, C. Ch., 88

Goveia, E. V., 53

Groot, Silvia W. de, 2, 53, 54

Growth rate, of Surinam population, 37, 227

Hakka, 36

Haller, missionary, 129

Hartsinck, J. J., 1, 54, 55, 56, 58, 61, 63, 160

Henriques, F., 3, 4, 14, 15, 175, 203, 262

Herlein, J. D., 1, 52, 54, 56, 70

Herskovits, Frances S., 2, 10, 12, 157, 233, 248, 261

Herskovits, M. J., 2, 3, 4, 7, 10-13, 14, $157,158,184,233,235,236,248,253$, 261

Heyde, B., 128

Hindi, 36

Hindustani, 2, 11, 138, 143, 162-163, 214,228 ; and instability of marriage, 
177 ; immigration of, $31,36,39$; political party, 27, 36; population, 1, 27, $36-37,38,42,45,113,135,227$; small-scale agriculture, 32-33, 112; and illegitimacy, 187, 189, 191, see Asiatic Marriage Act and Creole, lower-class

Hoetink, H., 3

Homosexuality, 247, see women

Hostmann, F. W. R., 57, 64

Household, 43 (def.) ; financing of, 150151, 216; economic aspects of the, 144 ; expenditure, 153-162; first phase of the, 203, 205-209, 218, 247; housekeeping allowance, 144, 154-155, 178180, 246; income, 150-153, 166; neolocal settlement of, 167 ; occupational structure of heads of, 146-150; second phase of, 203-204, 209-212, 218; structure of households, 194-195

Household, head of, 43; de facto, 7, 204 ; female, $3,17,108,124,139,207-$ 208, 211, 217-218, 234, 246, 263, 266; interconnectedness of the different types of, 202-203; de jure, 7, 204; male, 139, 205-206; types of, 135-136, 195-202, see women and matrifocality Housing, age of, 141 ; conditions of, 138139,141 ; different categories of, 138139 ; electricity, gas, water and sewerage, 141-142; furnishing of, 142, 166 ; number of beds per household, 140, 235 ; overcrowding, 139, 140, 206, 234 ; ownership of, 143,166; renting of, $139,143,155-156$; shortage of, 155

Illegitimacy, 183, 185-187, 189-194, $197-$ 198,225 ; and casual affairs, 193, 215216, see Asiatic marriage Act and Children, premarital

Incomes, irregularity of and instability of man-woman relationships, $8,16,73$, $105,107,115,117,178-179,264-265$, 269

Indonesians, see Javanese

Instability, of casual affairs, 215 ; of concubinage, 175-178, 210; of marriage, $126,176-178,210$; of man-woman relationship, 107-108, 115, 118, 207, $210,219,267$; of slave relationships, $56-63,77$; of Surinam-style marriage, 71 ; of unions, $5,8-9,71,126,175-$
177, 251, 266, 267-268, see separate sale and unions, alternative

Ismael, J., 31

Javanese (Indonesians), 2, 27, 45, 46, $138,143,190,214,237,247$; cultural contact with, 11,39; and illegitimacy, 187, 189, 191 ; immigrants, 31 , $36,39,113$; and instability of marriage, 177; population, $1,36-38,42$, 113,135 ; and small-scale agriculture, 32-33, 112, see Asiatic Marriage Act and dukuns

Jews, 50, 68, 70, 127, 134, 189; cultural contact with, $40,102,241$; as planters, 25-26, 28, 82

Joode Savane, 28

Kanten, 78

Kappler, A., 2, 69, 70, 71

Karbaat, J., 228

Kasmoni, 162

Kerr, M., 235

Kielstra, J. C., 188

Kinship, 7, 194; bilateral, 7; matrilineal, $7,22,64,98,99,100,195,244$; patrilineal, 7, 195, 253; system, 7, 194; terminology, 194-195, see women

Klerk, C. J. M. de, 2, 31, 188

Kloos, P., 2

Köbben, A. J. F., 2

Kompe, 247

Kookraam, 142

Kool, R., 35

Koto Yaki, 157, 249

Kruyer, G. J., 2, 110, 120, 121, 122, 186

Kuhn, F. A., 58, 75, 78, 79, 228

Kunstadter, P., 18

Kurekure, 238

Kuyp, E. van der, 37, 47, 77

Lammens, A. F., 60, 69, 71, 72, 79, 160, 238

Lampe, P. H. J., 233

Lamur, H., 37

Land van Van Dijk, 190

Lebanese, 1

Legitimation, 104, 107, 129, 189, 195, 197, 200-202, 215; in connection with concubinage or Creole common law 
marriages, $189,192-193,198$; in Surinam-style marriages, $70,103,104$; in visiting relationships, 151,201 , see Marriage Act for Asians and customary law marriage

Lesbianism, see women

Lewis, O., 18, 19, 174, 269

Lichtenbergh, Ph. J. van, 26

Lier, R. A. J. van, 2, 11, 12, 13, 26, 29, $32,35,37,39,51,52,54,58,61,65$, $68,70,71,79,93,95,105,106,110$, $111,112,122,125,158,189,248,265$

Lier, W. F. van, 167, 258

Lobi singi, 184

Locher, G. W., 265

Lukuman, see popular healer

Lutheran Church, 38, 67, 82, 128, 134, 220, 261, see Churches

Magic, 158, 184, 241; black, 159, 184$185,192,233,235,258$; white, 159 , 184

Malinowski, B., 262

Man-woman relationship, 206, 240-241, 246-247, 179-185, 206, 246-247

Marginal position of men in household, 7, 16, 64, 200, 204, 208, 268

Marks, A. F., 23, 263

Marriage, legal, 3-5, 9-10, 16, 49, 68, $71,102-104,126-127,186,203,215$, $266,267,269$; conversion of concubinage into, 169-171, 174; dissolution of, see divorce; issue of among slaves, $17,55,74,82,85,88-92,266-267$; among Mulattoes, 71, 104-105; norms governing conclusion of, $5,130,167$ $168,171-172,174,197,266,267$; reasons for not marrying, 165,167 173 ; socio-econ. status of, $5,166-167$, 224, 267; (in) stability of, see instability; between white men and Negro women, 70-71, see Creole, lower-class and Masters

Marriage Act for Asians, 127, 187-189 Massa Gran Gado, 158

Masters, the, 17, 40-41, 50, 53-55, 58, $62,64-65,79,80,84,98-99,107$; Church of, 66-67, 134-135, 186; family life of the, 62-63, 67-73, 101-102, 104; interests of and separate sales, 59, 74, 85-86, 90-93; and regulation of family life of slaves, $52,55-56,66,74,81-82,85$
Mati, 247-251

Matriarchal, 7

Matricentric, 6, 7

Matrifocality, 6-10, 16, 18, 49, 64-65, $72-73,107,121,164,204,263,266$, 269 ; latent, 73, 206-207, 269; manifest, 73, 208-209, 212, 216, 269; transitional phase, 208-209; types of, $8-10$, see households, female head of

Matthews, B., 3, 14

Mauricius, J. J., 65, 66

Measures for the improvement of slaves' family life and reproductive capacity, $74,80-81$; private measures, $81-82$; missionary activities, see Churches; state interference, 88-96

Mechanics, the, 251

Medical societies, 160-161, 253

Menopause, 209, 241, 249

Métraux, A., 253

Migration, Creole urban, 108-113, 122, 144; effect of on sex ratio, 16, 18, 134; male labour, 6, 16, 121, 180-182, 201; to the Netherlands and Antilles, $123-124,180,182,190,201$

Moravian Mission, 38, 41, 67, 83-85, 94, $112,124,134-135,188,220,222,227$, 255, 260-261, see Alliance

Mintz, S., 17

Morpurgo, A. J., 157

Mortuary and funeral rites, 159, 161, 252-262

Moslem faith, 38, 127, 134-135, 188-189

Mother and child, bond between, 7, 206, 217-218, 243; headed, 6 ; son relationship, 151, 172, 180, 211, 216, 243244 , see old age, daughter and slave

Moynihan, D. H., 6, 177

Mulattoes, free, 50, 118; family life of, $49,58,62,71-73,101-105,213$; funerals of, 160 ; illegitimacy, 186

Murdock, G. P., 185

Navelstring, 223, 236

Negro, 39, 51, see Bush Negro; Creole, 1, 39, 52; English, 36; gateway, 79, 138; Guyanese family, 6, 15-16, 203206, 218; of the New World, 2, 10, 13, 39, 253; North American family, $4-6,11-13,18,168,175-177,200$, 235-236, 267; populations of the Americas, 10; Salt Water, 39, 52, 66; 
'slavery America', 3, see Negroes, free Negroes, free, 50, 118; family life of, 49, 58, 62, 67, 71-73, 101-102, 105-107, 213 ; funerals of, 160 ; and illegitimacy, 186

Neigungsehe, 60-62, 96

Nepveu, J., 63

Nettelbeck, German sailor, 52

Obiaman, see popular healer

Ogrí ai, 238

Oil refining industry, 123, 182, 265

Old age, 202, 252, 219; children as security for, $172,180,215-217,219$, $223,227-228,232$; home ownership as security for, 143, 252

Oostburg, B. E. J., 48

Ostendorf, F. W., 228

Otterbein, K. F., 17

Panday, R. M. N., 30

Panhuys, L. C. van, 126

Paramaribo, city of, 25, 27-28, 34, 54, $68,113,120,122,132,137-138,153$, 234 ; city of the (lower-class) Creole, $11,20,42,113,120,136,263$; comparison between West Indian family system of British Guyana and of, 203218; agriculture around, 32, 105-106, 111,148 ; migration to, $33,42,108$ $109,110,112-113,122,133$; population of, 50-51, 75-77, 101-102, 110, 187,220 , see housing and unemployment

Paramaribo, J. J. van, 66

Perret Gentil, H. C., 88, 92, 106

Pierce, 2, 195

Pikin jari, 138

Plantaadje-reglement, see Slave Code

Plantation, agriculture, 25, 28, 29-32, $49,74,77-78,84,97,109-112,116$, 118, 263; America, 3; Code, see Slave Code; colony, 21, 25, 28-29, 40, 49, $53,54,61,68,74,94,263$; crops grown on, $28-29,32,34,49,77$, see Masters and slaves

Plural society of Surinam, 2, 27, 35-37, 44, 232

Pollak-Eltz, A., 158

Polyandry, 59-60, 86
Polygyny, 12, 86, 95; and visiting relationship, 56, 60, 266

Popular healer, 157-159, 184, 233, 262

Popular medicine, 44, 184, 228-229

"Porck-knocker", 114

Poverty, 25; certificate of, 125, 130; (sub)culture of, 18-19, 174; degree of among lower-class Creoles, 162-163; discrimination through at burial, 161, 261, see old age

Prati Lobi, 185

Pregnancy, traditional practices in connection with, 232-237; during slavery, 78, 81-82, 93, 234

Pronk, B., 2, 159, 177

Quintus Bosz, A. J. A., 28, 53, 55, 80-81

Raders, R. F. Baron van, 105, 106

Rainwater, L., 6

Red Slaves, see slaves

Register of Freed Persons of Paramaribo, $75,96,97,130,131$

Rek, J. de, 257

Renselaar, H. C. van, 2, 40, 56, 162, 188

Research, social in Surinam, 1-2

Réveil Movement, 80

Rice, 33, 112

Rijk, J. G., 93

Rivière, P. G., 2

Roman Catholic, Church, 38, 41; Church Marriage, 85, 86-88, 92, 95, 96, 98, 127, 267; Mission, 38, 41, 83, 86-88, $112,128,134,135,201,220,222,255$, see Churches

Rustenburg, Government plantation, 93

Sack, A. von, $66,77,81$

Sale, separate, of slaves, $58,65-66,74$, $81,91,93,95,98$; consequences of on slaves' family life, $58-59,64,74$, 85-88, 96; of husbands and wives, 74, 81, 87-88, 91-92, 95-96, 124

Salt Water Negro, see Negro

Samson, Elisabeth, 71

Schimmelpenninck van der Oye, A. J. Baron, 247

Schimpf, Ch. P., 86 
Schneider, H. G., 62, 85, 126, 128-130, 186

Schvaneveldt, J. D., 20

Sex ratio, unequal, 134; impact of on lower-class Creole's family life, 105, 107,219 ; impact of on slaves' family life, $58-60,75-77,94,101,266$; and lesbianism, 249-250; and West Indian family system, 16-18, 20

Simey, T. S., 3-4, 14-15, 203

Simons, R. D. G. Ph., 233

Situationsehe, 60-61

Slave(s), 38, 40-42, 105, 121; burial societies, 160; christening of, see Churches; Code, 53, 78, 80; domestic, 50-51, 54, 56, 59, 92, 102, 110; emancipated, 17, 68, 107, 109-110, 124-125, $127-128,130$; family life of the, 55$65,74,98,99,100-101,132$; field, 51-53; hiring out of, 58-59; household, 63-65, 96-101; import of, 29-30, 38, $51,66,74-75,82$; legal position of, $53,55,65,69,80,85,89,91,95-96$, $98,108,136$; malnutrition, disease and poor housing among, 75, 77-80, 136; man-woman relationships, 17, 55-56, 85-88, 96-101, 108, 126, 266; and manumission, 50, 81, 102; manumitted, 32, 70, 96, 103-104; marriages, 55-56, 82, 85, 87, 92-93, 96, 98, 267; mother-child relation, 52, 64-65, 98; Negro, 1, 38-39, 45, 51, 57-58, 88-89, 90-91; plantation, 29, 38, 51, 53-54, $56,59,61,77,84,92,110,228,264$; population, 40, 49-51, 66, 74-76, 80$81,96,99,101$; population policy, 74 ; rebellions, 29, 53; reproduction rate, $75,77-78,82$; runaway, 39 ; $53-54$; Surinam Culture, 40-41, 263; sale of, 52,65 ; stimulation of reproduction rate after abolition slave trade, 74,81 82; town, 51, 54, 79, 92; trade, 29-30, 51-52, 83, see instability, marriage, and separate sale

Slavery, $15,80,118,126-127,190,264$, 266 ; abolition of, see abolition; circumstances under, $1,53-54,77-80$, 264; disintegrative effects of, 12-15; Negroid family system during, 20, 41, 263 ; organization of, 51-55; West Indian, 17

Small-scale agriculture, 29, 31, 32-33; Creole, 32, 110-113
Smith, M. G., 3, 6, 16-17

Smith, R. T., 3, 6, 7, 10, 14, 15, 16, $175,203-204,205,206,209,210,211$, 218

Social control, 96 ; exercised by the Yorka, 158; among Creoles, 132, 171, 190, 211, 218

Solien de Gonzales, N., 16

Speckmann, J. D., 2, 31, 44, 162, 177, 188

Spicer, E. H., 265

Sranang, 36, 44-45, 126

Staal, G. J., 52

State, interference with respect to the family life of the slaves, see measures; supervision of ex-slaves, 30, 108-113, 125-128

Stedman, J. G., 75

Steinberg, H. G., 63, 83, 84, 85, 93, 128, 129

Stöppel, J., 87, 88

"Sub-lessees", 114

"Suckling fees", 151

Sugar, 28-30, 49, 53

Surinam, 24-40

Surinam-style marriage, 69-73, 102-105, 173, 186, 188

Suriname, De Geoctroyeerde Sociëteit van, 26, 83

Survivals, see African

Sypesteyn, C. A. van, 50, 53, 75-76, 78, $97,110,125$

Tapu, 233

Tapu bere, 237

Teenstra, M. D., 53, 66, 69-72, 76, 82, 102-103

Tai-hede, 157

Timber industry, 34, 112, 120, 201

Thoden van Velzen, H. U. E., 2

Thomas, Father, 87

Traa, A. van, 114, 116, 119

Treef geloof, 77

Trefu, 233, see Treef geloof

Twins, 236-237

Tylor, E. B., 11

Uden Masman, H., 88, 92, 106

Unemployment, female, 121, 123, 144 ; latent, 145 ; male, $8-9,18,35,178$, 204, 208, 268; relief scheme, 122-123, 
144-145, 149, 152, 166, 179, 201-202, 219,252 , see civil service and economic position of Creole lower class

Unger, S. W., 29, 30

Unions, alternative, $3-5,8,12,49,55-$ $56,124,135-136,164-165,194,203$, 263, 266, 269; choice out of, 165-173; differentiation among, 173-175; reasons for termination of, 178-185

Vaillant, C. R., 91, 92

Verbond, see Alliance

Vierkandt, A., 61

Visiting relationship, 3 (def.), 4-5, 9, 12 , 16,17 ; during slavery, $55-57,60,64$, 266; of lower-class Creoles, 108, 151, $165,175,176,184,193,201,202,212$, $214,215,266$; termination of, 175 176,201

Voorhoeve, J., 40, 252

Waal Malefijt, A. de, 2, 31, 229

Wagley, Ch., 3

Wake, 44, 253-255, 258, 260-262

Walvis, W. Ghr., 37

Weatherley, U. G., 265

Weddings, 5, 44, 171, 253, 267

Wengen, G. D. van, 2

Wennekers, P., 87, 88

West Indian family system, 1, 3-20, 49, $124,185,202,232,246,247,263$; of Paramaribo, 20, 135-136, 219, 265270 ; as an adaptation of the African family system, 12, see Creole, lowerclass family system
Western family system, $9,10,74,185$; rate of assimilation to, 5, 13, 267, 270

Wetering, W. van, 241

Wie Eegie Sanie, 188

Wilberforce, W., 80

William I, King of the Netherlands, 87

Willoughby, Francis, Baron of Parham, 25,28

Winkels, W. E. H., 79

Winti, 158-159

Wintiman, see popular healer

Wintipree, 159, 262

Witches'-broom disease, 32, 111

Wisi, see black magic

Wolbers, J., 96, 104-106

Women $\left(\mathbf{s}^{\prime}\right)$, attitude towards childbearing, 217, 223; attitude towards marriage, 172-173, 269; dependence on matrilineal kinship ties, 205, 208-209, $217,243-244,252,268$; economic independence of, $8,58,61,64-65,121$, 218, 264, 268-269; jealousy among, 184; homosexual relations between, 247-251, 268; money-making activities of, 73, 107, 120-121, 144, 148-149, $152,179,202,205,208,218,268$, 269; position in family, $8,12,206$, 208, 209

Yancey, W. L., 6

Yorka, 158-159, 235

Zeelandia, Fort, 104

Zinzendorf, N. L., Count of, 83

Zobre, Mr., 71

Zorg en Hoop, i3? 